Cochrane Database of Systematic Reviews

\title{
Treatments for women with gestational diabetes mellitus: an overview of Cochrane systematic reviews (Review)
}

Martis R, Crowther CA, Shepherd E, Alsweiler J, Downie MR, Brown J

Martis R, Crowther CA, Shepherd E, Alsweiler J, Downie MR, Brown J.

Treatments for women with gestational diabetes mellitus: an overview of Cochrane systematic reviews.

Cochrane Database of Systematic Reviews 2018, Issue 8. Art. No.: CD012327.

DOI: 10.1002/14651858.CD012327.pub2.

www.cochranelibrary.com 
HEADER 1

ABSTRACT

PLAIN LANGUAGE SUMMARY

BACKGROUND

OBJECTIVES

METHODS

Figure 1.

RESULTS

DISCUSSION

AUTHORS' CONCLUSIONS

ACKNOWLEDGEMENTS

REFERENCES

ADDITIONAL TABLES

APPENDICES

CONTRIBUTIONS OF AUTHORS

DECLARATIONS OF INTEREST

SOURCES OF SUPPORT

INDEX TERMS

\section{TABLE OF CONTENTS}

1

3

5

9

9

11

13

22

30

30

31

43

106

109

109

109

109 
[Overview of Reviews]

\section{Treatments for women with gestational diabetes mellitus: an overview of Cochrane systematic reviews}

Ruth Martis ${ }^{1}$, Caroline A Crowther ${ }^{1,2}$, Emily Shepherd ${ }^{2}$, Jane Alsweiler ${ }^{3}$, Michelle R Downie ${ }^{4}$, Julie Brown 5

1Liggins Institute, The University of Auckland, Auckland, New Zealand. 2ARCH: Australian Research Centre for Health of Women and Babies, Robinson Research Institute, Discipline of Obstetrics and Gynaecology, The University of Adelaide, Adelaide, Australia. ${ }^{3} \mathrm{Neonatal}$ Intensive Care Unit, Auckland Hospital, Auckland, New Zealand. ${ }^{4}$ Department of Medicine, Southland Hospital, Invercargill, New Zealand. ${ }^{5}$ Department of Obstetrics and Gynaecology, The University of Auckland, Auckland, New Zealand

Contact address: Julie Brown, Department of Obstetrics and Gynaecology, The University of Auckland, Park Rd, Grafton, Auckland, 1142, New Zealand. juliebrown571@gmail.com.

Editorial group: Cochrane Pregnancy and Childbirth Group.

Publication status and date: New, published in Issue 8, 2018.

Citation: Martis R, Crowther CA, Shepherd E, Alsweiler J, Downie MR, Brown J. Treatments for women with gestational diabetes mellitus: an overview of Cochrane systematic reviews. Cochrane Database of Systematic Reviews 2018, Issue 8. Art. No.: CD012327. DOI: 10.1002/14651858.CD012327.pub2.

Copyright @ 2018 The Cochrane Collaboration. Published by John Wiley \& Sons, Ltd.

\section{A B S T R A C T}

\section{Background}

Successful treatments for gestational diabetes mellitus (GDM) have the potential to improve health outcomes for women with GDM and their babies.

\section{Objectives}

To provide a comprehensive synthesis of evidence from Cochrane systematic reviews of the benefits and harms associated with interventions for treating GDM on women and their babies.

\section{Methods}

We searched the Cochrane Database of Systematic Reviews (5 January 2018) for reviews of treatment/management for women with GDM. Reviews of pregnant women with pre-existing diabetes were excluded.

Two overview authors independently assessed reviews for inclusion, quality (AMSTAR; ROBIS), quality of evidence (GRADE), and extracted data.

\section{Main results}

We included 14 reviews. Of these, 10 provided relevant high-quality and low-risk of bias data (AMSTAR and ROBIS) from 128 randomised controlled trials (RCTs), 27 comparisons, 17,984 women, 16,305 babies, and 1441 children. Evidence ranged from high- to very low-quality (GRADE). Only one effective intervention was found for treating women with GDM.

\section{Effective}

Lifestyle versus usual care

Lifestyle intervention versus usual care probably reduces large-for-gestational age (risk ratio (RR) $0.60,95 \%$ confidence interval (CI) 0.50 to $0.71 ; 6$ RCTs, $N=2994$; GRADE moderate-quality).

\section{Promising}

Treatments for women with gestational diabetes mellitus: an overview of Cochrane systematic reviews (Review) 
No evidence for any outcome for any comparison could be classified to this category.

\section{Ineffective or possibly harmful}

\section{Lifestyle versus usual care}

Lifestyle intervention versus usual care probably increases the risk of induction of labour (IOL) suggesting possible harm (average RR 1.20, 95\% $\mathrm{Cl} 0.99$ to 1.46; 4 RCTs, N = 2699; GRADE moderate-quality).

\section{Exercise versus control}

Exercise intervention versus control for return to pre-pregnancy weight suggested ineffectiveness (body mass index, BMI) MD $0.11 \mathrm{~kg} / \mathrm{m}^{2}$, $95 \% \mathrm{Cl}-1.04$ to $1.26 ; 3$ RCTs, $\mathrm{N}=254$; GRADE moderate-quality).

\section{Insulin versus oral therapy}

Insulin intervention versus oral therapy probably increases the risk of IOL suggesting possible harm (RR $1.3,95 \% \mathrm{Cl} 0.96$ to $1.75 ; 3 \mathrm{RCTs}$, $\mathrm{N}=348$; GRADE moderate-quality).

\section{Probably ineffective or harmful interventions}

Insulin versus oral therapy

For insulin compared to oral therapy there is probably an increased risk of the hypertensive disorders of pregnancy (RR $1.89,95 \% \mathrm{Cl} 1.14$ to 3.12; 4 RCTs, $N=1214$; GRADE moderate-quality).

\section{Inconclusive}

\section{Lifestyle versus usual care}

The evidence for childhood adiposity $\mathrm{kg} / \mathrm{m}^{2}$ (RR $0.91,95 \% \mathrm{Cl} 0.75$ to $1.11 ; 3 \mathrm{RCTs}, \mathrm{N}=767$; GRADE moderate-quality) and hypoglycaemia was inconclusive (average RR $0.99,95 \% \mathrm{Cl} 0.65$ to $1.52 ; 6 \mathrm{RCTs}, \mathrm{N}=3000$; GRADE moderate-quality).

\section{Exercise versus control}

The evidence for caesarean section (RR $0.86,95 \% \mathrm{Cl} 0.63$ to $1.16 ; 5 \mathrm{RCTs}, \mathrm{N}=316$; GRADE moderate quality) and perinatal death or serious morbidity composite was inconclusive (RR $0.56,95 \% \mathrm{Cl} 0.12$ to $2.61 ; 2 \mathrm{RCTs}, \mathrm{N}=169$; GRADE moderate-quality).

\section{Insulin versus oral therapy}

The evidence for the following outcomes was inconclusive: pre-eclampsia (RR 1.14, 95\% Cl 0.86 to $1.52 ; 10 \mathrm{RCTs}, \mathrm{N}=2060$ ), caesarean section (RR 1.03, 95\% Cl 0.93 to 1.14; $17 \mathrm{RCTs}, \mathrm{N}=1988$ ), large-for-gestational age (average RR 1.01, 95\% Cl 0.76 to $1.35 ; 13 \mathrm{RCTs}, \mathrm{N}=2352$ ), and perinatal death or serious morbidity composite (RR 1.03; 95\% Cl 0.84 to $1.26 ; 2$ RCTs, $\mathrm{N}=760$ ). GRADE assessment was moderatequality for these outcomes.

Insulin versus diet

The evidence for perinatal mortality was inconclusive (RR $0.74,95 \% \mathrm{Cl} 0.41$ to 1.33 ; $4 \mathrm{RCTs}, \mathrm{N}=1137$; GRADE moderate-quality).

Insulin versus insulin

The evidence for insulin aspart versus lispro for risk of caesarean section was inconclusive (RR 1.00, 95\% CI 0.91 to $1.09 ; 3$ RCTs, N = 410; GRADE moderate quality).

\section{No conclusions possible}

No conclusions were possible for: lifestyle versus usual care (perineal trauma, postnatal depression, neonatal adiposity, number of antenatal visits/admissions); diet versus control (pre-eclampsia, caesarean section); myo-inositol versus placebo (hypoglycaemia); metformin versus glibenclamide (hypertensive disorders of pregnancy, pregnancy-induced hypertension, death or serious morbidity composite, insulin versus oral therapy (development of type 2 diabetes); intensive management versus routine care (IOL, large-forgestational age); post- versus pre-prandial glucose monitoring (large-for-gestational age). The evidence ranged from moderate-, low- and very low-quality.

\section{Authors' conclusions}

Currently there is insufficient high-quality evidence about the effects on health outcomes of relevance for women with GDM and their babies for many of the comparisons in this overview comparing treatment interventions for women with GDM. Lifestyle changes (including as a 
minimum healthy eating, physical activity and self-monitoring of blood sugar levels) was the only intervention that showed possible health improvements for women and their babies. Lifestyle interventions may result in fewer babies being large. Conversely, in terms of harms, lifestyle interventions may also increase the number of inductions. Taking insulin was also associated with an increase in hypertensive disorders, when compared to oral therapy. There was very limited information on long-term health and health services costs. Further highquality research is needed.

\section{PLAIN LANGUAGE SUMMARY}

\section{Treatments to improve pregnancy outcomes for women who develop diabetes during pregnancy: an overview of Cochrane} systematic reviews

\section{What is the issue?}

The aim of this Cochrane overview was to provide a summary of the effects of interventions for women who develop diabetes during pregnancy (gestational diabetes mellitus, GDM) and the effects on women's health and the health of their babies. We assessed all relevant Cochrane Reviews (date of last search: January 2018).

\section{Why is this important?}

GDM can occur in mid-to-late pregnancy. High blood glucose levels (hyperglycaemia) possibly have negative effects on both the woman and her baby's health in the short- and long-term.

For women, GDM can mean an increased risk of developing high blood pressure and protein in the urine (pre-eclampsia). Women with GDM also have a higher chance of developing type 2 diabetes, heart disease, and stroke later in life. Babies born to mothers with GDM are at increased risk of being large, having low blood glucose (hypoglycaemia) after birth, and yellowing of the skin and eyes (jaundice). As these babies become children, they are at higher risk of being overweight and developing type 2 diabetes.

Several Cochrane Reviews have assessed different interventions for women with GDM. This overview brings these reviews together. We looked at diet, exercise, drugs, supplements, lifestyle changes, and ways GDM is managed or responded to by the healthcare team.

\section{What evidence did we find?}

We found 14 Cochrane systematic reviews and included 10 reviews covering 128 studies in our analysis, which included a total of 17,984 women, and their babies. The quality of the evidence ranged from very low to high.

We looked at:

- Dietary interventions (including change to low or moderate glycaemic index (GI) diet, calorie restrictions, low carbohydrate diet, high complex carbohydrate diet, high saturated fat diet, high fibre diet, soy-protein enriched diet, etc.)

We found there were not enough data on any one dietary intervention to be able to say whether it helped or not.

- Exercise programmes (including brisk walking, cycling, resistance circuit-type training, instruction on active lifestyle, home-based exercise programme, 6-week or 10-week exercise programme, yoga, etc.)

Similarly, there were not enough data on any specific exercise regimen to say if it helped or not.

- Taking insulin or other drugs to control diabetes (including insulin and oral glucose lowering drugs).

Insulin probably increases the risk of high blood pressure and its problems in pregnancy (hypertensive disorders of pregnancy) when compared to oral therapy (moderate-quality evidence).

- Supplements (myo-inositol given as a water-soluble powder or capsule).

We found there was not enough data to be able to say if myo-inositol was helpful or not.

- Lifestyle changes which combine two or more interventions such as: healthy eating, exercise, education, mindfulness eating (focusing the mind on eating), yoga, relaxation, etc.

Lifestyle interventions may be associated with fewer babies being born large (moderate-quality evidence) but may result in an increase in inductions of labour (moderate-quality evidence).

- Management strategies (including early birth, methods of blood glucose monitoring). 
We found little data for strategies which included planned induction of labour or planned birth by caesarean section, and there was no clear difference in outcomes among these care plans. Similarly, we found no clear difference among outcomes for different methods of blood glucose monitoring.

\section{What does this mean?}

There are limited data on the various interventions. Lifestyle changes (including as a minimum healthy eating, physical activity, and selfmonitoring of blood sugar levels) was the only intervention that showed possible health improvements for women and their babies. Lifestyle interventions may result in fewer babies being large. Conversely, in terms of harms, lifestyle interventions may also increase the number of inductions. Taking insulin was also associated with an increase in hypertensive disorders, when compared to oral therapy. There was very limited information on long-term health and health services costs. Women may wish to discuss lifestyle changes around their individual needs with their health professional. Further high-quality research is needed. 


\section{B A C K G R O U N D}

Gestational diabetes mellitus (GDM) is a condition that may occur in the second half of pregnancy when blood glucose control is more difficult to achieve, leading to hyperglycaemia (abnormally high concentration of glucose in the blood) that may affect the woman and her baby (ADA 2004; Holt 2013). The World Health Organization (WHO) defines GDM as "Carbohydrate intolerance resulting in hyperglycaemia or any degree of glucose intolerance with onset or first recognition during pregnancy usually from 24 weeks' gestation onwards" and resolves following the birth of the baby (WHO 2013). This definition clearly excludes women who may have undiagnosed pre-existing type 1 or type 2 diabetes mellitus first detected during screening in pregnancy (Nankervis 2013).

Recognised risk factors for developing GDM include obesity, advanced maternal age, weight gain in pregnancy, family history of diabetes and previous history of GDM, macrosomia (large baby), or unexplained stillbirth (Mokdad 2003; Yogev 2004; Boney 2005; Rosenberg 2005; Zhang 2010; Teh 2011). Certain ethnicities, such as Asian, African American, Native American, Hispanic, and Pacific Island women have an increased risk of GDM (Rosenberg 2005; Schneider 2012).

The prevalence of GDM is increasing globally and has been documented with significant variation between $2 \%$ to $26 \%$ depending on the ethnicity of the population screened and the diagnostic criteria used (Cheung 2003; Ferrara 2007; Sacks 2012; Nankervis 2013; NZ Ministry of Health 2014; NICE 2015). The reported global obesity epidemic is likely to increase the incidence of GDM (Zhang 2010; Schneider 2012), and recurrent GDM diagnosis in subsequent pregnancies for women who have had previously been diagnosed with GDM (Bottalico 2007; England 2015; Poomalar 2015). Therefore, GDM is a serious public health issue.

Successful glycaemic treatments for GDM have the potential to significantly impact on the short- and long-term health for the woman and her baby. Treatments for GDM aim to keep glucose levels within the recommended glycaemic reference range to prevent maternal hyper- or hypoglycaemia. Treatments may include dietary and exercise advice, subcutaneous insulin, oral hypoglycaemic agents, such as pharmacological medications, dietary supplements or nutraceuticals, antenatal breast milk expression, induction of labour or caesarean section (Horvath 2010; Kavitha 2013; Bas-Lando 2014; Forster 2014; Ryu 2014; Kalra 2015).

Currently there are several Cochrane systematic reviews that assess different treatment for women with GDM. This makes it difficult for clinicians, consumers, and guideline developers to easily interpret the available information. A Cochrane overview of systematic reviews would provide summary evidence of the effectiveness for each treatment for women with GDM and the effects on relevant health outcomes as a one-stop resource for health professionals, consumers and guideline developers to simplify clinical treatment decision-making, and assist with the process of guideline development.

\section{Description of the condition}

During pregnancy the continuous supply of appropriate and balanced nutrients from the pregnant woman to her baby is essential for optimal health and growth. Glucose is the primary source of energy for the fetus (Wilcox 2005; Hay 2006). Insulin is a peptide hormone secreted by the $\beta$ cells of the pancreatic islets of Langerhans and maintains normal glucose concentration by facilitating cellular glucose uptake, regulating carbohydrate, lipid and protein metabolism and promoting cell division and growth (Wilcox 2005). Either inadequate insulin secretion (such as in type 1 diabetes) or insulin resistance (such as in type 2 diabetes or GDM) (Devlieger 2008; Petry 2010), can result in hyperglycaemia. During the second half of pregnancy, insulin sensitivity falls by about 50\% (Di Cianni 2003; Lain 2007). This is a normal physiologic response ensuring that the growing fetus receives sufficient glucose and other nutrients from the mother via the placenta (Buchanan 1991). In some pregnant women abnormal insulin resistance may occur if they are unable to compensate for the increased demand of insulin (Ragnarsdottir 2010; McCance 2011; Catalano 2014). This results in GDM (ADA 2004; Holt 2013). It is known that the maternal-fetal placental glucose transfer favours the fetus (Suman Rao 2013; Sadovsky 2015). Women with GDM therefore transfer higher amounts of glucose to the fetus when uncontrolled severe and prolonged maternal hyperglycaemia is present (Wilcox 2005), resulting in a baby born large-for-gestational age (Ornoy 2005; Metzger 2008; Young 2013).

Lapolla 2005 suggests the two main contributors to insulin resistance include increased maternal adiposity and the insulin desensitising effects of hormones produced in the pregnancy, especially in the placenta. As the placenta grows during the pregnancy, so does the production of the placental hormones, leading to an insulin-resistant state (Evans 2009). GDM usually resolves promptly following the birth of the baby and the placenta, indicating insulin resistance decreases rapidly after birth. The identified hormones are tumour necrosis factor-alpha (TNF- $\alpha$ ), placental lactogen, placental growth hormone human chorionic somatomammotropin (HCS), cortisol, oestrogen, and progesterone (Clapp 2006; Devlieger 2008). HCS stimulates pancreatic secretion of insulin in the fetus and inhibits peripheral uptake of glucose in the mother (Lapolla 2005). If the pregnant woman's metabolism cannot compensate adequately for this, maternal hyperglycaemia results.

Maternal hyperglycaemia of varying degrees of severity has short- and long-term health implications for the woman and her baby. For the woman, these include a higher risk of developing gestational hypertension and pre-eclampsia during her pregnancy, having an increased risk of induction of labour, preterm birth, caesarean section, perineal trauma, postpartum haemorrhage (Crowther 2005; HAPO 2008; McCance 2011; NICE 2015), and significant long-term risks of developing cardiovascular disease with half the women with GDM at risk of developing type 2 diabetes within five to 10 years (Bellamy 2009; Garrison 2015). Health implications for the baby include an increased risk of being born macrosomic and large-for-gestational age (Ornoy 2005; Young 2013), birth trauma (e.g. shoulder dystocia, bone fractures, and nerve palsy) (Athukorala 2010), hyperbilirubinaemia (Harris 1997; Hedderson 2006), respiratory distress syndrome (Landon 2009), and neonatal hypoglycaemia (Devlieger 2008; Harris 2013). Neonatal hypoglycaemia may be associated with developmental delay in childhood (Lucas 1988), and, if prolonged or severe, may cause brain injury. Long-term health risks include higher rates of obesity, development of type 2 diabetes in childhood (Page 2014), and late onset diabetes, hypertension and cardiovascular disease in adulthood (Ornoy 2011). 


\section{Description of the interventions}

Effective interventions for treatment of GDM aim to reduce the risks of GDM for the mother and baby by normalising maternal glycaemia through treating maternal hyperglycaemia (Farrar 2017). Glucose control is usually measured by monitoring capillary blood glucose concentrations to ensure glucose concentrations are maintained within pre-defined glycaemic thresholds (Garrison 2015). This may be achieved through interventions such as the use of diet modifications (American Dietetic Association 2001; NZ Ministry of Health 2014; NICE 2015), physical exercises (Harris 2005), pharmacological interventions such as oral hypoglycaemic medications or subcutaneous insulin (ACOG 2013; NZ Ministry of Health 2014; NICE 2015), nutraceuticals (Thomas 2005; Hui 2009; Bagchi 2015) or other dietary supplements (D'Anna 2015; Paivaa 2015).

\section{Different types of diet}

The main treatment recommended for women with GDM is dietary modification (Bonomo 2005; Crowther 2005; Landon 2009; NZ Ministry of Health 2014; NICE 2015). Dietary advice is aimed at preventing maternal hyperglycaemia and ensuring the woman's diet provides sufficient energy and nutrients to enable normal fetal growth while avoiding accelerated fetal growth patterns, and minimising excessive maternal weight gain (Dornhorst 2002). The recommendation is that all women diagnosed with GDM need to consult with a diabetic specialised dietitian or experienced nutritionist to determine the appropriate individualised diet, taking cultural preferences into account (Cheung 2009; Serlin 2009).

Different types of diets recommended for treatment include low or moderate glycaemic index (GI) diets, high fibre or high fibreenriched diets, energy restricted diets, low carbohydrate diet or high complex carbohydrate diet and/or low monounsaturated fat diets (Rae 2000; Zhang 2006; Radesky 2008; Wolff 2008; Cheung 2009; Moses 2009; Louie 2011; Moreno-Castilla 2013; Asemi 2014b; Hernandez 2014; Viana 2014; Jamilian 2015; Ma 2015; Markovic 2016; NICE 2015).

\section{Physical activity}

It is unusual for GDM treatment recommendation to advise any physical activity modification alone. Some trials have evaluated the effects of physical exercise for women with GDM or type 2 diabetes. Physical exercises are usually recommended as lowimpact activities, such as walking, swimming, stationary cycling or special exercise classes for pregnant women (Davenport 2008; Mottola 2008; de Barros 2010; Manders 2010; Barakat 2012; Stafne 2012; ACOG 2015; Garrison 2015; Padayachee 2015).

\section{Combined dietary modification and exercise}

While often the initial treatment recommendation for women diagnosed with GDM is diet modification, it is common in clinical practice to combine diet with exercise advice during pregnancy (ACOG 2013; NZ Ministry of Health 2014; Garrison 2015; NICE 2015). This is often referred to as dietary and lifestyle advice (Artal 2007), or lifestyle modification programmes where women participate in a comprehensive program on nutrition, exercise, and appropriate weight gain in pregnancy (Harris 2005; Cheung 2009; Shirazian 2010).

\section{Pharmacological hypoglycaemic agents}

\section{Oral hypoglycaemic agents}

When glycaemic treatment targets are unable to be achieved, pharmacological hypoglycaemic agents may be considered. While traditionally this has meant subcutaneous insulin for the woman with GDM, there has been an increase in the use of oral pharmacological hypoglycaemic agents as an alternative (Tieu 2010; Ogunyemi 2011). Oral agents have lower costs, are easier to administer, and have greater acceptability for women with GDM (Ryu 2014). The most commonly used oral agents are sulphonylureas, which include acetohexamide, chlorpropamide, tolazamide, tolbutamide (first generation, usually not used to treat women with GDM) and glyburide (glibenclamide), glipizide and glimepiride (second generation) (Holt 2013; Kalra 2015); and biguanide (metformin) (Cheung 2009; Simmons 2015). Other oral hypoglycaemic agents used less frequently include alpha-glucosidase inhibitors (acarbose and miglitol) (Kalra 2015); thiazolidinediones (pioglitazone and rosiglitazone) and meglitinides (repaglinide and nateglinide) (Kavitha 2013).

Trials have compared different oral pharmacological hypoglycaemic agents with each other, with placebo, or with subcutaneous insulin and/or physical exercise and different diets (Langer 2000; Bertini 2005; Moretti 2008; Cheung 2009; Balsells 2015; Carroll 2015; Casey 2015).

Despite the widespread use of oral pharmacological hypoglycaemic agents, these are not licensed for use during pregnancy in many countries (including the USA, UK, Australia, New Zealand) (Berggren 2013). This is due to the concern that they can cross the placenta, in particular the firstgeneration oral hypoglycaemic agents. At this stage, randomised controlled trials (RCTs) conducted with glyburide (secondgeneration sulphonylureas) and biguanide (metformin) have not demonstrated short-term harm to the mother or her growing baby (Langer 2000; Bertini 2005; Blumer 2013; Kelley 2015), but the information on long-term safety of these drugs remains limited.

\section{Insulin}

Women with GDM, who have difficulty controlling their glucose concentrations with lifestyle changes, such as diet and exercise, with or without the addition of an oral pharmacological agent, require insulin (Mpondo 2015). Human insulin does not cross the placenta in clinically significant amounts and therefore is considered safe for the fetus when administered subcutaneously in pregnancy (Menon 1990; ADA 2015; Garrison 2015; Kelley 2015). Subcutanous exogenous insulin is designed to mimic the physiological secretion of endogenous insulin (Magon 2014; Home 2015). Some studies with insulin analogues indicate these can cross the placenta when an antigen-antibody complex is formed with immunoglobulins, which can carry the insulin analogues though the placenta (Jovanovic 2007; Durnwald 2013; Lv 2015). There is a need for large RCTs to establish the safe use in pregnancy of long-acting insulin analogues (glargine and detemir), as the effect of the transplacental insulin bound immunoglobulin A (IgA) is unclear (Balsells 1997; Negrato 2012; Durnwald 2013). While fetal macrosomia has been identified in some observational and RCTs of long-acting insulin analogues, other concerns, including fetal death, have been raised (Gamson 2004; Negrato 2012; Coiner 2014). 
There are several methods of administering insulin analogues. Historically and currently, insulin analogues have been administered subcutaneously as a basal-bolus regimen (given before each meal) as this provides the most effective glycaemic control (Nachum 1999; Cheung 2009). These daily multiple subcutaneous injections may include rapid- (lispro, aspart, glulisine), intermediate- (neutral protamine hagedorn (NPH)) and long-acting (glargine and detemir) insulin analogues (Singh 2007; Horvath 2010). Fast-acting and intermediate-acting insulin analogues are currently the preferred choice of treatment for women with GDM because there are limited data available for longacting insulin in pregnancy (Jovanovic 2007; Durnwald 2013).

An alternative insulin administration method is via a continuous subcutaneous insulin infusion pump (CSII). Modern pumps are small and lightweight, battery operated, and hold enough insulin for several days. This means frequent daily injections are not required. CSII pumps aim to maintain the basal rate of insulin, reducing the risk of maternal hypoglycaemia, and decreasing the risk of fasting hyperglycaemia. CSII pumps are not associated with worse maternal and perinatal outcomes (Simmons 2001; Secher 2010; Bernasko 2012; Kesavadev 2016). Women using CSII pumps during pregnancy for GDM and type 2 diabetes treatment preferred the flexible lifestyle with comparable healthcare costs (Gabbe 2000; Gonalez 2002; Wollitzer 2010).

Oral and nasal insulin are other alternatives to subcutaneous insulin and are currently under development because of their convenience, quick liver absorption and potentially avoiding adverse effects of weight gain and hypoglycaemia (Woodley 1994; Wang 1996; Carino 1999; Arbit 2004; lyer 2010; Heinemann 2011; Fonte 2013). Although some pharmaceutical companies have stopped developing inhaled (nasal) insulin, some trials are still ongoing (Hompesh 2009; Rosenstock 2009; Hollander 2010). It must be noted that research trials for oral and nasal insulin do not include women with GDM at this stage but are being considered for future research.

\section{Other interventions}

Other interventions reported in the literature for preventing GDM or treating women with GDM include dietary supplements and nutraceuticals. The term nutraceutical was created in 1989 by $\mathrm{Dr}$ Stephen DeFelice, chairperson of the Foundation for Innovation in Medicine, who combined the terms nutrition and pharmaceutical. Nutraceuticals are marketed as nutritional supplements and sold with the intent to treat or prevent disease (Brower 1999; Gupta 2010; Lakshmana Prabu 2012). They are not governmentally regulated or licensed (Zeisel 1999; Rajasekaran 2008). Currently over 470 nutraceutical products are available with reported health benefits (Brower 1999; Eskin 2005; Gupta 2010). While RCTs involving nutraceuticals are scant in the literature for the treatment or prevention of GDM, there is some evidence from mainly observational studies. Dietary fibre from psyllium has been used for glucose control and reducing lipid levels in hyperlipidaemia (Hamid 2000; Baljith 2007; Rajasekaran 2008; Babio 2010). Omega-3 fatty acids have been suggested to reduce glucose tolerance for humans predisposed to diabetes because insulin is required for synthesis of the long chain n-3 fatty acids (Sirtori 2002). The omega-3 fatty acid docosahexaenoic acid (DHA) involved with regulating insulin resistance has been recommended for women with GDM (Coleman 2001; Sirtori 2002; Thomas 2006; Gupta 2010). Magnesium has been shown to improve insulin sensitivity in non-diabetic participants
(Guerrero-Romer 2004; Mooren 2011; Wang 2013), as has chromium picolinate (Broadhurst 2006; Martin 2006; Paivaa 2015), calcium and vitamin D (Dror 2011; Burris 2012; Poel 2012; Asemi 2014a; Burris 2014). Cinnamon and extracts of bitter melon may have some effect as co-treatments in the prevention of diabetes (Rajasekaran 2008; Hui 2009).

Nutraceuticals should not be confused with dietary supplements, which are products intended to supplement the diet that contain one or more ingredients such as vitamins, mineral, a herb, an amino acid or a concentrate, metabolite, constituent, extract or combinations of these (Rajasekaran 2008).

Myo-inositol, an isomer of inositol, is a dietary supplement of naturally occurring sugar commonly found in cereals, corn, legumes, and meat. Small, low quality RCTs have shown a potential beneficial effect on improving insulin sensitivity and suggest that myo-inositol may be useful for women in preventing GDM, but not for treatment of GDM (Facchinetti 2013; Malvasi 2014; Crawford 2015; D'Anna 2015).

\section{How the intervention might work}

Treatment for women with GDM aims to normalise maternal fasting and postprandial glucose concentrations and modify fetal physiological responses to maternal hyperglycaemia, thereby reducing maternal and associated fetal and neonatal shortterm morbidity. Two large randomised trials (Crowther 2005; Landon 2009), demonstrated reductions in birthweight and largefor-gestational-age infants in women with GDM who received treatment compared with women with GDM who were not treated. Any intervention that helps to normalise maternal glucose concentrations may therefore be a useful treatment for women with GDM.

Human insulin stimulates glucose and amino acid uptake from the blood to various tissues and stimulation of anabolic processes for glycogen, protein, and lipid synthesis. Glucagon has opposing effects, causing release of glucose from glycogen, release of fatty acids from stored triglycerides, and stimulation of gluconeogenesis. Metabolic homeostasis is maintained by the balance between insulin and glucagon (Wahlqvist 1978; Bantle 1983).

\section{Different types of diet}

One of the aims of dietary advice for women with GDM is to prevent maternal hyperglycaemia. Different types of diets recommended for treatment include low- or moderate-GI diets, high fibre or high fibre-enriched diets, energy restricted diets, low carbohydrate diet or high complex carbohydrate diet and/or low monounsaturated fat diets.

Carbohydrates absorbed following digestion are converted into glucose (Wahlqvist 1978; Bantle 1983). Current recommendations for women with GDM are for carbohydrate-controlled and low-Gl diets, evenly distributed throughout the day, when remaining within the recommended glucose treatment targets (Clapp 2002; Dornhorst 2002; Ludwig 2002). Glycaemic index quantitatively defines the effect of carbohydrate-based foods on glucose concentrations (Foster-Powell 2002). Consumption of carbohydrates triggers the release of insulin and inhibits secretion of glucagon. Glucagon stimulates gluconeogenesis and release of the newly formed glucose from the liver into the blood. These 
actions produce a rapid return to fasting blood glucose levels and storage of glucose as glycogen or lipid (Kershaw 2006; Duncan 2007).

Likewise, a protein-rich meal leads to the release of insulin and glucagon. This rise of insulin associated with the protein meal stimulates uptake of the glucose formed in the liver by muscle and fat tissue (Nuttall 1984; van Loon 2000).

Other types of diets such as fat (polyunsaturated fatty acids may be protective against impaired glucose tolerance, and saturated fatty acids can increase glucose and insulin concentrations) and soluble fibre (which may lower blood cholesterol by binding to bile acids) are also thought to influence blood glucose concentrations (Zhang 2006; Babio 2010; Kim 2010).

\section{Physical activity}

Physical activity results in shifting fuel usage by the working muscle from primarily non-esterified fatty acids (NEFAs) to a blend of NEFAs, glucose, and muscle glycogen and improves insulin sensitivity in skeletal muscle and glucose control (Sigal 2004; Asano 2014). Glucose enters skeletal muscle cells via facilitated diffusion through a glucose transporter (GLUT4) and peripheral clearance of glucose in skeletal muscle depending on the blood flow to muscle through glycolysis and glycogenesis (Sakamoto 2002; Rose 2005; Richter 2013). Translocation of the GLUT4 transporter is induced by insulin and insulin-independent mechanisms (Richter 2001; Sigal 2004; Richter 2013). The improvements in insulin sensitivity after regular and sustained exercise, which improves blood supply to active skeletal muscle, include a decrease of insulin secretion and an increase of glucagon (Coderre 1995; Wojtaszewski 2002; Sigal 2004; Clapp 2006).

\section{Oral hypoglycaemic agents}

Second-generation sulphonylureas such as glyburide (glibenclamide), glipizide, and glimepiride (Holt 2013; Kalra 2015) work by lowering glucose concentration through stimulating the release of insulin by binding to specific receptors in pancreatic $\beta$ cell plasma membrane (Simonson 1984; Groop 1987; Groop 1991). Firstgeneration sulphonylureas have been identified in the literature as crossing the placenta, being secreted in breast milk, and have been associated with prolonged neonatal hypoglycaemia (Kemball 1970; Christesen 1998). Second-generation sulphonylureas are reported in the literature as less likely to cross the placenta (Elliott 1991; Langer 2000; Kraemer 2006; Cheung 2009; Schwarz 2013; Kalra 2015).

Biguanide (metformin) increases insulin sensitivity through the rate of hepatic glucose production, hepatic glycogenolysis, and by increasing insulin-stimulated uptake of glucose in skeletal muscles (Sirtori 1994; Langer 2007; Cheung 2009; Kavitha 2013; Kalra 2015; Simmons 2015). This process reduces insulin resistance. Biguanide does not stimulate the fetal pancreatic $\beta$ cells to produce insulin, and hence, is not associated with neonatal hyperinsulinaemia (Sirtori 1994; Ho 2007; Kavitha 2013).

Alpha-glucosidase inhibitors (acarbose and miglitol) reduce postprandial hyperglycaemia by slowing the absorption of carbohydrates in the intestines (Lebovitz 1997; Ho 2007; Kalra 2015). The effects of alpha-glucosidase inhibitors have not been studied well in pregnancy. Animal studies suggest that alpha- glucosidase inhibitors are not teratogenic (Young 2009; Holt 2013; Kalra 2015; Simmons 2015).

Thiazolidenediones (pioglitazone and rosiglitazone, Kavitha 2013), activate the peroxisome proliferator-activated receptor (a group of nuclear receptor proteins) reducing insulin resistance (Young 2009). The pharmacodynamics of these drugs are similar to glyburide (a second-generation sulphonylurea). Thiazolidenediones are bound to plasma proteins $(99.8 \%)$ and are metabolised in the liver (Stumvoll 2003; Langer 2007). While it appears that thiazolidinediones are not teratogenic, a high risk of placental transfer and an association with fetal death and growth restriction have been reported (Chan 2005; Holt 2013).

Meglitinides (repaglinide and nateglinide) act similarly to sulphonylurea but use different receptors by stimulating the pancreas to release insulin in response to a meal (Kavitha 2013). Meglitinides block ATP-dependent potassium channels in functioning pancreatic $\beta$ cells leading to the opening of calcium channels resulting in an influx of calcium. Increased intracellular calcium initiates and enhances insulin secretion (Rendell 2004; Kavitha 2013). Meglitinides agents have only been studied in non-pregnant participants with type 2 diabetes, and show some improvements with postprandial glycaemic results and $\mathrm{HbAlc}$ (Goldberg 1998; Rosenstock 2004). At this stage, meglitinides can not be recommended for use in pregnancy (Kavitha 2013).

\section{Insulin}

Human insulin is a pancreatic hormone (secreted by the $\beta$ cells of the pancreatic islets of Langerhans) that regulates the movement of glucose from blood into cells. Insulin lowers glucose concentration by stimulating peripheral glucose uptake and by inhibiting glucose production and release by the liver. Insulin inhibits lipolysis, proteolysis and gluconeogenesis and increases protein synthesis and conversion of excess glucose into fat (Kersten 2001; Wilcox 2005; Proud 2006). Treatment with exogenous subcutaneous insulin for women with GDM aims to achieve as close as possible physiological profile by mimicking the pancreatic basal insulin release. However, this is based on average plasma insulin profiles and it is difficult to factor in the individual variability of absorption, dietary intake and exercise (Hartman 2008; Grunberger 2013; Pagliuca 2014). Insulin treatment for women with GDM can include short- or rapid- (lispro, aspart, glulisine) and intermediateand long acting- (neutral protamine hagedorn (NPH), glargine, detemir) insulin analogues (Singh 2007; Horvath 2010; Pollex 2011; Ansar 2013; Magon 2014), given usually by daily multiple or single subcutaneous injections guided by recommended glycaemic targets. Table 1 identifies how the different subcutaneous insulin analogues act to achieve a more physiological profile. Please note that some studies results cited in Table 1 are for pregnant women who had either type 1 or type 2 diabetes only. More studies are needed that include women with GDM.

\section{Other interventions}

Supplemental nutraceuticals are believed to support the chemical food elements (nutrients) needed for the human body's metabolism and prescribed when there is a diagnosis of a nutrient depletion or required for strengthening the metabolism or prevention of disease (Lakshmana Prabu 2012). Currently there are over 470 nutraceuticals available including supplements for GDM (Eskin 2005; Gupta 2010). The mechanism of action for 
nutraceuticals and other dietary supplements are often not clear and further high-quality research is needed.

Myo-inositol is required for cell membrane formation and works on the insulin receptors of each cell so insulin can bind effectively thus reducing insulin resistance (Croze 2013). It is involved with mediating the pathway of intracellular insulin signals increasing cellular effectiveness of insulin within the cell (Larner 2010). Small randomised trials of low-quality conducted in Italy have shown some effect in preventing GDM (D'Anna 2013; Facchinetti 2013; Malvasi 2014; D'Anna 2015). Further high-quality research is needed to establish if myo-inositol improves health outcomes for mothers and their babies.

\section{Why it is important to do this overview}

There are several Cochrane systematic reviews about treatments for women with GDM. These include different types of diet, exercise, subcutaneous insulin, oral hypoglycaemic agents and other oral supplements as well as management recommendations such as induction of labour, caesarean section, antenatal breast milk expression, and blood glucose monitoring. This makes it difficult for clinicians, consumers, and guideline developers to easily access the available information. A Cochrane overview of systematic reviews would provide summary evidence of the effect on relevant health outcomes of different treatments for women with GDM as a onestop resource for health professionals, consumers and guideline developers aiding the simplifying of clinical treatment decisionmaking, and assisting with the process of guideline development.

\section{OB JECTIVES}

To provide a comprehensive synthesis of evidence from Cochrane systematic reviews of the benefits and harms associated with interventions for treating GDM on women and their babies.

\section{MET HODS}

The methodology for data collection and analysis is based on Chapter 22 (Overviews of reviews) of the Cochrane Handbook of Systematic Reviews of Interventions (Becker 2011). Only published Cochrane systematic reviews of randomised controlled trials (RCTs) focusing on treatments for women with gestational diabetes mellitus (GDM) were considered in this overview noting their publication and search dates. We did not attempt to update individual Cochrane systematic reviews that were due for update (two years since publication).

We contacted Cochrane Pregnancy and Childbirth to identify any relevant new reviews and review updates that were being undertaken and/or near completion for inclusion of the most update versions of reviews. Cochrane protocols and title registrations for interventions for women with GDM were found through the same process to identify future inclusions and were classified as ongoing Cochrane systematic reviews (Appendix 1). These reviews will be considered for inclusion in the update of this overview. Similarly, reviews with pre-specified overview outcomes, but with no outcome data (either no studies found or women with GDM did not feature in the included trial/s), were classified as reviews awaiting classification (Appendix 2) and will be added to this overview when future updates of the reviews include relevant data.

\section{Criteria for considering reviews for inclusion}

\section{Participants}

The participants in the Cochrane systematic reviews were women diagnosed with GDM receiving any form of treatment for GDM (as identified by the review). Women with type 1 and type 2 diabetes were excluded.

\section{Interventions}

We considered all treatments for women with GDM including:

- Any dietary modifications (including low-moderate glycaemic index (GI) diet, high to moderate $\mathrm{Gl}$ diet, energy-restricted diet, no energy restricted diet, Dietary Approaches to Stop Hypertension (DASH) diet, low carbohydrate diet, high carbohydrate diet, high unsaturated fat diet, low unsaturated fat diet, low GI diet, high fibre moderate GI diet, soy proteinenriched diet, high fibre diet, ethnic-specific diet).

- Any physical exercise (including brisk walking, resistance exercises, circuit workouts, elastic band exercises, any form of bicycling, low-intensity aerobic exercises, home-based exercises, mindfulness, yoga).

- Pharmacological treatments (oral hypoglycaemic agents including metformin, glibenclamide, acarbose, tolbutamide, chlorpropamide or combination of these therapies or subcutaneous insulin).

- Nutraceuticals or other dietary supplements (including myoinositol).

- Other interventions as identified by included reviews (including glycaemic treatment targets for GDM, management of labour and birth for women with GDM, lifestyle interventions).

Further descriptions of possible interventions are presented in Description of the interventions.

\section{Outcomes}

GDM is a complex condition with potential for short- and long-term adverse health outcomes and associated costs for the mother and her baby/child/adult. We therefore selected GRADE outcomes for the mother; the neonate/child/adult and health service.

\section{Maternal}

1. Hypertensive disorders of pregnancy (including pre-eclampsia, pregnancy-induced hypertension, eclampsia).

2. Caesarean section.

3. Development of type 2 diabetes.

4. Perineal trauma.

5. Return to pre-pregnancy weight.

6. Postnatal depression.

7. Induction of labour.

\section{Child (as neonate, child, adult)}

1. Large-for-gestational age.

2. Perinatal mortality.

3. Death or serious morbidity composite.

4. Neonatal hypoglycaemia.

5. Adiposity.

6. Diabetes (type1, type 2). 
7. Neurosensory disability.

\section{Health service}

1. Number of antenatal visits or admissions.

2. Length of postnatal stay (mother).

3. Length of postnatal stay (baby) (including neonatal intensive care unit or special care baby unit).

4. Costs associated with the treatment.

Cochrane systematic reviews that had pre-specified some or all the overview outcomes, but had no reported data or no included trials, were categorised as reviews awaiting further classification (Appendix 2) and will be reconsidered in future updates of this overview review.

\section{Search methods for identification of reviews}

We searched the Cochrane Database of Systematic Reviews on 5 January 2018 using the term 'gestational diabetes' in title, abstract, keywords. We also contacted Cochrane Pregnancy and Childbirth to identify any relevant planned or ongoing reviews. We did not apply any language or date restrictions (see Figure 1). Reviews of pregnant women with pre-existing diabetes were excluded. 


\section{Figure 1. Search flow diagram}

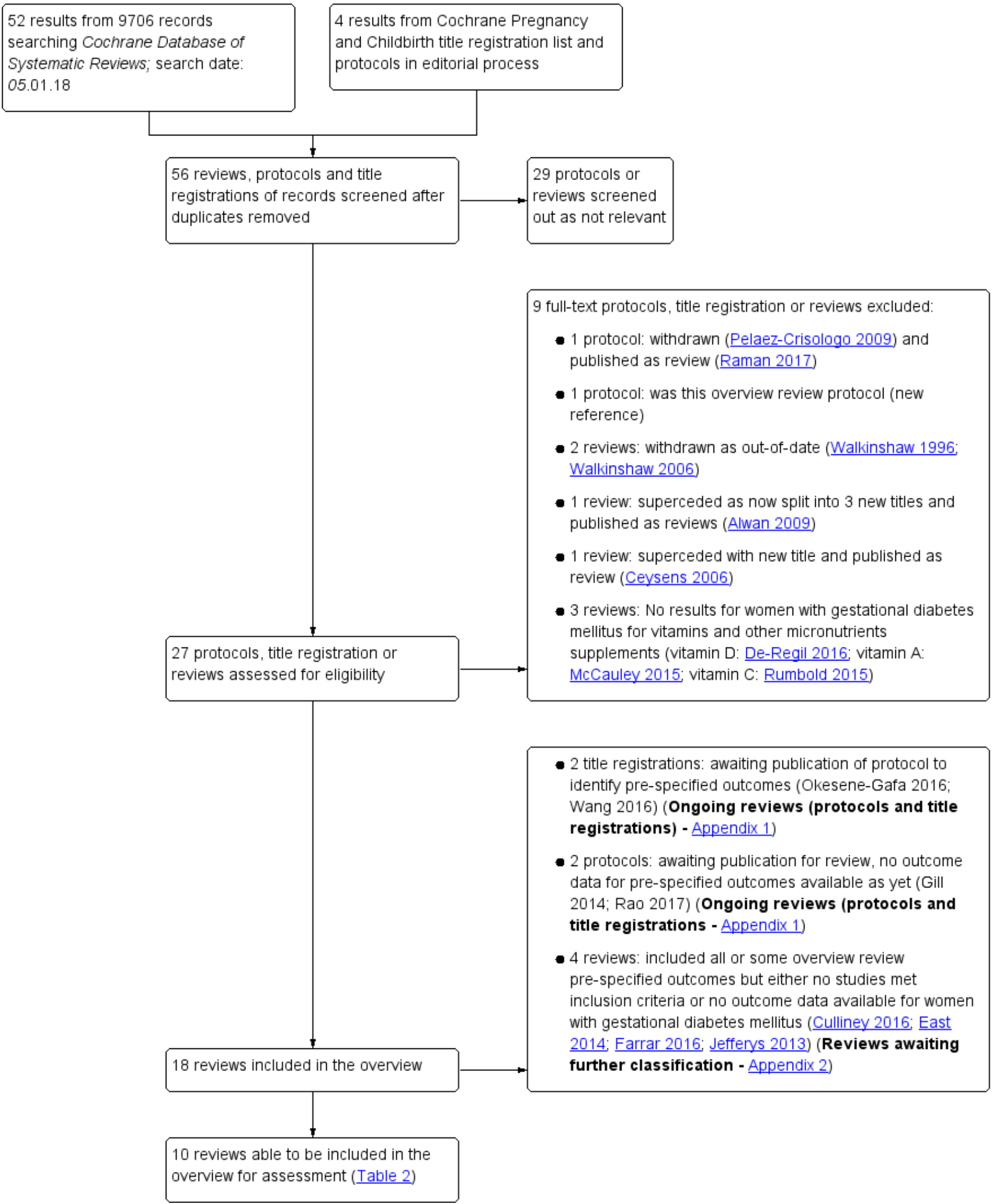

\section{Data collection and analysis}

Cochrane systematic reviews published addressing any treatments for women diagnosed with GDM were selected. Reviews and studies including treatment for pregnant women with known type I and type 2 diabetes were excluded. The methodology for data collection was based on Chapter 22 of the of the Cochrane Handbook of Sytematic Reviews of Interventions (Becker 2011). Where appropriate, the overview was prepared using Review Manager software (Review Manager 2014). 


\section{Selection of reviews}

Two overview authors independently assessed all potential Cochrane systematic reviews for inclusion identified through the search. We resolved disagreements through discussion. Overview authors who were authors of potentially relevant reviews for inclusion were not involved in the assessment of those reviews for the overview.

\section{Data extraction and management}

Two overview review authors, not involved in the included Cochrane systematic reviews, independently extracted data using a pre-defined data extraction form. We resolved any discrepancies through discussion. Where any information from the reviews was unclear or missing, we contacted the review authors.

Information from included reviews was extracted on the following.

- Population demographics: we summarised participants' characteristics with inclusion and exclusion criteria as reported in the included reviews (Table 2).

- Review characteristics: we reported the number of included trials and trial countries; design and publication years; the number of participants (women, babies, and children) in each review; the date of search conducted for each review; up-to-date status (< two years from publication was considered up-to-date); described the interventions and comparisons (Table 2); included all pre-specified outcomes relevant to the overview (Table 3).

- Statistical summaries: we reported statistical summaries by outcomes.

\section{Assessment of methodological quality of included reviews Quality of included trials within reviews}

We did not re-assess the quality of the trials in terms of risk of bias within the included Cochrane systematic reviews according to the review authors' assessments. However, we did re-assess risk of bias for trials where relevant outcomes had not been assessed using the GRADE approach. These trials were assessed using the Cochrane risk of bias tool and these assessments contributed to ascertain the study's quality according to GRADE criteria. We also noted and reported the publication and search date for each included review (Table 2).

\section{Quality of evidence in the included reviews}

Two overview authors who were not authors of the included Cochrane systematic reviews independently extracted outcomes that had been assessed using the GRADE approach in the reviews. Where the relevant outcomes had not been assessed using the GRADE approach, these were assessed independently by two overview authors using GRADE (Balshem 2011; GRADEpro). Where the overview authors disagreed with GRADE judgements in the

\section{AMSTAR score (of 11 criteria)}

Rating

\section{8 to 11}

High quality original review, we altered judgements and indicated where this was applied (see Table 4).

\section{GRADE assessment}

GRADEpro uses five criteria: study limitations (risk of bias), consistency of effect, imprecision, indirectness and publication bias to assess the quality of the body of evidence for pre-specified outcomes, as described in Chapter 5 of the GRADE Handbook. GRADE rates evidence quality as:

- high (further research is very unlikely to change confidence in the estimate of effect);

- moderate (further research is likely to have an important impact on confidence in the estimate of effects and may change the estimate);

- low (further research is very likely to have an important impact on confidence in the estimate of effect and is likely to change the estimate); or

- very low (any estimate of effect is very uncertain).

Where possible, we reported the quality of evidence as assessed by the Cochrane Review authors. Where these assessments were not available in the reviews, two overview authors (RM, JB) made judgements independently.

Two overview authors (RM, JB) generated 'Summary of findings' tables using GRADE for Cochrane systematic reviews included in the overview that did not produce 'Summary of findings' tables using GRADE. This was applied for Han 2012.

\section{Overall quality of the included reviews}

We used two different quality measurement assessment tools to assess the overall quality of the included reviews: 'Assessment of Multiple Systematic Reviews' (AMSTAR) (Shea 2007; Shea 2009) and 'Risk of Bias in Systematic Reviews' (ROBIS) (Whiting 2016).

\section{AMSTAR assessment}

Two overview authors who were not involved with the included Cochrane systematic reviews independently assessed the quality of the reviews using AMSTAR. We resolved differences through discussion. The AMSTAR instrument measures 11 components to assess the methodological quality of a systematic review (Shea 2007; Shea 2009). Each AMSTAR domain is rated as:

- 'yes' (Y) (clearly done);

- 'no' (N) (clearly not done);

- 'cannot answer' (CA); or

- 'not applicable' (NA).

High-quality reviews score eight or more 'yes' answers, moderatequality reviews score between four and seven, and low-quality systematic reviews score three or fewer 'yes' answers. 
The included Cochrane systematic reviews were assessed using the following AMSTAR questions.

1. Was an apriori design provided?

2. Was there duplicate study selection and data extraction?

3. Was a comprehensive literature search performed?

4. Was the status of publication (i.e. grey literature) used as an inclusion criterion?

5. Was a list of studies (included and excluded) provided?

6. Were the characteristics of the included studies provided?

7. Was the scientific quality of the included studies assessed and documented?

8. Was the scientific quality of the included studies used appropriately in formulating conclusions?

9. Were the methods used to combine the findings of studies appropriate?

10.Was the likelihood of publication bias assessed?

11.Was the conflict of interest included?

A score out of 11 is given regardless of any 'cannot answer' or 'not applicable' responses (https://amstar.ca/contact_us.php).

\section{ROBIS assessment}

Two overview authors who were not involved with the included Cochrane systematic reviews independently assessed the quality of the reviews using ROBIS (Whiting 2016). We resolved differences through discussion.

ROBIS considers risk of bias across four key domains. Each domain elicits information about possible limitations of the included Cochrane systematic review through a series of questions. Domain 1 - three have five questions each and Domain 4 has six questions. Questions are answered with yes, no, or unclear. The risk of bias for each domain is then judged and summarised as low, high or unclear concerns. Once all four domains are assessed, an overall judgement of risk of bias is made (low, high or unclear risk) (Whiting 2016). The included Cochrane systematic reviews were assessed using the following ROBIS domains.

Domain 1: study eligibility criteria.

Domain 2: identification and selection of studies.

Domain 3: data collection and study appraisal.

Domain 4: synthesis and findings.

\section{Data synthesis}

The characteristics of the included Cochrane systematic reviews are described in Table 2. We did not examine indirect comparisons nor conduct network meta-analyses. We summarised the results of the included Cochrane systematic reviews by categorising findings in the following framework organised by overview review outcomes.

- Effective interventions: indicating that the review found moderate- to high-quality evidence of effectiveness for an intervention.
- Promising interventions (more evidence needed): indicating that the review found moderate-quality evidence of effectiveness for an intervention, but more evidence is needed.

- Ineffective or possibly harmful interventions: indicating that the review found moderate- to high-quality evidence of lack of effectiveness for an intervention.

- Probably ineffective or harmful interventions (more evidence needed): indicating that the review found moderate-quality evidence suggesting lack of effectiveness for an intervention, but more evidence is needed.

- No conclusions possible due to lack of evidence: indicating that the review found low- or very low-quality evidence, or insufficient evidence to comment on the effectiveness of an intervention.

This approach to summarising the evidence was based on the publication of Effective Care in Pregnancy and Childbirth (Vol. 2: Materials and methods used in synthesizing evidence to evaluate the effects of care during pregnancy and childbirth) (Chalmers 1989) and a Cochrane overview of pain management in labour, which categorised interventions as "what works", "what may work", and "insufficient evidence to make a judgement" (Jones 2012).

\section{RES U LTS}

Our search of the Cochrane Database of Systematic Reviews on 5 January 2018 identified 52 reviews and published protocols from 9706 records, and four records from the Cochrane Pregnancy and Childbirth group's title registrations list, to provide a total of 56 records (Figure 1). Following screening of title and review abstracts for eligibility we excluded 29 titles, protocols and reviews as ineligible.

We excluded nine publications that were full-text reviews, protocols or registered titles (Figure 1). Further details are provided in the description of excluded reviews section following.

Two additional registered titles (Wang 2013; Okesene-Gafa 2016) and two protocols (Gill 2014; Rao 2017), which indicated treatment for women with GDM and had some or all of the pre-specified primary and secondary outcomes of this overview, were classified as ongoing reviews (Appendix 1). When published, these reviews will be considered for inclusion in future updates of this overview.

A further four Cochrane systematic reviews were classified as reviews awaiting further classification (Appendix 2). These reviews include some or all of the pre-specified GRADE outcomes of this overview, but either had no studies that met the inclusion criteria, or no outcome data reported for women with GDM (Jefferys 2013; East 2014; Culliney 2016; Farrar 2016). These reviews will be reassessed for future updates of this overview (Figure 1).

We included 14 Cochrane systematic reviews in this overview. Of these, 10 provided relevant outcome data reporting based on 128 RCTs (17,984 women; 16,305 babies, and 1441 children) (Han 2012; Brown 2016a; Martis 2016a; Raman 2017; Brown 2017a; Brown 2017b; Brown 2017c; Brown 2017d; Han 2017; Biesty 2018; Figure 1 ; Table 2). RCTs reported in multiple reviews were counted as one 
trial (Brown 2017b and Brown 2017c; Brown 2017b and Han 2017). However, when the same trial was reported in multiple reviews, but with participant numbers from different treatment arms (subsets), they were then counted as one trial each (Han 2017 and Brown 2017c; Han 2012 and Han 2017; Brown 2017b and Brown 2017c).

\section{Description of included reviews}

\section{Population}

All 10 reviews that provided relevant data for this overview included randomised trials that recruited women with GDM (Table 2).

\section{Settings}

The trials of the included reviews were conducted in a wide range of countries including some low- and middle-income countries (Table 2).

\section{Interventions and comparisons}

The 10 Cochrane systematic reviews that provided relevant data for this overview included a total of 27 comparisons (Table 2).

- One review focused on any dietary modifications for women with GDM:

* Different types of dietary advice for women with gestational diabetes mellitus (Han 2017).

- One review focused on any exercise for women with GDM:

* Exercise for pregnant women with gestational diabetes for improving maternal and fetal outcomes (Brown 2017c).

- One review focused oral pharmacological interventions for treatment for women with GDM:

* Oral anti-diabetic pharmacological therapies for the treatment of women with gestational diabetes (Brown 2017a).

- One review assessed nutraceuticals or other dietary supplements for treatment for women with GDM:

* Dietary supplementation with myo-inositol in women during pregnancy for treating gestational diabetes (Brown 2016a).

- Three reviews assessed other management strategies for women with GDM:

* Planned birth at or near term for improving health outcomes for pregnant women with gestational diabetes and their infants (Biesty 2018).

* Different intensities of glycaemic control for women with gestational diabetes mellitus (Martis 2016a).

* Different methods and settings for glucose monitoring for gestational diabetes during pregnancy (Raman 2017).

- One review assessed interventions for women with hyperglycaemia not meeting gestational diabetes and type 2 diagnostic criteria:

* Interventions for pregnant women with hyperglycaemia not meeting gestational diabetes and type 2 diagnostic criteria (Han 2012). The overview review authors agreed to include Han 2012 in this overview, as different countries have different diagnostic levels for confirming that a pregnant woman has GDM. It is highly likely that women with hyperglycaemia identified in one country as not meeting the gestational diagnostic threshold for GDM would be diagnosed as having GDM in another country.
- One review assessed lifestyle interventions for women with GDM:

* Lifestyle interventions for the treatment of women with gestational diabetes mellitus (Brown 2017b). Lifestyle interventions include at least two or more interventions such as dietary advice, self-monitoring blood glucose monitoring, education via group sessions or individual, mindfulness eating, yoga, relaxation, breathing, fetal growth monitoring, and other antenatal tests. See characteristics of included reviews for further intervention details (Table 2).

- One review assessed insulin treatment for women with GDM:

* Insulin for the treatment of women with gestational diabetes mellitus (Brown 2017d).

In total there were 128 RCTs in the 10 included Cochrane systematic reviews that provided relevant data which involved a total of 17,984 women; 16,305 babies; and 1441 children (Table 2).

The 10 reviews included from one (Martis 2016a; Biesty 2018) to 53 RCTs (Brown 2017d); 159 (Brown 2016a) to 7381 Brown 2017d women; 159 (Brown 2016a) to 6435 babies (Brown 2017d); and 674 (Brown 2017d) to 767 children (Brown 2017b).

Nine $(90 \%)$ of the included reviews had conducted searches in the last two years and were considered up-to-date (January 2016 to August 2017) (Biesty 2018; Brown 2017a; Brown 2017b; Brown 2017c; Brown 2017d; Han 2017; Martis 2016a; Raman 2017). One review listed the last search date as 30 September 2011 (Han 2012; Table 2).

Table 2 describes participant inclusion and exclusion criteria, interventions, and comparisons for each review.

\section{Outcomes reported}

We listed the pre-specified overview outcomes and indicated if the included reviews assessed these outcomes (Table 3 ).

\section{Description of excluded reviews}

We excluded nine publications that were full-text reviews, protocols or registered titles (Pelaez-Crisologo 2009; Martis 2016a; Walkinshaw 1996; Walkinshaw 2006; Alwan 2009; Ceysens 2006; De-Regil 2016; McCauley 2015; Rumbold 2015) (Figure 1). These included a protocol that was withdrawn (Pelaez-Crisologo 2009), and subsequently published as a review (Raman 2017) and included in the overview; the protocol for this overview (Martis 2016a); and two reviews that were withdrawn because they were out of date (Walkinshaw 1996; Walkinshaw 2006). Walkinshaw 1996 was superseded by Alwan 2009, which has now been superseded and split into three new reviews (Brown 2017a; Brown 2017b; Brown 2017d), which were included in this overview. A superseded review (Ceysens 2006), which has been revised and published (Brown 2017c), was included in this overview. Three reviews presented no results for women with GDM treated who were with vitamins and other micronutrients (vitamin D De-Regil 2016; vitamin A McCauley 2015; vitamin C Rumbold 2015; Table 5).

\section{Methodological quality of included reviews}

\section{Cochrane risk of bias assessments from included reviews}

Seven reviews in this overview stated that the overall judgement for risk of bias of trials included in the reviews was unclear due to lack of reporting of methodological details (Brown 2016a; Martis 
2016a; Raman 2017; Brown 2017a; Brown 2017b; Brown 2017c; Brown 2017d). One review reported an overall low risk (Biesty 2018) for most domains; one review reported an overall moderate-to-high risk of bias for most included trials (Han 2012); and one review reported an overall unclear to moderate risk of bias (Han 2017). Specific details of the assessment of risk of bias reported in the included reviews is summarised in Table 6.

\section{GRADE assessment}

The quality of the evidence reported from studies in the 10 included reviews that provided data for the overview as assessed by the Cochrane Review authors using the GRADE method varied widely, from very low- to high-quality. Most studies were assessed as providing low- to very low-quality evidence (Table 7; Table 8; Table 9).

\section{AMSTAR assessment}

All 10 included reviews that provided data for the overview were assessed at high methodological quality, and scored from 9 to 11 points using the AMSTAR tool (Han 2012; Brown 2016a; Martis 2016a; Han 2017; Raman 2017; Brown 2017a; Brown 2017b; Brown 2017c; Brown 2017d; Biesty 2018; Table 10).

AMSTAR assessments of the 10 included reviews that provided data for this overview were as follows:

1. All 10 reviews provided a priori design.

2. All 10 reviews reported duplicate study selection and data extraction.

3. All 10 reviews performed a comprehensive literature search.

4. All 10 reviews included searches of grey literature.

5. All 10 reviews provided a list of included and excluded studies.

6. All 10 reviews described the characteristics of the included studies.

7. All 10 reviews assessed and documented the scientific quality of the included studies.

8. All 10 reviews assessed the scientific quality of the included studies appropriately in formulating conclusion.

9. Eight reviews combined the findings of studies using appropriate methods. This was not applicable for two review because both included only one RCT.

10.Six reviews assessed the likelihood of publication bias. Four reviews did not mention that publication bias could not be assessed because there were fewer than 10 included studies but included test values or funnel plots.

11.Nine reviews clearly reported conflicts of interest.

\section{ROBIS assessment}

Overall, the ROBIS assessment for the 10 included reviews that provided data was judged as low risk of bias (Han 2012; Brown 2016a; Martis 2016a; Han 2017; Raman 2017; Brown 2017a; Brown 2017b; Brown 2017c; Brown 2017d; Biesty 2018; Table 11).

The assessment for each of the 10 included reviews of the four domains of the ROBIS tool are as follows.

Domain 1: all reviews were considered of low concern for specification of study eligibility criteria.
Domain 2: all reviews were considered of low concern regarding methods used to identify and/or select studies.

Domain 3: all reviews were considered of low concern regarding methods used to collect data and appraise studies.

Domain 4: all reviews were considered of low concern regarding synthesis and findings.

\section{Effect of interventions}

We summarised the results of the included reviews by categorising their findings using the following framework.

- Effective interventions: indicating that the review found moderate to high-quality evidence of effectiveness for an intervention.

- Promising interventions (more evidence needed): indicating that the review found moderate-quality evidence of effectiveness for an intervention, but more evidence is needed.

- Ineffective or possibly harmful interventions: indicating that the review found moderate to high-quality evidence of lack of effectiveness for an intervention.

- Probably ineffective or harmful interventions (more evidence needed): indicating that the review found moderate-quality evidence suggesting lack of effectiveness for an intervention, but more evidence is needed.

- No conclusions possible due to lack of evidence: indicating that the review found low- or very low-quality evidence, or insufficient evidence to comment on the effectiveness of an intervention, more evidence needed.

Further details are provided in Characteristics of included reviews (Table 2); and pre-specified GRADE outcomes in Summary of findings" tables for maternal (Table 7), child (as neonate, child, adult) (Table 8) and health service (Table 9). An assessment summary of interventions for all overview review GRADE outcomes is presented in Table 4.

\section{Maternal}

\subsection{Hypertensive disorders of pregnancy (including pre- eclampsia, pregnancy-induced hypertension, eclampsia as defined in reviews)}

Hypertensive disorders of pregnancy were reported at the end of pregnancy in seven reviews using various outcomes (any hypertensive disorder of pregnancy, pregnancy-induced hypertension, severe pregnancy-induced hypertension or preeclampsia, pre-eclampsia, eclampsia) (Han 2012; Han 2017; Raman 2017; Brown 2017a; Brown 2017b; Brown 2017c; Brown 2017d; Table 7). Evidence ranged from moderate- to very low-quality.

\subsection{Any hypertensive disorders of pregnancy (not defined)}

1.1.1 Glibenclamide versus placebo: $\mathrm{RR} 1.24,95 \% \mathrm{Cl} 0.81$ to 1.90 ; one trial, 375 women; very low-quality evidence (Brown 2017a).

1.1.2 Metformin versus glibenclamide: $\mathrm{RR} 0.70,95 \% \mathrm{Cl} 0.38$ to 1.30; three trials, 508 women; moderate-quality evidence (Brown 2017a).

1.1.3 Insulin versus oral therapy: $\mathrm{RR} 1.89,95 \% \mathrm{Cl} 1.14$ to 3.12 ; four trials, 1214 women; moderate-quality evidence (Brown 2017d). 
1.2 Pregnancy-induced hypertension

1.2.1 Glibenclamide versus placebo: $\mathrm{RR} 1.24,95 \% \mathrm{Cl} 0.71$ to 2.19 one trial, 375 women; low-quality evidence. Pregnancy-induced hypertension was defined as persistent systolic blood pressure $\geq$ $140 \mathrm{mmHg}$ or diastolic blood pressure $\geq 90 \mathrm{mmHg}$ (Brown 2017a).

1.2.2 Metformin versus glibenclamide: RR $0.71,95 \% \mathrm{Cl} 0.37$ to 1.37; two trials, 359 women; moderate-quality evidence. Pregnancyinduced hypertension was not defined (Brown 2017a).

1.2.3 Low- versus high-carbohydrate diet: RR $0.40,95 \% \mathrm{Cl} 0.13$ to 1.22; one trial, 150 women; very low-quality evidence. Pregnancyinduced hypertension was not defined (Han 2017).

1.2.4 High- versus low-unsaturated fat diet with matching calories: RR 0.54, $95 \% \mathrm{Cl} 0.06$ to 5.26; one trial, 27 women; very lowquality evidence. Pregnancy-induced hypertension was not defined (Han 2017).

1.2.5 Ethnic specific diet versus standard healthy diet: RR 0.33 , $95 \% \mathrm{Cl} 0.02$ to 7.32 ; one trial, 20 women; very low-quality evidence. Pregnancy-induced hypertension was not defined (Han 2017).

1.2.6 Insulin regimen A versus B: twice daily versus four times daily RR $1.11,95 \% \mathrm{Cl} 0.51$ to 2.42 ; one trial, 274 women; low-quality evidence. Pregnancy-induced hypertension was not defined (Brown 2017d).

\subsection{Pregnancy-induced hypertension or pre-eclampsia combined}

1.3.1 Glibenclamide versus placebo: $\mathrm{RR} 1.23,95 \% \mathrm{Cl} 0.59$ to 2.56; one trial, 375 women; low-quality evidence. Severe pregnancyinduced hypertension or pre-eclampsia was defined as proteinuria $\geq 2 \mathrm{~g}$ in 24 hours, or $\geq 2+$ on dipstick, blood pressure $\geq 160 \mathrm{mmHg}$ or diastolic pressure $\geq 110 \mathrm{mmHg}$, serum creatinine $>1.0 \mathrm{mg} / \mathrm{dL}$, platelets $<100,000 \mathrm{~mm}^{3}$, aspartate aminotransferase $>90$ units/L, or symptoms such as persistent headache, scotomata or epigastric pain (Brown 2017a).

1.3.2 Low-moderate versus moderate-high GI diet: RR 1.02, 95\% $\mathrm{Cl} 0.07$ to 15.86 ; one trial, 95 women; very low-quality evidence. Severe hypertension or pre-eclampsia was not defined (Han 2017).

1.3.3 Telemedicine versus standard care for glucose monitoring: RR $1.49,95 \% \mathrm{Cl} 0.69$ to 3.20 ; four trials, 275 women; very low-quality evidence. Pregnancy-induced hypertension or preeclampsia was not defined (Raman 2017).

\subsection{Pre-eclampsia (not defined)}

1.4.1 Metformin versus glibenclamide: $\mathrm{RR} 0.66,95 \% \mathrm{Cl} 0.11$ to 3.82; one trial, 149 women; very low-quality evidence (Brown 2017a).

1.4.2 Energy- versus no energy-restricted diet: $\mathrm{RR} 1.00,95 \% \mathrm{Cl}$ 0.51 to 1.97; one trial, 117 women; low-quality evidence (Han 2017).

1.4.3 Dietary Approaches to Stop Hypertension (DASH) diet versus control diet with matching macronutrient contents: $R R$ $1.00,95 \% \mathrm{Cl} 0.31$ to 3.26 ; three trials, 136 women; moderate-quality evidence (Han 2017).

1.4.4 High- versus low-unsaturated fat diet with matching calories: RR not estimable as there were no events in either group; one trial, 27 women;low-quality evidence (Han 2017).
1.4.5 Soy- versus no soy-protein diet: $\mathrm{RR} 2.00,95 \% \mathrm{Cl} 0.19$ to 21.03; one trial, 68 women; very low-quality evidence (Han 2017).

1.4.6 Lifestyle intervention versus usual care or diet alone: $R R$ $0.70,95 \% \mathrm{Cl} 0.40$ to 1.22 ; four trials, 2796 women; low-quality evidence (Brown 2017b).

1.4.7 Exercise versus control: $\mathrm{RR} 0.31,95 \% \mathrm{Cl} 0.01$ to 7.09 ; two trials, 48 women; low-quality evidence (Brown 2017c).

1.4.8 Intensive management versus routine care: $\mathrm{RR} 2.74,95 \% \mathrm{Cl}$ 0.26 to 29.07; one trial, 83 women; low-quality evidence (Han 2012).

1.4.9 Self- versus periodic-glucose monitoring: $\mathrm{RR} 0.18,95 \% \mathrm{Cl}$ 0.01 to 3.49; one trial, 59 women; very low-quality evidence (Raman 2017).

1.4.10 Post- versus pre-prandial glucose monitoring: RR 1.00 , $95 \% \mathrm{Cl} 0.15$ to 6.68 ; one trial, 66 women; very low-quality evidence (Raman 2017).

1.4.11 Insulin versus oral therapy: $R R 1.14,95 \% \mathrm{Cl} 0.86$ to $1.52 ; 10$ trials, 2060 women; moderate-quality evidence (Brown 2017d).

1.4.12 Insulin type A versus B: there were no events of preeclampsia reported from one trial comparing human insulin with insulin aspart in 320 women; low-quality evidence (Brown 2017d).

\subsection{Eclampsia (not defined)}

1.5.1 Low-moderate versus moderate-high GI diet: RR 0.34, 95\% $\mathrm{Cl} 0.01$ to 8.14; one trial, 83 women; very low-quality evidence (Han 2017).

\subsection{Caesarean section}

Casearean section was reported as an outcome in nine reviews (Biesty 2018; Brown 2017a; Brown 2017b; Brown 2017c;Brown 2017d Han 2012; Han 2017; Martis 2016a; Raman 2017). See Table 7. The quality of the evidence ranged from moderate- to very lowquality.

2.1 Induction of labour versus expectant management: RR 1.06, $95 \% \mathrm{Cl} 0.64$ to 1.77 ; one trial, 425 women; very low-quality evidence (Biesty 2018).

2.2 Glibenclamide versus placebo: $\mathrm{RR} 1.03,95 \% \mathrm{Cl} 0.79$ to 1.34 ; one trial, 375 women; very low-quality evidence (Brown 2017a).

2.3 Metformin versus glibenclamide: average $\mathrm{RR} 1.20,95 \% \mathrm{Cl} 0.83$ to 1.72; four trials, 554 women; low-quality evidence (Brown 2017a).

2.4 Glibenclamide versus acarbose: $\mathrm{RR} 0.95,95 \% \mathrm{Cl} 0.53$ to 1.70 ; one trial, 43 women; low-quality evidence (Brown 2017a).

2.5 Low-moderate versus moderate-high GI diet: RR 0.66, 95\% $\mathrm{Cl} 0.29$ to 1.47 ; one trial, 63 women;very low-quality evidence (Han 2017).

2.6 Energy- versus no energy-restricted diet: $\mathrm{RR} 1.12,95 \% \mathrm{Cl} 0.80$ to 1.56; two trials, 420 women; low-quality evidence (Han 2017).

2.7 DASH diet versus control diet with matching macronutrient contents: RR $0.53,95 \% \mathrm{Cl} 0.37$ to 0.76 ; two trials, 86 women; lowquality evidence (Han 2017). 
2.8 Low- versus high-carbohydrate diet: RR $1.29,95 \% \mathrm{Cl} 0.84$ to 1.99; two trials, 179 women; low-quality evidence (Han 2017).

2.9 High- versus low-unsaturated fat diet with matching calories: RR $1.08,95 \% \mathrm{Cl} 0.07$ to 15.50 ; one trial, 27 women; very low-quality evidence (Han 2017).

2.10 Low GI diet versus high fibre moderate-GI diet: RR 1.91, 95\% $\mathrm{Cl} 0.91$ to 4.03; one trial, 92 women; very low-quality evidence (Han 2017).

2.11 Diet + diet-related behavioural advice versus diet only: RR $0.78,95 \% \mathrm{Cl} 0.38$ to 1.62 ; one trial, 99 women;very low-quality evidence (Han 2017)

2.12 Soy- versus no soy-protein diet: $\mathrm{RR} 1.00,95 \% \mathrm{Cl} 0.57$ to 1.77 one trial 68 women;very low-quality evidence (Han 2017).

2.13 Ethnic-specific diet versus standard healthy diet: RR 1.20 , $95 \% \mathrm{Cl} 0.54$ to 2.67 ; one trial, 20 women; very low-quality evidence (Han 2017).

2.14 Lifestyle intervention versus usual care or diet alone: RR $0.90,95 \% \mathrm{Cl} 0.78$ to $1.05 ; 10$ trials, 3545 women; low-quality evidence (Brown 2017b).

2.15 Exercise versus control: $\mathrm{RR} 0.86,95 \% \mathrm{Cl} 0.63$ to 1.16 ; five trials, 316 women; moderate-quality evidence (Brown 2017c).

2.16 Intensive management versus routine care: $\mathrm{RR} 0.93,95 \% \mathrm{Cl}$ 0.68 to 1.27 ; three trials, 509 women; very low-quality evidence (Han 2012).

2.17 Strict versus less strict glycaemic control: $\mathrm{RR} 1.35,95 \% \mathrm{Cl}$ 0.83 to 2.18; one trial, 171 women; very low-quality evidence (Martis 2016a).

2.18 Telemedicine versus standard care for glucose monitoring: average RR $1.05,95 \% \mathrm{Cl} 0.72$ to 1.53; five trials, 478 women; very low-quality evidence (Raman 2017).

2.19 Self- versus periodic-glucose monitoring: average RR 1.18 $95 \% \mathrm{Cl} 0.61$ to 2.27 ; two trials, 400 women; low-quality evidence (Raman 2017).

2.20 Continuous- versus self-monitoring: $\mathrm{RR} 0.91,95 \% \mathrm{Cl} 0.68$ to 1.20 ; two trials, 179 women; very low-quality evidence (Raman 2017).

2.21 Post- versus pre-prandial glucose monitoring: RR $0.62,95 \%$ $\mathrm{Cl} 0.29$ to 1.29; one trial, 66 women; very low-quality evidence (Raman 2017).

2.22 Insulin versus oral therapy: $\mathrm{RR} 1.03,95 \% \mathrm{Cl} 0.93$ to $1.14 ; 17$ trials, 1988 women; moderate-quality evidence (Brown 2017d).

2.23 Insulin type A versus B: $\mathrm{RR} 1.00,95 \% \mathrm{Cl} 0.91$ to 1.09 ; three trials, 410 women; moderate-quality evidence (Brown 2017d).

2.24 Insulin versus diet: $\mathrm{RR} 0.85,95 \% \mathrm{Cl} 0.50$ to 1.42 ; two trials, 133 women; very low-quality evidence (Brown 2017d).

2.25 Insulin versus exercise: $\mathrm{RR} 1.50,95 \% \mathrm{Cl} 0.29$ to 7.87 ; one trial, 34 women; very low-quality evidence (Brown 2017d).
2.26 Insulin regimen A versus B: twice daily versus four times daily RR $0.99,95 \% \mathrm{Cl} 0.68$ to 1.44 ; one trial, 274 women; very lowquality evidence (Brown 2017d) or three times versus six times daily RR $1.06,95 \% \mathrm{Cl} 0.17$ to 6.72 ; one trial, 37 women; very low-quality evidence (Brown 2017d).

\subsection{Development of type 2 diabetes}

Development of type 2 diabetes was reported as an outcome in three reviews (Brown 2017b; Brown 2017d; Han 2017; Table 7). Time points for type 2 diabetes testing ranged from one to two weeks postpartum (Han 2017) up to 13 months postpartum (Han 2017). The Brown 2017b review did not define the test or the time point. The quality of the evidence ranged from moderate- to very low-quality. There was no clear evidence of a difference for the risk of development of type 2 diabetes for any of the comparisons reporting this outcome.

3.1 Oral Glucose Tolerance Test (OGTT) for diagnosis of type $\mathbf{2}$ diabetes

3.1.1 High- versus low-unsaturated fat diet with matching calories: at one to two weeks postpartum RR $2.00,95 \% \mathrm{Cl} 0.45$ to 8.94; one trial, 24 women; very low-quality evidence or at four to 13 months postpartum RR $1.00,95 \% \mathrm{Cl} 0.10$ to 9.61 ; one trial, six women; very low-quality evidence (Han 2017).

3.1.2 Low-GI diet versus high fibre moderate-GI diet: at three months postpartum RR $0.76,95 \% \mathrm{Cl} 0.11$ to 5.01 ; one trial, 58 women; very low-quality evidence (Han 2017).

3.1.3 Lifestyle intervention versus usual care or diet alone: RR $0.98,95 \% \mathrm{Cl} 0.54$ to 1.76 ; two trials, 486 women; low-quality evidence (Brown 2017b). Test and time frame not defined in the review.

3.1.4 Insulin versus oral therapy: $\mathrm{RR} 1.39,95 \% \mathrm{Cl} 0.80$ to 2.44 ; two trials, 754 women; moderate-quality evidence. One trial reported data at the six to eight weeks postpartum OGTT and the second trial reported data at one year postpartum (Brown 2017d).

3.1.5 Insulin versus diet: up to 15 years follow-up RR $0.98,95 \% \mathrm{Cl}$ 0.79 to 1.21; two trials, 653 women; very low-quality (Brown 2017d).

\subsection{Perineal trauma/tearing}

Perineal trauma/tearing was reported as an outcome by four reviews (Biesty 2018; Brown 2017a; Brown 2017b; Raman 2017; Table 7). The quality of the evidence ranged from moderate- to very low-quality. There was no clear evidence of a difference for the risk of perineal trauma/tearing for any of the comparisons reporting this outcome.

4.1 Induction of labour versus expectant management: RR 1.02, $95 \% \mathrm{Cl} 0.73$ to 1.43 ; one trial, 373 women; low-quality evidence (Biesty 2018).

4.2 Glibenclamide versus placebo: $\mathrm{RR} 0.98,95 \% \mathrm{Cl} 0.06$ to 15.62 ; one trial, 375 women; very low-quality evidence (Brown 2017a).

4.3 Metformin versus glibenclamide: $\mathrm{RR} 1.67,95 \% \mathrm{Cl} 0.22$ to 12.52; two trials, 308 women; low-quality evidence (Brown 2017a).

4.4 Lifestyle intervention versus usual care or diet alone: RR $1.04,95 \% \mathrm{Cl} 0.93$ to 1.18 ; one trial, 1000 women; moderate-quality evidence (Brown 2017b). 
4.5 Continuous- versus self-monitoring blood glucose: very low-quality evidence from one trial reported that "There were no statistically significant differences between the two groups ... in maternal lacerations". No data were available for metaanalysis" (Raman 2017).

4.6 Post- versus pre-prandial glucose monitoring: RR $0.38,95 \%$ $\mathrm{Cl} 0.11$ to 1.29 ; one trial, 66 women; very low-quality evidence (Raman 2017).

\subsection{Postnatal weight retention or return to pre-pregnancy weight}

Postnatal weight retention or return to pre-pregnancy weight was reported as an outcome by four reviews (Brown 2017b; Brown 2017c; Brown 2017d; Han 2017; Table 7). The timing of the measurement of the outcome varied among reviews and was reported at six to eight weeks, three months, seven months, and 12 months. One review did not report the timing. Evidence ranged from high- to very low-quality.

5.1 Lifestyle intervention versus usual care or diet alone: RR $1.20,95 \% \mathrm{Cl} 0.67$ to 2.17 ; one trial, 189 women; low-quality evidence (Brown 2017b). Return to pre-pregnancy weight was defined as the ability to meet postpartum weight goals at six weeks postpartum.

5.2 Lifestyle intervention versus usual care or diet alone: there was no clear difference for women who had GDM between the lifestyle intervention and usual care or diet alone group (RR 1.59, $95 \% \mathrm{Cl} 0.99$ to 2.57 ; one trial, 159 women; very low-quality evidence) (Brown 2017b). Return to pre-pregnancy weight was defined as the ability to meet postpartum weight goals at seven months postpartum.

5.3 Lifestyle intervention versus usual care or diet alone: RR $1.75,95 \% \mathrm{Cl} 1.05$ to 2.90 ; one trial, 156 women; low-quality evidence (Brown 2017b). Return to pre-pregnancy weight was defined as the ability to meet postpartum weight goals at seven months postpartum.

5.4 Low GI diet versus high-fibre moderate GI diet: RR 1.15, 95\% $\mathrm{Cl} 0.43$ to 3.07; one trial, 55 women; very low-quality evidence (Han 2017). Return to pre-pregnancy weight was defined as returned to within $1 \mathrm{~kg}$ of pre-pregnancy weight at three months postpartum.

5.5 Exercise versus control: MD $0.11 \mathrm{~kg} / \mathrm{m}^{2}, 95 \% \mathrm{Cl}-1.04$ to 1.26 ; three trials, 254 women; high-quality evidence (Brown 2017c). The timing for follow-up of the outcome of return to pre-pregnancy body mass index (BMI) was not defined.

5.6 Insulin versus oral therapy: postnatal weight at six to eight weeks postpartum MD $-1.60 \mathrm{~kg}, 95 \% \mathrm{Cl}-6.34$ to $3.14 ; 1$ trial, 167 women; low-quality evidence; or one year postpartum MD -3.70 kg, $95 \% \mathrm{Cl}-8.50$ to 1.10 ; one trial, 176 women; low-quality evidence (Brown 2017d).

\subsection{Postnatal depression}

Postnatal depression was reported as an outcome by one review (Brown 2017b). See Table 7. The quality of the evidence was lowquality.

6.1 Lifestyle intervention versus usual care or diet alone: RR $0.49,95 \% \mathrm{Cl} 0.31$ to 0.78 ; one trial, 573 women; low-quality evidence
(Brown 2017b). Postnatal depression was defined as Edinburgh Postnatal Depression Score $>12$.

\subsection{Induction of labour}

Induction of labour was reported as an outcome by seven reviews (Brown 2017a; Han 2017; Brown 2017b; Brown 2017c; Brown 2017d; Han 2012; Raman 2017; Table 7). The quality of the evidence ranged from high- to very low-quality.

7.1 Glibenclamide versus placebo: $\mathrm{RR} 1.18,95 \% \mathrm{Cl} 0.79$ to 1.76 ; one trial, 375 women; very low-quality evidence (Brown 2017a).

7.2 Metformin versus glibenclamide: $\mathrm{RR} 0.81,95 \% \mathrm{Cl} 0.61$ to 1.07 ; one trial, 159 women; low-quality evidence (Brown 2017a).

7.3 Low-moderate versus moderate-high GI diet: $\mathrm{RR} 0.88,95 \% \mathrm{Cl}$ 0.33 to 2.34; one trial, 63 women; low-quality evidence (Han 2017).

7.4 Energy-restricted diet versus no energy-restricted diet: RR $1.02,95 \% \mathrm{Cl} 0.68$ to 1.53 ; one trial, 114 women; low-quality evidence (Han 2017).

7.5 Lifestyle intervention versus usual care or diet alone: average RR $1.20,95 \% \mathrm{Cl} 0.99$ to 1.46; four trials, 2699 women; moderate-quality evidence (Brown 2017b).

7.6 Exercise versus control: $\mathrm{RR} 1.38,95 \% \mathrm{Cl} 0.71$ to 2.68 ; one trial, 40 women; very low-quality evidence (Brown 2017c).

7.7 Intensive management versus routine care: RR 17.69, 95\% $\mathrm{Cl} 1.03$ to 304.09; one trial, 83 women; very low-quality evidence (Han 2012). There were six events of induction of labour for women with GDM in the intensive management group but no events in the control group.

7.8 Telemedicine versus standard care for glucose monitoring: RR $1.06,95 \% \mathrm{Cl} 0.63$ to 1.77 ; one trial, 47 women; very low-quality evidence (Raman 2017).

7.9 Insulin versus oral therapy: average RR $1.30,95 \% \mathrm{Cl} 0.96$ to 1.75 ; 3 RCTs, 348 women; moderate-quality evidence (Brown 2017d).

\section{Neonatal}

\subsection{Large-for-gestational age (defined as $>90^{\text {th }}$ percentile in all} included reviews)

Large-for-gestational age was reported as an outcome by eight reviews (Biesty 2018; Brown 2016a; Brown 2017a; Brown 2017b; Brown 2017d; Han 2012; Han 2017; Raman 2017; Table 8). The quality of the evidence ranged frommoderate- to very low-quality.

8.1 Induction of labour versus expectant management: RR 0.53 , $95 \% \mathrm{Cl} 0.28$ to 1.02; one trial, 425 babies; low-quality evidence (Biesty 2018).

8.2 Glibenclamide versus placebo: $\mathrm{RR} 0.89,95 \% \mathrm{Cl} 0.51$ to 1.58 ; one trial, 375 babies; very low-quality evidence (Brown 2017a).

8.3 Metformin versus glibenclamide: $\mathrm{RR} 0.67,95 \% \mathrm{Cl} 0.24$ to 1.83 ; two trials, 246 babies; low-quality evidence (Brown 2017a).

8.4 Glibenclamide versus acarbose: $\mathrm{RR} 2.38,95 \% \mathrm{Cl} 0.54$ to 10.46 ; one trial, 43 babies; very low-quality evidence (Brown 2017a). 
8.5 Myo-inositol versus placebo: $\mathrm{RR} 0.36,95 \% \mathrm{Cl} 0.02$ to 8.58 ; one trial, 73 babies; very low-quality evidence (Brown 2016a).

8.6 Low-moderate versus moderate-high GI diet: $\mathrm{RR} 0.71,95 \% \mathrm{Cl}$ 0.22 to 2.34; two trials, 89 babies; low-quality evidence (Han 2017).

8.7 Energy- versus no energy-restricted diet: RR 1.17, 95\% Cl 0.65 to 2.12; one trial, 123 babies; low-quality evidence (Han 2017).

8.8 Low- versus high-carbohydrate diet: RR $0.51,95 \% \mathrm{Cl} 0.13$ to 1.95; one trial, 149 babies; very low-quality evidence (Han 2017).

8.9 High- versus low-unsaturated fat diet with matching calories: RR $0.54,95 \% \mathrm{Cl} 0.21$ to 1.37; one trial, 27 babies; very lowquality evidence (Han 2017).

8.10 Low-GI diet versus high-fibre moderate-GI diet: RR 2.87, $95 \% \mathrm{Cl} 0.61$ to 13.50 ; one trial, 92 babies; very low-quality evidence (Han 2017).

8.11 Diet + diet-related behavioural advice versus diet only: RR $0.73,95 \% \mathrm{Cl} 0.25$ to 2.14 ; one trial, 99 babies; very low-quality evidence (Han 2017).

8.12 Ethnic-specific diet versus standard healthy diet: RR 0.14 $95 \% \mathrm{Cl} 0.01$ to 2.45 ; one trial, 20 babies; very low-quality evidence (Han 2017).

8.13 Lifestyle intervention versus usual care or diet alone: RR $0.60,95 \% \mathrm{Cl} 0.50$ to 0.71 ; six trials, 2994 babies; moderate-quality evidence (Brown 2017b).

8.14 Intensive management versus routine care: RR $0.37,95 \%$ $\mathrm{Cl} 0.20$ to 0.66 ; three trials, 438 babies; low-quality evidence (Han 2012).

8.15 Telemedicine versus standard care for glucose monitoring: RR $1.41,95 \% \mathrm{Cl} 0.76$ to 2.64 ; three trials, 228 babies; very low-quality evidence (Raman 2017).

8.16 Self- versus periodic-glucose monitoring: $\mathrm{RR} 0.82,95 \% \mathrm{Cl}$ 0.50 to 1.37; two trials, 400 babies; low-quality evidence (Raman 2017).

8.17 Post- versus pre-prandial glucose monitoring: RR $0.29,95 \%$ $\mathrm{Cl} 0.11$ to 0.78 ; one trial, 66 babies; very low-quality evidence (Raman 2017).

8.18 Continuous- versus self-monitoring blood glucose: RR 0.67 $95 \% \mathrm{Cl} 0.43$ to 1.05 ; one trial, 106 babies; very low-quality evidence (Raman 2017).

8.19 Insulin versus oral therapy: average RR $1.01,95 \% \mathrm{Cl} 0.76$ to 1.35; 13 trials, 2352 babies; moderate-quality evidence (Brown 2017d).

8.20 Insulin type A versus B: RR $1.21,95 \% \mathrm{Cl} 0.58$ to 2.55 ; three trials, 411 babies; low-quality evidence (Brown 2017d).

8.21 Insulin versus diet: $\mathrm{RR} 0.85,95 \% \mathrm{Cl} 0.41$ to 1.78 ; one trial, 202 babies; very low-quality evidence (Brown 2017d).

8.22 Insulin regimen A versus B: twice daily versus four times daily RR $1.16,95 \% \mathrm{Cl} 0.79$ to 1.69 ; one trial, 274 babies; very lowquality evidence (Brown 2017d) or three times versus six times daily
RR $0.35,95 \% \mathrm{Cl} 0.04$ to 3.08; one trial, 37 babies; very low-quality evidence (Brown 2017d).

\subsection{Perinatal (fetal and neonatal death) and later infant mortality}

Perinatal (fetal and neonatal death) and later infant mortality was reported by seven reviews (Biesty 2018; Brown 2017a; Brown 2017b; Brown 2017c; Brown 2017d; Han 2017; Raman 2017; Table 8). All seven reviews reported perinatal mortality. None reported on later infant mortality. The quality of the evidence ranged from moderateto very low-quality. There was no clear evidence of a difference for the risk of perinatal mortality for any of the comparisons reporting this outcome.

9.1 Induction of labour versus expectant management: RR not estimable - no events of perinatal mortality recorded for babies born to mothers in either group; one trial, 425 babies; very lowquality evidence (Biesty 2018).

9.2 Metformin versus glibenclamide: average $\mathrm{RR} 0.92,95 \% \mathrm{Cl} 0.06$ to 14.55; two trials, 359 babies; very low-quality evidence (Brown 2017a). There were no deaths in each group in one trial and one death in each group for the second trial.

9.3 Glibenclamide versus acarbose: RR not estimable - no events of perinatal mortality recorded for babies born to mothers in either group; one trial, 43 babies; very low-quality evidence (Brown 2017a).

9.4 Energy- versus no energy restricted diet: RR not estimable no events of perinatal mortality; two trials, 423 babies; low-quality evidence) (Han 2017).

9.5 Low- versus high-carbohydrate diet: RR $3.00,95 \% \mathrm{Cl} 0.12$ to 72.49; one trial, 150 babies; very low-quality evidence (Han 2017). There was one event in the control group.

9.6 Lifestyle intervention versus usual care or diet alone: RR $0.09,95 \% \mathrm{Cl} 0.01$ to 1.70 ; two trials, 1988 babies; low-quality evidence (Brown 2017b). One trial had no events and one trial had five events in the control group.

9.7 Exercise versus control: RR not estimable - no events of perinatal mortality; one trial, 19 babies; very low-quality evidence (Brown 2017c).

9.8 Telemedicine versus standard care for glucose monitoring: RR not estimable - no events of perinatal mortality; two trials, 131 babies; very low-quality evidence (Raman 2017).

9.9 Self- versus periodic-glucose monitoring: $\mathrm{RR} 1.54,95 \% \mathrm{Cl} 0.21$ to 11.24 ; two trials, 400 babies; very low-quality evidence (Raman 2017).

9.10 Continuous- versus self-monitoring blood glucose: RR not estimable - no events of perinatal mortality; two trials, 179 babies; very low-quality evidence (Raman 2017).

9.11 Insulin versus oral therapy: $\mathrm{RR} 0.85,95 \% \mathrm{Cl} 0.29$ to $2.49 ; 10$ trials, 1463 babies; low-quality evidence (Brown 2017d),

9.12 Insulin versus diet: $\mathrm{RR} 0.74,95 \% \mathrm{Cl} 0.41$ to 1.33 ; four trials, 1137 babies; moderate-quality evidence (Brown 2017d), 
9.13 Insulin regimen A versus $\mathrm{B}$ : $\mathrm{RR} 3.04,95 \% \mathrm{Cl} 0.13$ to 74.07 ; one trial, 274 babies; very low-quality evidence; twice daily versus four times daily (Brown 2017d).

\subsection{Death or serious morbidity composite (as defined in} reviews, e.g. perinatal or infant death, shoulder dystocia, bone fracture or nerve palsy)

Death or serious morbidity composite (as defined in reviews, e.g. perinatal or infant death, shoulder dystocia, bone fracture or nerve palsy) was reported as an outcome in five reviews (Brown 2017a; Han 2017; Brown 2017b; Brown 2017c; Brown 2017d; Table 8). The components of the composite differed among trials. The quality of the evidence ranged from moderate- to very low-quality.

10.1 Metformin versus glibenclamide: $\mathrm{RR} 0.54,95 \% \mathrm{Cl} 0.31$ to 0.94; one trial, 159 babies; low-quality evidence (Brown 2017a). The morbidity composite included hypoglycaemia, hyperbilirubinaemia, macrosomia, respiratory illness, birth injury, stillbirth or neonatal death.

10.2 Ethnic specific diet versus standard healthy diet: RR not estimable - no events in either group; one trial, 20 babies; very low-quality evidence (Han 2017). The morbidity composite included hypoglycaemia, neonatal asphyxia, respiratory distress syndrome, hyperbilirubinaemia, and hypocalcaemia.

10.3 Lifestyle intervention versus usual care or diet alone: average RR $0.57,95 \% \mathrm{Cl} 0.21$ to 1.55; two trials, 1930 babies; very low-quality evidence (Brown 2017b). The death or serious morbidity composite included death, shoulder dystocia, bone fracture, and nerve palsy in one trial, and in the other trial included stillbirth, neonatal death, hypoglycaemia, hyperbilirubinaemia, elevated cord-blood C-peptide, and birth trauma. The review authors decided to include both trials in the meta-analysis because the direction of the treatment effect is the same for both trials.

10.4 Exercise versus control: RR $0.56,95 \% \mathrm{Cl} 0.12$ to 2.61 ; two trials, 169 babies; moderate-quality evidence (Brown 2017c).

10.5 Telemedicine versus standard care for glucose monitoring: RR $1.06,95 \% \mathrm{Cl} 0.68$ to 1.66 ; one trial, 57 infants; very low-quality evidence (Raman 2017).

10.6 Insulin versus oral therapy: $\mathrm{RR} 1.03,95 \% \mathrm{Cl} 0.84$ to 1.26 ; two trials, 760 babies; moderate-quality evidence (Brown 2017d).

10.7 Insulin regimen A versus B: $\mathrm{RR} 1.69,95 \% \mathrm{Cl} 1.08$ to 2.64 ; one trial 274 babies; very low-quality evidence Twice daily versus four times daily (Brown 2017d).

\subsection{Neonatal hypoglycaemia (as defined in the reviews)}

Neonatal hypoglycaemia was reported as an outcome by eight reviews (Biesty 2018; Brown 2016a; Brown 2017a; Brown 2017b; Brown 2017c; Brown 2017d; Han 2017; Raman 2017; Table 8). The quality of the evidence ranged from moderate- to very low-quality. Six reviews provided no definition for neonatal hypoglycaemia for specific comparisons, and five reviews provided definitions for specific comparisons, although these definitions varied.

\subsection{Neonatal hypoglycaemia (not defined in the reviews)}

11.1.1 Induction of labour versus expectant management: RR $0.74,95 \% \mathrm{Cl} 0.26$ to 2.09 ; one trial, 425 babies; very low-quality evidence (Biesty 2018).

11.1.2 Glibenclamide versus placebo: $\mathrm{RR} 1.97,95 \% \mathrm{Cl} 0.36$ to 10.62; one trial, 375 babies; very low-quality evidence (Brown 2017a).

11.1.3 Myo-inositol versus placebo: $\mathrm{RR} 0.05,95 \% \mathrm{Cl} 0.00$ to 0.85 ; one trial, 73 babies; low-quality evidence (Brown 2016a).

11.1.4 Energy- versus no energy-restricted diet: $\mathrm{RR} 1.06,95 \% \mathrm{Cl}$ 0.48 to 2.32; two trials, 408 babies; very low-quality evidence (Han 2017).

11.1.5 Low- versus high-carbohydrate diet: $\mathrm{RR} 0.91,95 \% \mathrm{Cl} 0.39$ to 2.12; one trial, 149 babies; very low-quality evidence (Han 2017).

11.1.6 Ethnic specific diet versus standard healthy diet: RR not estimable, no events in either group; one trial, 20 babies; very lowquality evidence) (Han 2017).

11.1.7 Lifestyle intervention versus usual care or diet alone: average RR $0.99,95 \% \mathrm{Cl} 0.65$ to 1.52 ; six trials, 3000 babies; moderate-quality evidence (Brown 2017b).

11.1.8 Exercise versus control: $\mathrm{RR} 2.00,95 \% \mathrm{Cl} 0.20$ to 20.04 ; one trial, 34 babies; low-quality evidence (Brown 2017c).

11.1.9 Self- versus periodic-glucose monitoring: $\mathrm{RR} 0.64,95 \% \mathrm{Cl}$ 0.39 to 1.06; two trials, 391 babies; low-quality evidence (Raman 2017).

11.1.10 Insulin versus diet: average $\mathrm{RR} 0.88,95 \% \mathrm{Cl} 0.34$ to $2.24 ; 3$ trials, 176 babies; very low-quality evidence (Brown 2017d).

\subsection{Neonatal hypoglycaemia (defined)}

11.2.1 Metformin versus glibenclamide: $\mathrm{RR} 0.86,95 \% \mathrm{Cl} 0.42$ to 1.77; four trials, 554 babies; low-quality evidence (Brown 2017a). Hypoglycaemia defined as blood glucose level $(B G L)<2.2 \mathrm{mmol} / \mathrm{L}$; $<40 \mathrm{mg} / \mathrm{dL}$.

11.2.2 Glibenclamide versus acarbose: $\mathrm{RR} 6.33,95 \% \mathrm{Cl} 0.87$ to 46.32; one trial, 43 babies; very low-quality evidence (Brown 2017a). Hypoglycaemia defined as $B G L<2.2 \mathrm{mmol} / \mathrm{L} ;<40 \mathrm{mg} / \mathrm{dL}$.

11.2.3 Soy- versus no soy-protein diet: $\mathrm{RR} 3.00,95 \% \mathrm{Cl} 0.33$ to 27.42; one trial, 68 babies; very low-quality evidence (Han 2017). Hypoglycaemia defined as $B G L<1.7 \mathrm{mmol} / \mathrm{L}(<30.6 \mathrm{mg} / \mathrm{dL})$.

11.2.4 Intensive management versus routine care: $R R=0.39,95 \%$ $\mathrm{Cl} 0.06$ to 2.54; two trials, 426 babies; very low-quality evidence (Han 2012). Hypoglycaemia defined in one trial as $B G L<1.7 \mathrm{mmol} / \mathrm{L}$ in two consecutive measurements and as $B G L<1.94 \mathrm{mmol} / \mathrm{L}$ in the other trial.

11.2.5 Telemedicine versus standard care for glucose monitoring: RR $1.14,95 \% \mathrm{Cl} 0.48$ to 2.72 ; three trials, 198 babies; very low-quality evidence (Raman 2017). Hypoglycaemia was defined in one trial as $B G L<2.6 \mathrm{mmol} / \mathrm{L}$,

11.2.6 Continuous- versus self-monitoring blood glucose: RR $0.79,95 \% \mathrm{Cl} 0.35$ to 1.78 ; two trials, 178 babies; very low-quality 
evidence (Raman 2017). Hypoglycaemia was defined in one trial as $\mathrm{BGL} \leq 45 \mathrm{mg} / \mathrm{dL}(2.5 \mathrm{mmol} / \mathrm{L})$.

11.2.7 Post- versus pre-prandial glucose monitoring: RR 0.14 , $95 \% \mathrm{Cl} 0.02$ to 1.10; one trial, 66 babies; very low-quality evidence (Raman 2017). Hypoglycaemia was defined as $\leq 30 \mathrm{mg} / \mathrm{dL}$ requiring glucagon or dextrose infusion for treatment during the first four days after birth.

11.2.8 Insulin versus oral therapy: average RR $1.14,95 \% \mathrm{Cl} 0.85$ to 1.52; 24 trials, 3892 babies; low-quality evidence (Brown 2017d). The definitions of neonatal hypoglycaemia varied among the trials reporting a definition.

11.2.9 Insulin type A versus B: human insulin versus another insulin preparation RR $2.28,95 \% \mathrm{Cl} 0.06$ to 82.02 ; three trials, 165 babies; very low-quality evidence (Brown 2017d).

11.2.10 Insulin versus diet: $\mathrm{RR} 0.88,95 \% \mathrm{Cl} 0.34$ to 2.24 ; three trials, 176 babies; very low-quality evidence (Brown 2017d).

11.2.11 Insulin versus exercise: $\mathrm{RR} 0.50,95 \% \mathrm{Cl} 0.05$ to 5.01 ; one trial, 34 babies; very low-quality evidence (Brown 2017d).

11.2.12 Insulin regimen A versus B: twice daily versus four times daily RR 8.12, 95\% Cl 1.03 to 64.03; one trial, 274 babies; very lowquality evidence (Brown 2017d).

\subsection{Adiposity (including skinfold thickness measurements (mm), fat mass)}

Neonatal adiposity was reported as an outcome by two reviews (Brown 2017b; Brown 2017d). No other measures of adiposity were reported. See Table 8. The quality of the evidence was low- to very quality.

\subsection{Neonate}

12.1.1 Lifestyle intervention versus usual care or diet alone: the evidence suggested a reduction for whole-body neonatal fat mass (estimated from skinfold thickness) for babies born to mothers with GDM in the lifestyle intervention group compared to the usual care or diet alone group (MD -37.30 g, 95\% Cl -63.97 g to $-10.63 \mathrm{~g}$; one trial, 958 babies; low-quality evidence) (Brown 2017b).

12.1.2 Insulin versus oral therapy: skinfold sum (MD $-0.80 \mathrm{~mm}$, $95 \% \mathrm{Cl}-2.33$ to 0.73 ; one trial, 82 infants; very low-quality evidence) or percentage fat mass (MD $-1.60 \%, 95 \% \mathrm{Cl}-3.77$ to 0.57 ; one trial, 82 infants; very low-quality evidence) (Brown 2017d).

\subsection{Child}

Childhood adiposity was reported as an outcome by two reviews (Brown 2017b; Brown 2017d). See Table 8. The quality of the evidence ranged from moderate- to very low-quality.

12.2.1 Lifestyle intervention versus usual care or diet alone: $R R$ $0.91 \mathrm{~kg} / \mathrm{m}^{2}, 95 \% \mathrm{Cl} 0.75$ to 1.11 ; three trials, 767 children; moderatequalityevidence (Brown 2017b). Childhood adiposity was measured as $\mathrm{BMI}>85^{\text {th }}$ percentile at four to five years follow-up in one trial, seven to 11 years follow-up in the second included trial, and five to 10 years follow-up in the third trial.

12.2.2 Lifestyle intervention versus usual care or diet alone: $M D$ 0.08 points, $95 \% \mathrm{Cl}-0.28$ to 0.44 ; one trial, 199 children; very low- quality evidence (Brown 2017b). Adiposity was measured as BMI z score at four to five years follow-up.

12.2.3 Insulin versus oral anti-diabetic pharmacological therapies: MD $0.50 \%, 95 \% \mathrm{Cl}-0.49$ to 1.49 ; one trial, 318 children; low-quality evidence (Brown 2017d). Adiposity was measured as total fat mass (\%) up to two-years of age.

\subsection{Child as an adult}

None of the included reviews reported any data for the child as an adult for the outcome of adiposity (including BMI, skinfold thickness, fat mass),

\subsection{Diabetes (type 2) child as later infant/childhood}

None of the included reviews reported any data for the child as later infant/childhood for the development of diabetes.

\subsection{Neurosensory disability in later childhood (as defined in reviews)}

One of the included reviews reported data for neurosensory disability in later childhood at 18 months follow-up (Brown 2017d). The evidence was low quality.

14.1 Insulin versus oral therapy: any mild developmental delay RR $1.07,95 \% \mathrm{Cl} 0.33$ to 3.44 ; one trial, 93 children; hearing impairment RR $0.31,95 \% \mathrm{Cl} 0.01$ to 7.49 ; one trial, 93 children; or visual impairment RR $0.31,95 \% \mathrm{Cl} 0.03$ to 2.90 ; one trial, 93 children; all low-quality evidence (Brown 2017d).

\section{Health service use}

\subsection{Number of antenatal visits or admissions}

The number of antenatal visits or admissions was reported as an outcome by three reviews (Brown 2017b; Han 2017; Raman 2017; Table 9). The quality of the evidence ranged from moderate- to very low-quality.

15.1 Soy protein-enriched diet versus no soy-protein diet: RR $0.75,95 \% \mathrm{Cl} 0.18$ to 3.10 ; one trial, 68 women; very low-quality evidence (Han 2017). The number of antenatal visits or admissions was defined as maternal hospitalisation.

15.2 Lifestyle intervention versus usual care or diet alone: RR $1.06,95 \% \mathrm{Cl} 0.87$ to 1.29 ; one trial, 1000 women; moderate-quality evidence (Han 2017). The number of antenatal visits or admissions was not defined.

15.3 Telemedicine versus standard care for glucose monitoring: MD -0.36 visits, $95 \% \mathrm{Cl}-0.92$ to 0.20 ; one trial, 97 women;very lowquality of evidence (Raman 2017). The number of antenatal visits or admissions was defined as being a visit to hospital or a health professional.

15.4 Self-monitoring versus periodic glucose monitoring: $M D$ 0.20 visits, $95 \% \mathrm{Cl}-1.09$ to 1.49 ; one trial, 58 women; very lowquality evidence (Raman 2017). The number of antenatal visits or admissions was defined as visits with the diabetes team.

15.5 Insulin versus oral therapy: MD 1.00 visits, $95 \% \mathrm{Cl}-0.08$ to 2.08; one trial, 404 women; low-quality evidence (Brown 2017d). The number of antenatal visits or admissions was defined as clinic visits. 


\subsection{Length of postnatal stay (mother)}

None of the included reviews reported maternal length of postnatal stay as an outcome.

\subsection{Length of postnatal stay (baby) including neonatal intensive care unit (NICU) or special care baby unit (SCBU)}

Length of infants' postnatal stay was reported as an outcome by three reviews (Brown 2017d; Han 2017; Raman 2017; Table 9). The quality of the evidence was very low-quality.

17.1 Diet + diet-related behavioural advice versus diet only: $\mathrm{RR} 1.33,95 \% \mathrm{Cl} 0.73$ to 2.44 ; one trial, 99 babies; very low-quality evidence) (Han 2017). The length of postnatal stay was defined as more than four days.

17.2 Telemedicine versus standard care for glucose monitoring: evidence from one included trial found no clear differences in length of postnatal stay for the baby but data could not be included in a meta-analysis (Raman 2017).

17.3 Continuous glucose monitoring versus self-monitoring blood glucose: MD -0.83 days, $95 \% \mathrm{Cl}-2.35$ to 0.69 ; one trial, 18 babies; very low-quality evidence (Raman 2017). The data referred to stay in NICU.

17.4 Insulin versus oral anti-diabetic pharmacological therapies: $\mathrm{MD}-0.20$ days, $95 \% \mathrm{Cl}-1.79$ to 1.39 ; three trials, 401 infants; very low-quality evidence (Brown 2017d). The data referred to stay in NICU.

\subsection{Costs associated with the treatment}

Costs associated with the treatment was reported as an outcome by three reviews (Brown 2017b; Brown 2017d; Raman 2017). The evidence was very low-quality.

18.1 Lifestyle intervention versus usual care or diet alone: moderate-quality evidence showed costs (in AUD) were higher for women with mild GDM and a singleton pregnancy in the lifestyle intervention group compared to the usual care or diet alone group, which was mainly due to increased surveillance and increased contact with health professionals (one trial, 1000 women) (Brown 2017b). The data were reported as direct costs per 100 women, but were not in a suitable format for inclusion in a meta-analysis and are summarised in Table 12.

18.2 Telemedicine versus standard care for glucose monitoring: very low-quality evidence from one included trial reported that the intervention "...was less expensive for the health system in terms of use of health professionals time" but no details were provided (Raman 2017).

18.3 Self-monitoring versus periodic monitoring: very lowquality evidence from a single trial reported that the direct costs, including glucometer rental, equipment purchase, and reagent strips, was less expensive for periodic glucose monitoring. Data were not suitable for meta-analysis (Raman 2017).

18.4 Insulin versus oral anti-diabetic pharmacological therapies: very low-quality evidence from one trial suggested that the monthly costs of insulin were higher than for glibenclamide. Evidence from one trial suggested that the costs of insulins (excluding syringes) was higher than for metformin or for combined metformin and insulin. The data were not suitable for meta-analysis (Brown 2017d).

\section{DISCUSSION}

\section{Summary of main results}

This overview included 14 Cochrane Reviews, 10 of which reported relevant data on 27 comparative treatments for women with gestational diabetes mellitus (GDM) and borderline GDM. These 10 Cochrane systematic reviews included 128 randomised controlled trials (RCTs) involving 17,984 women, 16,305 babies, and 1441 children. RCTs reported in multiple reviews were counted as one trial (Brown 2017b and Brown 2017c; Brown 2017b and Han 2017). However, when the same trial was reported in multiple reviews, but with participant numbers from different treatment arms (subsets), they were then counted as one trial each (Han 2017 and Brown 2017c; Han 2012 and Han 2017; Brown 2017b and Brown 2017c).

Data were available from the included reviews for 16 of 18 prespecified overview outcomes. A summary of the main results according to these overview review outcomes, following the framework and its categories as outlined in the Data synthesis section, are presented in Table 4.

We collated the interventions for treatment of women with GDM, and for the GRADE health outcomes of this overview, according to whether they had been found to be effective, promising, ineffective, probably ineffective, or no conclusion was made about effectiveness for health outcomes identified as important for women and their babies:

- Effective interventions: indicating that the review found moderate- to high-quality evidence of effectiveness for an intervention.

- Promising interventions (more evidence needed): indicating that the review found moderate-quality evidence of effectiveness for an intervention, but more evidence is needed.

- Ineffective or possibly harmful interventions: indicating that the review found moderate- to high-quality evidence of lack of effectiveness for an intervention.

- Probably ineffective or harmful interventions (more evidence needed): indicating that the review found moderate-quality evidence suggesting lack of effectiveness for an intervention, but more evidence is needed.

- No conclusions possible due to lack of evidence: indicating that the review found low- or very low-quality evidence, or insufficient evidence to comment on the effectiveness of an intervention, more evidence needed.

The overall evidence of various interventions for the treatment of women with GDM and their effects on the health of the woman and her baby are limited by quantity and quality. Lifestyle interventions in comparison to usual care were found to be probably 'effective' in reducing large-for-gestational age. There were no interventions that could be classified as 'promising interventions'. 'Ineffective or harmful' interventions included: lifestyle interventions versus usual care which probably increase the risk of induction of labour (IOL); exercise versus control for return to pre-pregnancy weight; and insulin versus oral therapy which probably increase the risk of IOL. 'Probably ineffective' interventions included insulin versus oral therapy, which probably increases the risk of the hypertensive 
disorders of pregnancy. The evidence was inconclusive for all other interventions. Some interventions are multi-component and it was not possible to determine which specific components were most promising. Long-term health outcomes for women and their infants and costs are not well reported. Most of the dietary treatments assessed were from interventions reported as single studies that had relatively small numbers of participants, and only a few trials compared the same or similar dietary interventions.

This overview summarises the evidence from Cochrane systematic reviews of RCTs for treatments for women with GDM on relevant health outcomes and may be used by clinicians, clinical guideline developers, consumers, and policymakers to aid decision making to guide clinical practice, health services and future primary research. For further information we suggest referring to the individual Cochrane systematic reviews for details for the context and components of the interventions.

\section{For the mother}

1.0 Hypertensive disorders of pregnancy (including preeclampsia, pregnancy-induced hypertension, eclampsia)

\section{Summary for the risk of any hypertensive disorders of pregnancy (not defined) in women with GDM}

\section{Probably ineffective or harmful interventions}

- Moderate-quality evidence suggested that insulin possibly increased the risk of hypertensive disorders of pregnancy (not defined) compared with oral therapy.

\section{No conclusions possible: low- to very low-quality evidence, or insufficient evidence to comment on the effectiveness, more evidence needed}

- Moderate-quality evidence showed no clear difference for metformin versus glibenclamide.

- Very low-quality evidence showed no clear difference for glibenclamide versus placebo

\section{Summary for the risk of pregnancy-induced hypertension in women with GDM}

No conclusions possible: low- to very low-quality evidence, or insufficient evidence to comment on the effectiveness, more evidence needed

- Moderate-quality evidence showed no clear difference for metformin versus glibenclamide.

- Low-quality evidence showed no clear difference for glibenclamide versus placebo or insulin regimen A versus B.

- Very low-quality evidence showed no clear difference for low-versus high-carbohydrate diet; high-versus low-unsaturated fat diet with matching calories; and ethnic specific diet versus standard healthy diet

\section{Summary for the risk of pregnancy-induced hypertension or pre-eclampsia (combined) in women with GDM}

No conclusions possible: low- to very low-quality evidence, or insufficient evidence to comment on the effectiveness, more evidence needed

- Low-quality evidence showed no clear difference for glibenclamide versus placebo.

- Very low-quality evidence showed no clear difference for low-moderate versus moderate-high GI diet or telemedicine versus standard care for glucose monitoring

\section{Summary for the risk of pre-eclampsia (not defined) in women with GDM}

\section{Probably ineffective or harmful interventions (more evidence needed): indicating that the review found moderate-quality ev-} idence suggesting lack of effectiveness for an intervention, more evidence needed

- Moderate-quality evidence showed no clear difference for the DASH diet versus control diet with matching macronutrient contents or insulin versus oral therapy. 
No conclusions possible: low- to very low-quality evidence, or insufficient evidence to comment on the effectiveness, more evidence needed

- Low-quality evidence showed no clear difference for energy-versus no energy-restricted diet; high-versus low-unsaturated fat diet with matching calories; lifestyle intervention versus usual care or diet alone; exercise versus control; intensive management versus routine care or insulin type $A$ versus $B$.

- Very low-quality evidence showed no clear difference for metformin versus glibenclamide; soy- versus no soy-protein diet or managed by self- versus periodic-glucose monitoring or post- versus pre-prandial glucose monitoring

Summary for the risk of eclampsia (not defined) for women with GDM

No conclusions possible: low- to very low-quality evidence, or insufficient evidence to comment on the effectiveness, more evidence needed

- Very low-quality evidence showed no clear difference for low-moderate versus moderate-high GI diet

\subsection{Caesarean section}

Summary for the risk of caesarean section for women with GDM

No conclusions possible: low- to very low-quality evidence, or insufficient evidence to comment on the effectiveness, more evidence needed

- Moderate-quality evidence showed no clear difference for insulin versus oral therapy or insulin type A versus B. Moderate-quality evidence showed no clear difference (the direction of the effect suggested benefit) for exercise versus control.

- Low-quality evidence suggested a possible reduction for the risk of birth by caesarean section for the DASH diet compared to the control diet with matching macronutrient contents group.

- Low-quality evidence showed no clear difference for metformin versus glibenclamide; glibenclamide versus acarbose; energy-versus no energy-restricted diet; low-versus high-carbohydrate diet and lifestyle intervention versus usual care or diet alone.

- Very low-quality evidence showed no clear difference for induction of labour versus expectant management; glibenclamide versus placebo; low-moderate versus moderate-high GI diet; low-GI diet versus high-fibre moderate-GI diet; diet + diet-related behavioural advice versus diet only; soy-versus no soy-protein diet; high- versus low-unsaturated fat diet with matching calories; ethnic specific diet versus standard healthy diet; intensive management versus routine care; strict versus less strict glycaemic control; telemedicine versus standard care for glucose monitoring; self- versus periodic-glucose monitoring; continuous- versus self-monitoring; postversus pre-prandial glucose monitoring; insulin versus diet; insulin versus exercise or insulin regimen A versus B

\subsection{Development of type 2 diabetes}

\section{Summary for the risk of development of type 2 diabetes for women with GDM}

No conclusions possible: low- to very low-quality evidence, or insufficient evidence to comment on the effectiveness, more evidence needed

- Moderate-quality evidence showed no clear difference for insulin versus oral therapy (up to one year postpartum).

- Low-quality evidence showed no clear difference for lifestyle intervention versus usual care or diet alone (diagnostic test or timeframe not defined).

- Very low-quality evidence showed no clear difference for high-versus low-unsaturated fat diet with matching calories using the Oral Glucose Tolerance Test (OGTT) for diagnosis of type 2 diabetes at one- to two-weeks postpartum or at four to 13 months postpartum. There was no clear difference for the treatment with low-GI diet versus high fibre moderate-GI diet using the OGTT at three months postpartum. There was no clear difference between insulin and diet up to 15 years follow-up 


\subsection{Perineal trauma/tearing}

\section{Summary for the risk of perineal trauma for women with GDM}

No conclusions possible: low- to very low-quality evidence, or insufficient evidence to comment on the effectiveness, more evidence needed

- Moderate-quality evidence showed no clear difference for lifestyle intervention versus usual care or diet alone.

- Low-quality evidence showed no clear difference for induction of labour versus expectant management or metformin versus glibenclamide.

- Very low-quality evidence showed no clear difference for glibenclamide versus placebo or continuous-versus self-monitoring blood glucose

\subsection{Postnatal weight retention or return to pre-pregnancy} weight

\section{Summary for postnatal weight retention or return to pre-pregnancy weight for women with GDM}

Ineffective or possibly harmful interventions: indicating that the review found moderate to high-quality evidence of lack of effectiveness for an intervention

- Moderate-quality evidence showed no clear difference for return to pre-pregnancy BMI (at follow-up, timing not defined) for women with GDM who were treated with exercise versus control.

No conclusions possible: low- to very low-quality evidence, or insufficient evidence to comment on the effectiveness, more evidence needed

- Low-quality evidence suggested benefit by an increased number of women meeting postpartum weight goals, that is returning to their pre-pregnancy weight at twelve months postpartum for women with GDM who were treated with lifestyle intervention compared to usual care or diet alone.

- Low-quality evidence showed no clear difference for postnatal weight retention or return to pre-pregnancy weight at six weeks postpartum for women with GDM who were treated with lifestyle intervention versus usual care or diet alone or insulin versus oral therapy up to one-year follow-up.

- Very low-quality evidence showed no clear difference for postnatal weight retention or return to pre-pregnancy weight at three months postpartum for women with GDM who were treated with low-GI diet versus high-fibre moderate-GI diet; or lifestyle intervention versus usual care or diet alone at eight months postpartum

\subsection{Postnatal depression}

Summary for the risk of postnatal depression in women with GDM

No conclusions possible: low- to very low-quality evidence, or insufficient evidence to comment on the effectiveness, more evidence needed

- Low-quality evidence suggested a decrease for the risk of developing postnatal depression when treated with lifestyle intervention compared to usual care or diet alone

\subsection{Induction of labour}

\section{Summary for the risk of induction of labour for women with GDM}

Ineffective or possibly harmful interventions: indicating that the review found moderate to high-quality evidence of lack of effectiveness for an intervention 
- Moderate-quality evidence showed no clear difference for lifestyle intervention versus usual care or diet alone. The direction of the treatment effect suggests increased likelihood of IOL for women treated with lifestyle interventions. Insulin treatment may possibly be associated with an increased risk of induction of labour compared with oral therapy but there is insufficient evidence.

\section{No conclusions possible: low- to very low-quality evidence, or insufficient evidence to comment on the effectiveness, more evidence needed}

- Very low-quality evidence suggested an increased risk of induction in labour for intensive management compared to the routine care.

- Low-quality evidence showed no clear difference for metformin versus glibenclamide; low-moderate versus moderate-high GI diet or energy- versus no energy-restricted diet.

- Very low-quality evidence showed no clear difference for glibenclamide versus placebo, exercise versus control or telemedicine versus standard care for glucose monitoring

\subsection{Large-for-gestational age}

\section{Summary for risk of large-for-gestational age for infants born to mothers with GDM}

\section{Effective interventions: indicating that the review found moderate to high-quality evidence of effectiveness for an interven-} tion

- Moderate-quality evidence suggested a benefit by a reduction in the risk of large-for-gestational age for babies born to mothers who were treated with lifestyle intervention compared to the usual care or diet alone. The evidence was assessed as moderate due to risk of bias concerns. However, it is still considered to be strong enough evidence to be considered under this category.

No conclusions possible: low to very low-quality evidence, or insufficient evidence to comment on the effectiveness, more evidence needed

- Moderate-quality evidence found no clear difference for insulin or oral therapy.

- Low-quality evidence suggested a benefit by a reduction in the risk of large-for-gestational age for babies born to mothers who were treated with intensive management compared to routine care.

- Low-quality evidence found no clear evidence of a difference for induction of labour compared to expectant management; or with glibenclamide versus acarbose; low-moderate versus moderate-high GI diet; energy- versus no energy-restricted diet; insulin type A versus $B$ or management with self- versus periodic-glucose monitoring; intensive management versus routine care.

- Very low-quality evidence showed no clear difference for glibenclamide versus placebo; metformin versus glibenclamide; myo-inositol versus placebo; low- versus high-carbohydrate diet; high- versus low-unsaturated fat diet with matching calories; low-Gl diet versus high-fibre moderate-GI diet; diet + diet-related behavioural advice versus diet only; or ethnic specific diet versus standard healthy diet; insulin versus diet; insulin regimen A versus B or managed by telemedicine versus standard care for glucose monitoring.

- Very low-quality evidence showed a reduction in the risk of large-for-gestational age for babies born to mothers with GDM managed by post- versus pre-prandial glucose monitoring

\subsection{Perinatal (fetal and neonatal death) mortality}

Summary for the risk of perinatal (fetal and neonatal death) mortality for infants born to mothers with GDM

No conclusions possible: low- to very low-quality evidence, or insufficient evidence to comment on the effectiveness, more evidence needed

- Moderate-quality evidence found no clear difference for insulin versus diet.

- Low-quality evidence showed no clear difference for energy-versus no energy-restricted diet; lifestyle intervention versus usual care or diet alone or insulin versus oral anti-diabetic pharmacological therapies.

- Very low-quality evidence showed no clear difference for induction of labour versus expectant management; glibenclamide versus acarbose; metformin versus glibenclamide; exercise versus control; low-diet versus high-carbohydrate diet; insulin regimen A versus B or managed with telemedicine versus standard care; continuous- versus self-monitoring blood glucose or self- versus periodic-glucose monitoring 


\subsection{Death or serious morbidity composite}

\section{Summary for the risk of death or serious morbidity composite for infants born to mothers with GDM}

No conclusions possible: low- to very low-quality evidence, or insufficient evidence to comment on the effectiveness, more evidence needed

- Moderate-quality evidence showed no clear difference for insulin versus oral anti-diabetic pharmacological therapies.

- Moderate-quality evidence showed no clear difference exercise versus control although the direction of the effect suggested benefit favouring exercise.

- Low-quality evidence suggested a reduction in the risk of death or serious morbidity composite outcomes for babies born to mothers with GDM who were treated with metformin compared to glibenclamide.

- Very low-quality evidence showed an increased risk of a death or serious morbidity composite for twice daily insulin regimen versus four times daily insulin regimen.

- Very low-quality evidence showed no clear difference for ethnic specific diet versus standard healthy diet; lifestyle intervention versus usual care or diet alone; or managed by telemedicine versus standard care for glucose monitoring

\subsection{Neonatal hypoglycaemia}

\section{Summary for the risk of neonatal hypoglycaemia for infants born to mothers with GDM}

No conclusions possible: low- to very low-quality evidence, or insufficient evidence to comment on the effectiveness, more evidence needed

- Moderate-quality evidence showed no clear difference for the risk of neonatal hypoglycaemia (not defined) for babies born to mothers with GDM who were treated with lifestyle intervention versus usual care or diet alone

- Low-quality evidence suggested a reduced risk of neonatal hypoglycaemia for babies born to mothers with GDM who were treated with myo-inositol versus placebo (hypoglycaemia not defined).

- Low-quality evidence showed no clear difference for metformin versus glibenclamide; insulin versus oral hypoglycaemic pharmacological therapies or managed with self- versus periodic-glucose monitoring (hypoglycaemia not defined).

- Very low-quality evidence showed no clear difference for glibenclamide versus acarbose (hypoglycaemia defined); exercise versus control (hypoglycaemia not defined); soy- versus no soy-protein diet; intensive management versus routine care (hypoglycaemia defined); induction of labour versus expectant management; glibenclamide versus placebo; energy- diet versus no energy-restricted diet; low-versus high-carbohydrate diet; ethnic specific diet versus standard healthy diet (hypoglycaemia not defined); insulin type $A$ versus $B$; insulin versus diet; insulin versus exercise; insulin regimen A versus B; telemedicine versus standard care for glucose monitoring or continuous- versus self-monitoring blood glucose (hypoglycaemia defined)

\subsection{Adiposity (including skinfold thickness measurements (mm), fat mass)}

Summary for the risk of adiposity for the offspring born to mothers with GDM

\section{For the neonate}

No conclusions possible: low- to very low-quality evidence, or insufficient evidence to comment on the effectiveness, more evidence needed

- Moderate-quality evidence found no clear difference in percentage fat mass for insulin versus oral therapy.

- Low-quality evidence suggested a benefit by a reduced whole-body neonatal fat mass for lifestyle intervention compared to usual care or diet alone. As previous reported there was also a reduction for preterm birth, birthweight and macrosomia for these babies in the treatment group.

- Very low-quality evidence found no clear difference for skinfold sum or percentage fat mass for insulin versus oral therapy.

\section{For the child}


No conclusions possible: low- to very low-quality evidence, or insufficient evidence to comment on the effectiveness, more evidence needed

- Moderate-quality evidence showed no clear difference for childhood BMI for lifestyle intervention versus usual care or diet alone at four to five years of age (one trial), seven to 11 years of age (one trial) or five to 10 years of age (one trial).

- Low-quality evidence showed no clear difference for childhood total fat mass (\%) at two-year follow-up for insulin versus oral therapy.

- Very low-quality evidence showed no clear difference in childhood BMI z score for lifestyle intervention versus usual care or diet alone at four to five years of age

\subsection{Diabetes (type 2) as a child/adult}

\subsection{Neurosensory disability in later childhood}

No data were reported for this outcome in any of the included reviews.

\section{Summary for the risk of neurosensory disability in later childhood in children born to mothers with GDM}

\section{No conclusions possible: low- to very low-quality evidence, or insufficient evidence to comment on the effectiveness, more} evidence needed

- Low-quality evidence suggested no clear evidence of a difference for the risk of any mild developmental delay, hearing or visual impairment in later childhood (18 months) for children born to mothers who had GDM treated with either insulin or oral anti-diabetic pharmacological therapies

\subsection{Number of antenatal visits or admissions}

\section{Summary for the number of antenatal visits or admissions for women with GDM}

\section{No conclusions possible: low- to very low-quality evidence, or insufficient evidence to comment on the effectiveness, more} evidence needed

- Moderate-quality evidence showed no clear difference in the number of antenatal clinic visits for lifestyle interventions versus usual care.

- Low-quality evidence showed no clear difference in the number of clinic visits for women treated with insulin versus oral anti-diabetic pharmacological therapies.

- Very low-quality evidence showed no clear difference in number of antenatal visits or admissions for health service use for women with GDM who were treated with soy protein-enriched diet versus no soy protein diet or managed by telemedicine versus standard care for glucose monitoring or self- versus periodic-glucose monitoring

\subsection{Length of postnatal stay (mother)}

No data were reported for this outcome in any of the included reviews.
17.0 Length of postnatal (baby) including neonatal intensive care unit (NICU) or special care baby unit (SCBU)

\section{Summary for the for length of postnatal stay (baby) including NICU or SCBU}

No conclusions possible: low- to very low-quality evidence, or insufficient evidence to comment on the effectiveness, more evidence needed

- Very low-quality evidence showed no clear difference for length of postnatal stay for babies born to mothers with GDM who were treated with diet + diet-related behavioural advice versus diet only; insulin versus oral anti-diabetic pharmacological therapies or those managed by continuous- versus self-monitoring of blood glucose 


\subsection{Costs associated with the treatment}

\section{Summary}

\section{No conclusions possible: low- to very low-quality evidence, or insufficient evidence to comment on the effectiveness, more evidence needed}

- Moderate-quality evidence suggested increased total costs per 100 women of approximately AUD 33,000 associated with the treatment and of approximately AUD 6000 associated costs for the families of women with GDM who were treated with lifestyle intervention compared to usual care or diet alone (Table 12). This was mainly due to increased surveillance and increased contact with health professionals. The table was reprinted with permission from Brown 2017b. Although these data were assessed as being 'moderate-quality', since it was based on narrative data, it could not be classified as 'promising'.

- Very low-quality evidence suggested decreased costs for telemedicine versus standard care and self-versus periodic-monitoring.

- Very low-quality evidence suggested increased costs for insulin versus oral antidiabetic pharmacological therapy

\section{Overall completeness and applicability of evidence}

This overview review summarised published Cochrane systematic reviews of RCTs of different treatments for women with GDM and the effects on relevant health outcomes. Data were available from the included reviews for 16 of 18 pre-specified GRADE outcomes. None of the included reviews reported data for the infant as an adult. The evidence in this overview review can be applied to women with GDM in most countries as the trials of the included reviews were conducted in a wide range of countries, although there was a lack of trials from lower- or middle-income countries. Evidence from published or planned Cochrane systematic reviews is lacking on the use of micronutrients and phytochemicals such as cinnamon, zinc, chromium, omega-3 fatty acids, and magnesium to treat women with GDM. There are a large number of relevant outcomes reported in the included reviews that we were unable to address in this overview including short- and long-term maternal, neonatal and child outcomes. We suggest that the reader refers to the individual Cochrane Reviews for completeness.

\section{Quality of the evidence}

The included Cochrane systematic reviews were assessed with the AMSTAR tool and found to be high quality overall (Table 10). We used to ROBIS tool and assessed low overall risk of bias (Table 11).

Nine of the 10 included Cochrane systematic reviews that provided data for this overview used GRADE to assess for the quality of evidence for agreed GRADE pre-specified outcomes (Biesty 2018; Brown 2017a; Brown 2017b; Brown 2017c; Brown 2017d; Brown 2016a; Han 2017; Martis 2016a; Raman 2017). We undertook the GRADE assessments for Han 2012; these are included in Table 7; Table 8; Table 9. All included reviews assessed the risk of bias of the included randomised trials, following the current guidance as outlined in the Cochrane Handbook for Systematic Reviews of Interventions (Higgins 2011). The quality of included randomised trials in these reviews were highly variable within and among the included reviews from high risk of bias to low risk of bias. Evidence was often downgraded for imprecision as evidence was based on one trial with small numbers, with wide confidence intervals and performance bias for not blinding participants and personnel to the intervention. Also, for many of the interventions being assessed, masking of participants and health professionals to the interventions was not possible. Where the authors of this overview disagreed with GRADE judgements in the original review, we altered the judgements and indicated where this had been done (Table 4).

\section{Potential biases in the overview process}

We were aware that there were risks of introducing bias at all stages of the overview review process and took steps to minimise this. All included Cochrane systematic reviews used a published protocol that aimed to minimise bias and we similarly developed and published a Cochrane overview protocol (Martis 2016b). A minimum of two overview authors independently assessed Cochrane systematic reviews for inclusion, carried out data extraction and quality assessment, and assessed the quality of the evidence using the ARMSTAR, ROBIS and GRADE approaches. One potential source of bias relates to authors of this overview being authors of some of the included reviews. As pre-specified in our protocol, data extraction and quality assessment for these reviews was carried out by two overview authors who were not the review authors. Where the authors of this overview disagreed with GRADE judgements in the original review, we altered the judgements, and indicated where this had been done (Table 4).

We undertook a comprehensive search of the Cochrane Database of Systematic Reviews without language or date restrictions, and identified published reviews (Figure 1), as well as planned and ongoing reviews (registered titles and protocols) (Appendix 1). While the included reviews were judged to be of high quality and low risk of bias, one included review was not considered to be up-to-date (Han 2012). It is possible that additional trials assessing interventions for women with hyperglycaemia not meeting gestational diabetes diagnostic criteria have been published, but are not yet included in the relevant Cochrane systematic review. Han 2012 assessed interventions for women with hyperglycaemia not meeting gestational diabetes and type 2 diagnostic criteria. We agreed to include the review in this overview, as different countries have different diagnostic levels for confirming that a pregnant woman has GDM. It is highly possible that women with hyperglycaemia identified in one country as not meeting the gestational diagnostic threshold for GDM would be diagnosed as having GDM in another country. This could be a potential bias for over reporting results.

Furthermore, recent trials of treatments for women with GDM may have been conducted, but not yet published. Once published, the trials may be included in the relevant Cochrane systematic reviews. 
Such new evidence will be considered for inclusion in an update of this overview.

\section{Agreements and disagreements with other studies or reviews}

We did not identify any other overview of Cochrane systematic reviews, and as far as we are aware, we have included all relevant Cochrane systematic reviews assessing treatments for women with GDM.

\section{AUTHORS' CONCLUSIONS}

\section{Implications for practice}

There is insufficient high-quality evidence about the effects on health outcomes of relevance for women with GDM and their babies for many of the comparisons in this overview comparing treatment interventions for women with GDM.

Lifestyle interventions that include advice on diet and physical activity have become the mainstay of treatment, and are recommended in many national clinical practice guidelines. Many of the lifestyle and exercise interventions reported in the reviews are multi-component, and identifying which of any of the individual components are effective or not effective is not possible with the evidence currently available. Most dietary treatments assessed in the included reviews are from interventions reported as single studies, with small numbers of participants, and only a few trials have compared the same or similar dietary interventions.

Lifestyle changes (including as a minimum healthy eating, physical activity, and self-monitoring of blood sugar levels) was the only intervention that showed possible health improvements for women and their babies. Lifestyle interventions may result in fewer babies being large. Conversely, in terms of harms, lifestyle interventions may also increase the number of inductions. Taking insulin was also associated with an increase in hypertensive disorders, when compared to oral therapy. There was very limited information on long-term health and health services costs.

For further information we suggest referring to the individual Cochrane systematic reviews for details on the context and components of the interventions.

\section{Implications for research}

This overview review highlights that there is insufficient evidence to make conclusions on the effects for many treatments for women with GDM on relevant health outcomes.

High-quality research is required to identify the most effective components or combination of components in lifestyle interventions.

Lifestyle including dietary interventions may also be beneficial, but any effect is currently difficult to identify because of the multiple comparisons, often small sample sizes, and few trials.

Further research should be sufficiently powered to enable important differences in relevant core clinical outcomes, identified in this overview, for women with GDM and their infants to be detected. Outcomes should include long-term outcomes and the costs for treatments, family and service costs.

\section{ACKNOWLEDGEMENTS}

We acknowledge the support from the Liggins Institute, The University of Auckland, Auckland, New Zealand, the Australian and New Zealand Satellite of the Cochrane Pregnancy and Childbirth Review Group (funded by NHMRC), and the Cochrane Pregnancy and Childbirth editorial team in Liverpool, UK. We would like to acknowledge the support of Gill Gyte and Heather Welford for their assistance in preparing the plain language summary.

As part of the pre-publication editorial process, the overview was commented on by three peers (an editor and two referees who are external to the editorial team), a member of the Pregnancy and Childbirth Group's international panel of consumers, and the Group's Statistical Adviser.

This project was supported by the National Institute for Health Research, via Cochrane Infrastructure funding to Cochrane Pregnancy and Childbirth and a Cochrane Review Incentive Scheme Award: 16/72/03. The views and opinions expressed herein are those of the authors, and do not necessarily reflect those of the Systematic Reviews Programme, NIHR, NHS or the Department of Health. 


\section{R E F E R E N C E S}

\section{References to included reviews}

\section{Biesty 2018}

Biesty LM, Egan AM, Dunne F, Dempsey E, Meskell P, Smith V, et al. Planned birth at or near term for improving health outcomes for pregnant women with gestational diabetes and their infants. Cochrane Database of Systematic Reviews 2018, Issue 1. [DOI: 10.1002/14651858.CD012910]

\section{Brown 2016a}

Brown J, Crawford TJ, Alsweiler J, Crowther CA. Dietary supplementation with myo-inositol in women during pregnancy for treating gestational diabetes. Cochrane Database of Systematic Reviews 2016, Issue 9. [DOI: 10.1002/14651858.CD012048.pub2]

\section{Brown 2017a}

Brown J, Martis R, Hughes B, Rowan J, Crowther CA. Oral antidiabetic pharmacological therapies for the treatment of women with gestational diabetes. Cochrane Database of Systematic Reviews 2017, Issue 1. [DOI: 10.1002/14651858.CD011967.pub2]

\section{Brown 2017b}

Brown J, Alwan NA, West J, Brown S, McKinlay CJD, Farrar D, et al. Lifestyle interventions for the treatment of women with gestational diabetes. Cochrane Database of Systematic Reviews 2017, Issue 5. [DOI: 10.1002/14651858.CD011970.pub2]

\section{Brown 2017c}

Brown J, Ceysens G, Boulvain M. Exercise for pregnant women with gestational diabetes for improving maternal and fetal outcomes. Cochrane Database of Systematic Reviews 2017, Issue 6. [DOI: 10.1002/14651858.CD012202.pub2]

\section{Brown 2017d}

Brown J, Grzeskowiak L, Williamson K, Downie MR, Crowther CA. Insulin for the treatment of women with gestational diabetes. Cochrane Database of Systematic Reviews 2017, Issue 11. [DOI: 10.1002/14651858.CD012037.pub2]

\section{Culliney 2016}

Culliney KAT, Parry GK, Brown J, Crowther CA. Regimens of fetal surveillance of suspected large-for-gestational-age fetuses for improving health outcomes. Cochrane Database of Systematic Reviews 2016, Issue 4. [DOI: 10.1002/14651858.CD011739.pub2]

\section{East 2014}

East CE, Dolan WJ, Forster DA. Antenatal breast milk expression by women with diabetes for improving infant outcomes. Cochrane Database of Systematic Reviews 2014, Issue 7. [DOI: 10.1002/14651858.CD010408.pub2]

\section{Farrar 2016}

Farrar D, Tuffnell DJ, West J, West HM. Continuous subcutaneous insulin infusion versus multiple daily injections of insulin for pregnant women with diabetes. Cochrane Database of Systematic Reviews 2016, Issue 6. [DOI: 10.1002/14651858.CD005542.pub3]

\section{Han 2012}

Han S, Crowther CA, Middleton P. Interventions for pregnant women with hyperglycaemia not meeting gestational diabetes and type 2 diabetes diagnostic criteria. Cochrane Database of Systematic Reviews 2012, Issue 1. [DOI: 10.1002/14651858.CD009037.pub2]

\section{Han 2017}

Han S, Middleton P, Shepherd E, Van Ryswyk E, Crowther CA. Different types of dietary advice for women with gestational diabetes mellitus. Cochrane Database of Systematic Reviews 2017, Issue 2. [DOI: 10.1002/14651858.CD009275.pub3]

\section{Jefferys 2013}

Jefferys AE, Siassakos D, Draycott T, Akande VA, Fox R. Deflation of gastric band balloon in pregnancy for improving outcomes. Cochrane Database of Systematic Reviews 2013, Issue 4. [DOI: 10.1002/14651858.CD010048.pub2]

\section{Martis 2016a}

Martis R, Brown J, Alsweiler J, Crawford TJ, Crowther CA. Different intensities of glycaemic control for women with gestational diabetes mellitus. Cochrane Database of Systematic Reviews 2016, Issue 4. [DOI: 10.1002/14651858.CD011624.pub2]

\section{Raman 2017}

Raman P, Sherpherd E, Dowsell T, Middleton P, Crowther CA. Different methods and settings for glucose monitoring for gestational diabetes during pregnancy. Cochrane Database of Systematic Reviews 2017, Issue 10. [DOI: 10.1002/14651858.CD011069.pub2]

\section{References to excluded reviews}

Alwan 2009

Alwan N, Tuffnell DJ, West J. Treatments for gestational diabetes. Cochrane Database of Systematic Reviews 2009, Issue 3. [DOI: 10.1002/14651858.CD003395.pub2]

\section{Brown 2015}

Brown J, Alwan NA, West J, Brown S, McKinlay CJD, Farrar D, et al. Lifestyle interventions for the treatment of women with gestational diabetes. Cochrane Database of Systematic Reviews 2015, Issue 11. [DOI: 10.1002/14651858.CD011970]

\section{Ceysens 2006}

Ceysens G, Rouiller D, Boulvain M. Exercise for diabetic pregnant women. Cochrane Database of Systematic Reviews 2006, Issue 3. [DOI: 10.1002/14651858.CD004225.pub2]

\section{Ceysens 2016}

Ceysens G, Brown J, Boulvain M. Exercise for pregnant women with gestational diabetes for improving maternal and fetal outcomes. Cochrane Database of Systematic Reviews 2016, Issue 5. [DOI: 10.1002/14651858.CD012202] 


\section{De-Regil 2016}

De-Regil LM, Palacios C, Lombardo LK, Peña-Rosas JP. Vitamin $D$ supplementation for women during pregnancy. Cochrane Database of Systematic Reviews 2016, Issue 1. [DOI: 10.1002/14651858.CD008873.pub3]

\section{Gill 2014}

Gill MG, Nguyen TMN, Bain E, Crowther CA, Middleton P. Home versus hospital glucose monitoring for gestational diabetes during pregnancy. Cochrane Database of Systematic Reviews 2014, Issue 4. [DOI: 10.1002/14651858.CD011069]

\section{McCauley 2015}

McCauley ME, van den Broek N, Dou L, Othman M. Vitamin A supplementation during pregnancy for maternal and newborn outcomes. Cochrane Database of Systematic Reviews 2015, Issue 10. [DOI: 10.1002/14651858.CD008666.pub3]

\section{Rao 2017}

Rao U, de Vries B, Ross GP, Gordon. Fetal biometry for guiding the medical management of women with gestational diabetes mellitus for improving maternal and perinatal health. Cochrane Database of Systematic Reviews 2017, Issue 2. [DOI: 10.1002/14651858.CD012544]

\section{Rumbold 2015}

Rumbold A, Ota E, Nagata C, Shahrook S, Crowther CA. Vitamin C supplementation in pregnancy. Cochrane Database of Systematic Reviews 2015, Issue 9. [DOI: 10.1002/14651858.CD004072.pub3]

\section{Walkinshaw 1996}

Walkinshaw SA. Dietary regulation for gestational diabetes. Cochrane Database of Systematic Reviews 1996, Issue 4. [DOI: 10.1002/14651858.CD000070.pub2]

\section{Walkinshaw 2006}

Walkinshaw SA. Very tight versus tight control for diabetes in pregnancy. Cochrane Database of Systematic Reviews 2006, Issue 2. [DOI: 10.1002/14651858.CD000226.pub2]

\section{Additional references}

\section{ACOG 2013}

American College of Obstetricians and Gynecologists Committee on Practice Bulletins - Obstetrics. Practice Bulletin No. 137: Gestational diabetes mellitus. Obstetrics and Gynecology 2013 (replaces Practice Bulletin Number 30, September 2001);122:406-16. [DOI: 10.1097/01.AOG.0000433006.09219.f1]

\section{ACOG 2015}

ACOG, American College of Obstetrians and Gynecologists. Physical activity and exercise during pregnancy and the postpartum period. Committee Opinion Number 650. www.acog.org/-/media/Committee-Opinions/Committee-onObstetric-Practice/co650.pdf?dmc $=1 \&$ ts $=20171002$ T0942544903 (accessed October 2017)

\section{ADA 2004}

American Diabetes Association. Gestational diabetes mellitus. Diabetes Care 2004;27(S1):S88-90.

\section{ADA 2015}

American Diabetes Association. Management of diabetes in pregnancy. Standards of medical care in diabetes-2015. Diabetes Care 2015;38(1):S77-9. [DOI: http://dx.doi.org/10.2337/ dc15-S015]

\section{American Dietetic Association 2001}

American Dietetic Association. Medical Nutrition Therapy Evidence Based Guides for Practice: Nutrition Practice Guidelines for Gestational Diabetes Mellitus. Chicago, IL: American Dietetic Association, 2001.

\section{Ansar 2013}

Ansar S, Mian S, Roth S, Hebdon GM, Aldasouqi S, Gossain VV. Safety of insulin glargine in pregnancy. Journal of Diabetes \& Metabolism 2013;4(2):240. [DOI: org/10.4172/2155-6156.1000240]

\section{Arbit 2004}

Arbit $\mathrm{E}$. The physiological rationale for oral insulin administration. Diabetes Technology Therapy 2004;6:510-7.

\section{Artal 2007}

Artal R, Catanzaro RB, Gavard JA, Mostello DJ, Friganza JC. A lifestyle intervention of weight-gain restriction: diet and exercise in obese women with gestational diabetes mellitus. Applied Physiology Nutritional Metabolism 2007;32(3):596-601. [PUBMED: 17510701]

\section{Asano 2014}

Asano RY, Sales MM, Browne RAV, Moraes JFVN, Júnior HJC, Moraes MR, et al. Acute effects of physical exercise in type 2 diabetes: A review. World Journal of Diabetes 2014;5(5):659-65. [DOI: 10.4239/wjd.v5.i5.659]

\section{Asemi 2014a}

Asemi Z, Karamali M, Esmaillzadeh A. Effects of calcium-vitamin D co-supplementation on glycaemic control, inflammation and oxidative stress in gestational diabetes: a randomised placebo-controlled trial. Diabetologia 2014;57(9):1798-806. [DOI: $10.1007 / s 00125-014-3293-x]$

\section{Asemi 2014b}

Asemi Z, Samimi M, Tabassi Z, Esmaillzadeh A. The effect of DASH diet on pregnancy outcomes in gestational diabetes: A randomized controlled clinical trial. European Journal of Clinical Nutrition 2014;68(4):490-5.

\section{Athukorala 2010}

Athukorala C, Rumbold AR, Willson KJ, Crowther CA. The risk of adverse pregnancy outcomes in women who are overweight or obese. BMC Pregnancy and Childbirth 2010;10:56. [DOI: 10.1186/1471-2393-10-56]

\section{Babio 2010}

Babio NR, Balanza R, Basulto J, Bulló M, Salas-Salvadó J. Dietary fibre: influence on body weight, glycemic control 
and plasma cholesterol profile. Nutricion Hospitalaria 2010;25(3):327-40. [ISSN: 0212-1611]

\section{Bagchi 2015}

Bagchi D, Swaroop A, Bagchi M. Genomics, Proteomics and Metabolomics in Nutraceuticals and Functional Foods. 2nd Edition. Chichester (UK): John Wiley \& Sons, Inc, 2015. [ISBN 978-1-118-93042-7]

\section{Baljith 2007}

Singh B. Psyllium as therapeutic and drug delivery agent. International Journal of Pharmaceutics 2007;334(1-2):1-14.

\section{Balsells 1997}

Balsells M, Gorcoy R, Mauricio D. Insulin antibody response to a short course of human insulin therapy in women with gestational diabetes. Diabetes Care 1997;20(1):172-5.

\section{Balsells 2015}

Balsells M, García-Patterson A, Solà I, Roqué M, Gich I, Corcoy R. Glibenclamide, metformin, and insulin for the treatment of gestational diabetes: a systematic review and meta-analysis. BMJ Research 2015;350:h102. [DOI: 10.1136/bmj.h102]

\section{Balshem 2011}

Balshem H, Helfand M, Schünemann HJ, Oxman AD, Kunz R, Brozek J, et al. GRADE guidelines: 3. Rating the quality of evidence. Journal of Clinical Epidemiology 2011;64(4):401-6. [DOI: 10.1016/j.jclinepi.2010.07.015]

\section{Bantle 1983}

Bantle JP, Laine DC, Castle GW, Thomas JW, Hoogwerf BJ, Goetz FC. Postprandial glucose and insulin responses to meals containing different carbohydrates in normal and diabetic subjects. New England Journal of Medicine 1983;309(1):7-12.

\section{Barakat 2012}

Barakat R, Cordero Y, Coteron J, Luaces M, Montejo R. Exercise during pregnancy improves maternal glucose screen at 24-28 weeks: a randomised controlled trial. British Journal of Sports Medicine 2012;46(9):656-61. [DOI: 10.1136/ bjsports-2011-090009]

\section{Bas-Lando 2014}

Bas-Lando M, Srebnik N, Farkash R, loscovich A, Samueloff A, Grisaru-Granovsky S. Elective induction of labor in women with gestational diabetes mellitus: an intervention that modifies the risk of cesarean section. Archives of Gynecology and Obstetrics 2014;290(5):905-12. [10.1007/s00404-014-3313-6.PMID: 24973018]

\section{Becker 2011}

Becker LA, Oxman AD. Chapter 22: Overviews of reviews. In: Higgins JPT, Green S editor(s). Cochrane Handbook for Systematic Reviews of Interventions. Version 5.1.0 [updated March 2011]. Available from www.cochrane-handbook.org: The Cochrane Collaboration, 2011.

\section{Bellamy 2009}

Bellamy L, Casas J, Hingorani AD, Williams D. Type 2 diabetes mellitus after gestational diabetes: a systematic review and meta-analysis. Lancet 2009;373(9677):1773-9.

\section{Berggren 2013}

Berggren EK, Bogress KA. Oral agents for the management of gestational diabetes. Clinical Obstetrics and Gynecology 2013;56(4):827-36.

\section{Bernasko 2012}

Bernasko J. Insulin pump therapy for pregnancy: a primer. Journal of Maternal-Fetal and Neonatal Medicine 2012;25(6):552-7. [DOI: 10.3109/14767058.2011.598586]

\section{Bertini 2005}

Bertini AM, Silva JC, Taborda W, Becker F, Lemos Bebber FR, Zucco Viesi JM, et al. Perinatal outcomes and the use of oral hypoglycemic agents. Journal of Perinatal Medicine 2005;33(6):519-23. [PUBMED: 16318615]

\section{Blumer 2013}

Blumer I, Hadar E, Hadden DR, Jovanovc L, Mestman JH, Murad $\mathrm{MH}$, et al. Diabetes and pregnancy: an endocrine society clinical practice guideline. Journal of Clinical Endocinology Metabolism 2013;98(11):4227-49.

\section{Bolli 2000}

Bolli GB, Owens DR. Insulin glargine. Lancet 2000;356(9228):443-5. [DOI: 10.1016/S0140-6736(00)02546-0]

\section{Boney 2005}

Boney CM, Verma A, Tucker R, Vohr BR. Metabolic syndrome in childhood: association with birth weight, maternal obesity, and gestational diabetes mellitus. Pediatrics 2005;115(3):e290-6.

\section{Bonomo 2005}

Bonomo M, Corica D, Mion E, Goncalves D, Motta G, Merati R, et al. Evauating the therapeutic approach in pregnancies complicated by borderline glucose intolerance: a randomized clinical trial. Diabetes Medicine 2005;22(11):1536-41.

\section{Bottalico 2007}

Bottalico JN. Recurrent gestational diabetes: risk factors, diagnosis, management and implications. Seminars in Perinatology 2007;31(3):176-84.

\section{Broadhurst 2006}

Broadhurst CL, Domenico P. Clinical studies on chromium picolinate supplementation in diabetes mellitus - a review. Diabetes Technology Therapeutics 2006;8(6):677-87.

\section{Brower 1999}

Brower V. Nutraceuticals: poised for a healthy slice of the healthcare market?. Nature Biotechnology 1999;16(8):728-31.

\section{Buchanan 1991}

Buchanan TA. Glucose metabolism during pregnancy: normal physiology and implication for diabetes mellitus. Israel Journal of Medical Sciences 1991;27(8-9):432-41. 


\section{Burris 2012}

Burris HH, Rifas-Shiman SL, Kleinman K, Litonjua AA, Huh SY, Rich-Edwards JW, et al. Vitamin $D$ deficiency in pregnancy and gestational diabetes mellitus. American Journal of Obstetric Gynecology 2012;207(3):182 e1-8. [DOI: org/10.1016/ j.ajog.2012.05.022]

\section{Burris 2014}

Burris HH, Camargo CA. Vitamin D and gestational diabetes mellitus. Current Diabetes Reports 2014;14(1):451-61. [DOI: 10.1007/s11892-013-0451-3]

\section{Callesen 2013}

Callesen NF, Damm J, Mathiesen JM, Ringholm L, Damm P, Mathiesen ER. Treatment with the long-acting insulin analogues detemir or glargine during pregnancy in women with type 1 diabetes: comparison of glycaemic control and pregnancy outcome. Journal of Maternal, Fetal and Neonatal Medicine 2013;26(6):588-92. [DOI: 10.3109/14767058.2012.743523]

\section{Carino 1999}

Carino GP, Mathiowitz E. Oral insulin delivery. Advance Drug Delivery Review 1999;35(2-3):249-57.

\section{Carroll 2015}

Carroll D, Kelley KW. In women with gestational diabetes requiring drug treatment, glibenclamide may be inferior to insulin and metformin: metformin (plus insulin when required) performs better than insulin. Evidence Based Medicine 2015;20(4):127. [DOI: 10.1136/ebmed-2015-110186]

\section{Casey 2015}

Casey BM, Duryea EL, Abbassi-Ghanavati M, Tudela CM, Shivvers SA, McIntire DD, et al. Glyburide in women with mild gestational diabetes: A randomized controlled trial. Obstetrics and Gynecology 2015;126(2):303-9.

\section{Catalano 2014}

Catalano PM. Trying to understand gestational diabetes. Diabetic Medicine 2014;31(3):273-81.

\section{Chalmers 1989}

Chalmers I, Hetherington J, Elbourne D, Keirse MJNC, Enkin M. Materials and methods used in synthesizing evidence to evaluate the effects of care during pregnancy \& childbirth. In: Chalmers I, Enkin, M, Keirse MJNC editor(s). Effective Care in Pregnancy and Childbirth. Vol. 2, Oxford (UK): Oxford University Press, 1989:39-65.

\section{Chan 2005}

Chan LY, Yeung JH, Lau TK. Placental transfer of rosiglitazone in the first trimester of human pregnancy. Fertility and Sterility 2005;83(4):955-8.

\section{Cheung 2003}

Cheung NW, Byth K. Population health significance of gestational diabetes. Diabetes Care 2003;26(7):2005-9.

\section{Cheung 2009}

Cheung NW. The management of gestational diabetes. Vascular Health and Risk Management 2009;5(1):153-64.

\section{Christesen 1998}

Christesen $\mathrm{H}$, Melender A. Prolonged elimination of tolbutamide in a premature newborn with hyperinsulinaemic hypoglycaemia. European Journal of Endocrinology 1998;138(6):698-701.

\section{Clapp 2002}

Clapp JF. Maternal carbohydrate intake and pregnancy outcome. Proceedings of the Nutrition Society 2002;61(1):45-50.

\section{Clapp 2006}

Clapp JF. Effects of diet and exercise on insulin resistance during pregnancy. Metabolic Syndrome and Related Disorders 2006;4(2):84-90.

\section{Coderre 1995}

Coderre L, Kandror KV, Vallega G, Pilch PF. Identification and characterization of an exercise-sensitive pool of glucose transporters in skeletal muscle. Journal of Biological Chemistry 1995;270(46):27584-8.

\section{Coiner 2014}

Coiner J, Rowe M, deVente J. The treatment of diabetes in pregnancy; metformin vs glyburide and insulin - biomedical evidence of fetopathy. American Journal of Obstetrics and Gynecology 2014;210(1 Suppl):S148.

\section{Coleman 2001}

Coleman MD, Eason RC, Bailey CJ. The therapeutic use of lipoic acid in diabetes: a current perspective. Environmental Toxicology and Pharmacology 2001;10(4):167-72.

\section{Crawford 2015}

Crawford TJ, Crowther CA, Alsweiler J, Brown J. Antenatal dietary supplementation with myo-inositol in women during pregnancy for preventing gestational diabetes. Cochrane Database of Systematic Reviews 2015, Issue 12. [DOI: 10.1002/14651858.CD011507.pub2]

\section{Crowther 2005}

Crowther CA, Hiller JE, Moss JR, McPhee AJ, Jeffries WS, Robinson JS. Effect of treatment of gestational diabetes mellitus on pregnancy outcomes. New England Journal of Medicine 2005;352(24):2477-86.

\section{Croze 2013}

Croze ML, Soulage CO. Potential role and therapeutic interests of myo-inositol in metabolic diseases. Biochimie 2013;95(10):1811-27.

\section{D'Anna 2013}

D’Anna R, Scilipoti A, Giordano D, Caruso C, Cannata ML, Interdonato $\mathrm{ML}$, et al. Myo-inositol supplementation and onset of gestational diabetes mellitus in pregnant women with a family history of type 2 diabetes: a prospective, randomized, placebo-controlled study. Diabetes Care 2013;36(4):854-8.

\section{D'Anna 2015}

D’Anna R, Di Benedetto A, Scilipoti A, Santamaria A, Interdonato ML, Petrella E, et al. Myo-Inositol supplementation for prevention of gestational diabetes in obese pregnant 
women. A randomized controlled trial. Obstetrics 2015;126(2):310-5

\section{Davenport 2008}

Davenport MH, Mottola MF, McManus R, Grattond R. A walking intervention improves capillary glucose control in women with gestational diabetes mellitus: a pilot study. Applied Physiology, Nutrition, and Metabolism 2008;33(3):511-7. [DOI: 10.1139/ H08-018]

\section{de Barros 2010}

de Barros MC, Lopes MA, Francisco RP, Sapienza AD, Zugaib M. Resistance exercise and glycemic control in women with gestational diabetes mellitus. American Journal of Obstetrics and Gynecology 2010;203(6):556 e1-6. [DOI: 10.1016/ j.ajog.2010.07.015; PUBMED: 20864072]

\section{Devlieger 2008}

Devlieger R, Casteels K, Van Assche FA. Reduced adaptation of the pancreatic $B$ cells during pregnancy is the major causal factor for gestational diabetes: current knowledge and metabolic effects on the offspring. Acta Obstetricia et Gynecologica Scandinavica 2008;87(12):1266-70.

\section{Di Cianni 2003}

Di Cianni G, Miccoli R, Volpe L, Lencioni C, Del Prato S. Intermediate metabolism in normal pregnancy and in gestational diabetes. Diabetes Metabolism Research Review 2003;19(4):259-70

\section{Dornhorst 2002}

Dornhorst A, Frost $\mathrm{G}$. The principles of dietary management of gestational diabetes: reflection on current evidence. Journal of Human Nutrition and Dietetics 2002;15(2):145-56.

\section{Dror 2011}

Dror DK. Vitamin D status during pregnancy: maternal, fetal, and postnatal outcomes. Current Opinion in Obstetrics and Gynecology 2011;23(6):422-6. [PMID: 21986726]

\section{Duncan 2007}

Duncan RE, Ahmadian M, Jaworski K, Sarkadi-Nagy E, Sook Sul H. Regulation of lipolysis in adipocytes. Annual Review of Nutrition 2007;27:79-101. [DOI: 10.1146/ annurev.nutr.27.061406.093734]

\section{Durnwald 2008}

Durnwald CP, Landon MB. A comparison of lispro and regular insulin for the management of type 1 and type 2 diabetes in pregnancy. Journal of Maternal and Fetal Neonatal Medicine 2008;21(5):309-13.

\section{Durnwald 2013}

Durnwald CP. Insulin analogues in the treatment of gestational diabetes mellitus. Clinical Obstetrics and Gynecology 2013;56(4):816-26.

\section{Egerman 2009}

Egerman RS, Ramsey RD, Kao LW, Bringman JJ, Haerian HM, Kao JL, et al. Perinatal outcomes in pregnancies managed with antenatal insulin glargine. American Journal of Perinatology 2009;26(8):591-5.

\section{Elliott 1991}

Elliott BD, Langer O, Schenker S, Johnson RF. Insignificant transfer of glyburide occurs across the human placenta. American Journal of Obstetrics and Gynecology 1991;165(4 Pt 1):807-12

\section{England 2015}

England L, Kotelchuck M, Wilson HG, Diop H, Oppedisano P, Kim SY, et al. Estimating the recurrence rate of gestational diabetes mellitus (GDM) in Massachusetts 1998-2007: Methods and findings. Maternal Child Health Journal 2015;19(10):2303-13. [DOI: 10.1007/s10995-015-1750-x]

\section{Eskin 2005}

Eskin NAM, Tamir S. Dictionary of Nutraceuticals and Functional Foods. Boca Raton (FL): CRC Press, Taylor \& Francis, 2005.

\section{Evans 2009}

Evans MJ. Diabetes and pregnancy: a review of pathology. British Journal of Diabetes \& Vascular Disease 2009;9:201. [DOI: 10.1177/1474651409344924]

\section{Facchinetti 2013}

Facchinetti F, Pignatti L, Interdonato ML, Neri I, Bellei G, D’Anna R. Myoinositol supplementation in pregnancies at risk for gestational diabetes. Interim analysis of a randomized controlled trial. American Journal of Obstetrics and Gynecology 2013;208(Suppl 1):S36.

\section{Farrar 2017}

Farrar D, Simmonds M, Bryant M, Sheldon TA, Tuffnell D, Golder SP, et al. Treatments for gestational diabetes: A systematic review and meta-analysis. BMJ Open 2017;7(7):e015557. [10.1136/ bmjopen-2016-015557]

\section{Ferrara 2007}

Ferrara A. Increasing prevalence of gestational diabetes mellitus: a public health perspective. Diabetes Care 2007;30(S2):S141-6. [DOI: 10.2337/dc07-s206]

\section{Fonte 2013}

Fonte P, Araújo F, Reis, S, Sarmento B. Oral insulin delivery: How far are we?. Journal of Diabetes Science and Technology 2013;7(2):520-31.

\section{Forster 2014}

Forster DA, Jacobs S, Amir LH, Davis P, Walker SP, McEgan K, et al. Safety and efficacy of antenatal milk expressing for women with diabetes in pregnancy: protocol for a randomised controlled trial. BMJ Open 2014;4:e006571. [10.1136/ bmjopen-2014-006571]

\section{Foster-Powell 2002}

Foster-Powell K, Holt SH, Brand-Miller JC. International table of glycemic index and glycemic load values. American Journal of Clinical Nutrition 2002;76(1):5-56. 


\section{Gabbe 2000}

Gabbe SG, Holing E, Temple P, Brown ZA. Benefits, risks, costs, and patient satisfaction associated with insulin pump therapy for the pregnancy complicated by type 1 diabetes mellitus. American Journal of Obstetrics and Gynecology 2000;182(6):1283-91. [DOI: 10.1067/mob.2000.106182]

\section{Gamson 2004}

Gamson K, Chia S, Jovanovic L. The safety and efficacy of insulin analogs in pregnancy. Journal of Maternal-Fetal and Neonatal Medicine 2004;15(1):26-34.

\section{Garrison 2015}

Garrison A. Screening, diagnosis and management of gestational diabetes mellitus. Amercian Family Physician 2015;91(7):460-7.

\section{Goldberg 1998}

Goldberg RB, Einhorn D, Lucas CP, Rendell MS, Damsbo P, Huang WC, et al. A randomized placebo-controlled trial of repaglinide in the treatment of type 2 diabetes. Diabetes Care 1998;21(11):1897-903.

\section{Gonalez 2002}

Gonzalez JL. Management of diabetes in pregnancy. Clinical Obstetrics and Gynecology 2002;45(1):165-9.

\section{Graves 2006}

Graves DE, White JC, Kirk JK. The use of insulin glargine with gestational diabetes mellitus. Diabetes Care 2006;29(2):471-2.

\section{Groop 1987}

Groop L, Luzi L, Melander A, Groop PH, Ratheiser K, Simonson DC, et al. Different effects of glyburide and glipizide on insulin secretion and hepatic glucose production in normal and NIDDM subjects. Diabetes 1987;36(11):1320-8.

\section{Groop 1991}

Groop LC, Barzilai N, Ratheiser K, Luzi L, Wahlin-Boll E, Melander A, et al. Dose-dependent effects of glyburide on insulin secretion and glucose uptake in humans. Diabetes Care 1991;14(8):724-7.

\section{Grunberger 2013}

Grunberger $\mathrm{G}$. The need for better insulin therapy. Diabetes, Obesity and Metabolism 2013;15(Suppl 1):1-5.

\section{Guerrero-Romer 2004}

Guerrero-Romero F, Tamez-Perez HE, Gonzalez-Gonzalez G, Salinas-Martínez AM, Montes-Villarreal J, Treviño-Ortiz JH, et al. Oral magnesium supplementation improves insulin sensitivity in non-diabetic subjects with insulin resistance. A double-blind placebo-controlled randomized trial. Diabetes Metabolism 2004;30(3):253-8. [PMID: 15223977]

\section{Gupta 2010}

Gupta S, Chauhan D, Mehla K, Sood P, Nair A. An overview of nutraceuticals: current scenario. Journal of Basic and Clinical Pharmacy 2010;1(2):55-62.

\section{Hamid 2000}

Hamid AA, Luan YS. Functional properties of dietary fibre prepared from defatted rice bran. Food Chemistry 2000;68:15-9.

\section{HAPO 2008}

HAPO Study Cooperative Research Group. Hyperglycemia and adverse pregnancy outcomes. New England Journal of Medicine 2008;358:1991-2002. [DOI: 10.1056/NEJMoa0707943]

\section{Harris 1997}

Harris SB, Caulfield LE, Sugamori ME. The epidemiology of diabetes in pregnant native Canadians: A risk profile. Diabetes Care 1997;20(9):1422-5. [DOI: 10.2337/diacare.20.9.1422]

\section{Harris 2005}

Harries GD, Russell DW. Diabetes management and exercise in pregnant patients with diabetes. Cinical Diabetes 2005;23(4):165-8.

\section{Harris 2013}

Harris DL, Weston PJ, Signa M, Chase JG, Harding JE. Dextrose gel for neonatal hypoglycaemia (the Sugar Babies Study): a randomised, double-blind, placebo-controlled trial. Lancet 2013;382(9910):2077-83. [DOI: 10.1016/S0140-6736(13)61645-1]

\section{Hartman 2008}

Hartman I. Insulin analogs: impact on treatment success, satisfaction, quality of life, and adherence. Clinical Medical Research 2008;6(2):54-67.

\section{Hay 2006}

Hay WW Jr. Placental-fetal glucose exchange and fetal glucose metabolism. Transactions of the American Clinical and Climatological Association 2006;117:321-40.

\section{Hedderson 2006}

Hedderson MM, Weiss NS, Sacks DA, Pettitt DJ, Selby JV, Quesenberry CP, et al. Pregnancy weight gain and risk of neonatal complications: Macrosomia, hypoglycemia, and hyperbilirubinemia. Obstetrics and Gynecology 2006;108(5):1153-61. [DOI: 10.1097/01.AOG.0000242568.75785.68]

\section{Heinemann 2011}

Heinemann L. New ways of insulin delivery. International Journal of Clinical Practice. Supplement 2011;175:31-46.

\section{Hernandez 2014}

Hernandez TL, Van Pelt RE, Anderson MA, Daniels LJ, West NA, Donahoo WT, et al. A higher-complex carbohydrate diet in gestational diabetes mellitus achieves glucose targets and lowers postprandial lipids: A randomized crossover study. Diabetes Care 2014;37(5):1254-62. [DOI: 10.2337/dc13-2411]

\section{Higgins 2011}

Higgins JPT, Altman DG, Sterne JAC (editors). Chapter 8: Assessing risk of bias in included studies. Cochrane Handbook for Systematic Reviews of Interventions. 5.1.0 (updated March 2011). The Cochrane Collaboration, 2011. 


\section{Ho 2007}

Ho FLW, Liew CF, Cunanan EC, Lee KO. Oral hypoglycaemic agents for diabetes in pregnancy - an appraisal of the current evidence for oral anti-diabetic drug use in pregnancy. Annals Academy of Medicine 2007;36(8):672-8.

\section{Hod 2005}

Hod M. For the Novorapid insulin trial of the safety and efficacy of insulin Aspart for the treatment of Type 1 Diabetic Women during Pregnancy: Study design. Conference Proceedings. European Association for the Study of Diabetes. 2005.

\section{Hod 2014}

Hod M, Mathiesen ER, Jovanovic L, McCance DR, IvanisevicM, Durán-Garcia S, et al. A randomized trial comparing perinatal outcomes using insulin detemir or neutral protamine Hagedorn in type 1 diabetes. Journal of Maternal, Fetal and Neonatal Medicine 2014;27(1):7-13. [DOI: 10.3109/14767058.2013.799650]

\section{Hollander 2010}

Hollander PA, Cefalu WT, Mitnick M. Titration of inhaled human insulin (Exubera) in a treat-to-target regimen for patients with type 2 diabetes. Diabetes Technology Therapy 2010;12(3):185-91.

\section{Holt 2013}

Holt RI, Lambert KG. The use of oral hypoglycaemic agents in pregnancy. Diabetic Medicine 2013;31(3):282-91.

\section{Home 2015}

Home PD. Plasma insulin profiles after subcutaneous injection: how close can we get to physiology in people with diabetes? Diabetes, Obesity and Metabolism 2015;17(11):1011-20.

\section{Hompesh 2009}

Hompesh M, Kollmeier A, Rave K, Heinemann L, Mitnick M, Davies $\mathrm{S}$, et al. Glycaemic exposure is affected favourably by inhaled human insulin (Exubera) as compared with subcutaneous insulin glargine (Lantus) in patients with type 2 diabetes. Diabetes Technology Therapy 2009;11(5):307-13.

\section{Horvath 2010}

Horvath K, Koch K, Jeitler K, Matyas E, Bender R, Bastian H, et al. Effects of treatment in women with gestational diabetes mellitus: systematic review and meta-analysis. BMJ Research 2010;340:c1395. [DOI: 10.1136/bmj.c1395]

\section{Hui 2009}

Hui H, Tang G, Go VL. Hypoglycemic herbs and their action mechanisms. Chinese Medicine 2009;4:11. [DOI: 10.1186/1749-8546-4-11]

\section{Iyer 2010}

lyer $\mathrm{H}$, Khedkar A, Verma M. Oral insulin - a review of current status. Diabetes, Obesity and Metabolism 2010;12(3):179-85.

\section{Jamilian 2015}

Jamilian M, Asemi Z. The effect of soy intake on metabolic profiles of women with gestational diabetes mellitus. Journal of Clinical Endocrinology and Metabolism 2015;100(12):4654-61.

\section{Jones 2012}

Jones L, Othman M, Dowswell T, Alfirevic Z, Gates S, Newburn $M$, et al. Pain management for women in labour: an overview of systematic reviews. Cochrane Database of Systematic Reviews 2012, Issue 3. [DOI: 10.1002/14651858.CD009234.pub2]

\section{Jovanovic 2007}

Jovanovic L, Pettitt DJ. Treatment with insulin and its analogs in pregnancies complicated by diabetes. Diabetes Care 2007;30(Suppl 2):S220-4.

\section{Kalra 2015}

Kalra B, Gupta Y, Singla R, Klara S. Use of oral anti-diabetic agents in pregnancy: A pragmatic approach. North American Journal of Medicine \& Science 2015;7(1):6-12.

\section{Kavitha 2013}

Kavitha N, De S, Kanagasabai S. Oral hypoglycemic agents in pregnancy: an update. Journal of Obstetrics and Gynecology of India 2013;63(2):82-7. [DOI: 10.1007/s13224-012-0312-z]

\section{Kelley 2015}

Kelley KW, Carroll DG, Meyer A. A review of current treatment strategies for gestational diabetes mellitus. Drugs in Context 2015;4:212282. [DOI: 10.7573/dic.212282]

\section{Kemball 1970}

Kemball ML, Mclver C, Milner RDG, Nourse CH, Schiff D, Tiernan JR. Neonatal hypoglycaemia in infants of diabetic mothers given sulphonylurea drugs in pregnancy. Archives of Disease in Childhood 1970;45(243):696-701.

\section{Kershaw 2006}

Kershaw EE, Hamm JK, Verhagen LAW, Peroni O, Katic M, Flier JS. Adipose triglyceride lipase function, regulation by insulin, and comparison with adiponutrin. Diabetes 2006;55(1):148-57.

\section{Kersten 2001}

Kersten S. Mechanisms of nutritional and hormonal regulation of lipogenesis. EMBO Reports 2001;2(4):282-6. [DOI: 10.1093/ embo-reports/kve071]

\section{Kesavadev 2016}

Kesavadev J. Insulin pump therapy in pregnancy. Diabetes in Pregnancy 2016;66(11):S39-44.

\section{Kim 2010}

Kim C. Gestational diabetes: risks, management, and treatment options. International Journal of Women's Health 2010;7(2):339-51.

\section{Kraemer 2006}

Kraemer J, Klein J, Lubetsky A, Koren G. Perfusion studies of glyburide transfer across the human placenta: Implications for fetal safety. American Journal of Obstetrics and Gynecology 2006;195(1):270-4. 


\section{Lain 2007}

Lain KY, Catalano PM. Metabolic changes in pregnancy. Clinical Obstetrics and Gynecology 2007;50(4):938-48.

\section{Lakshmana Prabu 2012}

Lakshmana Prabu S, Suriya Prakash TNK, Dinesh Kumar C, Suresh Kumar S, Ragavendran T. Nutraceuticals: A review. Elixir Pharmacy 2012;46(2012):8372-7.

\section{Landon 2009}

Landon MB, Spong CY, Thom E, Carpenter MW, Ramin SM, Casey B, et al. A multicenter, randomized trial of treatment for mild gestational diabetes. New England Journal of Medicine 2009;361(14):1339-48.

\section{Langer 2000}

Langer O, Conway DL, Berkus MD, Xenakis EM, Gonzales O. A comparison of glyburide and insulin in women with gestational diabetes mellitus. New England Journal of Medicine 2000;343(16):1134-8.

\section{Langer 2007}

Langer O. Oral anti-hyperglycemic agents for the management of gestational diabetes mellitus. Obstetrics and Gynecology Clinics of North America 2007;34(2):255-74.

\section{Lapolla 2005}

Lapolla A, Dalfra MG, Fedele D. Insulin therapy in pregnancy complicated by diabetes: are insulin analogs a new tool? Diabetes Metabolism Research Review 2005;21(3):241-52.

\section{Larner 2010}

Larner J, Brautigan DL, Thorner MO. D-Chiro-Inositol glycans in insulin signalling and insulin resistance. Molecular Medicine 2010;16(11-12):543-51.

\section{Lebovitz 1997}

Lebovitz HE. Alpha-glucosidase inhibitors. Endocrinology and Metabolism Clinics of North America 1997;26(3):539-51.

\section{Louie 2011}

Louie JC, Markovic TP, Perera N, Foote D, Petocz P, Ross GP, et al. A randomized controlled trial investigating the effects of a low-glycemic index diet on pregnancy outcomes in gestational diabetes mellitus. Diabetes Care 2011;34(11):2341-6. [DOI: 10.2337/dc11-0985]

\section{Lucas 1988}

Lucas A, Morley R, Cole T. Adverse neurodevelopmental outcome of moderate neonatal hypoglycaemia. BMJ Clinical Research 1988;297(6659):1304-8.

\section{Ludwig 2002}

Ludwig DS. The glycemic index: physiological mechanisms relating to obesity, diabetes, and cardiovascular disease. JAMA 2002;287(18):2414-23. [DOI: 10.1001/jama.287.18.2414]

\section{Lv 2015}

Lv S, Wang JY, Xu Y. Safety of insulin analogs during pregnancy: a meta-analysis. Archives of Gynecology and Obstetrics 2015;292(4):749-56. [DOI: 10.1007/s00404-015-3692-3]

\section{Ma 2015}

Ma WJ, Huang ZH, Huang BX, Qi BH, Zhang YJ, Xiao BX, et al. Intensive low-glycaemic-load dietary intervention for the management of glycaemia and serum lipids among women with gestational diabetes: a randomized control trial. Public Health Nutrition 2015;18(8):1506-13.

\section{Magon 2014}

Magon N, Seshiah V. Gestational diabetes mellitus: Insulinic management. Journal of Obstetrics and Gynecology of India 2014;64(2):82-90. [DOI: 10.1007/s13224-014-0525-4]

\section{Malvasi 2014}

Malvasi A, Casciaro F, Minervini MM, Kosmas I, Mynbaev OA, Pacella E, et al. Myo-inositol, D-chiro-inositol, folic acid and manganese in second trimester of pregnancy: a preliminary investigation. European Review for Medical and Pharmacological Sciences 2014;18(2):270-4.

\section{Manders 2010}

Manders RJ, Van Dijk JW, van Loon LJ. Low-intensity exercise reduces the prevalence of hyperglycemia in type 2 diabetes. Medical Science Sports Exercise 2010;42(2):219-25. [DOI: 10.1249/MSS.0b013e3181b3b16d]

\section{Markovic 2016}

Markovic TP, Muirhead R, Overs S, Ross GP, Louie JCY, Kizirian N, et al. Randomized controlled trial investigating the effects of a low-glycemic index diet on pregnancy outcomes in women at high risk of gestational diabetes mellitus: The GI Baby 3 Study. Diabetes Care 2016;39(1):31-8. [DOI: 10.2337/dc15-0572]

\section{Martin 2006}

Martin J, Wang ZQ, Zhang XH, Wachtel D, Volaufova J, Matthews DE, et al. Chromium picolinate supplementation attenuates body weight gain and increases insulin sensitivity in subjects with type 2 diabetes. Diabetes Care 2006;29(8):1826-32.

\section{Mathiesen 2012}

Mathiesen ER, Hod M, Ivanisevic M, Duran Garcia S, Brøndsted L, Jovanovic L, et al. Detemir in Pregnancy Study Group. Maternal efficacy and safety outcomes in a randomized controlled trial comparing insulin detemir with NPH insulin in 310 pregnant women with type 1 diabetes. Diabetes Care 2012;35(10):2012-7. [PMID: 22851598 ]

\section{McCance 2011}

McCance DR. Pregnancy and diabetes. Best Practice \& Research. Clinical Endocrinology \& Metabolism 2011;25(6):945-58.

\section{Menon 1990}

Menon RK, Gohen RM, Sperling MA. Transplacental passage of insulin in pregnant women with insulin-dependent diabetes mellitus. New England Journal of Medicine 1990;323(5):309-15.

\section{Metzger 2008}

Metzger BE, Contreras M, Sacks DA, Watson W, Dooley SL, Foderaro M, et al. Hyperglycemia and adverse pregnancy outcomes. New England Journal of Medicine 2008;358(19):1991-2002. 


\section{Mokdad 2003}

Mokdad AH, Ford ES, Bowman BA, Dieta WH, Vinicor F, Bales VS, et al. Prevalence of obesity, diabetes and obesity-related health risk factors, 2001. JAMA 2003;289(1):76-9.

\section{Mooren 2011}

Mooren FC, Krüger K, Völker K, Golf SW, Wadepuhl M, Kraus A. Oral magnesium supplementation reduces insulin resistance in non-diabetic subjects - a double-blind, placebocontrolled, randomized trial. Diabetes, Obesity \& Metabolism 2011;13(3):281-4. [DOI: 10.1111/j.1463-1326.2010.01332.x]

\section{Moreno-Castilla 2013}

Moreno-Castilla C, Hernandez M, Bergua M, Alvarez MC, Arce MA, Rodriguez $\mathrm{K}$, et al. Low-carbohydrate diet for the treatment of gestational diabetes mellitus. Diabetes Care 2013;36(8):2233-8. [DOI: $10.2337 / \mathrm{dc} 12-2714]$

\section{Moretti 2008}

Moretti ME, Rezvani M, Koren G. Safety of glyburide for gestational diabetes: A meta-analysis of pregnancy outcomes. Annals of Pharmacotherapy 2008;42(4):483-9.

\section{Moses 2009}

Moses RG, Barker M, Winter M, Petcoz P, Brand-Miller JC. Can a low-glycemic index diet reduce the need for insulin in gestational diabetes mellitus? A randomized trial. Diabetes Care 2009;32(6):996-1000.

\section{Mottola 2008}

Mottola MF. The role of exercise in the prevention and treatment of gestational diabetes mellitus. Current Diabetes Reports 2008;8(4):299-304. [PUBMED: 18631443]

\section{Mpondo 2015}

Mpondo BCT, Ernest A, Dee HE. Gestational diabetes mellitus: challenges in diagnosis and management. Journal of Diabetes and Metabolic Disorders 2015;14:42. [DOI: 10.1186/ s40200-015-0169-7]

\section{Nachum 1999}

Nachum Z, Ben-Shlomo I, Weiner E, Shalev E. Twice daily insulin versus four times daily insulin dose regimens for diabetes in pregnancy: randomised controlled trial. BMJ 1999;319(7210):1223-7.

\section{Nankervis 2013}

Nankervis A, Mclntyre HD, Moses R, Ross GP, Callaway L, Porter $\mathrm{C}$, et al. Consensus Guidelines for the Testing and Diagnosis of Gestational Diabetes Mellitus in Australia. Sydney (Australia): Australasian Diabetes in Pregnancy Society, 2013.

\section{Negrato 2012}

Negrato CA, Montenegro RM, Von Kostrisch LM, Guedes MF, Mattar R, Gomes MB. Insulin analogues in the treatment of diabetes in pregnancy. Arquivos Brasileiros de Endocrinologia \& Metabologia 2012;56(7):405-14.

\section{NICE 2015}

National Institute for Health and Clinical Excellence. Diabetes in Pregnancy: Management of Diabetes and its Complications from Preconception to the Postnatal Period. NICE Guideline NG3. London (UK): National Institute for Health and Care Excellence, 2015.

\section{Nuttall 1984}

Nuttall FQ, Mooradian AD, Gannon MC, Billington C, Krezowski P. Effect of protein ingestion on the glucose and insulin response to a standardized oral glucose load. Diabetes Care 1984;7(5):465-70. [DOI: 10.2337/diacare.7.5.465]

\section{NZ Ministry of Health 2014}

NZ Ministry of Health. Screening, Diagnosis and Management of Gestational Diabetes in New Zealand: A Clinical Practice Guideline. Wellington (New Zealand): Ministry of Health, 2014.

\section{Ogunyemi 2011}

Ogunyemi DA, Fong A, Rad S, Kjos SL. Attitudes and practices of healthcare providers regarding gestational diabetes: results of a survey conducted at the 2010 meeting of the International Association of Diabetes in Study group (IADPSG). Diabetes Medicine 2011;28(8):976-86.

\section{Okesene-Gafa 2018}

Okesene-Gafa KAM, Brown J, McCowan L, Crowther CA. Probiotics for treating women with gestational diabetes for improving maternal and fetal health and well-being. Cochrane Database of Systematic Reviews 2018, Issue 2. [DOI: 10.1002/14651858.CD012970]

\section{Ornoy 2005}

Ornoy A. Growth and neurodevelopment outcome of children born to mothers with pre-gestational and gestational diabetes. Pediatric Endocrinology Reviews 2005;3(2):104-13.

\section{Ornoy 2011}

Ornoy A. Prenatal origin of obesity and their complications: Gestational diabetes, maternal overweight and the paradoxical effects of fetal growth restriction and macrosomia. Reproductive Toxicology 2011;32:205-12.

\section{Padayachee 2015}

Padayachee C, Coombes JS. Exercise guidelines for gestational diabetes mellitus. World Journal of Diabetes 2015;6(8):1033-44. [DOI: 10.4239/wjd.v6.i8.1033]

\section{Page 2014}

Page KA, Romero A, Buchanan TA, Xiang AH. Gestational diabetes mellitus, maternal obesity and adiposity in offspring. Journal of Pediatrics 2014;164(4):807-10. [DOI: org/10.1016/ j.jpeds.2013.11.063]

\section{Pagliuca 2014}

Pagliuca FW, Millman JR, Gurtler M, Segel M, Van Dervort A, Ryu JH, et al. Generation of functional human pancreatic $\beta$ cells in vitro. Cell 2014;159(2):428-39.

\section{Paivaa 2015}

Paivaa AN, de Lima JG, de Medeiros ACQ, Figueiredo HAO, de Andrade RL, Ururahye MAG, et al. Beneficial effects of oral chromium picolinate supplementation on glycemic control in patients with type 2 diabetes: A randomized clinical

Treatments for women with gestational diabetes mellitus: an overview of Cochrane systematic reviews (Review) 
study. Journal of Trace Elements in Medicine and Biology 2015;32:66-72.

\section{Pelaez-Crisologo 2009}

Pelaez-Crisologo MG, Castillo-Torralba MN, Festin MR. Different techniques of blood glucose monitoring in women with gestational diabetes for improving maternal and infant health (withdrawn protocol). onlinelibrary.wiley.com/ doi/10.1002/14651858.CD007790/pdf (accessed October 2017).

\section{Petry 2010}

Petry CJ. Gestational diabetes: risk factors and recent advances in its genetics and treatment. British Journal of Nutrition 2010;104(6):1-13. [DOI: http://dx.doi.org/10.1017/ S0007114510001741]

\section{Poel 2012}

Poel YHM, Hummel P, Lips P, Stam F, van der Ploeg T, Simsek S. Vitamin $D$ and gestational diabetes: A systematic review and meta-analysis. European Journal of Internal Medicine 2012;23:465-9. [DOI: 10.1016/j.ejim.2012.01.007]

\section{Pollex 2011}

Pollex E, Moretti ME, Koren G, Feig DS. Safety of insulin glargine use in pregnancy: a systematic review and meta-analysis. Annals of Pharmacotherapy 2011;45(1):9-16. [DOI: 10.1345/ aph.1P327]

\section{Poomalar 2015}

Poomalar GK. Changing trends in management of gestational diabetes mellitus. World Journal of Diabetes 2015;6(2):284-95. [DOI: 10.4239/wjd.v6.i2.284]

\section{Price 2007}

Price N, Bartlett C, Gillmer M. Use of insulin glargine during pregnancy: a case-control pilot study. British Journal of Obstetrics and Gynaecology 2007;114(4):453-7.

\section{Proud 2006}

Proud CG. Regulation of protein synthesis by insulin. Biochemical Society Transactions 2006;34(Pt 2):213-6.

\section{Pöyhönen-Alho 2007}

Pöyhönen-Alho M, Rönnemaa T, Saltevo J, Ekblad U, Kaaja RJ. Use of insulin glargine during pregnancy. Acta Obstetricia et Gynecologica Scandinavica 2007;86(10):1171-4.

\section{Radesky 2008}

Radesky JS, Oken E, Rifas-Shiman SL, Kleinman KP, RichEdwards JW, Gillman MW. Diet during early pregnancy and development of gestational diabetes. Paediatric and Perinatal Epidemiology 2008;22(1):47-59. [DOI: 10.1111/ j.1365-3016.2007.00899.x]

\section{Rae 2000}

Rae A, Bond D, Evans S, North F, Roberman B, Walters B. A randomised controlled trial of dietary energy restriction in the management of obese women with gestational diabetes. Australian and New Zealand Journal of Obstetrics and Gynaecology 2000;40(4):416-22. [DOI: 10.1111/ j.1479-828X.2000.tb01172.x]

\section{Ragnarsdottir 2010}

Ragnarsdottir L, Conroy S. Development of macrosomia resulting from gestational diabetes mellitus: physiology and social determinants of health. Advances in Neonatal Care 2010;10(1):7-12.

\section{Rajasekaran 2008}

Rajasekaran A, Sivagnanam G, Xavier R. Nutraceuticals as therapeutic agents: a review. Research Journal of Pharmacy and Technology 2008;1(4):328-40. [ISSN: 0974-3618]

\section{Rendell 2004}

Rendell. Advances in diabetes for the millennium: Drug therapy of type 2 diabetes. Medscape General Medicine 2004;6(Suppl 3):9.

\section{Review Manager 2014 [Computer program]}

The Nordic Cochrane Centre, The Cochrane Collaboration. Review Manager (RevMan). Version 5.3. Copenhagen: The Nordic Cochrane Centre, The Cochrane Collaboration, 2014.

\section{Richter 2001}

Richter EA, Derave W, Wojtaszewski JFP. Glucose, exercise and insulin: emerging concepts. Journal of Physiology 2001;535(Pt 2):313-22. [DOI: 10.1111/j.1469-7793.2001.t01-2-00313.x]

\section{Richter 2013}

Richter EA, Hargreaves M. Exercise, GLUT4, and skeletal muscle glucose uptake. Physiology Review 2013;93(3):993-1017. [DOI: 10.1152/physrev.00038.2012.]

\section{Rose 2005}

Rose AJ, Richter EA. Skeletal muscle glucose uptake during exercise: how is it regulated?. Physiology (Bethesda) 2005;20:260-70.

\section{Rosenberg 2005}

Rosenberg TJ, Garbers S, Lipkind H, Chiasson MA. Maternal obesity and diabetes as risk factors for adverse pregnancy outcomes: Differences among four racial/ethnic groups. American Journal of Public Health 2005;95(9):1545-51.

\section{Rosenstock 2004}

Rosenstock J, Hassman DR, Madder RD, Brazinsky SA, Farrell J, Khutoryansky A, et al. Repaglinide versus nateglinide monotherapy: A randomized multicenter study. Diabetes Care 2004;27(6):1265-70.

\section{Rosenstock 2009}

Rosenstock J, Cefalu WT, Hollander PA. Safety and efficacy of inhaled human insulin (Exubera) during discontinuation and re-administration of therapy in adults with type 2 diabetes: a 3 year randomised controlled trial. Diabetes Technology Therapy 2009;11:697-705.

\section{Ryu 2014}

Ryu RJ, Hays KE, Hebert MF. Gestational diabetes mellitus management with oral hypoglycemic agents. Seminars in Perinatology 2014;38(8):508-15. 


\section{Sacks 2012}

Sacks DA, Hadden DR, Maresh M, Deerochanawong C, Dyer AR, Metzger BE, et al. Frequency of gestational diabetes mellitus at collaborating centers based on IADPSG consensus panel-recommended criteria: the Hyperglycemia and Adverse Pregnancy Outcome (HAPO) Study. Diabetes Care 2012;35(3):526-8. [DOI: 10.2337/dc11-1641]

\section{Sadovsky 2015}

Sadovsky Y, Jansson T. Placenta and placental transport function. Chapter 39. In: Plant TM, Zeleznik AJ editor(s). Knobil and Neill's Physiology of Reproduction. 4th Edition. Vol. 2, London (UK): Elsevier, Academic Press, 2015:1741-81. [DOI: 10.1016/B978-0-12-397175-3.01001-2; ISBN: 978-0-12-416593-9 ]

\section{Sakamoto 2002}

Sakamoto K, Goodyear LJ. Intracellular signaling in contracting skeletal muscle. Journal of Applied Physiology 2002;93(1):369-83.

\section{Schneider 2012}

Schneider S, Bock C, Wetzel M, Maul H, Loerbroks A. The prevalence of gestational diabetes in advanced economies. Journal of Perinatal Medicine 2012;40(5):511.

\section{Schwarz 2013}

Scwarz R, Rosenn B, Aleksa K, Koren G. Transplacental transfer of glyburide; is it clinically significant?. American Journal of Obstetrics and Gynecology 2013;208(Suppl 1):S25.

\section{Secher 2010}

Secher AL, Schmidt S, Nørgaard K, Mathiesen ER. Continuous glucose monitoring-enabled insulin-pump therapy in diabetic pregnancy. Acta Obstetricia et Gynecologica Scandinavica 2010;89(9):1233-7.

\section{Serlin 2009}

Serlin DC, Lash RW. Diagnosis and management of gestational diabetes mellitus. American Family Physician 2009;80(1):57-62.

\section{Shea 2007}

Shea BJ, Grimshaw JM, Wells GA, Boers M, Andersson N, Hamel C. Development of AMSTAR: a measurement tool to assess the methodological quality of systematic reviews. BMC Medical Research Methodology 2007;15(7):10. [DOI: 10.1186/1471-2288-7-10]

\section{Shea 2009}

Shea BJ, Hamel C, Wells GA, Bouter LM, Kristjansson E, Grimshaw J, et al. AMSTAR is a reliable and valid measurement tool to assess the methodological quality of systematic reviews. Journal of Clinical Epidemiology 2009;62(10):1013-20.

\section{Shirazian 2010}

Shirazian T, Monteith S, Friedman F, Rebarber A. Lifestyle modification program decreases pregnancy weight gain in obese women. American Journal of Perinatology 2010;27(5):411-4. [DOI: 10.1055/s-0029-1243368]

\section{Sigal 2004}

Sigal RJ, Kenny GP, Wasserman DH, Castaneda-Scepa C. Physical activity/exercise and type 2 diabetes. Diabetes Care 2004;27(10):2518-39.

\section{Simmons 2001}

Simmons D, Thompson CF, Conroy C, Scott DJ. Use of insulin pumps in pregnancies complicated by type 2 diabetes and gestational diabetes in a multiethnic community. Diabetes Care 2001;24(12):2078-82.

\section{Simmons 2015}

Simmons D. Safety considerations with pharmacological treatment of gestational diabetes mellitus. Drug Safety 2015;38(1):65-78. [DOI: 10.1007/s40264-014-0253-9]

\section{Simonson 1984}

Simonson DC, Ferrannini E, Bevilacqua S, Smith D, Barrett E, Carlson R, et al. Mechanism of improvement of glucose metabolism after chronic glyburide therapy. Diabetes Care 1984;33(9):828-45.

\section{Singh 2007}

Singh C, Jovanovic L. Insulin analogues in the treatment of diabetes in pregnancy. Obstetrics and Gynecology Clinics of North America 2007;34(2):275-91.

\section{Sirtori 1994}

Sirtori CR, Pasik C. Re-evaluation of a biguanide, metformin: mechanism of action and tolerability. Pharmacological Research 1994;30(3):187-228.

\section{Sirtori 2002}

Sirtori CR, Galli C. N-3 fatty acids and diabetes. Biomedicine and Pharmacotherapy 2002;56(8):397-406.

\section{Stafne 2012}

Stafne SN, Salvesen KÅ, Romundstad PR, Eggebø TM, Carlsen SM, Mørkved S. Regular exercise during pregnancy to prevent gestational diabetes: a randomized controlled trial. Obstetrics \& Gynecology 2012;119(1):29-36. [DOI: 10.1097/ AOG.0b013e3182393f86]

\section{Stumvoll 2003}

Stumvoll M. Thiazolidenedines - some recent developments. Expert Opinion on Investigational Drugs 2003;12(7):1179-87.

\section{Suffecool 2015}

Suffecool K, Rosenn B, Niederkofler EE, Kiernan UA, Foroutan J, Antwi K, et al. Insulin detemir does not cross the human placenta. Diabetes Care 2015;38(2):e20-e21. [DOI: 10.2337/ dc14-2090]

\section{Suman Rao 2013}

Suman Rao PN, Shashidhar A, Ashok C. In utero fuel homeostasis: Lessons for a clinician. Indian Journal of Endocrinology and Metabolism 2013;17(1):60-8.

\section{Teh 2011}

Teh WT, Teede HJ, Paul E, Harrison CL, Wallace EM, Allan C. Risk factors for gestational diabetes mellitus: implications for the 
application of screening guidelines. Australian and New Zealand Journal of Obstetrics and Gynaecology 2011;51(1):26-30.

\section{Thomas 2005}

Thomas AM, Gutrierrez YM. American Dietetic Association Guide to Gestational Diabetes Mellitus. Chicago (IL): American Dietetic Association, 2005. [ISBN 0-88091-349-5]

\section{Thomas 2006}

Thomas B, Ghebremeskel K, Lowy C, Crawford M, OffleyShore B. Nutrient intake of women with and without gestational diabetes with a specific focus on fatty acids. Nutrition 2006;22(3):230-6. [PMID: 16500549]

\section{Tieu 2010}

Tieu J, Coat S, Hague W, Middleton P. Oral anti-diabetic agents for women with pre-existing diabetes mellitus/impaired glucose tolerance or previous gestational diabetes mellitus. Cochrane Database of Systematic Reviews 2010, Issue 10. [DOI: 10.1002/14651858.CD007724.pub2]

\section{van Loon 2000}

van Loon LJC, Saris WHM, Verhagen H, Wagenmakers AJM. Plasma insulin responses after ingestion of different amino acid or protein mixtures with carbohydrate. American Journal for Clinical Nutrition 2000;72(1):96-105

\section{Viana 2014}

Viana LV, Gross JL, Azevedo MJ. Dietary interventions in patients with gestational diabetes mellitus: A systematic review and meta-analysis of randomised clinical trials on maternal and newborn outcomes. Diabetes Care 2014;37(12):3345-55. [DOI: $10.2337 / \mathrm{dc} 14-1530]$

\section{Wahlqvist 1978}

Wahlqvist ML, Wilmshurst EG, Richardson EN. The effect of chain length on glucose absorption and the related metabolic response. American Journal of Clinical Nutrition 1978;31(11):1998-2001.

\section{Wang 1996}

Wang W. Oral protein delivery. Journal of Drug Targeting 1996:4:195-232.

\section{Wang 2013}

Wang J, Persuitte G, Olendzki BC, Wedick NM, Zhang Z, Merriam PA, et al. Dietary magnesium intake improves insulin resistance among non-diabetic individuals with metabolic syndrome participating in a dietary trial. Nutrients 2013;5(10):3010-9. [DOI: 10.3390/nu5103910]

\section{Whiting 2016}

Whiting P, Savovic J, Higgins JPT, Caldwell DM, Reeves BC, Shea B, et al. ROBIS: a new tool to assess the risk of bias in systematic reviews was developed. Journal of Clinical Epidemiology 2016;69:225-34. [DOI: 10.1016/ j.jclinepi.2015.06.005]

\section{WHO 2013}

World Health Organization (WHO). Diagnostic Criteria and Classification of Hyperglycaemia First Detected in Pregnancy.
WHO/NMH/MND/13.2. Geneva (Switzerland): World Health Organization, 2013.

\section{Wilcox 2005}

Wilcox G. Insulin and insulin resistance. Clinical Biochemistry Review 2005;26(5):19-39.

\section{Wojtaszewski 2002}

Wojtaszewski JF, Nielsen JN, Richter EA. Effect of acute exercise on insulin signalling and action in humans. Journal of Applied Physiology 2002;93:384-92.

\section{Wolff 2008}

Wolff S, Legarth J, Vangsgaard K, Toubro S, Astrup A. A randomized trial of the effects of dietary counselling on gestational weight gain and glucose metabolism in obese pregnant women. International Journal of Obesity 2008;32(3):495-501. [DOI: 10.1038/sj.ijo.0803710]

\section{Wollitzer 2010}

Wollitzer AD, Zisser $\mathrm{H}$, Jovanovic L. Insulin pumps and their use in pregnancy. Diabetes Technology and Therapeutics 2010;12(Suppl 1):S33-6.

\section{Woodley 1994}

Woodley JF. Enzymatic barriers for GI peptide and protein delivery. Critical Reviews in Therapeutic Drug Carrier Systems 1994;11(2-3):61-95.

\section{Woolderink 2005}

Woolderink JM, van Loon AJ, Storms F, de Heide L, Hoogenberg K. Use of insulin glargine during pregnancy in seven type 1 diabetic women. Diabetes Care 2005;28(10):2594-5.

\section{Yogev 2004}

Yogev Y, Xenakis EMJ, Langer O. The association between preeclampsia and the severity of gestational diabetes: The impact of glycemic control. American Journal of Obstetrics Gynecology 2004;191(5):1655-60.

\section{Young 2009}

Young J, Anwar A. Diabetic medications in pregnancy. Current Diabetes Reviews 2009;5(4):252-8.

\section{Young 2013}

Young BC, Ecker JL. Fetal macrosomia and shoulder dystocia in women with gestational diabetes: risks amenable to treatment?. Current Diabetes Reports 2013;13(1):12-8.

\section{Zeisel 1999}

Zeisel SH. Regulation of nutraceuticals. Science 1999;285(5435):1853-5. [DOI: 10.1126/science.285.5435.1853]

\section{Zhang 2006}

Zhang C, Liu S, Solomon CG, Hu FB. Dietary fiber intake, dietary glycemic load, and the risk for gestational diabetes mellitus. Diabetes Care 2006;29(10):2223-30. [DOI: 10.2337/dc06-0266]

\section{Zhang 2010}

Zhang C. Risk factors for gestational diabetes: from an epidemiological standpoint. In: Kim C, Ferrara A editor(s). 
Gestational Diabetes During and after Pregnancy. London (UK): Springer, 2010:71-81.
References to other published versions of this review

\section{Martis 2016b}

Martis R, Brown J, Alsweiler J, Downie MR, Crowther CA. Treatments for women with gestational diabetes mellitus: an overview of Cochrane systematic reviews. Cochrane Database of Systematic Reviews 2016, Issue 8. [DOI: 10.1002/14651858.CD012327]

ADDITIONAL TABLES

Table 1. Type of subcutaneous insulin and action towards achieving a physiological profile

\begin{tabular}{ll}
\hline Type of Insulin & Action \\
\hline $\begin{array}{l}\text { Short- and rapid-acting in- } \\
\text { sulin }\end{array}$ & \\
\hline Lispro & $\begin{array}{l}\text { Amino acid substitutions (inverting lysine at position } 28 \text { and proline at position } 29 \text { on the } \beta \text {-chain } \\
\text { of the insulin molecule), monomeric in tissues (Magon 2014; Home 2015). Peak insulin action } \\
\text { achieved within } 1 \text { hour after injection and duration of action } 2 \text { to } 4 \text { hours (Durnwald 2008). Anti- } \\
\text { body levels not increased over those seen with regular human insulin. Does not seem to cross the } \\
\text { placenta (Jovanovic 2007) }\end{array}$ \\
\hline Aspart & $\begin{array}{l}\text { Amino acid substitutions (proline at position 28 on the } \beta \text {-chain of the insulin molecule with nega- } \\
\text { tively charged aspartic acid), monomeric in tissues (Magon 2014; Home 2015). Peak action 31-70 } \\
\text { minutes for } 2 \text { to } 4 \text { hours and lowers postprandial glucose levels significantly better than human in- } \\
\text { sulin (Jovanovic 2007; Magon 2014). No evidence that insulin aspart is teratogenic (Hod 2005) }\end{array}$ \\
\hline Glulisine & $\begin{array}{l}\text { Amino acid substitutions and reformulation, rapidly monomeric in tissues (Home 2015). Produces } \\
\text { peak blood glucose level at 15-20 minutes and lowers postprandial glucose levels significantly bet- } \\
\text { ter than human insulin (Jovanovic 2007). Adverse effects on embryo-fetal development were only } \\
\text { seen at animal maternal toxic dose levels inducing hypoglycaemia. No clinical data currently avail- } \\
\text { able for the use of Insulin glulisine in pregnancy (Magon 2014) }\end{array}$ \\
\hline
\end{tabular}

\section{Intermediate- and long-act- ing insulin}

Neutral Protamine Hagedorn $(\mathrm{NPH})$

Detemir
Protamine crystal suspension (Home 2015). NPH has an onset of action approximately after 90 minutes and a duration of action up to 16 to 18 hours (Jovanovic 2007; Magon 2014). No randomised controlled trials currently to confirm safety during pregnancy but several case reports and one case-control study indicate no fetal morbidity or macrosomia (Magon 2014)

Slowly absorbed and binds to albumin through a fatty-acid chain attached to the lysine at residue B29 resulting in reduction in its free level which slows distribution to peripheral target tissues with a duration of action of up to 24 hours (Magon 2014). Significant improvement in fasting plasma glucose with insulin detemir during pregnancy for T1DM without an increased incidence of hypoglycaemia, including at night. No adverse maternal or neonatal effects were identified (Mathiesen 2012; Callesen 2013; Hod 2014). Suffecool 2015 conducted a small study including 11 women with GDM and five women with type 2 diabetes receiving detemir assessing maternal and cord blood at birth. The results showed that while maternal detemir levels were in the expected range for adults, the hormone was undetectable in the cord blood, indicating that detemir does not cross the human placenta. Larger studies and randomised controlled trials are needed to confirm

Glargine

Slowly absorbed and replaces the human insulin amino acid asparagine at position A21 of the A chain with glycine and two arginine molecules are added to one end (C-terminal) of the B-chain with onset of action approximately after 90 minutes of injection and lasting for about 24 hours (Price 2007; Ansar 2013). Studies in non-pregnant participants have indicated that insulin glargine has a smooth peak-free profile of action, with a reduced incidence of nocturnal hypoglycaemia and better glycaemic control (Graves 2006; Magon 2014; Woolderink 2005). Concerns regarding insulin glargine's use in pregnancy are raised from case-control, case reports and retrospective studies (in-

Treatments for women with gestational diabetes mellitus: an overview of Cochrane systematic reviews (Review) 
Table 1. Type of subcutaneous insulin and action towards achieving a physiological profile (Continued)

cluding women with T1DM, T2DM and some with GDM) that have shown six- to eight-fold increased affinity for insulin growth factor (IGF)-1 receptor compared with human insulin. However, results of these studies found no association with increased fetal macrosomia or neonatal morbidity with the use of glargine in pregnancy (Bolli 2000; Egerman 2009; Lv 2015; Pöyhönen-Alho 2007). No randomised controlled trials currently to confirm safety during pregnancy

AbbreviationL GDM - gestational diabetes mellitus; T1DM - type 1 diabetes mellitus; T2DM - type 2 diabetes mellitus

Table 2. Characteristics of included reviews

\begin{tabular}{|c|c|c|c|c|c|}
\hline Review ID & $\begin{array}{l}\text { Date of } \\
\text { search and } \\
\text { date assessed } \\
\text { as up to date }\end{array}$ & $\begin{array}{l}\text { No. included tri- } \\
\text { als (countries, } \\
\text { design and publi- } \\
\text { cation years) }\end{array}$ & $\begin{array}{l}\text { No. of partic- } \\
\text { ipants in in- } \\
\text { cluded trials }\end{array}$ & $\begin{array}{l}\text { Inclusion and } \\
\text { exclusion } \\
\text { criteria for } \\
\text { types of par- } \\
\text { ticipants }\end{array}$ & Interventions and comparisons \\
\hline $\begin{array}{l}\text { Biesty } 2018 \\
\text { Elective deliv- } \\
\text { ery in diabet- } \\
\text { ic pregnant } \\
\text { women }\end{array}$ & $\begin{array}{l}\text { Search: } \\
15 \text { August } \\
2017 \\
\text { Up-to-date: } 15 \\
\text { August } 2017 \\
\text { Up-to-date }\end{array}$ & $\begin{array}{l}\text { Trials: } 1 \text { RCT } \\
\text { Countries: Multi- } \\
\text { centre (Israel, Italy } \\
\text { and Slovenia) } \\
\text { Published: } \\
\text { 2017: } 1 \text { RCT }\end{array}$ & $\begin{array}{l}425 \text { women } \\
425 \text { babies no } \\
\text { children }\end{array}$ & $\begin{array}{l}\text { Women diag- } \\
\text { nosed with } \\
\text { gestation- } \\
\text { al diabetes. } \\
\text { Women with } \\
\text { pre-gestation- } \\
\text { al diabetes } \\
\text { were exclud- } \\
\text { ed and trials } \\
\text { where data for } \\
\text { women with } \\
\text { GDM and pre- } \\
\text { gestational } \\
\text { data could not } \\
\text { be separated }\end{array}$ & $\begin{array}{l}\text { Planned birth (induction of labour or } \\
\text { caesarean section) at or near term ges- } \\
\text { tation versus expectant management }\end{array}$ \\
\hline $\begin{array}{l}\text { Brown 2017a } \\
\text { Oral anti-dia- } \\
\text { betic pharma- } \\
\text { cological ther- } \\
\text { apies for the } \\
\text { treatment of } \\
\text { women with } \\
\text { gestational di- } \\
\text { abetes }\end{array}$ & $\begin{array}{l}\text { Search: } \\
16 \text { May } 2016 \\
\text { (databases); } \\
14 \text { May } 2016 \\
\text { (clinical trial } \\
\text { registries) } \\
\text { Up-to-date: } 14 \\
\text { May } 2016 \\
\text { Up-to-date }\end{array}$ & $\begin{array}{l}\text { Trials: } 11 \text { RCTs } \\
\text { Countries: } \\
\text { Brazil } \\
\text { (3 RCTs); India } \\
\text { (2 RCTs); Israel } \\
\text { (1 RCT); } \\
\text { UK }\end{array}$ & $\begin{array}{l}1487 \text { women } \\
1487 \text { babies } \\
\text { no children }\end{array}$ & $\begin{array}{l}\text { Women diag- } \\
\text { nosed with } \\
\text { GDM (diagno- } \\
\text { sis as defined } \\
\text { by the indi- } \\
\text { vidual trial). } \\
\text { Women with } \\
\text { type } 1 \text { or type } \\
2 \text { diabetes di- } \\
\text { agnosed prior } \\
\text { to pregnancy } \\
\text { were excluded }\end{array}$ & $\begin{array}{l}\text { Comparing oral pharmacological an- } \\
\text { ti-diabetic agents used during pregnan- } \\
\text { cy (including metformin, glibenclamide, } \\
\text { acarbose, tolbutamide, chlorpropamide } \\
\text { or combination of these therapies) with } \\
\text { either placebo or no pharmacological } \\
\text { treatment or one agent versus another } \\
\text { agent or versus another intervention but } \\
\text { not insulin. }\end{array}$ \\
\hline
\end{tabular}

$(1 \mathrm{RCT})$;

South Africa (1

$\mathrm{RCT}$;

USA

(3 RCTs)

Published:

1971: 1 RCT

2005: 1 RCT

2006: 1 RCT

Treatments for women with gestational diabetes mellitus: an overview of Cochrane systematic reviews (Review) 
Table 2. Characteristics of included reviews (Continued)

\author{
2010: 1 RCT
}

2012: 1 RCT

2014: 1 RCT

2015: 5 RCT

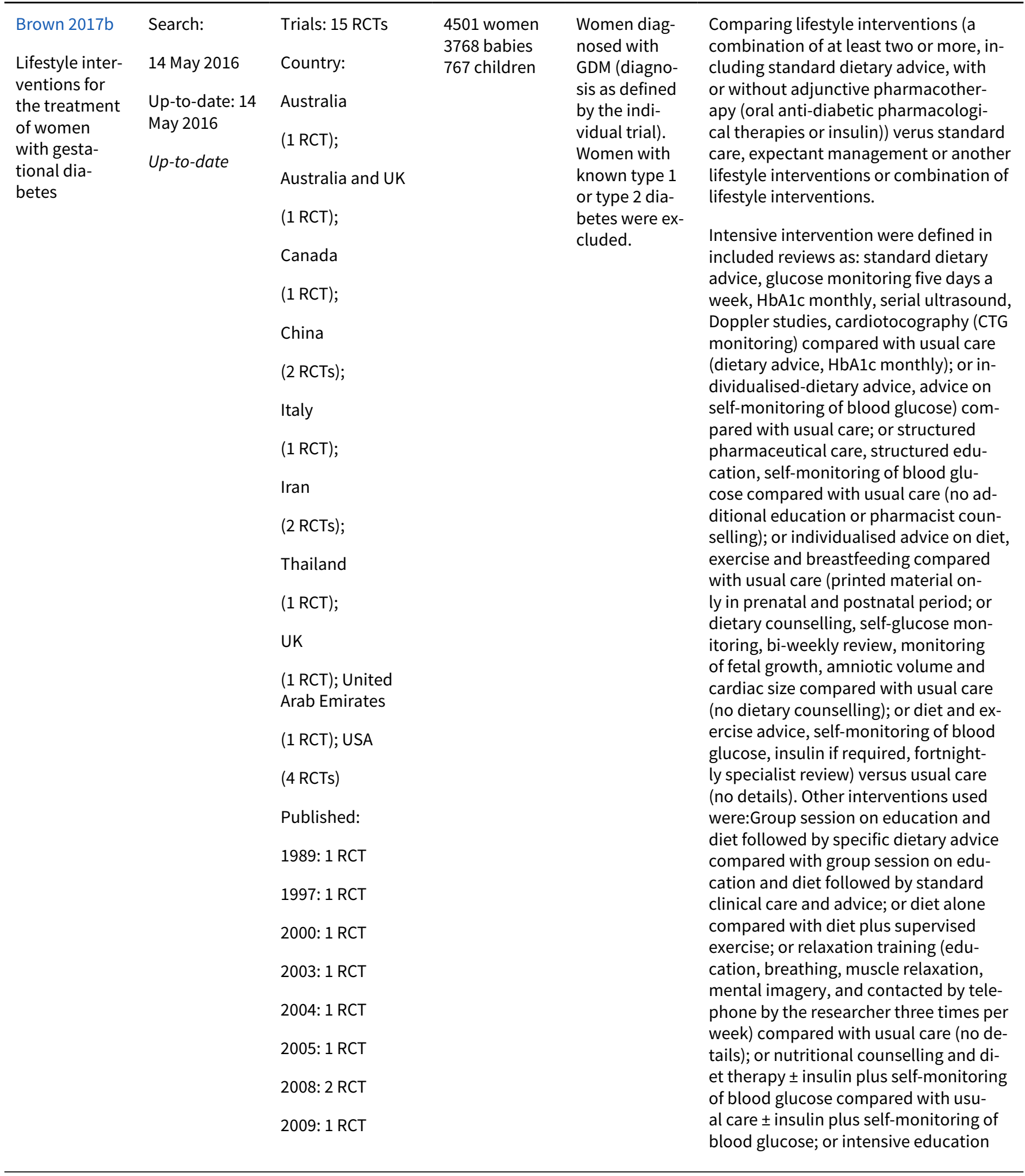

Treatments for women with gestational diabetes mellitus: an overview of Cochrane systematic reviews (Review) 
Table 2. Characteristics of included reviews (Continued) 2011: 1 RCT

2014: 5 RCT and spiritual intervention compared with standard education; or face-to-face education (risks of GDM, training on glycaemic control, exercise, diet, medication and follow-up) compared with usual care (no details); or individualised and group dietary and physical activity counselling, self-monitoring blood glucose compared with usual care (group education on exercise and physical activity, not specifically taught blood glucose self-monitoring); or mindfulness eating and yoga compared with standard diabetes care (no details); or combined behavioural and exercise compared with individualised-dietary advice alone

\begin{tabular}{|c|c|c|c|c|c|}
\hline $\begin{array}{l}\text { Brown } 2017 \text { c } \\
\text { Exercise for } \\
\text { pregnant } \\
\text { women with } \\
\text { gestational di- } \\
\text { abetes for im- } \\
\text { proving ma- } \\
\text { ternal and fe- } \\
\text { tal outcomes }\end{array}$ & $\begin{array}{l}\text { Search: } \\
27 \text { August } \\
2016 \text { (and } 18 \\
\text { August } 2016 \\
\text { for trial reg- } \\
\text { istries) } \\
\text { Up-to-date: } \\
18 \text { August } \\
2016 \\
\text { Up-to-date }\end{array}$ & $\begin{array}{l}\text { Trials: } 11 \text { RCTs } \\
\text { Countries: } \\
\text { Australia (1RCT); } \\
\text { Brazil } \\
\text { (3 RCTs); Canada } \\
\text { (2 RCTs); } \\
\text { Italy } \\
\text { (1 RCT); } \\
\text { Thailand } \\
\text { (1 RCT); } \\
\text { USA } \\
\text { (3 RCTs) } \\
\text { Published: } \\
\text { 1989: } 1 \text { RCT } \\
\text { 1991: } 1 \text { RCT } \\
\text { 1997: } 1 \text { RCT } \\
\text { 2004: } 1 \text { RCT } \\
\text { 2010: } 1 \text { RCT } \\
\text { 2012: } 1 \text { RCT } \\
\text { 2014: } 4 \text { RCT } \\
\text { 2015: } 1 \text { RCT }\end{array}$ & $\begin{array}{l}638 \text { women } \\
638 \text { babies } \\
\text { no children }\end{array}$ & $\begin{array}{l}\text { Pregnant } \\
\text { women diag- } \\
\text { nosed with } \\
\text { GDM (as de- } \\
\text { fined by trial- } \\
\text { ists). } \\
\text { Women with } \\
\text { known pre- } \\
\text { gestational di- } \\
\text { abetes (type } \\
1 \text { or type } 2 \text { di- } \\
\text { abetes) were } \\
\text { excluded }\end{array}$ & $\begin{array}{l}\text { Comparing any type of exercise pro- } \\
\text { gramme ( } \pm \text { standard care) at any stage } \\
\text { of pregnancy versus standard care or } \\
\text { another intervention } \\
\text { Exercises summarised from reviews } \\
\text { included individualised exercises fol- } \\
\text { low-up by kinesiologist; timed exercis- } \\
\text { es } 2 \text { to } 4 \text { times weekly with or without } \\
\text { supervision and telephone counselling; } \\
\text { brisk walking or resistance exercises: } \\
30 \text { minutes circuit workout with elas- } \\
\text { tic-band exercises; exercises in lab con- } \\
\text { ditions on cycles; home-based exercis- } \\
\text { es; supervised arm ergometer training } \\
\text { plus diet; low-intensity aerobic training } \\
\text { in cycle-ergometer and mindfulness eat- } \\
\text { ing and yoga exercise }\end{array}$ \\
\hline $\begin{array}{l}\text { Brown } 2017 d \\
\text { Insulin for the } \\
\text { treatment of } \\
\text { women with }\end{array}$ & $\begin{array}{l}\text { Search: } \\
1 \text { May } 2017 \\
\text { Up-to-date }\end{array}$ & $\begin{array}{l}\text { Trials: } 53 \text { RCTs } \\
\text { Countries: } \\
\text { Australia }\end{array}$ & $\begin{array}{l}7381 \text { women } \\
6435 \text { babies }\end{array}$ & $\begin{array}{l}\text { Women diag- } \\
\text { nosed with } \\
\text { GDM (diagno- } \\
\text { sis as defined } \\
\text { by the indi- }\end{array}$ & $\begin{array}{l}\text { Insulin with metformin; insulin with } \\
\text { glibenclamide; insulin with acarbose; in- } \\
\text { sulin with a combination of metformin } \\
\text { and glibenclamide; one preparation of } \\
\text { insulin with another preparation of in- }\end{array}$ \\
\hline
\end{tabular}

Treatments for women with gestational diabetes mellitus: an overview of Cochrane systematic reviews (Review) Copyright $\odot 2018$ The Cochrane Collaboration. Published by John Wiley \& Sons, Ltd. 
Table 2. Characteristics of included reviews (Continued)

gestational di- 1 May 2017 abetes

$\begin{array}{ll}\text { Up-to-date } & \text { Australia and New } \\ \text { Zealand }\end{array}$

(1 RCT);

Brazil

(3 RCTs)

Canada

(1 RCT);

Egypt

(3 RCTs);

Finland

(3 RCTs);

Ghana

(1 RCT);

India

(8 RCTs);

Iran

(5 RCTs);

Israel

(1 RCT);

Italy

(2 RCTs);

Malaysia

(1 RCT);

Pakistan

(3 RCTs);

Poland

(1 RCT);

South Africa (1

RCT);

Sweden

(1 RCT);

Turkey

(1 RCT);

Unkown vidual trial). Women with sulin; insulin with diet; insulin with exertype 1 or type 2 diabetes diagnosed prior to pregnancy were excluded cise; different regimens of insulin 
Table 2. Characteristics of included reviews (Continued)

(1 RCT);

USA

(15 RCTs)

Published:

19711 RCT

19752 RCTs

19781 RCT

19851 RCT

19901 RCT

19931 RCT

19992 RCTs

20001 RCT

20022 RCTs

20032 RCT

20052 RCTs

20077 RCTs

20083 RCTs

20091 RCT

20101 RCT

20112 RCTs

20123 RCTs

20135 RCTs

20145 RCTs

20155 RCTs

20165 RCTs

\begin{tabular}{|c|c|c|c|c|c|}
\hline $\begin{array}{l}\text { Brown 2016a } \\
\text { Dietary sup- } \\
\text { plementa- } \\
\text { tion with myo- } \\
\text { inositol in } \\
\text { women during } \\
\text { pregnancy for } \\
\text { treating ges- } \\
\text { tational dia- } \\
\text { betes }\end{array}$ & $\begin{array}{l}\text { Search: } \\
14 \text { May } 2016 \\
\text { Up-to-date: } 14 \\
\text { May } 2016 \\
\text { Up-to-date }\end{array}$ & $\begin{array}{l}\text { Countries: } \\
\text { Italy } \\
\text { (2 RCTs) } \\
\text { Published: } \\
\text { 2011: } 1 \text { RCT } \\
\text { 2013: } 1 \text { RCT }\end{array}$ & $\begin{array}{l}159 \text { women } \\
159 \text { babies no } \\
\text { children }\end{array}$ & $\begin{array}{l}\text { Pregnant } \\
\text { women with } \\
\text { a diagnosis of } \\
\text { GDM (as de- } \\
\text { fined by trial- } \\
\text { ists). Women } \\
\text { with pre-ex- } \\
\text { isting type } 1 \\
\text { or type } 2 \text { dia- } \\
\text { betes were ex- } \\
\text { cluded }\end{array}$ & $\begin{array}{l}\text { Comparing any dose of myo-inositol, } \\
\text { alone or in a combination preparation } \\
\text { for the treatment of women with GDM } \\
\text { with women who received no treat- } \\
\text { ment, placebo or another intervention. } \\
\text { The two included trials assessed } 4 \mathrm{~g} \\
\text { myo-inositol + } 400 \mu \mathrm{g} \text { folic acid orally } \\
\text { per day and exercise and dietary advice } \\
\text { versus placebo } 400 \mu \mathrm{g} \text { folic acid orally } \\
\text { per day and exercise and dietary advice }\end{array}$ \\
\hline Han 2017 & $\begin{array}{l}\text { Search: } \\
8 \text { March } 2016\end{array}$ & Trials: 19 RCTs & $\begin{array}{l}1398 \text { women } \\
1398 \text { babies } \\
\text { no children }\end{array}$ & $\begin{array}{l}\text { Women with } \\
\text { GDM regard- } \\
\text { less of gesta- }\end{array}$ & $\begin{array}{l}\text { Comparing any dietary advice with each } \\
\text { other; comparing two or more forms } \\
\text { of the same type of dietary advice with }\end{array}$ \\
\hline
\end{tabular}

Treatments for women with gestational diabetes mellitus: an overview of Cochrane systematic reviews (Review)

Copyright (c) 2018 The Cochrane Collaboration. Published by John Wiley \& Sons, Ltd. 
Table 2. Characteristics of included reviews (Continued)
Different Up-to-date: 22 Countries: Ausetary advice for women with gestational diabetes mellitus

$\begin{array}{ll}\text { Up-to-date: } 22 & \text { Countries: Aus- } \\ \text { March } 2016 & \text { tralia }\end{array}$

Up-to-date

(3 RCTs),

Canada types of di-
(2 RCTs),

China

(2 RCTs), Denmark

(1 RCT),

Italy

(2 RCTs); Iran

(4 RCTs); Mexico

(1 RCT); Poland

(1 RCT); Spain

(1 RCT); USA

(2 RCTs)

Published:

1990: 1 RCT

1995: 1 RCT

1997: 1 RCT

2000: 1 RCT

2001: 1 RCT

2007: 1 RCT

2009: 1 RCT

2010: 1 RCT

2011: 2 RCT

2012: 1 RCT

2013: 3 RCT

2014: 2 RCT

2015: 3 RCT ty or plurality. Exclusion criteria not described tion, age, pari- each other and/or different intensities of dietary interventions with each other. These trials include: low-moderate $\mathrm{GI}$ diet versus moderate-high $\mathrm{GI}$ diet, energy-restricted diet versus no energy-restricted diet, DASH (DietaryApproaches to StopHypertension) diet versus control diet with matching macronutrient contents, low-carbohydrate diet versus high-carbohydrate diet,high unsaturated fat diet versus low unsaturated diet with

matching calories, low-GI diet versus high-fibre moderate-GI diet, diet recommendation and diet-related behavioural advice versus diet recommendation, soy protein-enriched diet versus no soy protein diet, high-fibre versus standard-fibre diet, ethnic-specific diet versus standard healthy diet

\section{Pregnant} women with hyperglycaemia, regardless of gestation, age, parity or plurality, who do not meet
Comparing any form of management for women with pregnancy hyperglycaemia not meeting GDM criteria with standard antenatal care, included any type of dietary advice (standard or individualised), exercise and lifestyle advice (standard or individualised) and drug treatment including insulin and 2011

Not up-to-date 21 November
(1 RCT); tational di-

Treatments for women with gestational diabetes mellitus: an overview of Cochrane systematic reviews (Review) 
Table 2. Characteristics of included reviews (Continued)

abetes and

type 2 dia-

betes diag-

USA

(2 RCTs)

nostic criteria

Published:

1989: 1 RCT

1999: 1 RCT

2005: 1 RCT

2011: 1 RCT

\begin{tabular}{|c|c|}
\hline Trials: 1 RCT & 180 women \\
\hline Country: Canada & $\begin{array}{l}180 \text { babies no } \\
\text { children }\end{array}$ \\
\hline
\end{tabular}

Published:

tensities of 2016

glycaemic

control for

Up-to-date: 31

women with January 2016

1998: 1 RCT

gestational di-

abetes melli- Up-to-date the diagnos-

tic criteria for

GDM based

on OGTT re-

sults defined

by trialists.

Women with

pre-existing

diabetes mel-

litus and pre-

viously treat-

ed GDM were

not eligible oral drugs with one type of intervention compared with standard antenatal care

\section{All pregnant women diag- nosed with GDM (screen- \\ Comparing any glycaemic treatment targets used to guide treatment for women with GDM with another gly- caemic target.} ing and subsequent diagnosis and diagnostic criteria as identified in the individual trials). Women with known pre-existing type 1 or type 2 diabetes are excluded
Strict intensity of glycaemic control is defined in this one trial as: pre-prandial $5.0 \mathrm{mmol} / \mathrm{L}(90 \mathrm{mg} / \mathrm{dL})$ and at one-hour postprandial: $6.7 \mathrm{mmol} / \mathrm{L}(120 \mathrm{mg} / \mathrm{dL})$. Less strict glycaemic control is defined as: pre-prandial $5.8 \mathrm{mmol} / \mathrm{L}(104 \mathrm{mg} / \mathrm{dL})$ and at one-hour postprandial $7.8 \mathrm{mmol} /$ $\mathrm{L}(140 \mathrm{mg} / \mathrm{dL})$

\begin{tabular}{|c|c|c|c|c|c|}
\hline $\begin{array}{l}\text { Raman } 2017 \\
\text { Different } \\
\text { methods and } \\
\text { settings for } \\
\text { glucose moni- } \\
\text { toring for ges- } \\
\text { tational dia- } \\
\text { betes during } \\
\text { pregnancy }\end{array}$ & $\begin{array}{l}\text { Search: } \\
30 \text { September } \\
2017 \\
\text { Up-to-date: } \\
\text { October } 2017 \\
\text { Up-to-date }\end{array}$ & $\begin{array}{l}\text { Trials: } 11 \text { RCTs } \\
\text { Countries: } \\
\text { Canada } \\
\text { (1 RCT); China } \\
\text { (1 RCT); Finland } \\
\text { (1 RCT); Ireland } \\
\text { (1 RCT); Italy } \\
\text { (1 RCT); Spain } \\
\text { (1 RCT); } \\
\text { USA } \\
\text { (5 RCTs) } \\
\text { Published: } \\
\text { 1995: } 1 \text { RCT } \\
\text { 1997: } 1 \text { RCT } \\
2002: 1 \text { RCT } \\
2003: 1 \text { RCT }\end{array}$ & 1272 women & $\begin{array}{l}\text { Women diag- } \\
\text { nosed with } \\
\text { GDM during } \\
\text { their current } \\
\text { pregnancy, } \\
\text { as defined } \\
\text { by individ- } \\
\text { ual trialists. } \\
\text { Women of any } \\
\text { age, gestation } \\
\text { and parity } \\
\text { were includ- } \\
\text { ed. Women } \\
\text { with pre-ex- } \\
\text { isting type } 1 \\
\text { or type } 2 \text { dia- } \\
\text { betes were ex- } \\
\text { cluded }\end{array}$ & $\begin{array}{l}\text { Comparing different methods (includ- } \\
\text { ing timing and frequency) or settings, or } \\
\text { both, for blood glucose monitoring. } \\
\text { Compared telemedicine versus stan- } \\
\text { dard care; self monitoring versus peri- } \\
\text { odic glucose monitoring; continuous } \\
\text { glucose monitoring system versus self- } \\
\text { monitoring; modem verus telephone } \\
\text { transmission; postprandial versus pre- } \\
\text { prandial glucose monitoring }\end{array}$ \\
\hline
\end{tabular}


Table 2. Characteristics of included reviews (Continued) 20072 RCT

2009: 1 RCT

2010: 1 RCT

2012: 1 RCT

2015: 1 RCT

2016: 1 RCT

Abbreviations: GDM - gestational diabetes mellitus; RCT - randomised controlled trial; OGTT oral glucose tolerance test; GI gastrointestinal; HbA1c Haemoglobin A1c 


\begin{tabular}{|c|c|c|c|c|c|c|c|c|c|c|}
\hline Included review & $\begin{array}{l}\text { Biesty } \\
2018\end{array}$ & $\begin{array}{l}\text { Brown } \\
2017 a\end{array}$ & $\begin{array}{l}\text { Brown } \\
2017 b\end{array}$ & $\begin{array}{l}\text { Brown } \\
2017 c\end{array}$ & $\begin{array}{l}\text { Brown } \\
\text { 2017d }\end{array}$ & $\begin{array}{l}\text { Brown } \\
2016 a\end{array}$ & Han 2017 & Han 2012 & $\begin{array}{l}\text { Martis } \\
\text { 2016a }\end{array}$ & $\begin{array}{l}\text { Raman } \\
2017\end{array}$ \\
\hline Maternal & & & & & & & & & & \\
\hline $\begin{array}{l}\text { Hypertensive disorders } \\
\text { of pregnancy (including } \\
\text { preeclampsia, pregnan- } \\
\text { cy-induced hypertension, } \\
\text { eclampsia as defined in re- } \\
\text { views) }\end{array}$ & $\mathbf{x}$ & $\sqrt{ }$ & $\sqrt{ }$ & $\sqrt{ }$ & $\sqrt{ }$ & $\sqrt{ }$ & $\sqrt{ }$ & $\begin{array}{l}\sqrt{ } \\
\text { secondary } \\
\text { outcome } \\
\text { and pre- } \\
\text { eclampsia } \\
\text { only } \\
\text { in this re- } \\
\text { view }\end{array}$ & $\sqrt{ }$ & $\sqrt{ }$ \\
\hline $\begin{array}{l}\text { Mode of birth (caesarean } \\
\text { section) }\end{array}$ & $\sqrt{ }$ & $\begin{array}{l}\sqrt{ } \\
\text { called } \\
\text { 'caesarean } \\
\text { section' in } \\
\text { the review }\end{array}$ & $\sqrt{ }$ & $\sqrt{ }$ & $\sqrt{ }$ & $\begin{array}{l}\sqrt{ } \\
\text { called } \\
\text { 'caesarean } \\
\text { section' in } \\
\text { the review }\end{array}$ & $\sqrt{ }$ & $\begin{array}{l}\sqrt{ } \\
\text { includes al- } \\
\text { so normal } \\
\text { vaginal birth } \\
\text { and opera- } \\
\text { tive vaginal } \\
\text { birth }\end{array}$ & $\begin{array}{l}\sqrt{ } \\
\text { secondary } \\
\text { outcome } \\
\text { called } \\
\text { 'caesarean } \\
\text { section' in } \\
\text { the review }\end{array}$ & $\sqrt{ }$ \\
\hline $\begin{array}{l}\text { Development of } \\
\text { type } 2 \text { diabetes }\end{array}$ & $\mathbf{x}$ & $\sqrt{ }$ & $\sqrt{ }$ & $\sqrt{ }$ & $\sqrt{ }$ & $\sqrt{ }$ & $\sqrt{ }$ & $\mathbf{x}$ & $\sqrt{ }$ & $\sqrt{ }$ \\
\hline Induction of labour & $\mathbf{x}$ & $\sqrt{ }$ & $\sqrt{ }$ & $\sqrt{ }$ & $\sqrt{ }$ & $\sqrt{ }$ & $\sqrt{ }$ & $\sqrt{ }$ & $\sqrt{ }$ & $\sqrt{ }$ \\
\hline Perineal trauma/tearing & $\begin{array}{l}\sqrt{ } \\
\text { (called 'in- } \\
\text { tact per- } \\
\text { ineum)' in } \\
\text { review }\end{array}$ & $\sqrt{ }$ & $\sqrt{ }$ & $\sqrt{ }$ & $\sqrt{ }$ & $\sqrt{ }$ & $\sqrt{ }$ & $\sqrt{ }$ & $\sqrt{ }$ & $\sqrt{ }$ \\
\hline Postnatal depression & $\sqrt{ }$ & $\sqrt{ }$ & $\sqrt{ }$ & $\sqrt{ }$ & $\sqrt{ }$ & $\sqrt{ }$ & $\sqrt{ }$ & $\mathbf{x}$ & $\sqrt{ }$ & $\sqrt{ }$ \\
\hline $\begin{array}{l}\text { Postnatal weight retention } \\
\text { or return to pre-pregnancy } \\
\text { weight }\end{array}$ & $\mathbf{x}$ & $\sqrt{ }$ & $\sqrt{ }$ & $\sqrt{ }$ & $\sqrt{ }$ & $\sqrt{ }$ & $\sqrt{ }$ & $\sqrt{ }$ & $\sqrt{ }$ & $\sqrt{ }$ \\
\hline
\end{tabular}




\begin{tabular}{|c|c|c|c|c|c|c|c|c|c|c|}
\hline $\begin{array}{l}\text { Development of type } 2 \text { dia- } \\
\text { betes }\end{array}$ & $\mathbf{x}$ & $\sqrt{ }$ & $\mathbf{x}$ & $\sqrt{ }$ & $\sqrt{ }$ & $\mathbf{x}$ & $\sqrt{ }$ & $\sqrt{ }$ & $\mathbf{x}$ & $\sqrt{ }$ \\
\hline \multicolumn{11}{|l|}{ Neonatal/child/adult } \\
\hline $\begin{array}{l}\text { Perinatal (fetal and neona- } \\
\text { tal death) and later infant } \\
\text { mortality }\end{array}$ & $\sqrt{ }$ & $\sqrt{ }$ & $\sqrt{ }$ & $\begin{array}{l}\sqrt{ } \\
\text { does not in- } \\
\text { clude later } \\
\text { infant mor- } \\
\text { tality }\end{array}$ & $\sqrt{ }$ & $\begin{array}{l}\sqrt{ } \\
\text { called } \\
\text { 'perina- } \\
\text { tal mortal- } \\
\text { ity (still- } \\
\text { birth and } \\
\text { neonatal } \\
\text { mortality)' } \\
\text { in review; } \\
\text { does not } \\
\text { include } \\
\text { later in- } \\
\text { fant mor- } \\
\text { tality }\end{array}$ & $\begin{array}{l}\sqrt{ } \\
\text { does not } \\
\text { include } \\
\text { later in- } \\
\text { fant mor- } \\
\text { tality }\end{array}$ & $\begin{array}{l}\sqrt{ } \\
\text { does not in- } \\
\text { clude later } \\
\text { infant mor- } \\
\text { tality }\end{array}$ & $\begin{array}{l}\sqrt{ } \\
\text { later in- } \\
\text { fant mor- } \\
\text { tality not } \\
\text { stated }\end{array}$ & $\sqrt{ }$ \\
\hline $\begin{array}{l}\text { Large-for-gestational age } \\
\text { (as defined in reviews) }\end{array}$ & $\sqrt{ }$ & $\sqrt{ }$ & $\sqrt{ }$ & $\sqrt{ }$ & $\sqrt{ }$ & $\sqrt{ }$ & $\sqrt{ }$ & $\sqrt{ }$ & $\sqrt{ }$ & $\sqrt{ }$ \\
\hline $\begin{array}{l}\text { Death or serious morbidity } \\
\text { composite (as defined in re- } \\
\text { views, e.g. perinatal or in- } \\
\text { fant death, shoulder dysto- } \\
\text { cia, bone fracture or nerve } \\
\text { palsy) }\end{array}$ & $\mathbf{x}$ & $\sqrt{ }$ & $\sqrt{ }$ & $\sqrt{ }$ & $\sqrt{ }$ & $\sqrt{ }$ & $\sqrt{ }$ & $\mathbf{x}$ & $\sqrt{ }$ & $\sqrt{ }$ \\
\hline $\begin{array}{l}\text { Neurosensory disability in } \\
\text { later childhood (as defined } \\
\text { in reviews) }\end{array}$ & $\mathbf{x}$ & $\sqrt{ }$ & $\sqrt{ }$ & $\sqrt{ }$ & $\sqrt{ }$ & $\begin{array}{l}\sqrt{ } \\
\text { called } \\
\text { 'neurosen- } \\
\text { sory dis- } \\
\text { ability' in } \\
\text { this review }\end{array}$ & $\sqrt{ }$ & $\mathbf{x}$ & $\sqrt{ }$ & $\sqrt{ }$ \\
\hline $\begin{array}{l}\text { Adiposity neonate (includ- } \\
\text { ing skinfold thickness mea- } \\
\text { surements (mm), fat mass); } \\
\text { Adiposity child (including } \\
\text { BMI, skinfold thickness, fat } \\
\text { mass); Adiposity - adult (in- }\end{array}$ & $\mathbf{x}$ & $\sqrt{ }$ & $\sqrt{ }$ & $\sqrt{ }$ & $\sqrt{ }$ & $\sqrt{ }$ & $\sqrt{ }$ & $\begin{array}{l}\sqrt{ } \\
\text { three sep- } \\
\text { arate out- } \\
\text { comes: BMI, } \\
\text { fat mass/fat- }\end{array}$ & $\sqrt{ }$ & $\sqrt{ }$ \\
\hline
\end{tabular}




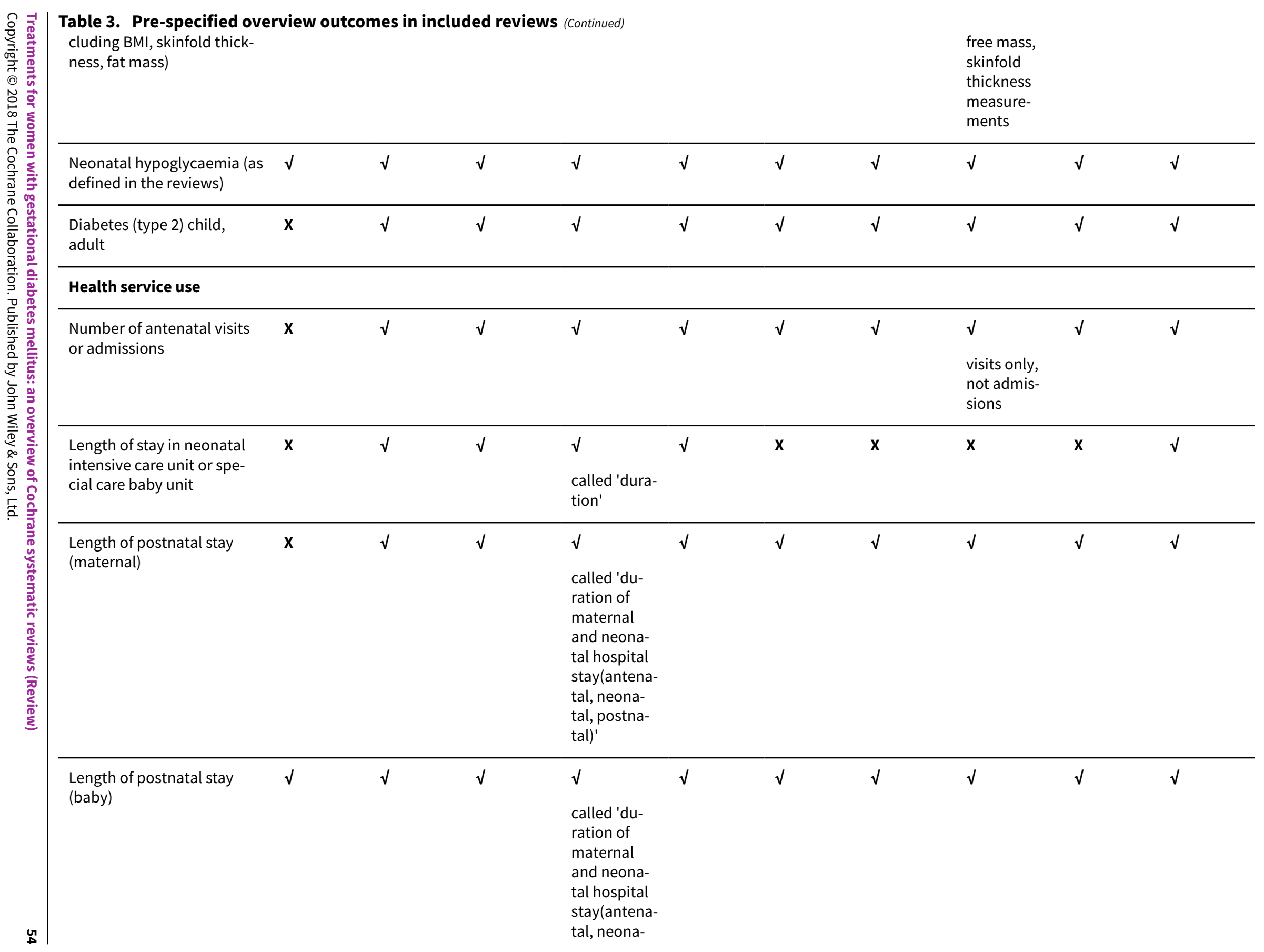




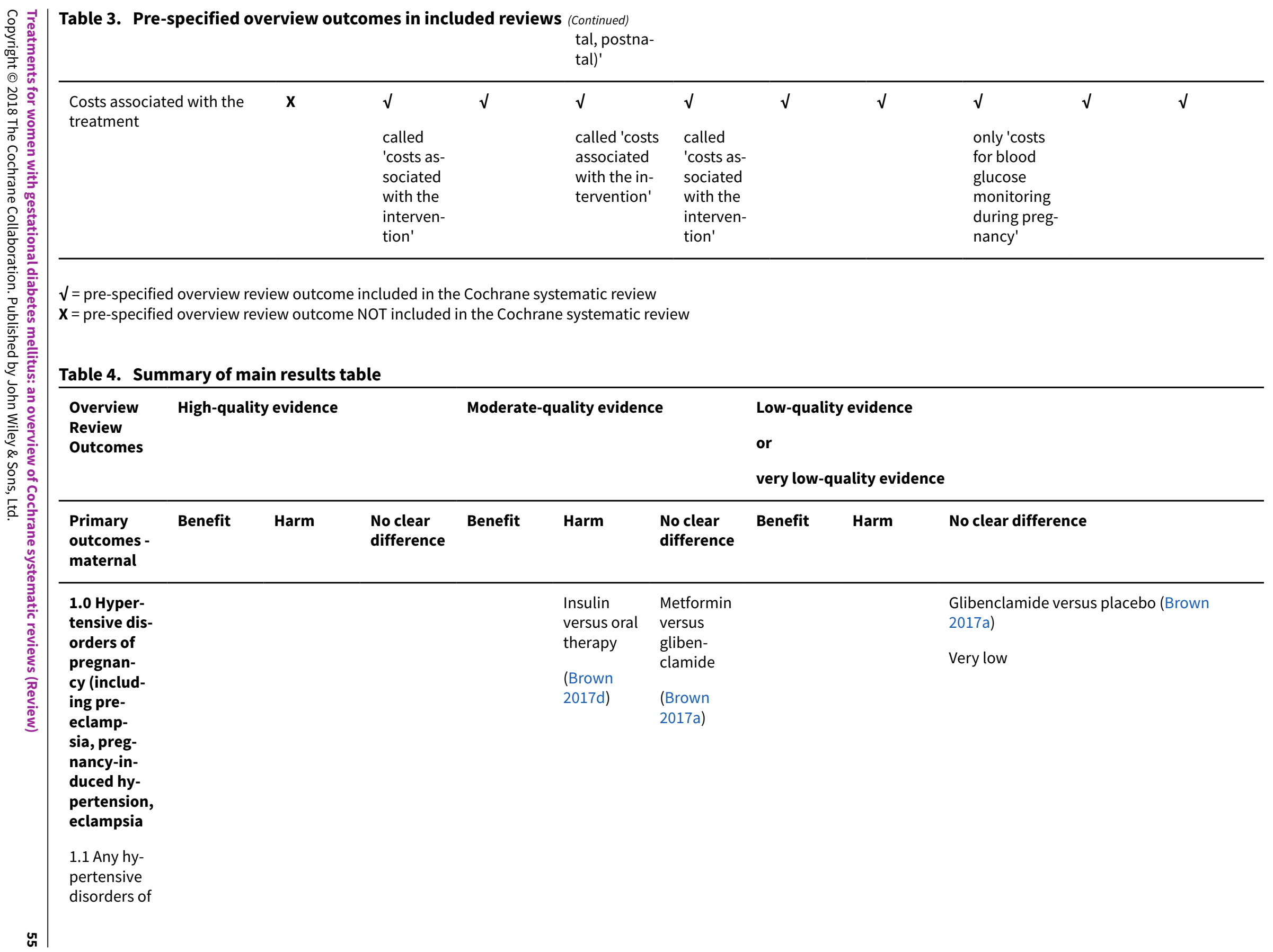




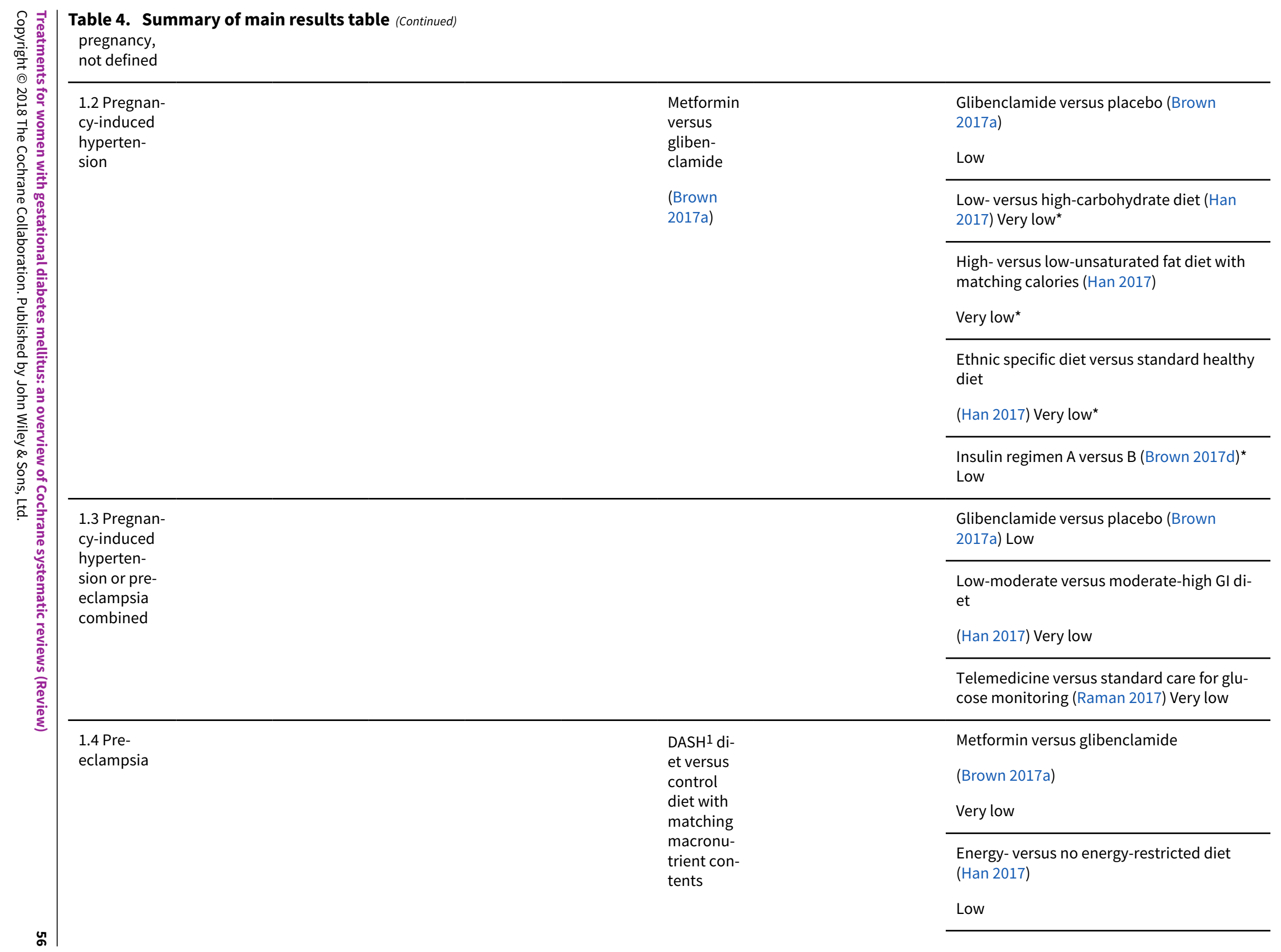




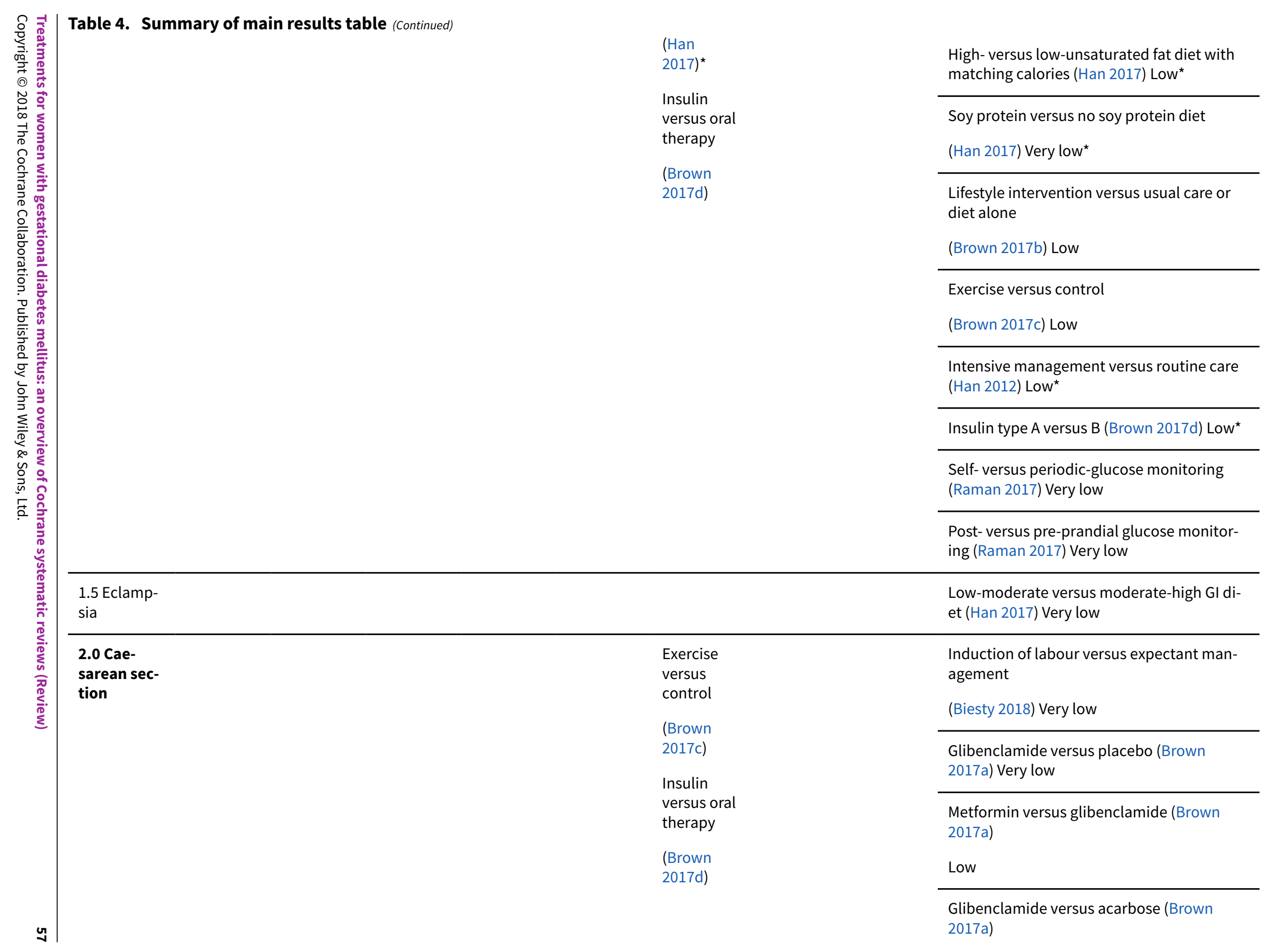




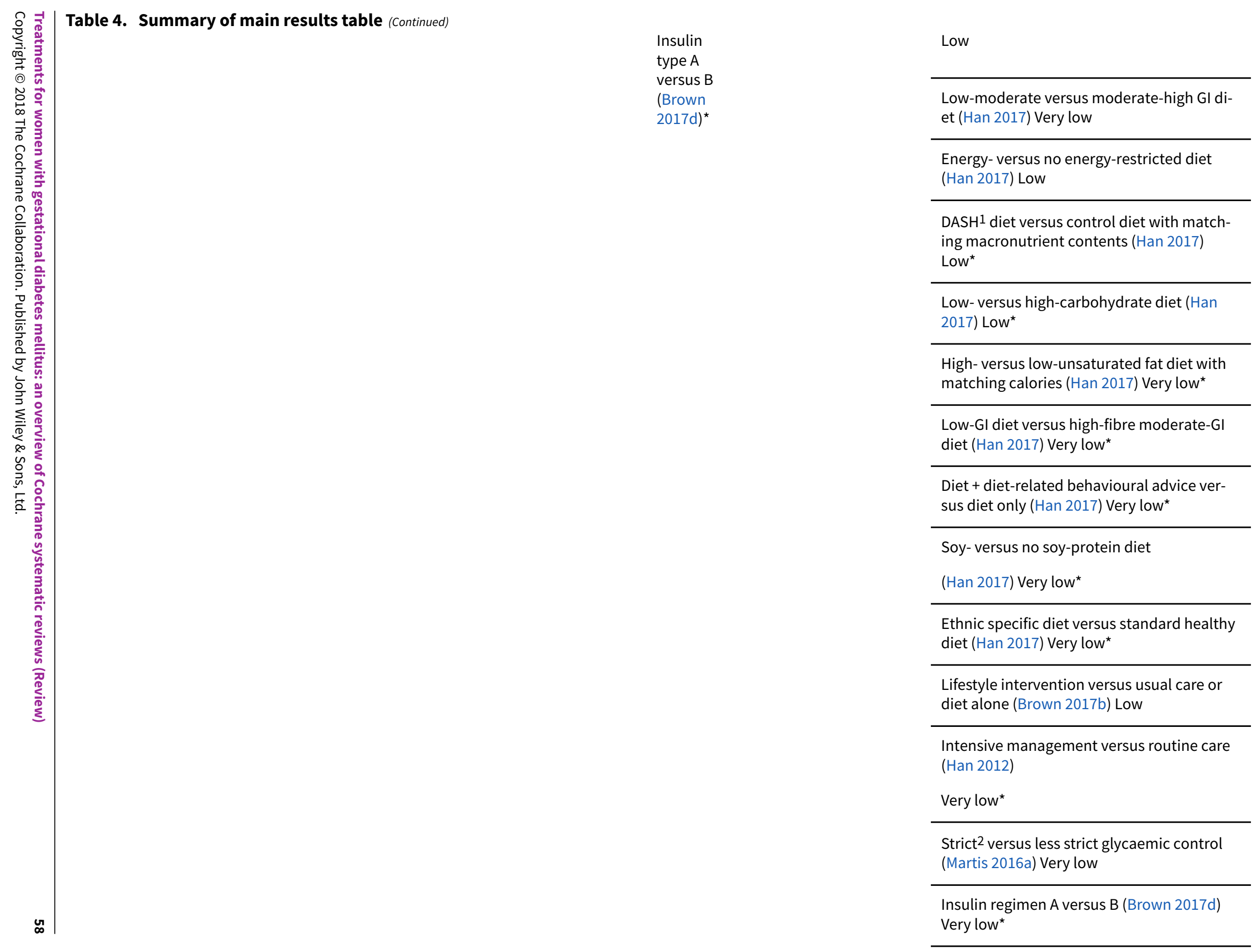




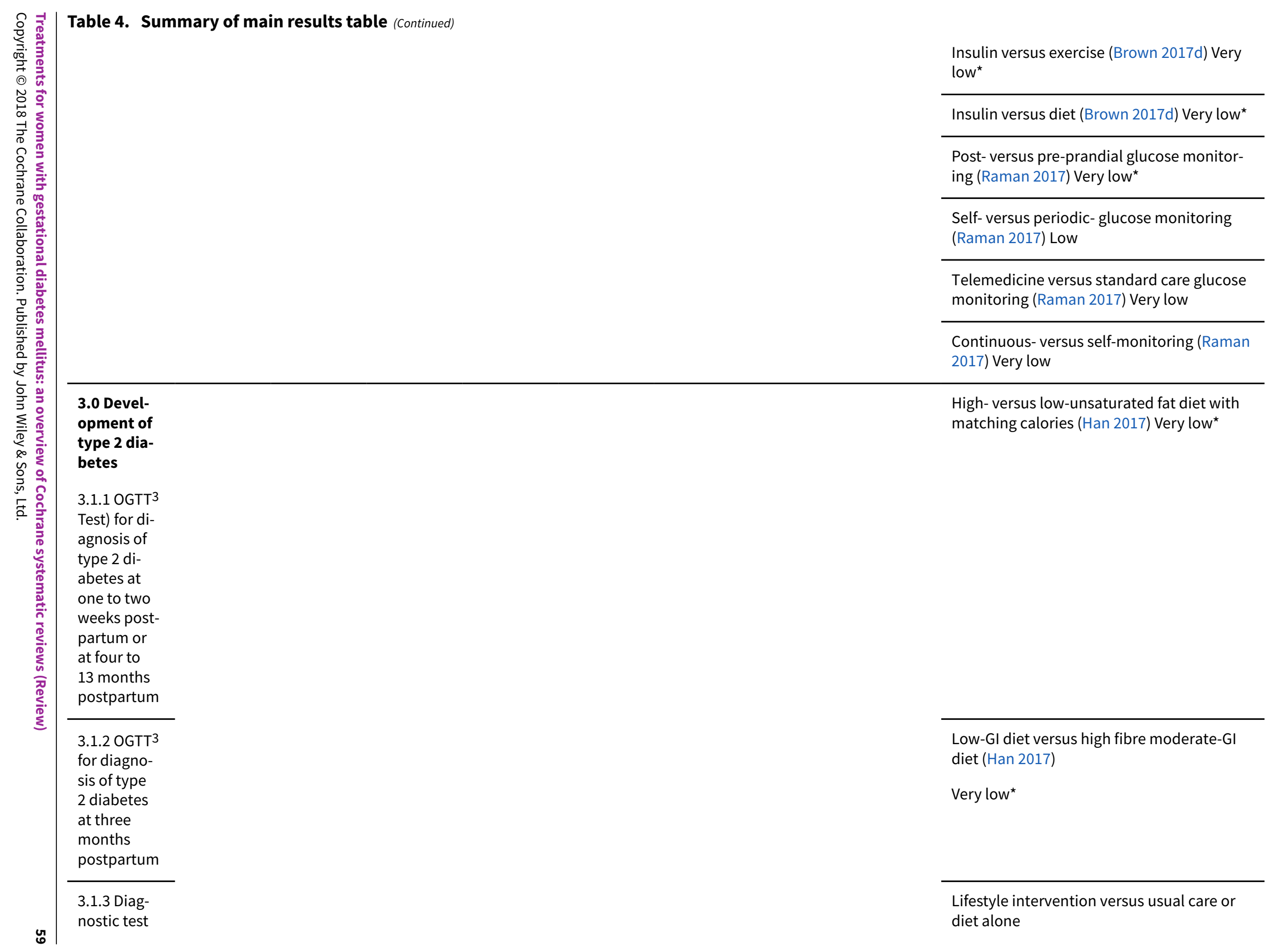

Continuous- versus self-monitoring (Raman

High- versus low-unsaturated fat diet with

3.0 Devel-

type 2 dia-

matching calories (Han 2017) Very low*

3.1.1 $\mathrm{OGTT}^{3}$

ype 2

3.1.2 OGTT $^{3}$

Low-GI diet versus high fibre moderate-GI

is of typ

Very low*

Lifestyle intervention versus usual care or diet alone 


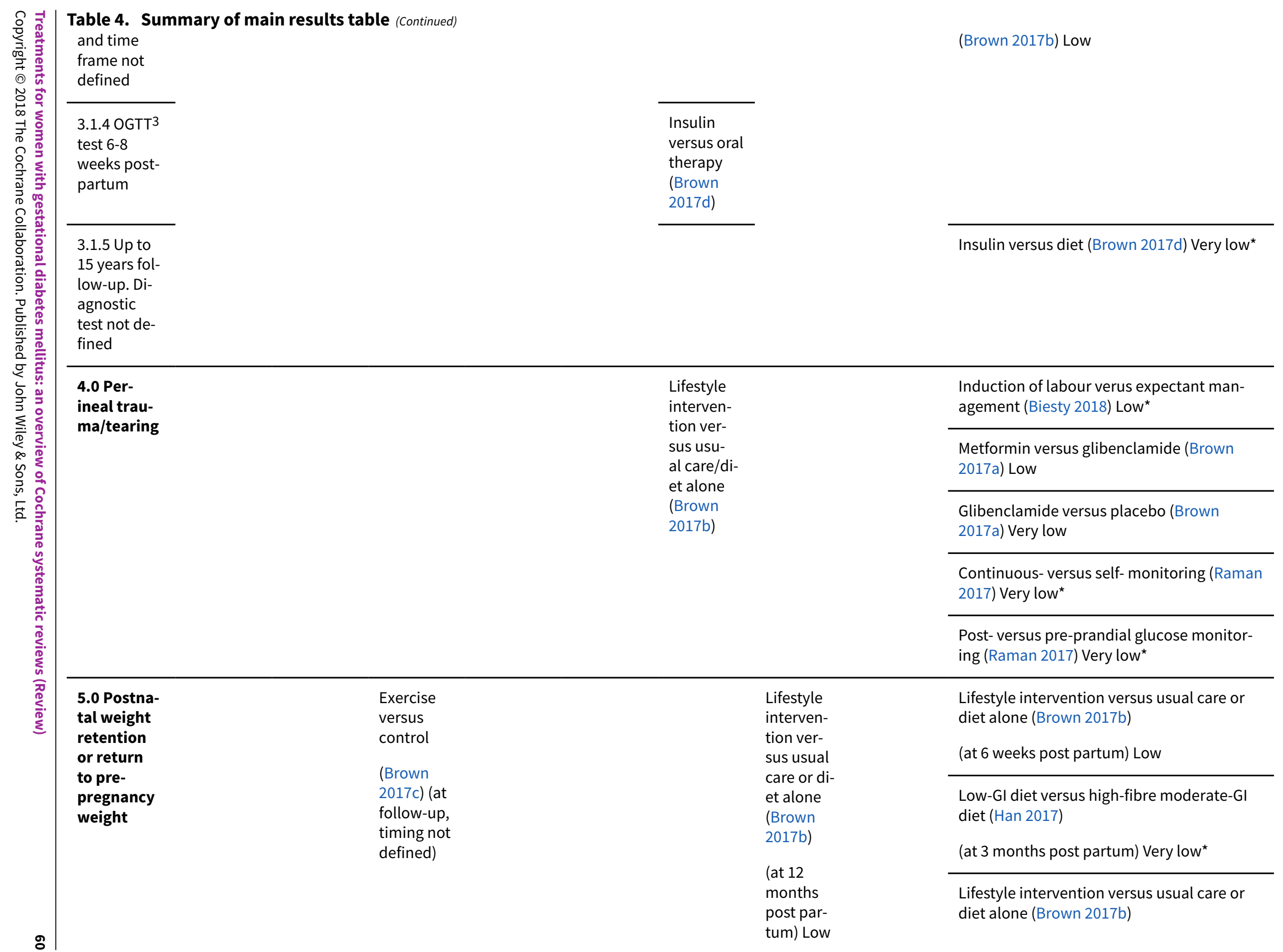




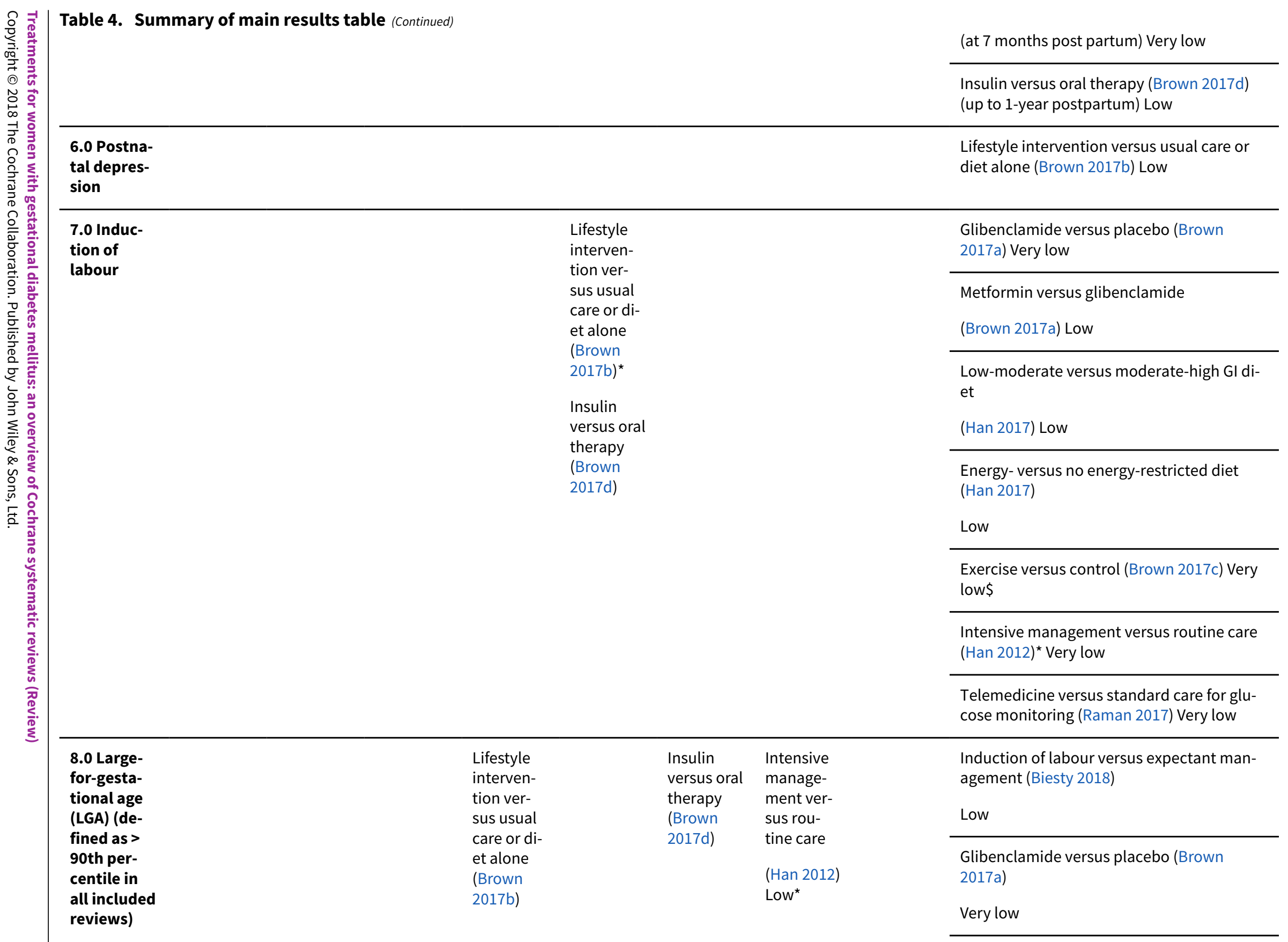




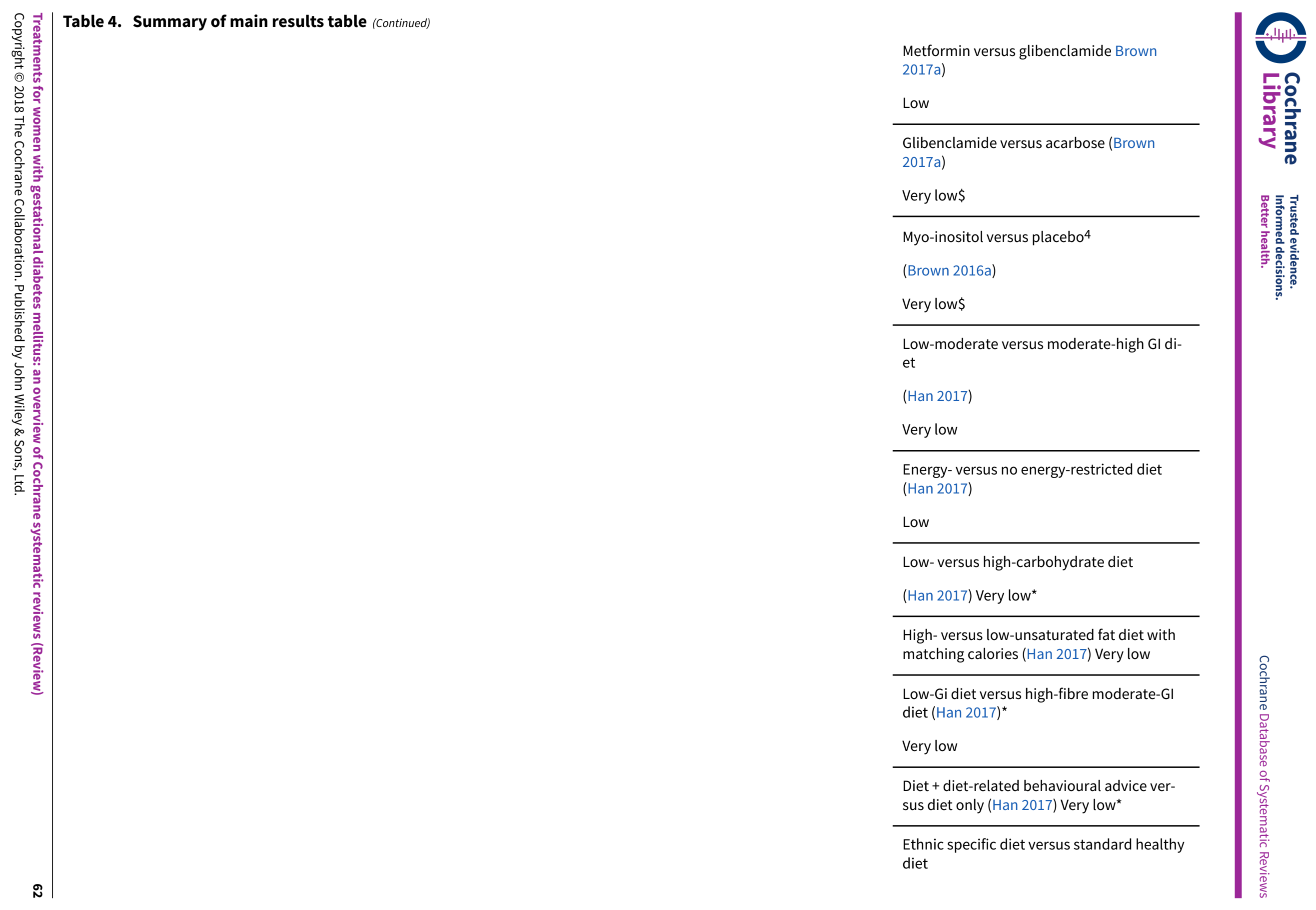




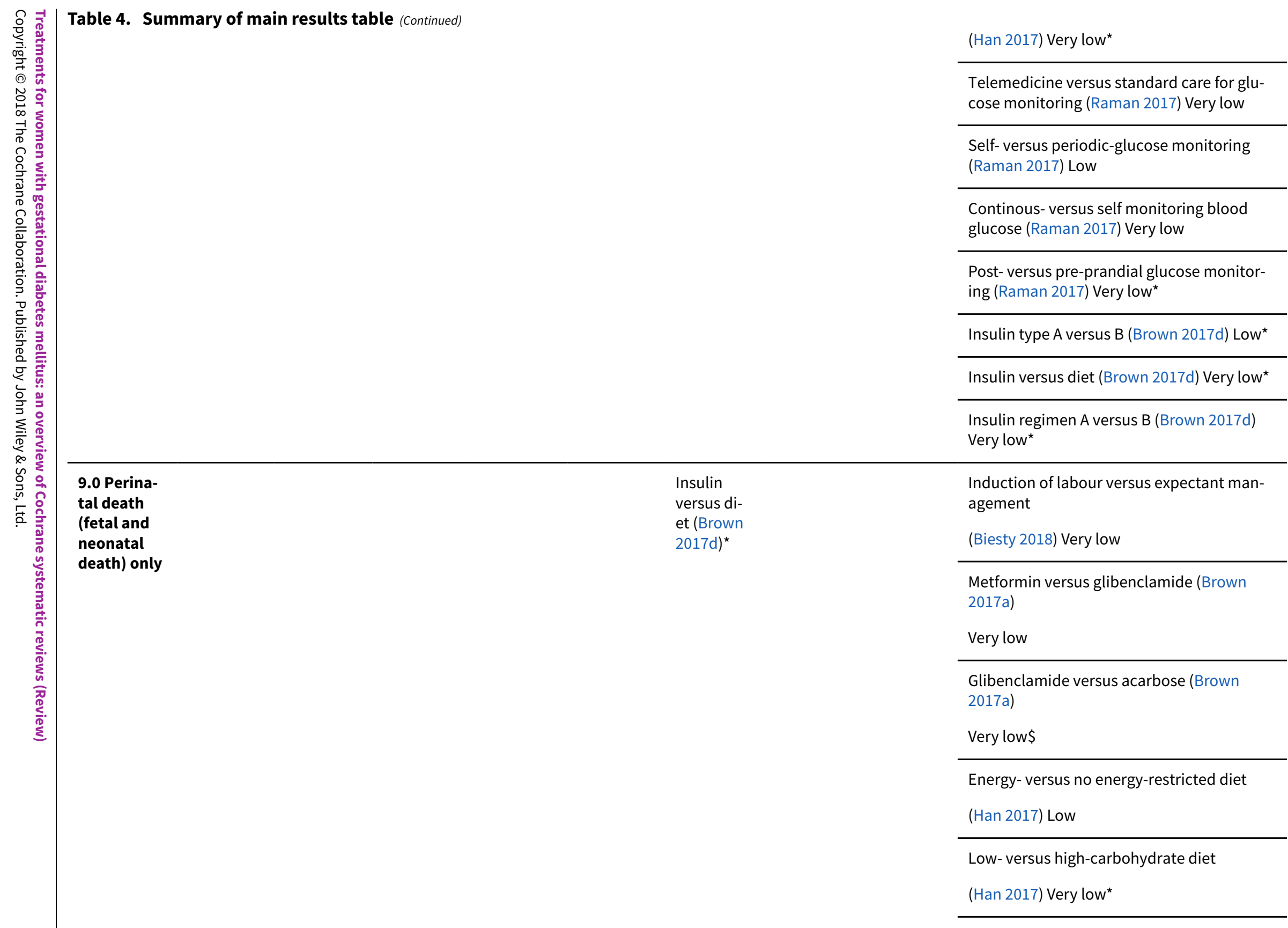




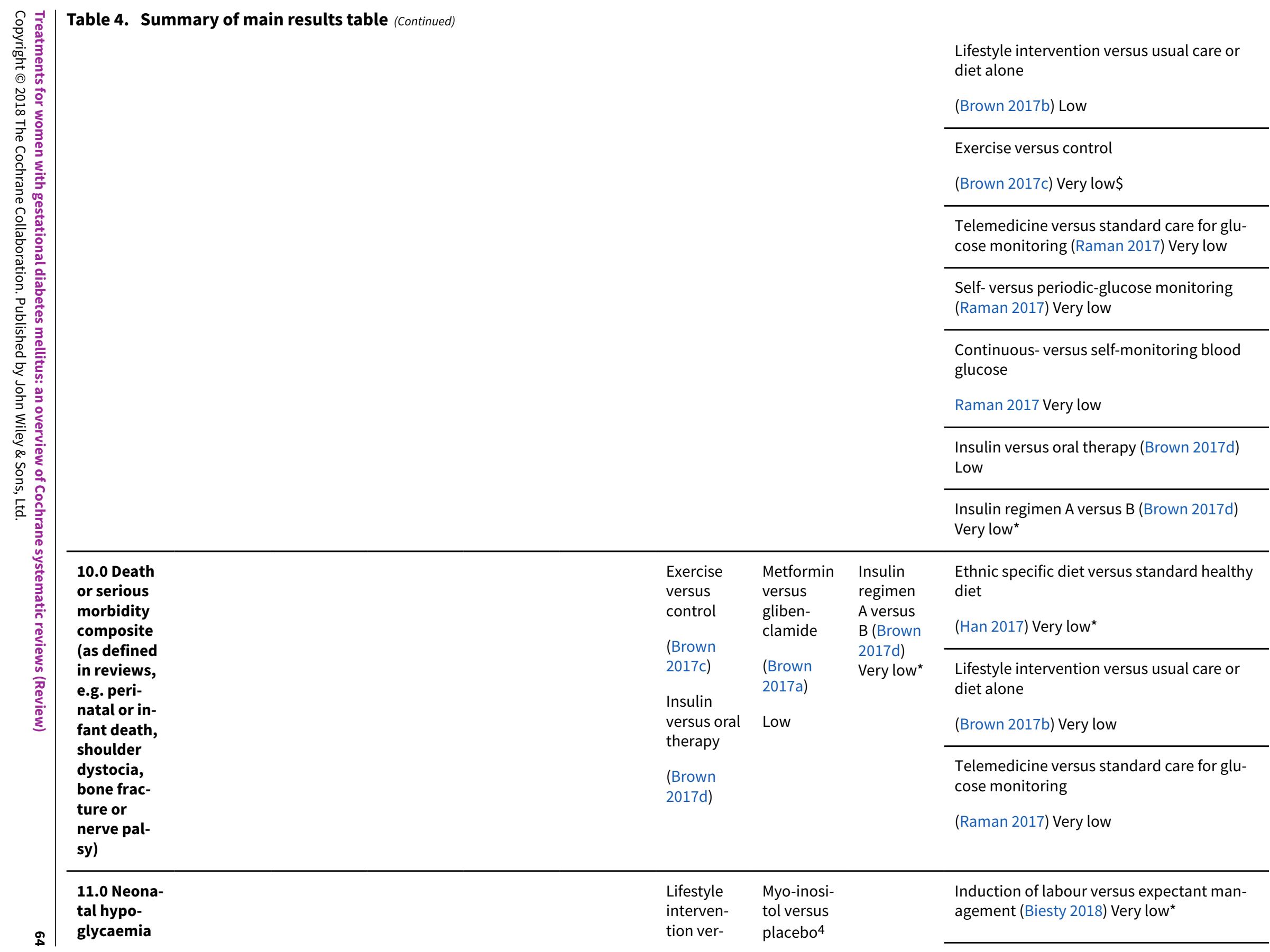




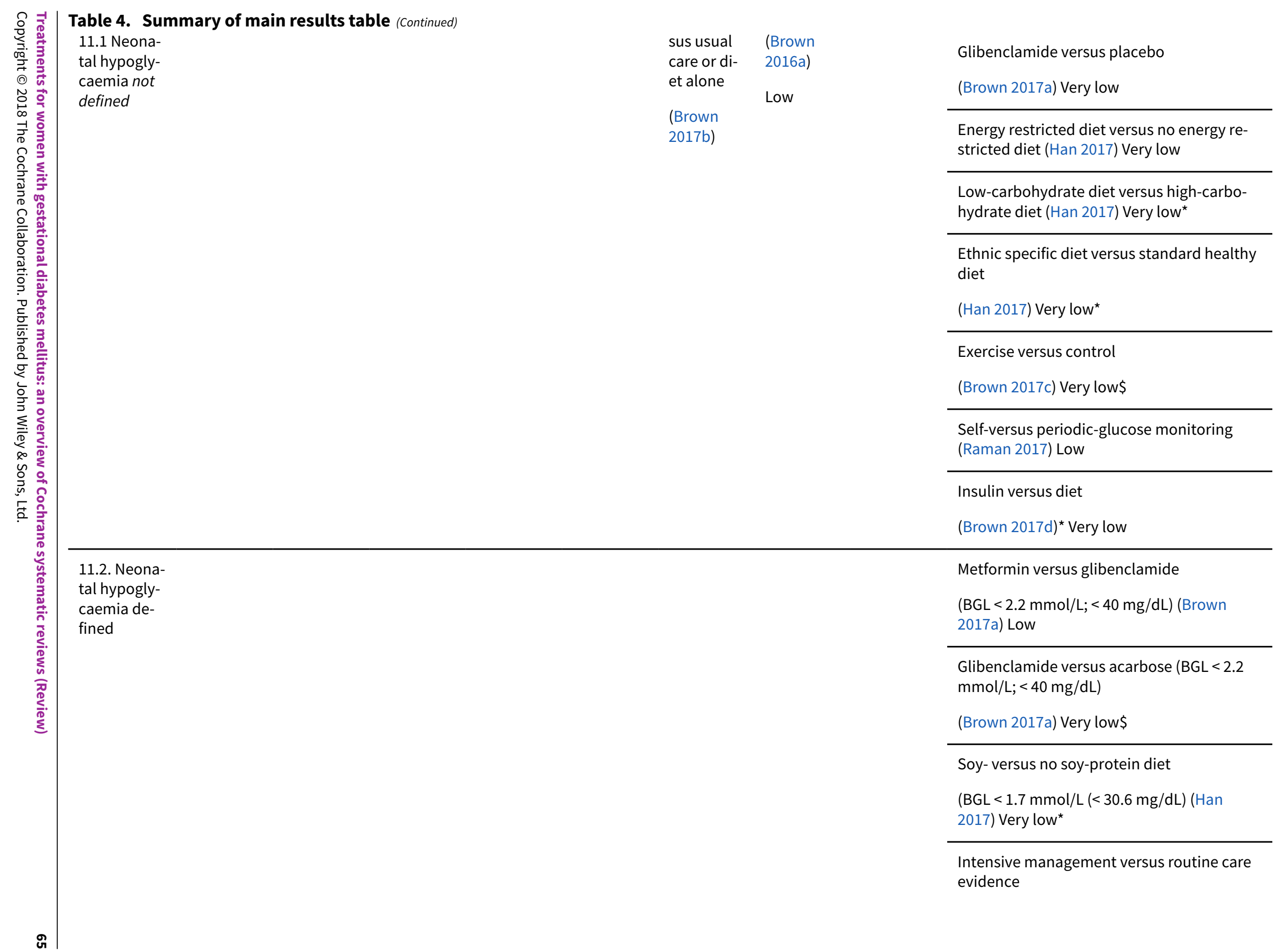




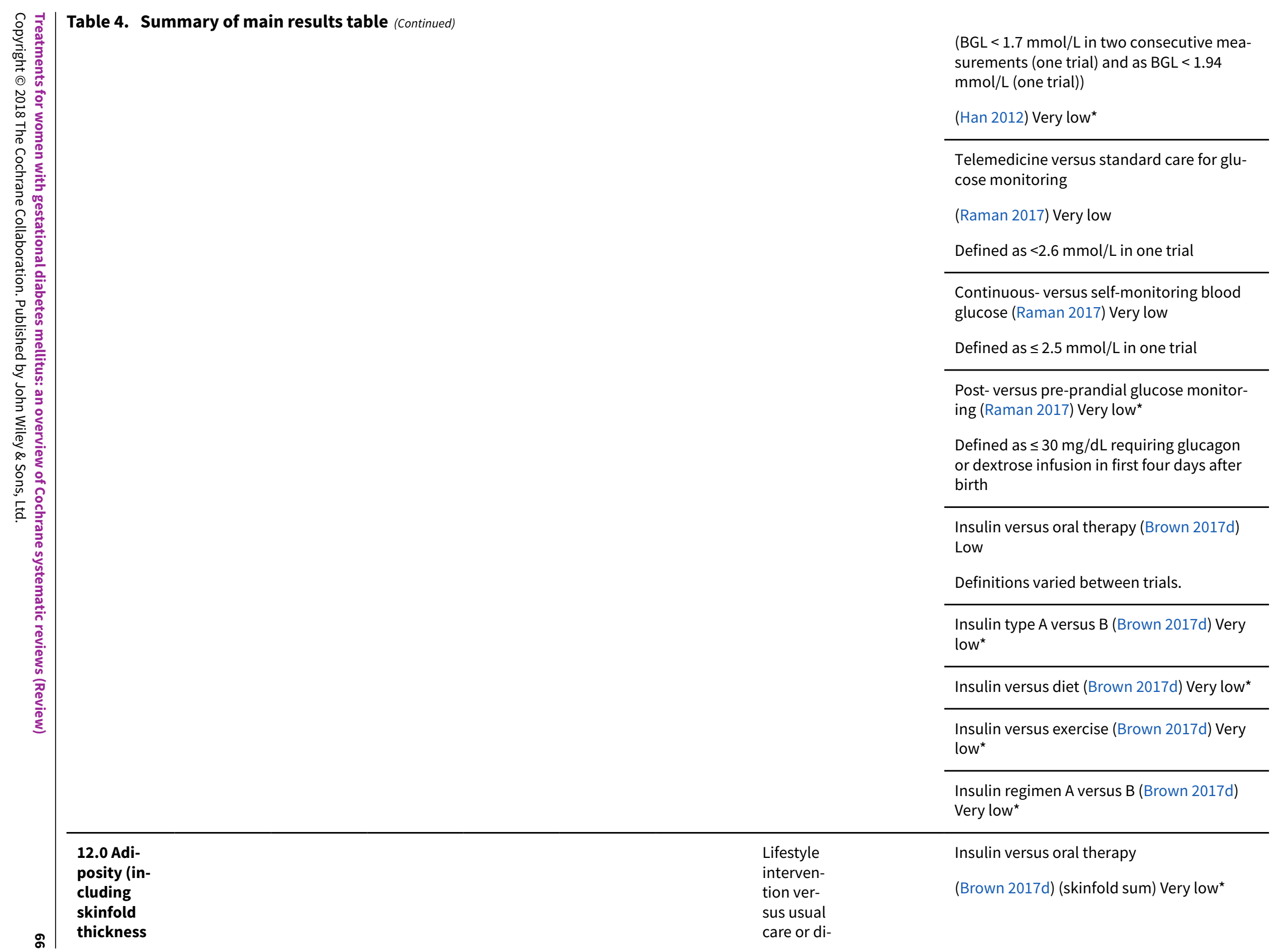

Post- versus pre-prandial glucose monitor-

Defined as $\leq 30 \mathrm{mg} / \mathrm{dL}$ requiring glucagon or dextrose infusion in first four days after

Low

Insulin type A versus B (Brown 2017d) Very

Insulin versus exercise (Brown 2017d) Very

Insulin regimen A versus B (Brown 2017d) 


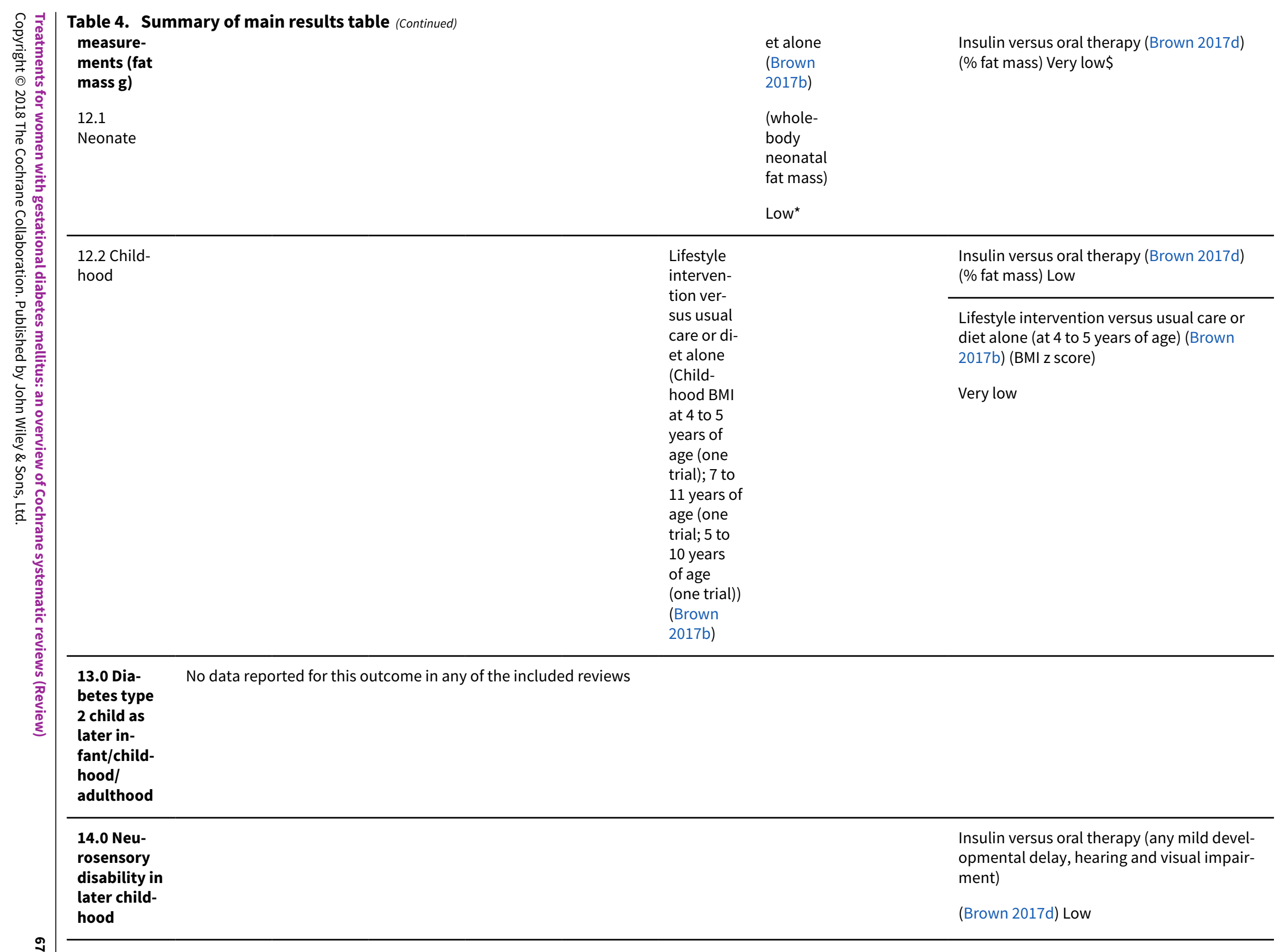




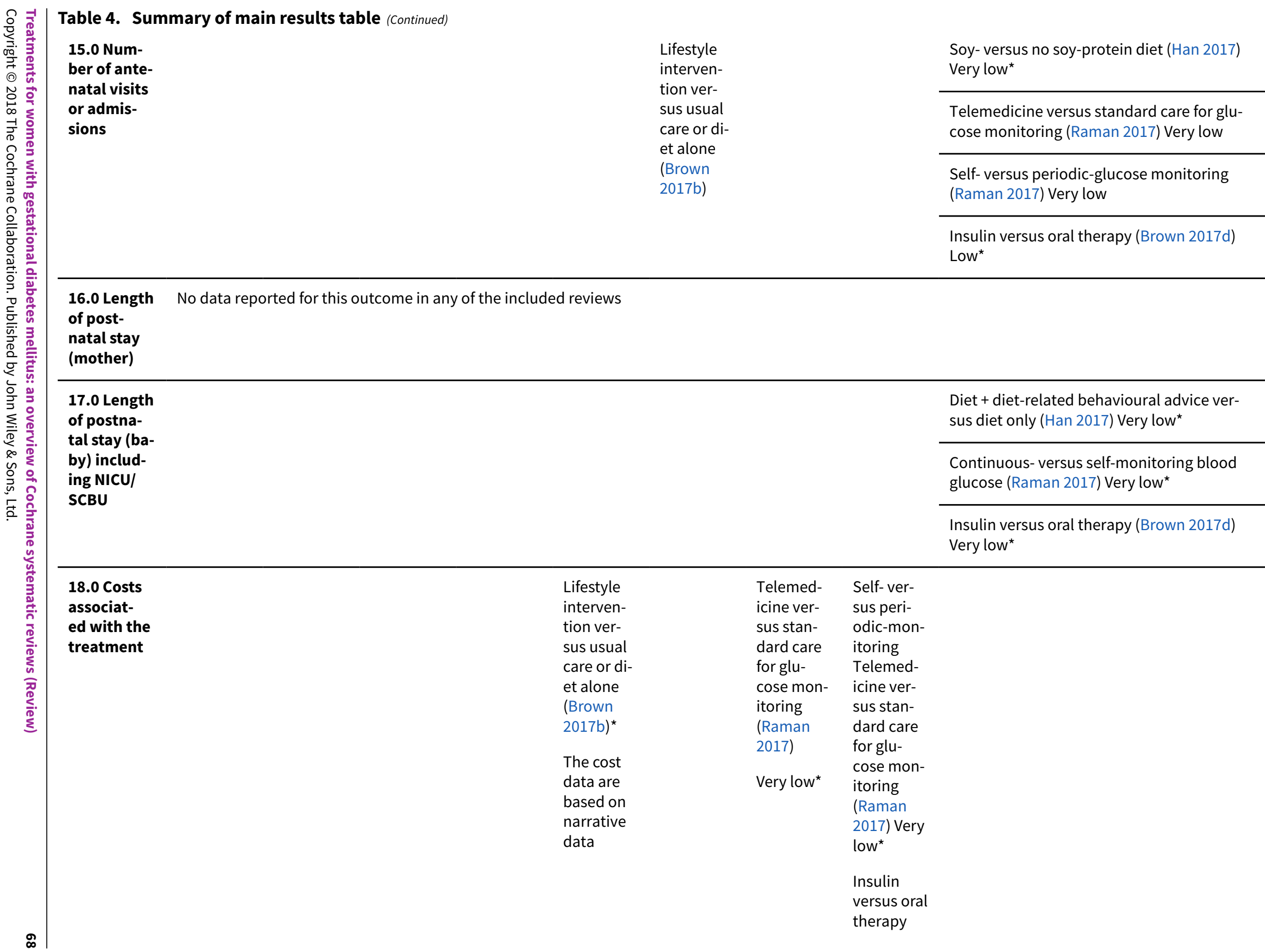




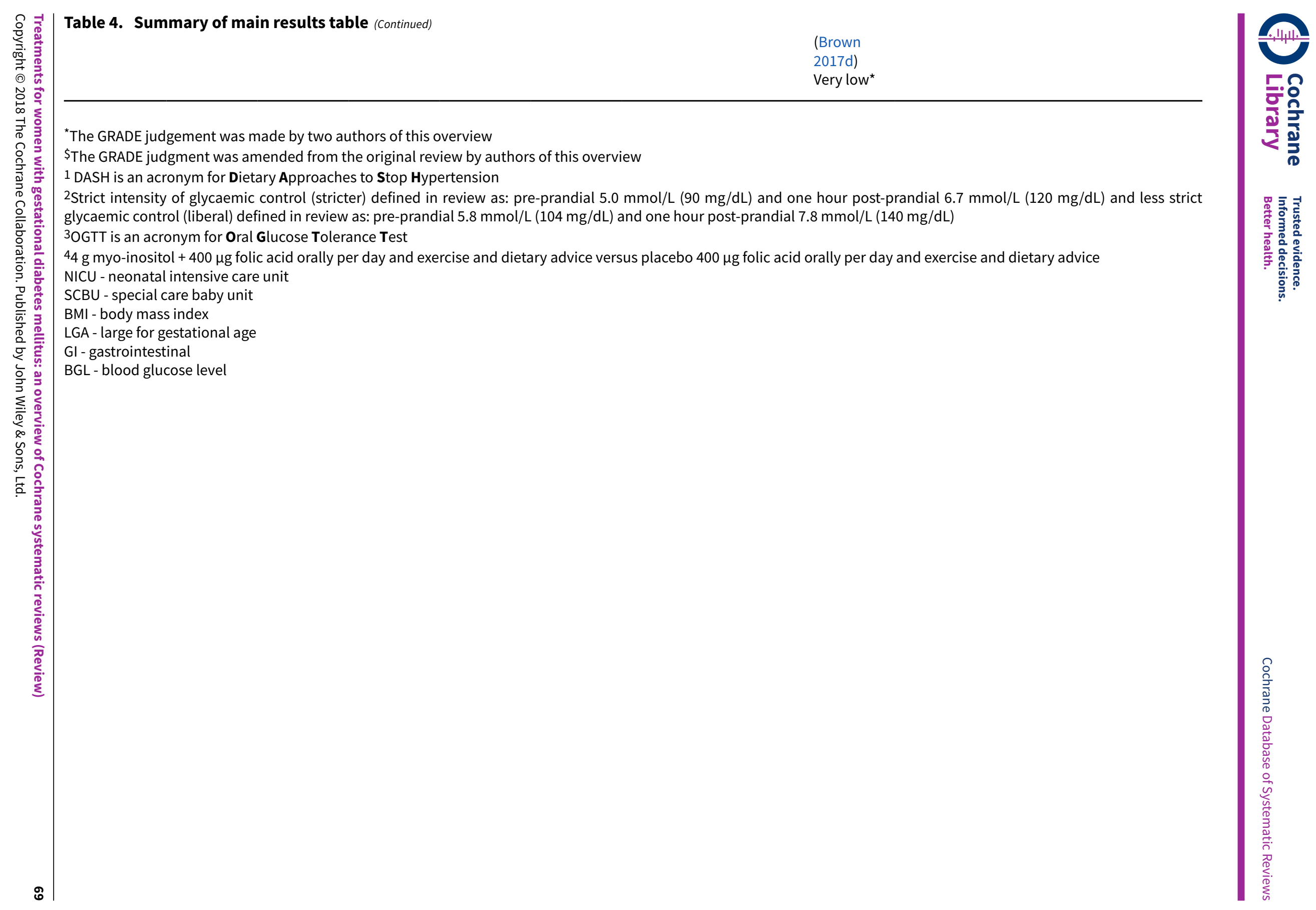


Table 5. Characteristics of excluded reviews

\section{Review ID and title Reason for exclusion}

Alwan 2009

Treatments for gestational diabetes

Most pre-specified overview outcomes included but this review was too large and has now been split into three reviews.

Two reviews are currently published as 'Oral anti-diabetic pharmacological therapies for the treatment of women with

gestational diabetes' Brown 2017a and 'Lifestyle interventions for the treatment of women with gestational diabetes' (Brown 2017b) and are included reviews in this overview. The other one is currently published as a protocol entitled 'Insulin for the treatment of women with gestational diabetes' New Reference (ongoing Cochrane systematic reviews - protocol and title registrations Appendix 1). The reviews and the protocol include all overview pre-specified primary outcomes for maternal and neonatal outcomes and all overview pre-specified secondary outcomes for maternal, maternal long-term, fetal/neonatal, later infant/childhood, child as an adult and health services use

\section{Ceysens 2006}

Exercise for diabetic pregnant women

This review, which included some of the pre-specified overview primary and secondary outcomes, was not up-to-date

and has now been superseded with a new title and is now published as a review entitled 'Exercise for pregnant women with gestational diabetes for improving maternal and fetal outcomes' (Brown 2017c) (Table 2 Characteristics of included reviews) and is an included review in this overview for assessment

De-Regil 2016

Vitamin D supplementation for women during pregnancy

McCauley 2015

Vitamin A supplementation during pregnancy for maternal and newborn outcomes
Some primary and secondary overview review pre-specified outcomes included but not later infant/childhood, child as an adult and health service use outcomes.

Pregnant women with pre-existing conditions (i.e. gestational diabetes) were excluded
Some overview review pre-specified outcomes included. Neonatal primary outcome: perinatal mortality; Maternal secondary outcomes: postpartum infection and maternal mortality. Fetal/neonatal secondary outcomes: stillbirth, preterm birth ( $<37$ weeks' gestation) and birthweight. No maternal long-term, later infant/childhood, child as an adult and health service use secondary outcomes.

No outcome data for women with GDM separated out for the above outcomes

\section{Rumbold 2015} pregnancy
Vitamin C supplementation in

Some overview review pre-specified outcomes included. Maternal primary outcome: hypertensive disorder of pregnancy and caesarean. Neonatal primary outcome: death or serious morbidity composite and neurosensory disability; maternal secondary outcomes: postpartum haemorrhage, maternal mortality, and women's view of care. Fetal/neonatal secondary outcomes: stillbirth, neonatal death, gestational age at birth, preterm birth ( $<37$ weeks' gestation), five-minute Apgar $<7$, birthweight, respiratory distress syndrome and neonatal jaundice. No later infant/childhood, child as an adult and health service use secondary outcomes. Of the 29 studies included in this review five studies excluded women with any diabetes in pregnancy.

No outcome data for women with GDM separated out for the above outcomes

\section{Walkinshaw 1996}

Dietary regulation for gestational diabetes

\section{Walkinshaw 2006}

Very tight versus tight control for diabetes in pregnancy
Pre-specified outcomes not available as this review has been withdrawn and is now included in the review currently published as 'Different types of dietary advice for women with gestational diabetes mellitus' (Han 2017), which is an included review in this overview review

Pre-specified outcomes not available as this review has been withdrawn because it is out-of-date. The review team were unable to prepare the update and it is now included in the review currently published as 'different intensities of glycaemic control for women with gestational mellitus' (Martis 2016a) 
Abbreviation: GDM - gestational diabetes mellitus

Table 6. Cochrane risk of bias assessments from included reviews

\begin{tabular}{|c|c|c|}
\hline Review ID and title & Summary of trial limitations (risk of bias) & Overall risk of bias \\
\hline $\begin{array}{l}\text { Biesty } 2018 \\
\text { Elective delivery in dia- } \\
\text { betic } \\
\text { pregnant women }\end{array}$ & $\begin{array}{l}\text { Sequence generation: } 1 \text { RCT low risk } \\
\text { Allocation concealment: } 1 \text { RCT low risk } \\
\text { Blinding (participants and personnel): } 1 \text { RCT high risk } \\
\text { Blinding (outcome assessors): } \\
1 \text { RCT high risk }\end{array}$ & $\begin{array}{l}\text { "We assessed the over- } \\
\text { all risk of bas as be- } \\
\text { ing low for most do- } \\
\text { mains, apart from per- } \\
\text { formance, detection } \\
\text { and attrition bias (for } \\
\text { outcome perineum in- } \\
\text { tact) which we assessed } \\
\text { as being high risk." }\end{array}$ \\
\hline
\end{tabular}

Selective reporting: 1 RCT low risk

Other: 1 RCT low risk

\section{Brown 2017a}

Oral anti-diabetic pharmacological

therapies for the treatment of women with gestational diabetes

Sequence generation: 5 RCTs low risk; 6 unclear risk

Allocation concealment: 6 RCTs low risk; 5 RCTs unclear risk

Blinding (participants and personnel): 2 RCTs low risk; 7 RCTs high risk; 2 RCTs unclear risk

Blinding (outcome assessors): 2 RCTs low risk; 9 RCTs unclear risk

Incomplete outcome data: 7 RCT low risk; 2 RCTs high risk; 2 RCTs unclear risk

Selective reporting: 3 RCTs low risk; 8 RCTs high risk

Other: 3 RCTs low risk; 6 RCTs high risk; 2 RCTs unclear risk

\section{Brown 2017b}

Lifestyle interventions for the

treatment of women with

gestational diabetes
Sequence generation: 10 RCTs low risk; 5 RCTs unclear risk

Allocation concealment: 5 RCTs low risk; 10 RCTs unclear risk

Blinding (participants and personnel): 9 RCTs high risk;

4 RCTs low risk; 2 RCTs unclear risk

Blinding (outcome assessors): 6 RCTs low risk; 9 RCTs unclear risk Incomplete outcome data: 3 RCTs high risk; 10 RCTs low risk; 2 RCTs unclear risk

Selective reporting: 11 RCTs high risk; 3 RCTs low risk; 1 RCT unclear risk

Other: 2 RCTs high risk; 13 RCTs low risk
"The overall risk of bias was 'unclear' due to inadequate reporting of methodology."
"Overall the evidence was judged to be of unclear risk of bias due to inadequate reporting of allocation concealment and blinding of outcome assessors and selective outcome reporting. There is variation between the trials with regards to the content of the lifestyle interventions. The evidence is dominated by two large trials (Crowther 2005; Landon 2009) that included 1000 women and 958 women, respectively. Both of these trials were judged to be at low risk of bias."

"We judged the overall risk of bias of the in- 
Table 6. Cochrane risk of bias assessments from included reviews (Continued)

Exercise for pregnant women

with gestational diabetes for

improving maternal and fetal outcomes

Allocation concealment: 3 RCTs low risk; 8 RCTs unclear risk

Blinding (participants and personnel): 3 RCTs high risk; 8 RCTs unclear risk

\section{Blinding (outcome assessors):}

2 RCTs low risk; 9 RCTs unclear risk

Incomplete outcome data: 2 RCTs high risk; 3 RCTs low risk; 6 RCTs unclear risk

Selective reporting: $1 \mathrm{RCT}$ low risk; $10 \mathrm{RCTs}$ unclear risk

Other: 3 RCTs low risk; 8 RCTs unclear risk

\section{Brown 2017d}

Insulin for the treatment of women with gestational diabetes
Sequence generation: 23 RCTs low risk; 29 RCTs unclear risk; 1 RCT high risk

Allocation concealment: 19 RCTs low risk; 33 RCTs unclear risk; 1 RCT high risk

Blinding (participants and personnel): 2 RCTs low risk; 11 RCTs unclear risk; 40 RCTs high risk

\section{Blinding (outcome assessors):}

5 RCTs low risk; 44 RCTs unclear risk; 4 RCTs high risk

Incomplete outcome data: 31 RCTs low risk; 14 RCTs unclear risk; 8 RCTs high risk

Selective reporting: 5 RCTs low risk; 14 RCTs unclear risk; 34 RCTs high risk

Other: 26 RCTs low risk; 7 RCTS unclear risk; 20 RCTs high risk

Brown 2016a
Dietary supplementa-
tion with
myo-inositol in women
during
pregnancy for treating
gestational diabetes

Sequence generation: 2 RCTs low risk

Allocation concealment: 1 RCT low risk; 1 RCT unclear risk

Blinding (participants and personnel): 1 RCT low risk; 1 RCT unclear risk

Blinding (outcome assessors):

2 RCTs unclear risk

Incomplete outcome data: 1 RCT low risk; 1 RCT unclear risk

Selective reporting: 1 RCT high risk; 1 RCT unclear risk

Other: 2 RCTs low risk

Han 2017
Different types of di-
etary
advice for women with
gestational diabetes
mellitus

Sequence generation: 11 RCTs low risk; 8 RCTs unclear risk

Allocation concealment: 4 RCTs low risk; 14 RCTs unclear risk; 1 RCT high risk

Blinding (participants and personnel): 4 RCTs low risk; 2 RCTs unclear risk; 13 RCTs high risk

"Overall, the risk of bias was unclear." cluded studies to be unclear due to lack of methodological details."
"Overall, the risk of bias of the included studies was judged to be unclear due to the lack of key methodological information."
Blinding (outcome assessors):

2 RCTs low risk, 16 RCTs unclear risk;

1 RCT high risk

Incomplete outcome data: 14 RCTs low risk; 3 RCTs unclear risk; 2 RCTs high risk

\author{
"In this update, we in- \\ cluded 19 trials ran- \\ domising 1398 women \\ with GDM, at an over- \\ all unclear to moderate \\ risk of bias."
}


Table 6. Cochrane risk of bias assessments from included reviews (Continued) Selective reporting: 16 RCTs unclear risk; 3 RCTs high risk

Other: 2 RCTs low risk

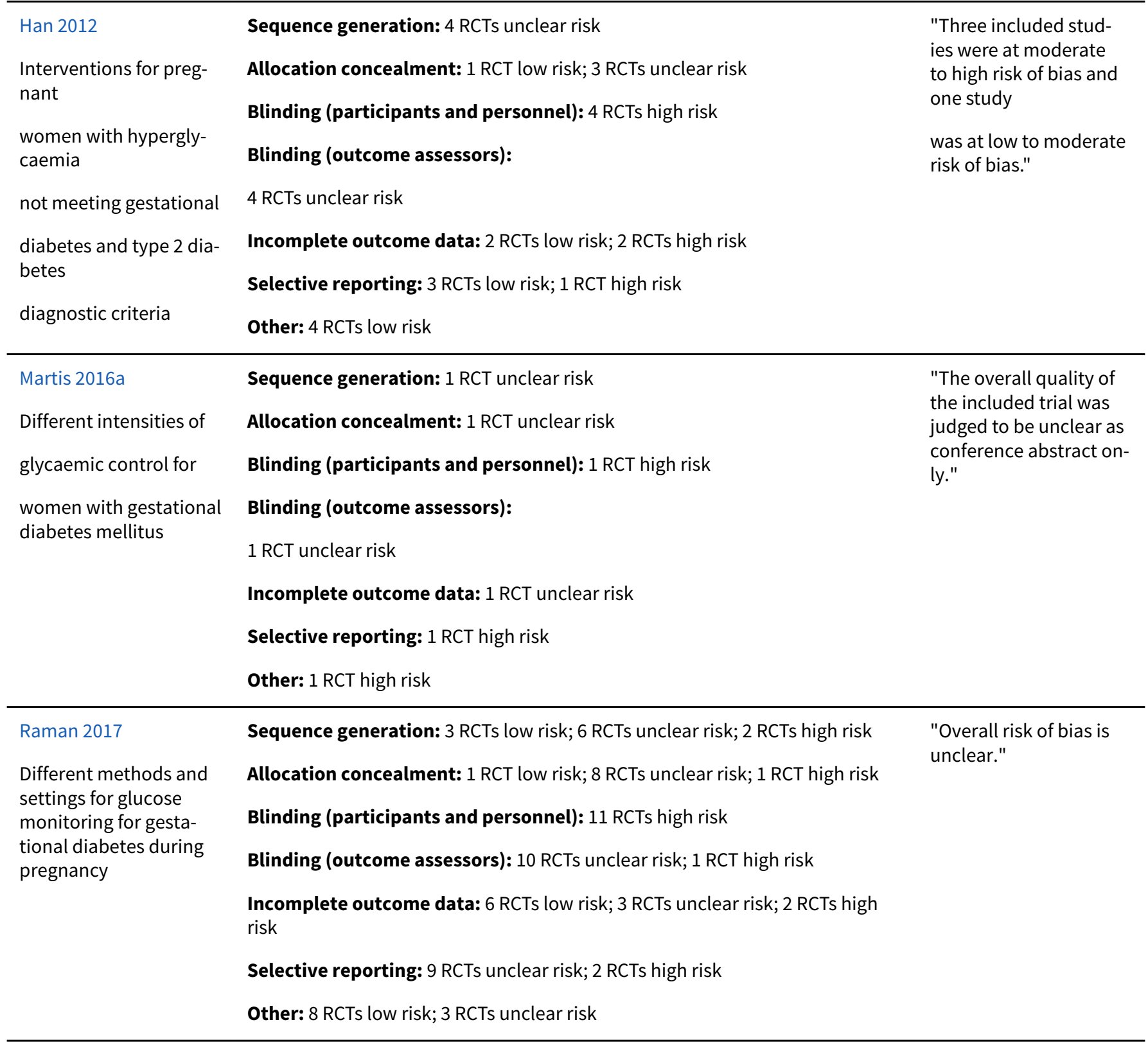

Table 7. GRADE Summary of findings table - Maternal

\begin{tabular}{lllllll}
\hline $\begin{array}{l}\text { Intervention } \\
\text { and comparison }\end{array}$ & $\begin{array}{l}\text { Assumed } \\
\text { risk with } \\
\text { compara- } \\
\text { tor }\end{array}$ & $\begin{array}{l}\text { Corre- } \\
\text { sponding } \\
\text { risk with } \\
\text { interven- } \\
\text { tion* }\end{array}$ & $\begin{array}{l}\text { Relative } \\
\text { effect } \\
(95 \% \mathrm{CI})\end{array}$ & $\begin{array}{l}\text { № of par- } \\
\text { ticipants } \\
\text { (studies) }\end{array}$ & $\begin{array}{l}\text { Quality of } \\
\text { the evi- } \\
\text { dence } \\
\text { (GRADE) }\end{array}$ & $\begin{array}{l}\text { Comments from included reviews } \\
\text { in quotation marks }\end{array}$ \\
& & & & $\begin{array}{l}\text { Comments without quotation } \\
\text { marks from overview review au- } \\
\text { thors }\end{array}$
\end{tabular}

\subsection{Hypertensive disorders of pregnancy (including pre-eclampsia, pregnancy-induced hypertension, eclampsia, as defined in reviews)}


Table 7. GRADE Summary of findings table - Maternal (Continued)

\begin{tabular}{|c|c|c|c|c|c|c|}
\hline $\begin{array}{l}\text { Brown 2017a } \\
\text { Glibenclamide } \\
\text { versus placebo } \\
\text { Any hyperten- } \\
\text { sive disorders of } \\
\text { pregnancy, not } \\
\text { defined }\end{array}$ & $\begin{array}{l}167 \text { per } \\
1000\end{array}$ & $\begin{array}{l}207 \text { per } \\
1000 \\
(135 \text { to } \\
317)\end{array}$ & $\begin{array}{l}\text { RR } 1.24 \\
(0.81 \text { to } \\
1.90)\end{array}$ & $\begin{array}{l}375 \\
(1 \mathrm{RCT})\end{array}$ & Very low & $\begin{array}{l}\text { "Evidence is based on one study and } \\
93 \% \text { were Hispanic women, results } \\
\text { may not be generalisable to other } \\
\text { populations. There is risk of bias, as } \\
\text { we did not find a published protocol } \\
\text { and there were more outcomes re- } \\
\text { ported in the published paper than } \\
\text { were listed in the trial registration } \\
\text { document." }\end{array}$ \\
\hline $\begin{array}{l}\text { Brown 2017a } \\
\text { Metformin ver- }\end{array}$ & 88 per 1000 & $\begin{array}{l}62 \text { per } 1000 \\
(33 \text { to } 114)\end{array}$ & $\begin{array}{l}\text { RR } 0.70 \\
(0.38 \text { to } \\
1.30)\end{array}$ & $\begin{array}{l}508 \\
\text { (3 RCTs) }\end{array}$ & Moderate & $\begin{array}{l}\text { "All studies were open label, some } \\
\text { risk of bias." }\end{array}$ \\
\hline
\end{tabular}

sus gliben-

clamide

\section{Any hyperten- \\ sive disorders of \\ pregnancy, not \\ defined}

\begin{tabular}{|c|c|c|c|c|c|c|}
\hline $\begin{array}{l}\text { Brown 2017d } \\
\text { Insulin versus } \\
\text { oral therapy }\end{array}$ & 36 per 1000 & $\begin{array}{l}69 \text { per } 1000 \\
(42 \text { to } 114)\end{array}$ & $\begin{array}{l}\text { RR } 1.89 \\
(1.14 \text { to } \\
3.12)\end{array}$ & $\begin{array}{l}1214 \\
\text { (4 RCTs) }\end{array}$ & Moderate & $\begin{array}{l}\text { Evidence downgraded for study limi- } \\
\text { tations }\end{array}$ \\
\hline $\begin{array}{l}\text { Any hyperten- } \\
\text { sive disorders of } \\
\text { pregnancy, not } \\
\text { defined }\end{array}$ & & & & & & \\
\hline
\end{tabular}

\begin{tabular}{|c|c|c|c|c|c|c|}
\hline $\begin{array}{l}\text { Brown 2017a } \\
\text { Glibenclamide } \\
\text { versus placebo } \\
\text { Pregnancy-in- } \\
\text { duced hyper- } \\
\text { tension }\end{array}$ & $\begin{array}{l}102 \text { per } \\
1000\end{array}$ & $\begin{array}{l}127 \text { per } \\
1000 \\
\text { (73 to } 224)\end{array}$ & $\begin{array}{l}\text { RR } 1.24 \\
(0.71 \text { to } \\
2.19)\end{array}$ & $\begin{array}{l}375 \\
(1 \mathrm{RCT})\end{array}$ & Low & $\begin{array}{l}\text { Evidence is based on one study and } \\
\text { imprecision as wide confidence inter- } \\
\text { val crossing the line of no effect }\end{array}$ \\
\hline $\begin{array}{l}\text { Brown } 2017 a \\
\text { Metformin ver- } \\
\text { sus gliben- } \\
\text { clamide } \\
\text { Pregnancy-in- } \\
\text { duced hyper- } \\
\text { tension }\end{array}$ & $\begin{array}{l}108 \text { per } \\
1000\end{array}$ & $\begin{array}{l}77 \text { per } 1000 \\
(40 \text { to } 148)\end{array}$ & $\begin{array}{l}\text { RR } 0.71 \\
(0.37 \text { to } \\
1.37)\end{array}$ & $\begin{array}{l}359 \\
(2 \mathrm{RCT})\end{array}$ & Moderate & $\begin{array}{l}\text { Risk of performance bias as study } \\
\text { participants and care providers were } \\
\text { not blinded in both trials and addi- } \\
\text { tionally one trial had reporting bias } \\
\text { for not reporting pre-specified out- } \\
\text { come for macrosomia }\end{array}$ \\
\hline $\begin{array}{l}\text { Han } 2017 \\
\text { Low- versus } \\
\text { high-carbohy- } \\
\text { drate diet } \\
\text { Pregnancy-in- } \\
\text { duced hyper- } \\
\text { tension }\end{array}$ & $\begin{array}{l}133 \text { per } \\
1000\end{array}$ & $\begin{array}{l}53 \text { per } 1000 \\
(17 \text { to } 163)\end{array}$ & $\begin{array}{l}\text { RR } 0.40 \\
(0.13 \text { to } \\
1.22)\end{array}$ & $\begin{array}{l}150 \\
(1 \mathrm{RCT})\end{array}$ & Very low & $\begin{array}{l}\text { Evidence is based on one study and } \\
\text { imprecision as wide confidence inter- } \\
\text { val crossing the line of no effect. Risk } \\
\text { of performance bias as study partic- } \\
\text { ipants and care providers were not } \\
\text { blinded }\end{array}$ \\
\hline
\end{tabular}


Table 7. GRADE Summary of findings table - Maternal (Continued)

\begin{tabular}{|c|c|c|c|c|c|c|}
\hline $\begin{array}{l}\text { Han } 2017 \\
\text { High- versus low- } \\
\text { unsaturated fat } \\
\text { diet with match- } \\
\text { ing calories }\end{array}$ & $\begin{array}{l}143 \text { per } \\
1000\end{array}$ & $\begin{array}{l}77 \text { per } 1000 \\
\text { (9 to } 751 \text { ) }\end{array}$ & $\begin{array}{l}\text { RR } 0.54 \\
(0.06 \text { to } \\
5.26)\end{array}$ & $\begin{array}{l}27 \\
(1 \mathrm{RCT})\end{array}$ & Very low & $\begin{array}{l}\text { Evidence is based on one study and } \\
\text { imprecision as wide confidence inter } \\
\text { val crossing the line of no effect. Risk } \\
\text { of performance bias as study partic- } \\
\text { ipants and care providers were not } \\
\text { blinded }\end{array}$ \\
\hline
\end{tabular}

\section{Pregnancy-in- duced hyper- tension}

\begin{tabular}{|c|c|c|c|c|c|c|}
\hline $\begin{array}{l}\text { Han } 2017 \\
\text { Ethnic specific } \\
\text { diet versus stan- } \\
\text { dard healthy diet } \\
\text { Pregnancy-in- } \\
\text { duced hyper- } \\
\text { tension }\end{array}$ & $\begin{array}{l}100 \text { per } \\
1000\end{array}$ & $\begin{array}{l}33 \text { per } 1000 \\
\text { (2 to } 732 \text { ) }\end{array}$ & $\begin{array}{l}\text { RR } 0.33 \\
(0.02 \text { to } \\
7.32)\end{array}$ & $\begin{array}{l}20 \\
(1 \mathrm{RCT})\end{array}$ & Very low & $\begin{array}{l}\text { Evidence is based on one study and } \\
\text { imprecision as wide confidence inter- } \\
\text { val crossing the line of no effect. Risk } \\
\text { of performance bias as study partic- } \\
\text { ipants and care providers were not } \\
\text { blinded and reporting bias as out- } \\
\text { comes were reported in figures with } \\
\text { no variance measures and no access } \\
\text { to the study protocol }\end{array}$ \\
\hline
\end{tabular}

\begin{tabular}{|c|c|c|c|c|c|c|}
\hline $\begin{array}{l}\text { Brown } 2017 d \\
\text { Insulin regimen A } \\
\text { versus B } \\
\text { Pregnancy-in- } \\
\text { duced hyper- } \\
\text { tension }\end{array}$ & 80 per 1000 & $\begin{array}{l}88 \text { per } 1000 \\
(41 \text { to } 193)\end{array}$ & $\begin{array}{l}\text { RR } 1.11 \\
(0.51 \text { to } \\
2.42)\end{array}$ & $\begin{array}{l}274 \\
(1 \mathrm{RCT})\end{array}$ & Low & $\begin{array}{l}\text { Twice daily versus four times daily. } \\
\text { Downgraded for imprecision (single } \\
\text { study, low event rates, wide confi- } \\
\text { dence intervals) }\end{array}$ \\
\hline $\begin{array}{l}\text { Brown 2017a } \\
\text { Glibenclamide } \\
\text { versus placebo } \\
\text { Severe hyper- } \\
\text { tension or pre- } \\
\text { eclampsia }\end{array}$ & 65 per 1000 & $\begin{array}{l}79 \text { per } 1000 \\
\text { (38 to } 165)\end{array}$ & $\begin{array}{l}\text { RR } 1.23 \\
(0.59 \text { to } \\
2.56)\end{array}$ & $\begin{array}{l}375 \\
(1 \mathrm{RCT})\end{array}$ & Low & $\begin{array}{l}\text { Evidence is based on one study and } \\
\text { imprecision as wide confidence inter- } \\
\text { val crossing the line of no effect }\end{array}$ \\
\hline $\begin{array}{l}\text { Han } 2017 \\
\text { Low-moderate } \\
\text { versus moder- } \\
\text { ate-high GI diet } \\
\text { Severe hyper- } \\
\text { tension or pre- } \\
\text { eclampsia }\end{array}$ & 21 per 1000 & $\begin{array}{l}21 \text { per } 1000 \\
\text { ( } 2 \text { to } 333)\end{array}$ & $\begin{array}{l}\text { RR } 1.02 \\
(0.07 \text { to } \\
15.86)\end{array}$ & $\begin{array}{l}95 \\
(1 \mathrm{RCT})\end{array}$ & Very low & $\begin{array}{l}\text { "Evidence is based on one study in } \\
\text { China. Study results may not be gen- } \\
\text { eralisable to other populations. Im- } \\
\text { precision as wide confidence interval } \\
\text { crossing the line of no effect with few } \\
\text { events and small sample size." }\end{array}$ \\
\hline $\begin{array}{l}\text { Raman } 2017 \\
\text { Telemedicine } \\
\text { versus standard } \\
\text { care for glucose } \\
\text { monitoring } \\
\text { Pregnancy-in- } \\
\text { duced hyper- } \\
\text { tension or pre- } \\
\text { eclampsia }\end{array}$ & 58 per 1000 & $\begin{array}{l}87 \text { per } 1000 \\
(40 \text { to } 187 \text { ) }\end{array}$ & $\begin{array}{l}\text { RR } 1.49 \\
(0.69 \text { to } \\
3.20)\end{array}$ & $\begin{array}{l}275 \\
\text { (4 RCTs) }\end{array}$ & Very low & $\begin{array}{l}\text { Downgraded for study limitations } \\
\text { (potentially or very serious design } \\
\text { limitations) and imprecision (wide } \\
\text { confidence intervals, small sample } \\
\text { size and few events) }\end{array}$ \\
\hline
\end{tabular}


Table 7. GRADE Summary of findings table - Maternal (Continued)

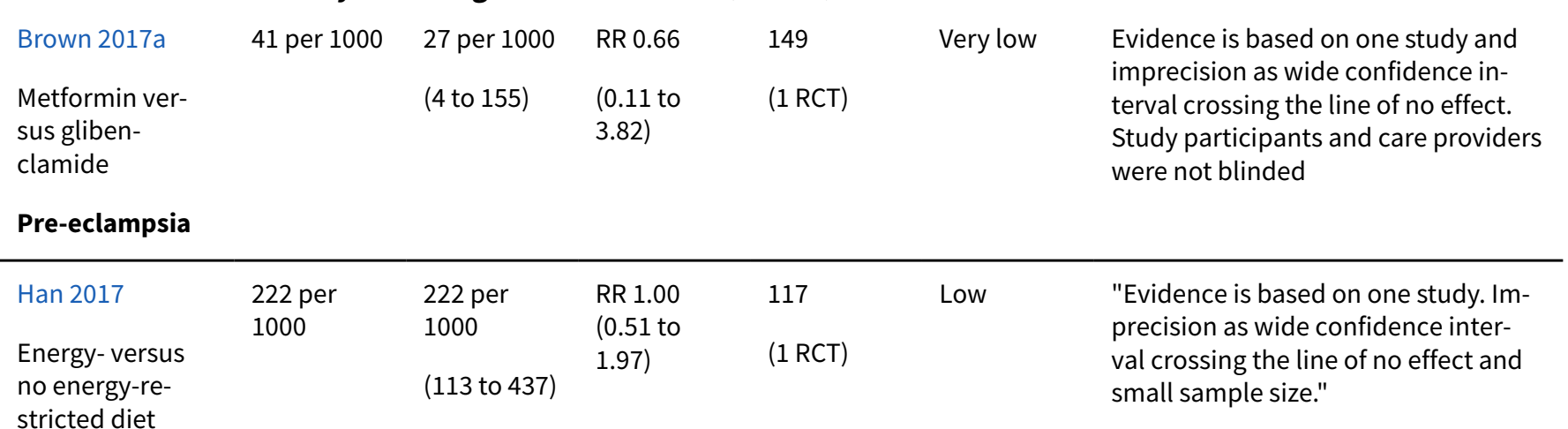

Pre-eclampsia

\begin{tabular}{|c|c|c|c|c|c|c|}
\hline $\begin{array}{l}\text { Han } 2017 \\
\text { DASH }{ }^{1} \text { diet ver- } \\
\text { sus control diet }\end{array}$ & 74 per 1000 & $\begin{array}{l}74 \text { per } 1000 \\
(0.31 \text { to } \\
240)\end{array}$ & $\begin{array}{l}\text { RR } 1.00 \\
(0.31 \text { to } \\
3.26)\end{array}$ & $\begin{array}{l}136 \\
\text { (3 RCTs) }\end{array}$ & Moderate & $\begin{array}{l}\text { Imprecision as wide confidence inter- } \\
\text { val crossing the line of no effect }\end{array}$ \\
\hline
\end{tabular}

sus control diet

macronutrient

contents

Pre-eclampsia

\begin{tabular}{|c|c|c|c|c|c|c|}
\hline $\begin{array}{l}\text { Han } 2017 \\
\text { High- versus low- } \\
\text { unsaturated fat } \\
\text { diet with match- } \\
\text { ing calories } \\
\text { Pre-eclampsia }\end{array}$ & $\begin{array}{l}\text { See com- } \\
\text { ment }\end{array}$ & $\begin{array}{l}\text { see com- } \\
\text { ment }\end{array}$ & $\begin{array}{l}\text { RR Not es- } \\
\text { timable }\end{array}$ & $\begin{array}{l}27 \\
(1 \mathrm{RCT})\end{array}$ & Low & $\begin{array}{l}\text { Evidence is based on one study. Risk } \\
\text { of performance bias as study partic- } \\
\text { ipants and care providers were not } \\
\text { blinded. Further risk of bias as both } \\
\text { groups of participants were unbal- } \\
\text { anced for BMI at baseline. There were } \\
\text { no events in both groups }\end{array}$ \\
\hline
\end{tabular}

\begin{tabular}{|c|c|c|c|c|c|c|}
\hline $\begin{array}{l}\text { Han } 2017 \\
\text { Soy- versus no } \\
\text { soy-protein diet } \\
\text { Pre-eclampsia }\end{array}$ & 29 per 1000 & $\begin{array}{l}59 \text { per } 1000 \\
\text { (6 to } 619)\end{array}$ & $\begin{array}{l}\text { RR } 2.00 \\
(0.19 \text { to } \\
21.03)\end{array}$ & $\begin{array}{l}68 \\
(1 \mathrm{RCT})\end{array}$ & Very low & $\begin{array}{l}\text { Evidence is based on one study. Im- } \\
\text { precision as wide confidence inter- } \\
\text { val crossing the line of no effect. Risk } \\
\text { of performance bias, as participants } \\
\text { and personnel were not blinded }\end{array}$ \\
\hline $\begin{array}{l}\text { Brown 2017b } \\
\text { Lifestyle inter- }\end{array}$ & $\begin{array}{l}129 \text { per } \\
1000\end{array}$ & $\begin{array}{l}90 \text { per } 1000 \\
\text { (51 to } 157 \text { ) }\end{array}$ & $\begin{array}{l}\text { RR } 0.70 \\
(0.40 \text { to } \\
1.22)\end{array}$ & $\begin{array}{l}2796 \\
\text { (4 RCTs) }\end{array}$ & Low & $\begin{array}{l}\text { "Evidence of inconsistency with } 1^{2}> \\
70 \% \text { downgraded two levels." }\end{array}$ \\
\hline
\end{tabular}

vention versus

usual care or diet

alone

\section{Pre-eclampsia}

\begin{tabular}{|c|c|c|c|c|c|c|}
\hline $\begin{array}{l}\text { Brown 2017c } \\
\text { Exercise versus } \\
\text { control } \\
\text { Pre-eclampsia }\end{array}$ & 43 per 1000 & $\begin{array}{l}13 \text { per } 1000 \\
\text { (0 to } 308)\end{array}$ & $\begin{array}{l}\text { RR } 0.31 \\
(0.01 \text { to } \\
7.09)\end{array}$ & $\begin{array}{l}48 \\
\text { (2 RCTs) }\end{array}$ & Low & $\begin{array}{l}\text { "Wide confidence intervals crossing } \\
\text { the line of no effect and low event } \\
\text { rates with a small sample size are } \\
\text { suggestive of imprecision and lack of } \\
\text { clarity for most items related to risk } \\
\text { of bias." }\end{array}$ \\
\hline Han 2012 & 21 per 1000 & $\begin{array}{l}57 \text { per } 1000 \\
(5 \text { to } 619)\end{array}$ & $\begin{array}{l}\text { RR } 2.74 \\
(0.26 \text { to } \\
29.07)\end{array}$ & $\begin{array}{l}83 \\
(1 \mathrm{RCT})\end{array}$ & Low & $\begin{array}{l}\text { Evidence is based on one small study } \\
\text { with few events and serious design } \\
\text { limitations and imprecision with wide }\end{array}$ \\
\hline
\end{tabular}


Table 7. GRADE Summary of findings table - Maternal (Continued)

Intensive man-

agement versus

routine care

\section{Pre-eclampsia}

\begin{tabular}{|c|c|c|c|c|c|c|}
\hline $\begin{array}{l}\text { Raman } 2017 \\
\text { Self- versus pe- } \\
\text { riodic-glucose } \\
\text { monitoring } \\
\text { Pre-eclampsia }\end{array}$ & 74 per 1000 & $\begin{array}{l}13 \text { per } 1000 \\
(139 \text { to } 519)\end{array}$ & $\begin{array}{l}\text { RR } 0.18 \\
(0.01 \text { to } \\
3.49) \\
\text { was report- } \\
\text { ed as RR } \\
0.17 \text { in text } \\
\text { of review } \\
\text { but in for- } \\
\text { est plot it is } \\
\text { RR } 0.18\end{array}$ & $\begin{array}{l}58 \\
(1 \mathrm{RCT})\end{array}$ & Very low & $\begin{array}{l}\text { Evidence is based on one small study } \\
\text { and risk of performance bias as study } \\
\text { participants and care providers were } \\
\text { not blinded. All other risk of bias as- } \\
\text { sessments are unclear. Wide confi- } \\
\text { dence interval crossing the line of no } \\
\text { effect }\end{array}$ \\
\hline
\end{tabular}

\begin{tabular}{|c|c|c|c|c|c|c|}
\hline $\begin{array}{l}\text { Raman } 2017 \\
\text { Post- versus pre- } \\
\text { prandial glucose } \\
\text { monitoring }\end{array}$ & 61 per 1000 & $\begin{array}{l}61 \text { per } 1000 \\
\text { (9 to } 405 \text { ) }\end{array}$ & $\begin{array}{l}\text { RR } 1.00 \\
(0.15 \text { to } \\
6.68)\end{array}$ & $\begin{array}{l}66 \\
(1 \mathrm{RCT})\end{array}$ & Very low & $\begin{array}{l}\text { Evidence downgraded for study lim- } \\
\text { itations and imprecision (wide confi- } \\
\text { dence intervals crossing the line of no } \\
\text { effect; single trial and small sample } \\
\text { size) }\end{array}$ \\
\hline
\end{tabular}

Pre-eclampsia

\begin{tabular}{|c|c|c|c|c|c|c|}
\hline $\begin{array}{l}\text { Brown 2017d } \\
\text { Insulin versus }\end{array}$ & 77 per 1000 & $\begin{array}{l}88 \text { per } 1000 \\
(66 \text { to } 117)\end{array}$ & $\begin{array}{l}\text { RR } 1.14 \\
(0.86 \text { to } \\
1.52)\end{array}$ & $\begin{array}{l}2060 \\
(10 \text { RCTs) }\end{array}$ & Moderate & $\begin{array}{l}\text { Evidence downgraded for study limi- } \\
\text { tations }\end{array}$ \\
\hline
\end{tabular}

oral therapy

Pre-eclampsia

\begin{tabular}{|c|c|c|c|c|c|c|}
\hline $\begin{array}{l}\text { Brown 2017d } \\
\text { Insulin type A } \\
\text { versus B } \\
\text { Pre-eclampsia }\end{array}$ & No events & No events & $\begin{array}{l}\text { Not es- } \\
\text { timable }\end{array}$ & $\begin{array}{l}320 \\
(1 \mathrm{RCT})\end{array}$ & Low & $\begin{array}{l}\text { There were no events of pre-eclamp- } \\
\text { sia reported in either group. } \\
\text { Evidence was downgraded for study } \\
\text { limitations and imprecision (single } \\
\text { trial, no events) }\end{array}$ \\
\hline $\begin{array}{l}\text { Han } 2017 \\
\text { Low-moderate } \\
\text { versus moder- } \\
\text { ate-high GI diet } \\
\text { Eclampsia }\end{array}$ & 24 per 1000 & $\begin{array}{l}8 \text { per } 1000 \\
(0-195)\end{array}$ & $\begin{array}{l}\text { RR } 0.34 \\
(0.01 \text { to } \\
8.14)\end{array}$ & $\begin{array}{l}83 \\
(1 \mathrm{RCT})\end{array}$ & Very low & $\begin{array}{l}\text { "Evidence is based on one study in } \\
\text { China. Study results may not be gen- } \\
\text { eralisable to other populations. Im- } \\
\text { precision as wide confidence interval } \\
\text { crossing the line of no effect with few } \\
\text { events and small sample size." }\end{array}$ \\
\hline
\end{tabular}

\subsection{Caesarean section}

\begin{tabular}{|c|c|c|c|c|c|c|}
\hline $\begin{array}{l}\text { Biesty } 2018 \\
\text { Induction of } \\
\text { labour versus ex- } \\
\text { pectant manage- } \\
\text { ment }\end{array}$ & $\begin{array}{l}118 \text { per } \\
1000\end{array}$ & $\begin{array}{l}126 \text { per } \\
1000 \\
(76 \text { to } 210)\end{array}$ & $\begin{array}{l}\text { RR } 1.06 \\
(0.64 \text { to } \\
1.77)\end{array}$ & $\begin{array}{l}425 \\
(1 \mathrm{RCT})\end{array}$ & Very low & $\begin{array}{l}\text { Evidence is based on one study with } \\
\text { design limitations and imprecision } \\
\text { with wide confidence intervals cross- } \\
\text { ing the line of no effect }\end{array}$ \\
\hline $\begin{array}{l}\text { Brown 2017a } \\
\text { Glibenclamide } \\
\text { versus placebo }\end{array}$ & $\begin{array}{l}360 \text { per } \\
1000\end{array}$ & $\begin{array}{l}371 \text { per } \\
1000 \\
\text { (285 to } 483)\end{array}$ & $\begin{array}{l}\text { RR } 1.03 \\
(0.79 \text { to } \\
1.34)\end{array}$ & $\begin{array}{l}375 \\
(1 \mathrm{RCT})\end{array}$ & Very low & $\begin{array}{l}\text { "Evidence is based on one study and } \\
93 \% \text { were Hispanic women, results } \\
\text { may not be generalisable to other } \\
\text { populations. There is risk of bias, as } \\
\text { we did not find a published protocol }\end{array}$ \\
\hline
\end{tabular}

Treatments for women with gestational diabetes mellitus: an overview of Cochrane systematic reviews (Review)

Copyright (c) 2018 The Cochrane Collaboration. Published by John Wiley \& Sons, Ltd. 
and there were more outcomes reported in the published paper than were listed in the trial registration document."

\begin{tabular}{|c|c|c|c|c|c|c|}
\hline $\begin{array}{l}\text { Brown } 2017 a \\
\text { Metformin ver- } \\
\text { sus gliben- } \\
\text { clamide }\end{array}$ & $\begin{array}{l}392 \text { per } \\
1000\end{array}$ & $\begin{array}{l}470 \text { per } \\
1000 \\
\text { (325 to } 674 \text { ) }\end{array}$ & $\begin{array}{l}\text { average RR } \\
1.20(0.83 \\
\text { to } 1.72)\end{array}$ & $\begin{array}{l}554 \\
\text { (4 RCTs) }\end{array}$ & Low & $\begin{array}{l}\text { "Three of the four studies were open } \\
\text { label and three of four studies were } \\
\text { unclear for blinding of outcome as- } \\
\text { sessors. Two studies reported addi- } \\
\text { tional outcomes that were not pre- } \\
\text { specified and heterogeneity was } \\
\text { high." }\end{array}$ \\
\hline
\end{tabular}

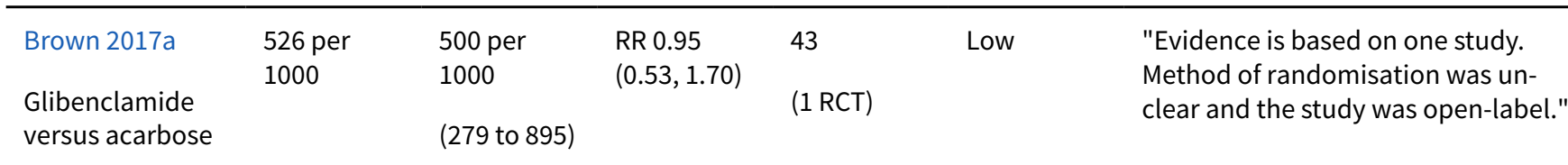

\begin{tabular}{llllll}
\hline Han 2017 & 344 per & 277 per & RR 0.66 & $63(1 \mathrm{RCT})$ & Very low \\
& 1000 & 1000 & $(0.29$ to & \\
Low-moderate & & $(1.47)$ & \\
$\begin{array}{l}\text { versus moder- } \\
\text { ate-high Gl diet }\end{array}$ & & & &
\end{tabular}

"Evidence is based on one study with unclear risk of selection and detection bias and high risk of performance bias. Imprecision as wide confidence interval crossing the line of no effect and small sample size."

\begin{tabular}{llllll}
\hline Han 2017 & 228 per 100 & $\begin{array}{l}255 \text { per } \\
1000\end{array}$ & $\begin{array}{l}\text { RR } 1.12 \\
(0.80 \text { to }\end{array}$ & 420 & Low \\
$\begin{array}{l}\text { Energy- versus } \\
\begin{array}{l}\text { no energy-re- } \\
\text { stricted diet }\end{array}\end{array}$ & & $(2$ RCTs) & \\
& & & &
\end{tabular}
"Design limitations: two studies at unclear risk of selection bias; one study at high risk of performance bias and unclear risk of detection bias. Im- precision with wide confidence inter- vals crossing the line of no effect."

\begin{tabular}{|c|c|c|c|c|}
\hline Han 2017 & 837 per & 444 per & RR 0.53 & 86 \\
\hline $\begin{array}{l}\text { DASH }{ }^{1} \text { diet ver- } \\
\text { sus control diet }\end{array}$ & 1000 & $\begin{array}{l}1000 \\
\text { (310 to } 636)\end{array}$ & $\begin{array}{l}(0.37 \text { to } \\
0.76)\end{array}$ & \\
\hline
\end{tabular}

with matching

macronutrient

contents

\begin{tabular}{|c|c|c|c|c|}
\hline Han 2017 & 278 per & 358 per & RR 1.29 & 179 \\
\hline $\begin{array}{l}\text { Low- versus } \\
\text { high-carbohy- } \\
\text { drate diet }\end{array}$ & 1000 & $\begin{array}{l}1000 \\
\text { (233 to } 553 \text { ) }\end{array}$ & $\begin{array}{l}(0.84 \text { to } \\
1.99)\end{array}$ & (2 RCTs) \\
\hline
\end{tabular}

Downgraded for study limitations (unclear risk of bias for allocation concealment and selective reporting in both trials and additionally in one trial risk of bias for blinding of participants, personnel and outcome assessors) and imprecision (small sample size)

Risk of performance bias as study participants and care providers were not blinded. Additioanlly one study had a high risk of bias for selective reporting as limited data was reported and no access to study protocol

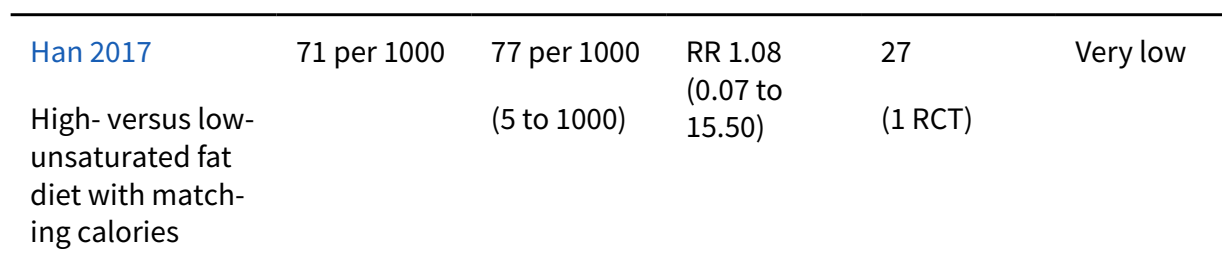

Evidence is based on one study and imprecision as wide confidence interval crossing the line of no effect. Risk of performance bias as study participants and care providers were not blinded. Further risk of bias as both groups of participants were unbalanced for BMI at baseline

\begin{tabular}{|c|c|c|c|c|c|c|}
\hline Han 2017 & $\begin{array}{l}178 \text { per } \\
1000\end{array}$ & $\begin{array}{l}340 \text { per } \\
1000\end{array}$ & RR 1.91 & $\begin{array}{l}92 \\
(1 \mathrm{RCT})\end{array}$ & Very low & $\begin{array}{l}\text { Evidence is based on one study and } \\
\text { imprecision as wide confidence in- } \\
\text { terval crossing the line of no effect. }\end{array}$ \\
\hline
\end{tabular}


Table 7. GRADE Summary of findings table - Maternal (Continued)

Low-GI diet versus high-fibre (162 to 716 )

(0.91 to 4.03
Risk of detection and attrition bias as study outcome assessors were not blinded and incomplete data reported. Baseline for blood glucose concentration were unbalanced between groups

\begin{tabular}{|c|c|c|c|c|c|c|}
\hline $\begin{array}{l}\text { Han } 2017 \\
\text { Diet + diet-relat- } \\
\text { ed behavioural } \\
\text { advice versus di- }\end{array}$ & $\begin{array}{l}260 \text { per } \\
1000\end{array}$ & $\begin{array}{l}203 \text { per } \\
1000 \\
(99 \text { to } 421)\end{array}$ & $\begin{array}{l}\text { RR } 0.78 \\
(0.38 \text { to } \\
1.62)\end{array}$ & $\begin{array}{l}99 \\
(1 \mathrm{RCT})\end{array}$ & Very low & $\begin{array}{l}\text { Evidence is based on one small study } \\
\text { and risk of performance bias as study } \\
\text { participants and care providers were } \\
\text { not blinded }\end{array}$ \\
\hline
\end{tabular}

\begin{tabular}{|c|c|c|c|c|c|c|}
\hline $\begin{array}{l}\text { Han } 2017 \\
\text { Soy-versus no } \\
\text { soy-protein diet }\end{array}$ & $\begin{array}{l}412 \text { per } \\
1000\end{array}$ & $\begin{array}{l}412 \text { per } \\
1000 \\
\text { (235 to } 729)\end{array}$ & $\begin{array}{l}\text { RR } 1.00 \\
(0.57 \text { to } \\
1.77)\end{array}$ & $\begin{array}{l}68 \\
(1 \mathrm{RCT})\end{array}$ & Very low & $\begin{array}{l}\text { Evidence is based on one small stud } \\
\text { and risk of performance bias as stud } \\
\text { participants and care providers were } \\
\text { not blinded }\end{array}$ \\
\hline
\end{tabular}

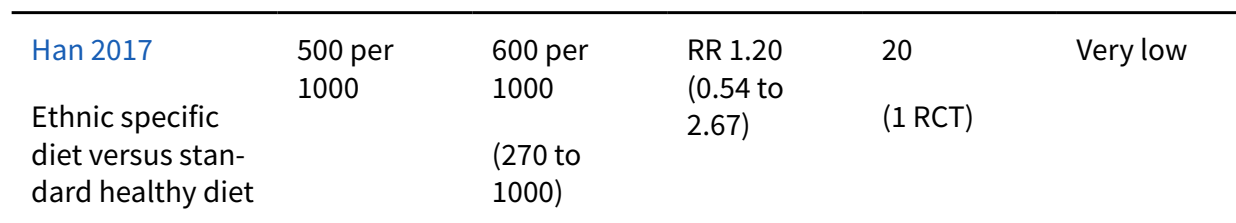

Evidence is based on one study and imprecision as wide confidence interval crossing the line of no effect. Risk of performance bias as study participants and care providers were not blinded and reporting bias as outcomes were reported in figures with no variance measures and no access to the study protocol

\begin{tabular}{|c|c|c|c|c|c|c|}
\hline $\begin{array}{l}\text { Brown 2017b } \\
\text { Lifestyle inter- } \\
\text { vention versus } \\
\text { usual care or diet } \\
\text { alone }\end{array}$ & $\begin{array}{l}380 \text { per } \\
1000\end{array}$ & $\begin{array}{l}342 \text { per } \\
1000 \\
\text { (296 to } 399)\end{array}$ & $\begin{array}{l}\text { RR } 0.90 \\
(0.78 \text { to } \\
1.05)\end{array}$ & $\begin{array}{l}3545 \\
\text { (10 RCTs) }\end{array}$ & Low & $\begin{array}{l}\text { "Evidence of selective reporting in } \\
\text { more than half of the trials reporting } \\
\text { this outcome and evidence of incon- } \\
\text { sistency with } 1^{2}=>50 \% \text { but }<70 \% \text {. } \\
\text { There is some suggestion of asymme- } \\
\text { try observed in the funnel plot." }\end{array}$ \\
\hline $\begin{array}{l}\text { Brown 2017c } \\
\text { Exercise versus } \\
\text { control }\end{array}$ & $\begin{array}{l}319 \text { per } \\
1000\end{array}$ & $\begin{array}{l}274 \text { per } \\
1000\end{array}$ & $\begin{array}{l}\text { RR } 0.86 \\
(0.63 \text { to } \\
1.16)\end{array}$ & $\begin{array}{l}316 \\
\text { (5 RCTs) }\end{array}$ & Moderate & $\begin{array}{l}\text { "Lack of clarity for most items related } \\
\text { to risk of bias." }\end{array}$ \\
\hline $\begin{array}{l}\text { Han } 2012 \\
\text { Intensive man- } \\
\text { agement versus } \\
\text { routine care }\end{array}$ & $\begin{array}{l}249 \text { per } \\
1000\end{array}$ & $\begin{array}{l}232 \text { per } \\
1000 \\
\text { (169 to } 316)\end{array}$ & $\begin{array}{l}\text { RR } 0.93 \\
(0.68 \text { to } \\
1.27)\end{array}$ & $\begin{array}{l}509 \\
\text { (3 RCTs) }\end{array}$ & Very low & $\begin{array}{l}\text { Evidence based on three RCTs with } \\
\text { serious/very serious design limita- } \\
\text { tions and imprecision with wide con- } \\
\text { fidence intervals crossing the line of } \\
\text { no effect }\end{array}$ \\
\hline $\begin{array}{l}\text { Martis } 2016 a \\
\text { Strict intensi- } \\
\text { ty² of glycaemic } \\
\text { control versus } \\
\text { less strict gly- } \\
\text { caemic control }\end{array}$ & $\begin{array}{l}244 \text { per } \\
1000\end{array}$ & $\begin{array}{l}330 \text { per } \\
1000 \\
\text { (203 to } 532 \text { ) }\end{array}$ & $\begin{array}{l}\text { RR } 1.35 \\
(0.83 \text { to } \\
2.18)\end{array}$ & $\begin{array}{l}171 \\
(1 \mathrm{RCT})\end{array}$ & Very low & $\begin{array}{l}\text { "Evidence based on one trial that was } \\
\text { only published in conference abstract } \\
\text { form. } \\
\text { Lack of detail to make a judgement } \\
\text { about random sequence generation, } \\
\text { allocation concealment, attrition bias } \\
\text { and reporting bias. Open label study } \\
\text { and no details regarding blinding of } \\
\text { outcome assessors was reported. } \\
\text { Wide confidence intervals that cross } \\
\text { the line of no effect." }\end{array}$ \\
\hline
\end{tabular}


Table 7. GRADE Summary of findings table - Maternal (Continued)

\begin{tabular}{|c|c|c|c|c|c|c|}
\hline Raman 2017 & 444 per & 467 per & Average RR & 478 & Very low & Downgraded for study limitations \\
\hline $\begin{array}{l}\text { Telemedicine } \\
\text { versus standard } \\
\text { care for glucose }\end{array}$ & 1000 & $\begin{array}{l}1000 \\
\text { (320 to } 680 \text { ) }\end{array}$ & $\begin{array}{l}1.05(0.72 \\
\text { to } 1.53)\end{array}$ & (5 RCTs) & & $\begin{array}{l}\text { (potentially or very serious desigr } \\
\text { limitations) and imprecision (wid } \\
\text { confidence intervals) and inconsi } \\
\text { tency }\left(1^{2}=62 \%\right)\end{array}$ \\
\hline
\end{tabular}

\begin{tabular}{|c|c|c|c|c|c|c|}
\hline $\begin{array}{l}\text { Raman } 2017 \\
\text { Self- versus pe- } \\
\text { riodic-glucose } \\
\text { monitoring }\end{array}$ & $\begin{array}{l}228 \text { per } \\
1000\end{array}$ & $\begin{array}{l}270 \text { per } \\
1000 \\
(139 \text { to } 519)\end{array}$ & $\begin{array}{l}\text { RR } 1.18 \\
(0.61 \text { to } \\
2.27)\end{array}$ & $\begin{array}{l}400 \\
\text { (2 RCTs) }\end{array}$ & Low & $\begin{array}{l}\text { Evidence downgraded for study lim- } \\
\text { itations and imprecision (wide confi- } \\
\text { dence intervals crossing the line of no } \\
\text { effect) }\end{array}$ \\
\hline
\end{tabular}

\begin{tabular}{|c|c|c|c|c|c|c|}
\hline $\begin{array}{l}\text { Raman } 2017 \\
\text { Continuous- ver- } \\
\text { sus self-monitor- } \\
\text { ing }\end{array}$ & $\begin{array}{l}500 \text { per } \\
1000\end{array}$ & $\begin{array}{l}455 \text { per } \\
1000 \\
(340 \text { to } 600)\end{array}$ & $\begin{array}{l}\text { RR } 0.91 \\
(0.68 \text { to } \\
1.20)\end{array}$ & $\begin{array}{l}179 \\
\text { (2 RCTs) }\end{array}$ & Very low & $\begin{array}{l}\text { Evidence downgraded for study lim- } \\
\text { itations and imprecision (wide confi- } \\
\text { dence intervals crossing the line of no } \\
\text { effect and small sample sizes) }\end{array}$ \\
\hline
\end{tabular}

\begin{tabular}{|c|c|c|c|c|c|c|}
\hline $\begin{array}{l}\text { Raman } 2017 \\
\text { Post-prandial } \\
\text { versus pre-pran- } \\
\text { dial monitoring }\end{array}$ & $\begin{array}{l}394 \text { per } \\
1000\end{array}$ & $\begin{array}{l}244 \text { per } \\
1000 \\
\text { (114 to } 508)\end{array}$ & $\begin{array}{l}\text { RR } 0.62 \\
(0.29 \text { to } \\
1.29)\end{array}$ & $\begin{array}{l}66 \\
(1 \mathrm{RCT})\end{array}$ & Very low & $\begin{array}{l}\text { Evidence downgraded for study lim- } \\
\text { itations and imprecision (wide confi- } \\
\text { dence intervals crossing the line of no } \\
\text { effect; single trial and small sample } \\
\text { size) }\end{array}$ \\
\hline $\begin{array}{l}\text { Brown 2017d } \\
\text { Insulin versus } \\
\text { oral therapy }\end{array}$ & $\begin{array}{l}394 \text { per } \\
1000\end{array}$ & $\begin{array}{l}405 \text { per } \\
1000 \\
\text { (366 to } 449 \text { ) }\end{array}$ & $\begin{array}{l}\text { RR } 1.03 \\
(0.93 \text { to } \\
1.14)\end{array}$ & $\begin{array}{l}1988 \\
\text { (17 RCTs) }\end{array}$ & Moderate & $\begin{array}{l}\text { Evidence downgraded for study limi- } \\
\text { tations (lack of blinding) }\end{array}$ \\
\hline $\begin{array}{l}\text { Brown 2017d } \\
\text { Insulin type A } \\
\text { versus B }\end{array}$ & $\begin{array}{l}763 \text { per } \\
1000\end{array}$ & $\begin{array}{l}763 \text { per } \\
1000 \\
\text { ( } 695 \text { to } 832 \text { ) }\end{array}$ & $\begin{array}{l}\text { RR } 1.00 ; \\
(0.91 \text { to } \\
1.09)\end{array}$ & $\begin{array}{l}410 \\
\text { (3 RCTs) }\end{array}$ & Moderate & $\begin{array}{l}\text { Evidence downgraded for study limi- } \\
\text { tations (insufficient details) }\end{array}$ \\
\hline $\begin{array}{l}\text { Brown 2017d } \\
\text { Insulin versus di- } \\
\text { et }\end{array}$ & $\begin{array}{l}328 \text { per } \\
1000\end{array}$ & $\begin{array}{l}279 \text { per } \\
1000 \\
\text { (164 to } 466)\end{array}$ & $\begin{array}{l}\text { RR } 0.85 \\
(0.50 \text { to } \\
1.42)\end{array}$ & $\begin{array}{l}133 \\
\text { (2 RCTs) }\end{array}$ & Very low & $\begin{array}{l}\text { Evidence downgraded for study lim- } \\
\text { itations (inadequate randomisation } \\
\text { and allocation concealment, insuf- } \\
\text { ficient details) and imprecision (few } \\
\text { studies and small sample size) }\end{array}$ \\
\hline $\begin{array}{l}\text { Brown 2017d } \\
\text { Insulin versus ex- } \\
\text { ercise }\end{array}$ & $\begin{array}{l}118 \text { per } \\
1000\end{array}$ & $\begin{array}{l}176 \text { per } \\
1000 \\
(34 \text { to } 926)\end{array}$ & $\begin{array}{l}\text { RR } 1.50 ; \\
(0.29 \text { to } \\
7.87)\end{array}$ & $\begin{array}{l}34 \\
(1 \mathrm{RCT})\end{array}$ & Very low & $\begin{array}{l}\text { Evidence downgraded for study lim- } \\
\text { itations (insufficient details) and im- } \\
\text { precision (single small study, wide } \\
\text { confidence intervals) }\end{array}$ \\
\hline $\begin{array}{l}\text { Brown } 2017 d \\
\text { Insulin regimen A } \\
\text { versus B } \\
\text { Twice daily ver- } \\
\text { sus four times } \\
\text { daily } \\
\text { Three times ver- } \\
\text { sus six times dai- } \\
\text { ly }\end{array}$ & $\begin{array}{l}283 \text { per } \\
1000 \\
105 \text { per } \\
1000\end{array}$ & $\begin{array}{l}280 \text { per } \\
1000 \\
(192 \text { to } 407) \\
112 \text { per } \\
1000 \\
(18 \text { to } 707)\end{array}$ & $\begin{array}{l}\text { RR } 0.99 \\
(0.68 \text { to } \\
1.44) \\
\text { RR } 1.06 \\
(0.17 \text { to } \\
6.72)\end{array}$ & $\begin{array}{l}274 \\
(1 \mathrm{RCT}) \\
37 \\
(1 \mathrm{RCT})\end{array}$ & Very low & $\begin{array}{l}\text { Evidence downgraded for study lim- } \\
\text { itations (insufficient details) and im- } \\
\text { precision (single small study, wide } \\
\text { confidence intervals) }\end{array}$ \\
\hline
\end{tabular}

\subsection{Development of type 2 diabetes}

Treatments for women with gestational diabetes mellitus: an overview of Cochrane systematic reviews (Review) 
Table 7. GRADE Summary of findings table - Maternal (Continued)

\begin{tabular}{|c|c|c|c|c|c|c|}
\hline $\begin{array}{l}\text { Han } 2017 \\
\text { High- versus low- } \\
\text { unsaturated fat } \\
\text { diet with match- } \\
\text { ing calories } \\
\text { OGTT }^{3} \text { for diag- } \\
\text { nosis of type } 2 \\
\text { diabetes at one } \\
\text { to two weeks } \\
\text { postpartum }\end{array}$ & $\begin{array}{l}167 \text { per } \\
1000\end{array}$ & $\begin{array}{l}333 \text { per } \\
1000 \\
(75 \text { to } 1000)\end{array}$ & $\begin{array}{l}\text { RR } 2.00 \\
(0.45 \text { to } \\
8.94)\end{array}$ & $\begin{array}{l}24 \\
(1 \mathrm{RCT})\end{array}$ & Very low & $\begin{array}{l}\text { Evidence is based on one study and } \\
\text { imprecision as wide confidence inter- } \\
\text { val crossing the line of no effect. Risk } \\
\text { of performance bias as study partic- } \\
\text { ipants and care providers were not } \\
\text { blinded. Further risk of bias as both } \\
\text { groups of participants were unbal- } \\
\text { anced for BMI at baseline }\end{array}$ \\
\hline
\end{tabular}

\begin{tabular}{|c|c|c|c|c|c|c|}
\hline $\begin{array}{l}\text { Han } 2017 \\
\text { Low-GI diet ver- } \\
\text { sus high fibre } \\
\text { moderate-GI diet } \\
\text { OGTT³ for diag- } \\
\text { nosis of type } \\
\mathbf{2} \text { diabetes at } \\
\text { three months }\end{array}$ & 80 per 1000 & $\begin{array}{l}61 \text { per } 1000 \\
\text { (9 to } 401 \text { ) }\end{array}$ & $\begin{array}{l}\text { RR } 0.76 \text {, } \\
(0.11 \text { to } \\
5.01)\end{array}$ & $\begin{array}{l}58 \\
(1 \mathrm{RCT})\end{array}$ & Very low & $\begin{array}{l}\text { Imprecision - evidence is based on } \\
\text { one study and wide confidence in- } \\
\text { terval crossing the line of no effect. } \\
\text { Risk of detection and attrition bias } \\
\text { as study outcome assessors were not } \\
\text { blinded and incomplete data report- } \\
\text { ed. Baseline for blood glucose con- } \\
\text { centration were unbalanced between } \\
\text { groups }\end{array}$ \\
\hline
\end{tabular}

postpartum

Han 2017
High- versus low-
unsaturated fat
diet with match-
ing calories

OGTT' ${ }^{\text {for diag- }}$ -
nosis of type 2
diabetes at four
to 13 months
postpartum

$\begin{array}{lllll}333 \text { per } & 333 \text { per } & \text { RR } 1.00 & 6 & \text { Very low } \\ 1000 & 1000 & (0.10 \text { to } & (1 \mathrm{RCT}) & \\ & (33 \text { to } 1000) & 9.61) & & \end{array}$
Evidence is based on one study and imprecision as wide confidence inter- val crossing the line of no effect. Risk of performance bias as study partic- ipants and care providers were not blinded. Further risk of bias as both groups of participants were unbal- anced for BMI at baseline

\begin{tabular}{|c|c|c|c|c|c|c|}
\hline $\begin{array}{l}\text { Brown 2017b } \\
\text { Lifestyle inter- } \\
\text { vention versus } \\
\text { usual care or diet } \\
\text { alone } \\
\text { Test and time } \\
\text { frame not de- } \\
\text { fined }\end{array}$ & 83 per 1000 & $\begin{array}{l}81 \text { per } 1000 \\
\text { (45 to } 146)\end{array}$ & $\begin{array}{l}\text { RR } 0.98 \\
(0.54 \text { to } \\
1.76)\end{array}$ & $\begin{array}{l}486 \\
(2 \mathrm{RCTs})\end{array}$ & Low & $\begin{array}{l}\text { "Evidence of risk of bias with one of } \\
\text { the two studies not blinding partici- } \\
\text { pants/researcher and evidence of risk } \\
\text { of bias for attrition." }\end{array}$ \\
\hline $\begin{array}{l}\text { Brown } 2017 d \\
\text { Insulin versus } \\
\text { oral therapy } \\
\text { Up to one-year } \\
\text { postpartum }\end{array}$ & 52 per 1000 & $\begin{array}{l}73 \text { per } 1000 \\
\text { (42 to } 128)\end{array}$ & $\begin{array}{l}\text { RR } 1.39 \\
(0.80 \text { to } \\
2.44)\end{array}$ & $\begin{array}{l}754 \\
(2 \mathrm{RCTs})\end{array}$ & Moderate & $\begin{array}{l}\text { Evidence downgraded for study limi- } \\
\text { tations (blinding and insufficient de- } \\
\text { tails to judge randomisation and allo- } \\
\text { cation concealment) }\end{array}$ \\
\hline $\begin{array}{l}\text { Brown 2017d } \\
\text { Insulin versus di- } \\
\text { et }\end{array}$ & $\begin{array}{l}345 \text { per } \\
1000\end{array}$ & $\begin{array}{l}338 \text { per } \\
1000 \\
(272 \text { to } 417)\end{array}$ & $\begin{array}{l}\text { RR 0.98; } \\
(0.79 \text { to } \\
1.21)\end{array}$ & $\begin{array}{l}653 \\
(2 \mathrm{RCTs})\end{array}$ & Very low & $\begin{array}{l}\text { Evidence downgraded for study lim- } \\
\text { itations (inadequate randomisation } \\
\text { and allocation concealment, insuf- }\end{array}$ \\
\hline
\end{tabular}


Table 7. GRADE Summary of findings table - Maternal (Continued)

Up to 15 years

postpartum

ficient details) and imprecision (few studies and small sample size)

\subsection{Perineal trauma}

\begin{tabular}{|c|c|c|c|c|c|c|}
\hline $\begin{array}{l}\text { Biesty } 2018 \\
\text { Induction of } \\
\text { labour versus ex- } \\
\text { pectant manage- } \\
\text { ment }\end{array}$ & $\begin{array}{l}263 \text { per } \\
1000\end{array}$ & $\begin{array}{l}268 \text { per } \\
1000 \\
\text { (192 to } 376)\end{array}$ & $\begin{array}{l}\text { RR } 1.02 \\
(0.73 \text { to } \\
1.43)\end{array}$ & $\begin{array}{l}373 \\
(1 \mathrm{RCT})\end{array}$ & Low & $\begin{array}{l}\text { Evidence was downgraded for stud } \\
\text { limitations and imprecision (single } \\
\text { study). } \\
\text { Outcome measured as 'intact per- } \\
\text { ineum' }\end{array}$ \\
\hline
\end{tabular}

$\begin{array}{llllll}\text { Brown 2017a } & 5 \text { per } 1000 & \begin{array}{l}5 \text { per } 1000 \\ (0 \text { to } 84)\end{array} & \begin{array}{l}\text { RR 0.98 } \\ (0.06 \text { to } \\ \text { 15.62) }\end{array} & \begin{array}{l}375 \\ (1 \mathrm{RCT})\end{array} & \text { Very low } \\ \begin{array}{l}\text { Glibenclamide } \\ \text { versus placebo }\end{array} & & & & \end{array}$

"Evidence is based on one study and 93\% were Hispanic women, results may not be generalisable to other populations. We did not find a published protocol and there were more outcomes reported in the published paper than were listed in the trial registration document".

"There are wide confidence intervals crossing the line of no effect and low event rates suggestive of imprecision. Event rates were low $1 / 189$ for anti-diabetic pharmacological therapy and $1 / 186$ in the control (placebo) group."

\begin{tabular}{|c|c|c|c|c|c|c|}
\hline $\begin{array}{l}\text { Brown } 2017 a \\
\text { Metformin ver- } \\
\text { sus gliben- } \\
\text { clamide }\end{array}$ & 6 per 1000 & $\begin{array}{l}11 \text { per } 1000 \\
\text { (1 to } 81 \text { ) }\end{array}$ & $\begin{array}{l}\text { RR } 1.67 \\
(0.22 \text { to } \\
12.52)\end{array}$ & $\begin{array}{l}308 \\
\text { (2 RCTs) }\end{array}$ & Low & $\begin{array}{l}\text { "All studies were open label and wide } \\
\text { confidence intervals along with low } \\
\text { event rates suggest imprecision. Low } \\
\text { event rates }(2 / 154 \text { for metformin and } \\
1 / 154 \text { for glibenclamide." }\end{array}$ \\
\hline
\end{tabular}

\begin{tabular}{|c|c|c|c|c|c|c|}
\hline $\begin{array}{l}\text { Brown 2017b } \\
\text { Lifestyle inter- } \\
\text { vention versus } \\
\text { usual care or diet } \\
\text { alone }\end{array}$ & $\begin{array}{l}498 \text { per } \\
1000\end{array}$ & $\begin{array}{l}518 \text { per } \\
1000 \\
\text { (463 to } 588 \text { ) }\end{array}$ & $\begin{array}{l}\text { RR } 1.04 \\
(0.93 \text { to } \\
1.18)\end{array}$ & $\begin{array}{l}1000 \\
(1 \mathrm{RCT})\end{array}$ & Moderate & $\begin{array}{l}\text { "Imprecision - evidence is based on a } \\
\text { single trial." }\end{array}$ \\
\hline
\end{tabular}

\begin{tabular}{|c|c|c|c|c|c|c|}
\hline $\begin{array}{l}\text { Raman } 2017 \\
\text { Continuous- ver- } \\
\text { sus self-monitor- } \\
\text { ing }\end{array}$ & $\begin{array}{l}\text { See com- } \\
\text { ment }\end{array}$ & $\begin{array}{l}\text { See com- } \\
\text { ment }\end{array}$ & - & $\begin{array}{l}73 \\
(1 \mathrm{RCT})\end{array}$ & Very low & $\begin{array}{l}\text { One included trial reported "There } \\
\text { were no statistically significant differ- } \\
\text { ences between the two groups... in } \\
\text { maternal lacerations." } \\
\text { Evidence downgraded for study limi- } \\
\text { tations and imprecision (single trial, } \\
\text { small sample size) }\end{array}$ \\
\hline $\begin{array}{l}\text { Raman } 2017 \\
\text { Post- versus pre- } \\
\text { prandial glucose } \\
\text { monitoring }\end{array}$ & $\begin{array}{l}242 \text { per } \\
1000\end{array}$ & $\begin{array}{l}92 \text { per } 1000 \\
(27 \text { to } 313)\end{array}$ & $\begin{array}{l}\text { RR } 0.38 \\
(0.11 \text { to } \\
1.29)\end{array}$ & $\begin{array}{l}66 \\
(1 \mathrm{RCT})\end{array}$ & Very low & $\begin{array}{l}\text { Evidence downgraded for study lim- } \\
\text { itations (insufficient details and lack } \\
\text { of blinding). } \\
\text { imprecision (single small study, low } \\
\text { event rates, wide confidence inter- } \\
\text { vals) }\end{array}$ \\
\hline
\end{tabular}

\subsection{Postnatal weight retention or return to pre-pregnancy weight}

Treatments for women with gestational diabetes mellitus: an overview of Cochrane systematic reviews (Review) 
Table 7. GRADE Summary of findings table - Maternal (Continued)

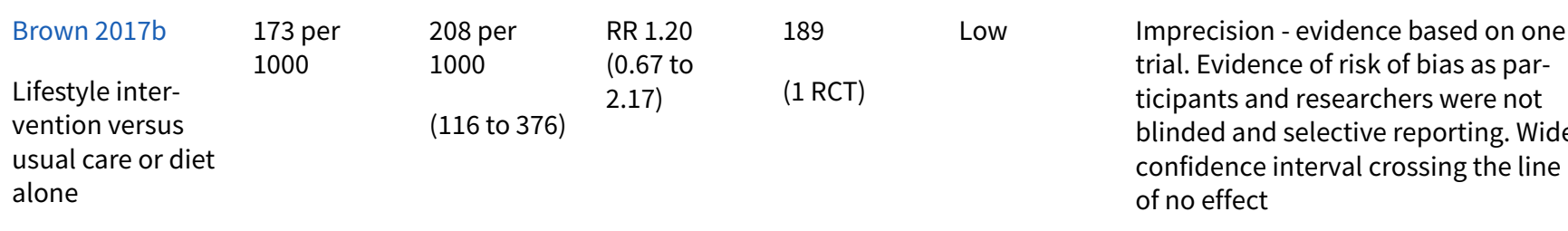

\section{At six weeks} postpartum

\begin{tabular}{|c|c|c|c|c|c|c|}
\hline $\begin{array}{l}\text { Han } 2017 \\
\text { Low-GI diet ver- } \\
\text { sus high fibre } \\
\text { moderate-GI diet } \\
\text { At three months } \\
\text { postpartum }\end{array}$ & $\begin{array}{l}217 \text { per } \\
1000\end{array}$ & $\begin{array}{l}250 \text { per } \\
1000 \\
\text { (93 to } 667 \text { ) }\end{array}$ & $\begin{array}{l}\text { RR } 1.15 \\
(0.43 \text { to } \\
3.07)\end{array}$ & $\begin{array}{l}555 \\
(1 \mathrm{RCT})\end{array}$ & Very low & $\begin{array}{l}\text { Imprecision - evidence based on one } \\
\text { trial. Evidence of risk of bias as par- } \\
\text { ticipants and researchers were not } \\
\text { blinded and attrition bias for incom- } \\
\text { plete data. Wide confidence interval } \\
\text { crossing the line of no effect }\end{array}$ \\
\hline $\begin{array}{l}\text { Brown 2017b } \\
\text { Lifestyle inter- } \\
\text { vention versus } \\
\text { usual care or diet } \\
\text { alone }\end{array}$ & $\begin{array}{l}239 \text { per } \\
1000\end{array}$ & $\begin{array}{l}379 \text { per } \\
1000 \\
\text { ( } 236 \text { to } 613 \text { ) }\end{array}$ & $\begin{array}{l}\text { RR } 1.59 \\
(0.99 \text { to } \\
2.57)\end{array}$ & $\begin{array}{l}159 \\
(1 \mathrm{RCT})\end{array}$ & Very low & $\begin{array}{l}\text { Imprecision - evidence based on one } \\
\text { trial. Evidence of risk of bias as par- } \\
\text { ticipants and researchers were not } \\
\text { blinded and selective reporting evi- } \\
\text { dent. Wide confidence interval cross- } \\
\text { ing the line of no effect }\end{array}$ \\
\hline
\end{tabular}

\section{At seven \\ months post- \\ partum}

\begin{tabular}{|c|c|c|c|c|c|c|}
\hline $\begin{array}{l}\text { Brown 2017b } \\
\text { Lifestyle inter- } \\
\text { vention versus } \\
\text { usual care or diet } \\
\text { alone }\end{array}$ & $\begin{array}{l}214 \text { per } \\
1000\end{array}$ & $\begin{array}{l}375 \text { per } \\
1000 \\
\text { (225 to } 621)\end{array}$ & $\begin{array}{l}\text { RR } 1.75 \\
(1.05 \text { to } \\
2.90)\end{array}$ & $\begin{array}{l}156 \\
(1 \mathrm{RCT})\end{array}$ & Low & $\begin{array}{l}\text { "Imprecision - evidence is based on } \\
\text { a single trial. Evidence of risk of bias } \\
\text { as unclear allocation concealment } \\
\text { and no blinding of participants and } \\
\text { researchers." }\end{array}$ \\
\hline
\end{tabular}

\section{At 12 months postpartum}

\begin{tabular}{|c|c|c|c|c|c|c|}
\hline $\begin{array}{l}\text { Brown } 2017 \mathrm{c} \\
\text { Exercise versus } \\
\text { control } \\
\text { At follow-up } \\
\text { (timing not de- } \\
\text { fined) }\end{array}$ & $\begin{array}{l}\text { The ma- } \\
\text { ternal BMI } \\
\text { (follow-up) } \\
\mathrm{kg} / \mathrm{m}^{2} \text { was } \\
0\end{array}$ & $\begin{array}{l}\text { MD } 0.11 \\
\text { higher } \\
\text { (-1.04 low- } \\
\text { er to } 1.26 \\
\text { higher) }\end{array}$ & $\begin{array}{l}\text { MD } 0.11 \\
(-1.04 \text { to } \\
1.26)\end{array}$ & $\begin{array}{l}254 \\
\text { (3 RCTs) }\end{array}$ & High & $\begin{array}{l}\text { No evidence of significant risk of bias, } \\
\text { inconsistency or imprecision }\end{array}$ \\
\hline $\begin{array}{l}\text { Brown } 2017 d \\
\text { Insulin versus } \\
\text { oral therapy } \\
\text { Six to eight } \\
\text { weeks postpar- } \\
\text { tum } \\
\text { One year post- } \\
\text { partum }\end{array}$ & $\begin{array}{l}\text { The mean } \\
\text { weight at } 6 \\
\text { to } 8 \text { weeks } \\
\text { postpartum } \\
\text { was } 80.8 \mathrm{~kg} \\
\text { The mean } \\
\text { weight at } \\
\text { one-year } \\
\text { post-par- } \\
\text { tum was } \\
81.8 \mathrm{~kg}\end{array}$ & $\begin{array}{l}\text { MD } 1.60 \mathrm{~kg} \\
\text { lower ( } 6.34 \\
\mathrm{~kg} \text { lower } \\
\text { to } 3.14 \mathrm{~kg} \\
\text { higher) } \\
\text { MD } 3.70 \mathrm{~kg} \\
\text { lower ( } 8.50 \\
\text { kg lower } \\
\text { to } 1.10 \mathrm{~kg} \\
\text { higher) }\end{array}$ & $\begin{array}{l}\text { MD } 1.60 \mathrm{~kg} \\
(-6.34 \text { to } \\
3.14) \\
\text { MD }-3.70 \\
\mathrm{~kg}(-8.50 \text { to } \\
1.10)\end{array}$ & $\begin{array}{l}167 \\
(1 \mathrm{RCT}) \\
176 \\
(1 \mathrm{RCT})\end{array}$ & $\begin{array}{l}\text { Low } \\
\text { Low }\end{array}$ & $\begin{array}{l}\text { Evidence downgraded for study limi- } \\
\text { tations (lack of blinding; insufficient } \\
\text { methodological details to judge ran- } \\
\text { domisation or allocation conceal- } \\
\text { ment) and imprecision (wide confi- } \\
\text { dence intervals and a single study) }\end{array}$ \\
\hline
\end{tabular}


Table 7. GRADE Summary of findings table - Maternal (Continued)

\subsection{Post-natal depression}

\begin{tabular}{llllll}
\hline $\begin{array}{l}\text { Brown 2017b } \\
\text { 169 per }\end{array}$ & 83 per 1000 & RR 0.49 & 573 & Low & $\begin{array}{l}\text { "Imprecision - evidence is based on a } \\
\text { single trial and evidence of risk of at- } \\
\text { trition bias." }\end{array}$ \\
$\begin{array}{l}\text { Lifestyle inter- } \\
\begin{array}{l}\text { vention versus } \\
\text { usual care or diet }\end{array}\end{array}$ & & $(53$ to 132) & $\begin{array}{l}(0.31 \text { to } \\
0.78)\end{array}$ & $(1 \mathrm{RCT})$ & \\
$\begin{array}{l}\text { alone } \\
\end{array}$ & & & & \\
\hline
\end{tabular}

\subsection{Induction of labour}

\begin{tabular}{|c|c|c|c|c|c|c|}
\hline Brown 2017a & 188 per & 222 per & RR 1.18 & 375 & Very low & "Evidence is based on one study and \\
\hline $\begin{array}{l}\text { Glibenclamide } \\
\text { versus placebo }\end{array}$ & 1000 & $\begin{array}{l}1000 \\
(149 \text { to } \\
331)\end{array}$ & $\begin{array}{l}(0.79 \text { to } \\
1.76)\end{array}$ & (1 RCT) & & $\begin{array}{l}\text { 93\% were Hispanic women, results } \\
\text { may not be generalisable to other } \\
\text { populations. We did not find a pub- } \\
\text { lished protocol and there were more } \\
\text { outcomes reported in the published } \\
\text { paper than were listed in the trial reg- } \\
\text { istration document." }\end{array}$ \\
\hline
\end{tabular}

\begin{tabular}{|c|c|c|c|c|c|c|}
\hline $\begin{array}{l}\text { Brown 2017a } \\
\text { Metformin ver- } \\
\text { sus gliben- }\end{array}$ & $\begin{array}{l}613 \text { per } \\
1000\end{array}$ & $\begin{array}{l}496 \text { per } \\
1000 \\
\text { (374 to }\end{array}$ & $\begin{array}{l}\text { RR } 0.81 \\
(0.61 \text { to } \\
1.07)\end{array}$ & $\begin{array}{l}159 \\
(1 \mathrm{RCT})\end{array}$ & Low & $\begin{array}{l}\text { "Evidence is based on one study. } \\
\text { Method of randomisation was un- } \\
\text { clear and the study was open-label". }\end{array}$ \\
\hline
\end{tabular}

clamide

\begin{tabular}{|c|c|c|c|c|c|c|}
\hline $\begin{array}{l}\text { Han } 2017 \\
\text { Low-moderate } \\
\text { versus moder- } \\
\text { ate-high Gl diet }\end{array}$ & $\begin{array}{l}219 \text { per } \\
1000\end{array}$ & $\begin{array}{l}193 \text { per } \\
1000 \\
\text { (72 to } 512 \text { ) }\end{array}$ & $\begin{array}{l}\text { RR } 0.88 \\
(0.33 \text { to } \\
2.34)\end{array}$ & $\begin{array}{l}63 \\
(1 \mathrm{RCT})\end{array}$ & Low & $\begin{array}{l}\text { "One small study at unclear risk of se- } \\
\text { lection and detection bias and high } \\
\text { risk of performance bias. Wide confi- } \\
\text { dence interval crossing the line of no } \\
\text { effect." }\end{array}$ \\
\hline $\begin{array}{l}\text { Han } 2017 \\
\text { Energy- versus } \\
\text { no energy-re- } \\
\text { stricted diet }\end{array}$ & $\begin{array}{l}451 \text { per } \\
1000\end{array}$ & $\begin{array}{l}460 \text { per } \\
1000 \\
\text { (307 to } 690)\end{array}$ & $\begin{array}{l}\text { RR } 1.02 \\
(0.68 \text { to } \\
1.53)\end{array}$ & $\begin{array}{l}114 \\
(1 \mathrm{RCT})\end{array}$ & Low & $\begin{array}{l}\text { "One small study at unclear risk of se- } \\
\text { lection and detection bias and wide } \\
\text { confidence interval crossing the line } \\
\text { of no effect." }\end{array}$ \\
\hline $\begin{array}{l}\text { Brown } 2017 \mathrm{~b} \\
\text { Lifestyle inter- } \\
\text { vention versus } \\
\text { usual care or diet } \\
\text { alone }\end{array}$ & $\begin{array}{l}211 \text { per } \\
1000\end{array}$ & $\begin{array}{l}252 \text { per } \\
1000 \\
\text { (220 to } 285)\end{array}$ & $\begin{array}{l}\text { Average RR } \\
1.20(0.99 \\
\text { to } 1.46)\end{array}$ & $\begin{array}{l}2699 \\
\text { (4 RCTs) }\end{array}$ & Moderate & Evidence of risk of bias \\
\hline $\begin{array}{l}\text { Brown } 2017 \text { c } \\
\text { Exercise versus } \\
\text { control }\end{array}$ & $\begin{array}{l}400 \text { per } \\
1000\end{array}$ & $\begin{array}{l}552 \text { per } \\
1000 \\
(284 \text { to } \\
1000)\end{array}$ & $\begin{array}{l}\text { RR } 1.38 \\
(0.71 \text { to } \\
2.68)\end{array}$ & $\begin{array}{l}40 \\
(1 \mathrm{RCT})\end{array}$ & Very low & $\begin{array}{l}\text { "Imprecision - low event rates and } \\
\text { small sample size. Lack of clarity for } \\
\text { most items related to risk of bias." }\end{array}$ \\
\hline $\begin{array}{l}\text { Han } 2012 \\
\text { Intensive man- } \\
\text { agement versus } \\
\text { routine care }\end{array}$ & 0 per 1000 & $\begin{array}{l}0 \text { per } 1000 \\
(0 \text { to } 0)\end{array}$ & $\begin{array}{l}\text { RR } 17.69 \\
(1.03 \text { to } \\
304.09)\end{array}$ & $\begin{array}{l}83 \\
(1 \mathrm{RCT})\end{array}$ & Very low & $\begin{array}{l}\text { Evidence is based on one small study } \\
\text { with few events and serious design } \\
\text { limitations and imprecision with wide } \\
\text { confidence intervals crossing the line } \\
\text { of no effect }\end{array}$ \\
\hline Raman 2017 & $\begin{array}{l}538 \text { per } \\
1000\end{array}$ & $\begin{array}{l}571 \text { per } \\
1000(339 \\
\text { to } 953)\end{array}$ & $\begin{array}{l}\text { RR } 1.06 \\
(0.63 \text { to } \\
1.77)\end{array}$ & $\begin{array}{l}47 \\
(1 \mathrm{RCT})\end{array}$ & Very low & $\begin{array}{l}\text { Downgraded for study limitations } \\
\text { and imprecision (wide confidence in- }\end{array}$ \\
\hline
\end{tabular}


Table 7. GRADE Summary of findings table - Maternal (Continued)

Telemedicine versus standard

tervals, small sample size and low care for glucose events) monitoring

\begin{tabular}{|c|c|c|c|c|c|c|}
\hline $\begin{array}{l}\text { Brown } 2017 d \\
\text { Insulin versus } \\
\text { oral therapy }\end{array}$ & $\begin{array}{l}408 \text { per } \\
1000\end{array}$ & $\begin{array}{l}535 \text { per } \\
1000 \\
\text { (424 to } 669 \text { ) }\end{array}$ & $\begin{array}{l}\text { Average RR } \\
1.30(0.96 \\
\text { to } 1.75)\end{array}$ & $\begin{array}{l}348 \\
\text { (3 RCTs) }\end{array}$ & Moderate & $\begin{array}{l}\text { Evidence downgraded for study limi- } \\
\text { tations (lack of blinding) }\end{array}$ \\
\hline
\end{tabular}

${ }^{*}$ The risk in the intervention group (and its $95 \%$ confidence interval) is based on the assumed risk in the comparison group and the relative effect of the intervention (and its $95 \% \mathrm{Cl}$ ).

Cl: confidence interval; $\mathbf{R C T}$ : randomised controlled trial; RR: risk ratio; OR: odds ratio

\section{GRADE Working Group grades of evidence}

High quality: We are very confident that the true effect lies close to that of the estimate of the effect

Moderate quality: We are moderately confident in the effect estimate: The true effect is likely to be close to the estimate of the effect, but there is a possibility that it is substantially different

Low quality: Our confidence in the effect estimate is limited: The true effect may be substantially different from the estimate of the effect

Very low quality: We have very little confidence in the effect estimate: The true effect is likely to be substantially different from the estimate of effect

1 DASH is an acronym for Dietary Approaches to Stop Hypertension

2Strict intensity of glycaemic control (stricter) defined in review as: pre-prandial $5.0 \mathrm{mmol} / \mathrm{L}(90 \mathrm{mg} / \mathrm{dL})$ and one hour post-prandial 6.7 $\mathrm{mmol} / \mathrm{L}(120 \mathrm{mg} / \mathrm{dL}$ ) and less strict glycaemic control (liberal) defined in review as: pre-prandial $5.8 \mathrm{mmol} / \mathrm{L}$ (104 mg/dL) and one hour post-prandial $7.8 \mathrm{mmol} / \mathrm{L}(140 \mathrm{mg} / \mathrm{dL})$

3OGTT is an acronym for Oral Glucose Tolerance Test

Table 8. GRADE Summary of findings table - Child (as neonate, child, adult)

\begin{tabular}{|c|c|c|c|c|c|c|}
\hline $\begin{array}{l}\text { Intervention and } \\
\text { comparison and } \\
\text { outcome }\end{array}$ & $\begin{array}{l}\text { Assumed } \\
\text { risk with } \\
\text { compara- } \\
\text { tor }\end{array}$ & $\begin{array}{l}\text { Corre- } \\
\text { sponding } \\
\text { risk with } \\
\text { interven- } \\
\text { tion* }\end{array}$ & $\begin{array}{l}\text { Relative } \\
\text { effect } \\
(95 \% \mathrm{Cl})\end{array}$ & $\begin{array}{l}\text { № of par- } \\
\text { ticipants } \\
\text { (studies) }\end{array}$ & $\begin{array}{l}\text { Quality of } \\
\text { the evi- } \\
\text { dence } \\
\text { (GRADE) }\end{array}$ & $\begin{array}{l}\text { Comments from included re- } \\
\text { views in quotation marks } \\
\text { Comments without quotation } \\
\text { marks from overview review au- } \\
\text { thors }\end{array}$ \\
\hline \multicolumn{7}{|c|}{ 8.0 Large-for-gestational age (LGA) (as defined in reviews) } \\
\hline $\begin{array}{l}\text { Biesty } 2018 \\
\text { Induction of labour } \\
\text { versus expectant } \\
\text { management }\end{array}$ & $\begin{array}{l}114 \text { per } \\
1000\end{array}$ & $\begin{array}{l}60 \text { per } 1000 \\
(32 \text { to } 116)\end{array}$ & $\begin{array}{l}\text { RR } 0.53 \\
(0.28 \text { to } \\
1.02)\end{array}$ & $\begin{array}{l}425 \\
(1 \mathrm{RCT})\end{array}$ & Low & $\begin{array}{l}\text { Evidence is based on one small } \\
\text { study with design limitations. Wide } \\
\text { confidence intervals crossing the } \\
\text { line of no effect }\end{array}$ \\
\hline \multicolumn{7}{|l|}{$\begin{array}{l}\text { LGA defined as > } \\
\text { 90th percentile }\end{array}$} \\
\hline $\begin{array}{l}\text { Brown } 2017 a \\
\text { Glibenclamide ver- } \\
\text { sus placebo } \\
\text { LGA defined > 90th } \\
\text { percentile }\end{array}$ & $\begin{array}{l}118 \text { per } \\
1000\end{array}$ & $\begin{array}{l}105 \text { per } \\
1000 \\
(60 \text { to } 187)\end{array}$ & $\begin{array}{l}\text { RR } 0.89 \\
(0.51 \text { to } \\
1.58)\end{array}$ & $\begin{array}{l}375 \\
(1 \mathrm{RCT})\end{array}$ & Very low & $\begin{array}{l}\text { "Evidence is based on one study } \\
\text { and } 93 \% \text { were Hispanic women, } \\
\text { results may not be generalisable to } \\
\text { other populations. There is risk of } \\
\text { bias, as we did not find a published } \\
\text { protocol and there were more out- } \\
\text { comes reported in the published } \\
\text { paper than were listed in the trial } \\
\text { registration document." }\end{array}$ \\
\hline
\end{tabular}


Table 8. GRADE Summary of findings table - Child (as neonate, child, adult) (Continued)

\begin{tabular}{|c|c|c|c|c|c|c|}
\hline $\begin{array}{l}\text { Brown } 2017 \text { a } \\
\text { Metformin versus } \\
\text { glibenclamide } \\
\text { LGA defined as > } \\
\text { 90th percentile }\end{array}$ & $\begin{array}{l}193 \text { per } \\
1000\end{array}$ & $\begin{array}{l}129 \text { per } \\
1000 \\
(46 \text { to } 354)\end{array}$ & $\begin{array}{l}\text { RR } 0.67 \\
(0.24 \text { to } \\
1.83)\end{array}$ & $\begin{array}{l}246 \\
\text { (2 RCTs) }\end{array}$ & Low & $\begin{array}{l}\text { "Allocation concealment was un- } \\
\text { clear in one study and one study } \\
\text { was open label. Inconsistent as } \\
\text { heterogeneity was } \text { I }^{2}=54 \% \text {, which } \\
\text { could not be explained by the diag } \\
\text { nostic criteria used." }\end{array}$ \\
\hline $\begin{array}{l}\text { Brown } 2017 a \\
\text { Glibenclamide ver- } \\
\text { sus acarbose }\end{array}$ & $\begin{array}{l}105 \text { per } \\
1000\end{array}$ & $\begin{array}{l}251 \text { per } \\
1000 \\
(57 \text { to } \\
1000)\end{array}$ & $\begin{array}{l}\text { RR } 2.38 \\
(0.54 \text { to } \\
10.46)\end{array}$ & $\begin{array}{l}43 \\
(1 \mathrm{RCT})\end{array}$ & Very low & $\begin{array}{l}\text { "Evidence is based on one small } \\
\text { study with wide confidence inter- } \\
\text { vals and evidence of selective re- } \\
\text { porting." }\end{array}$ \\
\hline
\end{tabular}

LGA defined as > 90th percentile

\begin{tabular}{|c|c|c|c|c|c|c|}
\hline $\begin{array}{l}\text { Brown 2016a } \\
\text { Myo-inositol versus } \\
\text { placebo } 2\end{array}$ & 26 per 1000 & $\begin{array}{l}9 \text { per } 1000 \\
\text { (1 to } 226 \text { ) }\end{array}$ & $\begin{array}{l}\text { RR } 0.36 \\
(0.02 \text { to } \\
8.58)\end{array}$ & $\begin{array}{l}73 \\
(1 \mathrm{RCT})\end{array}$ & Very low & $\begin{array}{l}\text { "Evidence is based on one small } \\
\text { study with low event rates - } 0 / 35 \\
\text { events in myo-inositol group and } \\
1 / 38 \text { events } \\
\text { in the placebo group." }\end{array}$ \\
\hline $\begin{array}{l}\text { LGA defined as > } \\
\text { 90th centile }\end{array}$ & & & & & & \\
\hline
\end{tabular}

\begin{tabular}{|c|c|c|c|c|c|c|}
\hline $\begin{array}{l}\text { Han } 2017 \\
\text { Low-moderate ver- } \\
\text { sus moderate-high } \\
\text { GI diet } \\
\text { LGA defined as } \geq \\
\text { 90th percentile for } \\
\text { gestational age }\end{array}$ & $\begin{array}{l}146 \text { per } \\
1000\end{array}$ & $\begin{array}{l}104 \text { per } \\
1000 \\
\text { (32 to } 342 \text { ) }\end{array}$ & $\begin{array}{l}\text { RR } 0.71 \\
(0.22 \text { to } \\
2.34)\end{array}$ & $\begin{array}{l}89 \\
\text { (2 RCTs) }\end{array}$ & Low & $\begin{array}{l}\text { "One study at unclear risk of selec- } \\
\text { tion bias and two studies at risk of } \\
\text { performance bias and unclear risk } \\
\text { of detection bias. Wide confidence } \\
\text { intervals crossing the line of no ef- } \\
\text { fect and small sample size." }\end{array}$ \\
\hline
\end{tabular}

\begin{tabular}{|c|c|c|c|c|c|c|}
\hline $\begin{array}{l}\text { Han } 2017 \\
\text { Energy-versus no } \\
\text { energy-restricted } \\
\text { diet }\end{array}$ & $\begin{array}{l}246 \text { per } \\
1000\end{array}$ & $\begin{array}{l}288 \text { per } \\
1000 \\
\text { (160 to } 522)\end{array}$ & $\begin{array}{l}\text { RR } 1.17 \\
(0.65 \text { to } \\
2.12)\end{array}$ & $\begin{array}{l}123 \\
\text { (1 RCT) }\end{array}$ & Low & $\begin{array}{l}\text { "One study at unclear risk of selec- } \\
\text { tion and detection bias and wide } \\
\text { confidence interval crossing the } \\
\text { line of no effect and small sample } \\
\text { size." }\end{array}$ \\
\hline
\end{tabular}

\section{LGA defined as $\geq$ \\ 90th percentile for gestational age}

\begin{tabular}{|c|c|c|c|c|c|c|}
\hline $\begin{array}{l}\text { Han } 2017 \\
\text { Low- versus high- } \\
\text { carbohydrate diet } \\
\text { LGA defined as } \geq \\
\text { 90th percentile for } \\
\text { gestational age }\end{array}$ & 80 per 1000 & $\begin{array}{l}41 \text { per } 1000 \\
(10 \text { to } 156)\end{array}$ & $\begin{array}{l}\text { RR } 0.51 \\
(0.13 \text { to } \\
1.95)\end{array}$ & $\begin{array}{l}149 \\
(1 \mathrm{RCT})\end{array}$ & Very low & $\begin{array}{l}\text { Imprecision - evidence is based on } \\
\text { one study and wide confidence in- } \\
\text { terval crossing the line of no effect. } \\
\text { Risk of performance bias as partic- } \\
\text { ipants and researchers were not } \\
\text { blinded }\end{array}$ \\
\hline $\begin{array}{l}\text { Han } 2017 \\
\text { High- versus low- } \\
\text { unsaturated fat diet } \\
\text { with matching calo- } \\
\text { ries }\end{array}$ & $\begin{array}{l}571 \text { per } \\
1000\end{array}$ & $\begin{array}{l}309 \text { per } \\
1000 \\
\text { (120 to } 783)\end{array}$ & $\begin{array}{l}\text { RR } 0.54 \\
(0.21 \text { to } \\
1.37)\end{array}$ & $\begin{array}{l}27 \\
(1 \mathrm{RCT})\end{array}$ & Very low & $\begin{array}{l}\text { Imprecision - evidence is based on } \\
\text { one study and wide confidence in- } \\
\text { terval crossing the line of no effect. } \\
\text { Risk of performance bias as partic- } \\
\text { ipants and researchers were not } \\
\text { blinded. Baselines for BMI were } \\
\text { unbalanced between groups }\end{array}$ \\
\hline
\end{tabular}


Table 8. GRADE Summary of findings table - Child (as neonate, child, adult) (Continued)

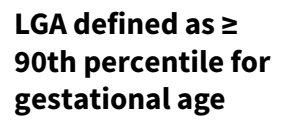

\begin{tabular}{|c|c|c|c|c|c|c|}
\hline $\begin{array}{l}\text { Han } 2017 \\
\text { Low-Gi diet versus } \\
\text { high-fibre moder- } \\
\text { ate-GI diet } \\
\text { LGA defined as } \geq \\
\text { 90th percentile for } \\
\text { gestational age }\end{array}$ & 44 per 1000 & $\begin{array}{l}128 \text { per } \\
1000 \\
\text { ( } 27 \text { to } 600 \text { ) }\end{array}$ & $\begin{array}{l}\text { RR } 2.87 \\
(0.61 \text { to } \\
13.50)\end{array}$ & $\begin{array}{l}92 \\
(1 \mathrm{RCT})\end{array}$ & Very low & $\begin{array}{l}\text { Imprecision - evidence is based } \\
\text { on one study and wide confidence } \\
\text { interval crossing the line of no ef- } \\
\text { fect. Risk of detection bias as out- } \\
\text { come assessors were not blinded. } \\
\text { Incomplete data reported (attri- } \\
\text { tion bias) and blood glucose con- } \\
\text { centration unbalanced at baseline }\end{array}$ \\
\hline $\begin{array}{l}\text { Han } 2017 \\
\text { Diet + diet-related } \\
\text { behavioural advice } \\
\text { versus diet only } \\
\text { LGA defined as } \geq \\
\text { 90th percentile for } \\
\text { gestational age }\end{array}$ & $\begin{array}{l}140 \text { per } \\
1000\end{array}$ & $\begin{array}{l}102 \text { per } \\
1000 \\
\text { (35 to } 300 \text { ) }\end{array}$ & $\begin{array}{l}\text { RR } 0.73 \\
(0.25 \text { to } \\
2.14)\end{array}$ & $\begin{array}{l}99 \\
(1 \mathrm{RCT})\end{array}$ & Very low & $\begin{array}{l}\text { Imprecision - evidence is based on } \\
\text { one study and wide confidence in- } \\
\text { terval crossing the line of no effect. } \\
\text { Risk of performance bias as par- } \\
\text { ticipants and personnel were not } \\
\text { blinded }\end{array}$ \\
\hline
\end{tabular}

\begin{tabular}{|c|c|c|c|c|c|c|}
\hline $\begin{array}{l}\text { Han } 2017 \\
\text { Ethnic specific di- } \\
\text { et versus standard } \\
\text { healthy diet } \\
\text { LGA defined as } \geq \\
\text { 90th percentile for } \\
\text { gestational age }\end{array}$ & $\begin{array}{l}300 \text { per } \\
1000\end{array}$ & $\begin{array}{l}42 \text { per } 1000 \\
\text { ( } 3 \text { to } 735 \text { ) }\end{array}$ & $\begin{array}{l}\text { RR } 0.14 \\
(0.01 \text { to } \\
2.45)\end{array}$ & $\begin{array}{l}20 \\
(1 \mathrm{RCT})\end{array}$ & Very low & $\begin{array}{l}\text { Imprecision - evidence is based } \\
\text { on one study and wide confidence } \\
\text { interval crossing the line of no ef- } \\
\text { fect. Risk of performance bias as } \\
\text { participants and personnel were } \\
\text { not blinded and selective reporting } \\
\text { (reporting bias). Low event rates, } \\
\text { as there were no events in the in- } \\
\text { tervention group and three events } \\
\text { in the control group }\end{array}$ \\
\hline
\end{tabular}

\begin{tabular}{|c|c|c|c|c|c|c|}
\hline $\begin{array}{l}\text { Brown } 2017 b \\
\text { Lifestyle interven- } \\
\text { tion versus usual } \\
\text { care or diet alone } \\
\text { LGA not defined }\end{array}$ & $\begin{array}{l}189 \text { per } \\
1000\end{array}$ & $\begin{array}{l}113 \text { per } \\
1000 \\
\text { (95 to } 134 \text { ) }\end{array}$ & $\begin{array}{l}\text { RR } 0.60 \\
(0.50 \text { to } \\
0.71)\end{array}$ & $\begin{array}{l}2994 \\
\text { (6 RCTs) }\end{array}$ & Moderate & $\begin{array}{l}\text { "Several included studies had high } \\
\text { risk of bias for lack of blinding, in- } \\
\text { complete outcome data and selec- } \\
\text { tive reporting. Allocation conceal- } \\
\text { ment was in unclear in two of the } \\
\text { six studies." }\end{array}$ \\
\hline
\end{tabular}

\begin{tabular}{|c|c|c|c|c|c|c|}
\hline $\begin{array}{l}\text { Han } 2012 \\
\text { Intensive manage- }\end{array}$ & $\begin{array}{l}171 \text { per } \\
1000\end{array}$ & $\begin{array}{l}63 \text { per } 1000 \\
(34 \text { to } 113)\end{array}$ & $\begin{array}{l}\text { RR } 0.37 \\
(0.20 \text { to } \\
0.66)\end{array}$ & $\begin{array}{l}438 \\
\text { (3 RCTs) }\end{array}$ & Low & $\begin{array}{l}\text { Evidence based on three studies } \\
\text { with serious/very serious design } \\
\text { limitations }\end{array}$ \\
\hline
\end{tabular}

ment versus routine

care

\section{LGA defined as $\geq$ 90th percentile for gestational age}

\begin{tabular}{|c|c|c|c|c|c|c|}
\hline $\begin{array}{l}\text { Raman } 2017 \\
\text { Telemedicine ver- } \\
\text { sus standard care } \\
\text { for glucose moni- } \\
\text { toring }\end{array}$ & $\begin{array}{l}126 \text { per } \\
1000\end{array}$ & $\begin{array}{l}178 \text { per } \\
1000 \\
\text { (96 to } 333 \text { ) }\end{array}$ & $\begin{array}{l}\text { RR } 1.41 \\
(0.76 \text { to } \\
2.64)\end{array}$ & $\begin{array}{l}228 \\
\text { (3 RCTs) }\end{array}$ & Very low & $\begin{array}{l}\text { Evidence downgraded for study } \\
\text { limitations and imprecision (wide } \\
\text { confidence intervals crossing the } \\
\text { line of no effect; small sample size } \\
\text { and few events }\end{array}$ \\
\hline
\end{tabular}

\section{LGA not defined}


Table 8. GRADE Summary of findings table - Child (as neonate, child, adult) (Continued)

\begin{tabular}{|c|c|c|c|c|c|c|}
\hline Raman 2017 & 142 per & 117 per & RR 0.82 & 400 & Low & Evidence downgraded for study \\
\hline $\begin{array}{l}\text { Self- versus period- } \\
\text { ic-glucose monitor- } \\
\text { ing }\end{array}$ & 1000 & $\begin{array}{l}1000 \\
\text { (71 to } 195)\end{array}$ & $\begin{array}{l}\text { ( } 0.50 \text { to } \\
1.37)\end{array}$ & (2 RCTs) & & $\begin{array}{l}\text { limitations and imprecision (wide } \\
\text { confidence intervals crossing the } \\
\text { line of no effect) }\end{array}$ \\
\hline
\end{tabular}

\section{LGA not defined}

\begin{tabular}{|c|c|c|c|c|c|c|}
\hline $\begin{array}{l}\text { Raman } 2017 \\
\text { Continuous- ver- } \\
\text { sus self-monitoring } \\
\text { blood glucose }\end{array}$ & $\begin{array}{l}527 \text { per } \\
1000\end{array}$ & $\begin{array}{l}353 \text { per } \\
1000 \\
\text { ( } 227 \text { to } 554 \text { ) }\end{array}$ & $\begin{array}{l}\text { RR } 0.67 \\
(0.43 \text { to } \\
1.05)\end{array}$ & $\begin{array}{l}106 \\
(1 \mathrm{RCT})\end{array}$ & Very low & $\begin{array}{l}\text { Evidence downgraded for study } \\
\text { limitations and imprecision (wide } \\
\text { confidence intervals crossing the } \\
\text { line of no effect and small sample } \\
\text { size) }\end{array}$ \\
\hline
\end{tabular}

LGA not defined

\begin{tabular}{|c|c|c|c|c|c|c|}
\hline $\begin{array}{l}\text { Raman } 2017 \\
\text { Post- versus pre- } \\
\text { prandial glucose } \\
\text { monitoring }\end{array}$ & $\begin{array}{l}424 \text { per } \\
1000\end{array}$ & $\begin{array}{l}123 \text { per } \\
1000 \\
(47 \text { to } 331)\end{array}$ & $\begin{array}{l}\text { RR } 0.29 \\
(0.11 \text { to } \\
0.78)\end{array}$ & $\begin{array}{l}66 \\
(1 \mathrm{RCT})\end{array}$ & Very low & $\begin{array}{l}\text { Evidence downgraded for impre- } \\
\text { cision (wide confidence intervals } \\
\text { crossing the line of no effect, single } \\
\text { trial, small sample sizes) and study } \\
\text { limitations }\end{array}$ \\
\hline
\end{tabular}

\section{LGA not defined}

\begin{tabular}{|c|c|c|c|c|c|c|}
\hline $\begin{array}{l}\text { Brown } 2017 d \\
\text { Insulin versus oral } \\
\text { therapy } \\
\text { Birthweight > 90th } \\
\text { percentile }\end{array}$ & $\begin{array}{l}159 \text { per } \\
1000\end{array}$ & $\begin{array}{l}161 \text { per } \\
1000 \\
\text { (121 to } 215)\end{array}$ & $\begin{array}{l}\text { average RR } \\
1.01(0.76 \\
\text { to } 1.35)\end{array}$ & $\begin{array}{l}2352 \\
(13 \mathrm{RCTs})\end{array}$ & Moderate & $\begin{array}{l}\text { Evidence downgraded for study } \\
\text { limitations (lack of blinding) }\end{array}$ \\
\hline $\begin{array}{l}\text { Brown 2017d } \\
\text { Insulin type A ver- } \\
\text { sus B } \\
\text { LGA not defined }\end{array}$ & 58 per 1000 & $\begin{array}{l}70 \text { per } 1000 \\
\text { (34 to } 148)\end{array}$ & $\begin{array}{l}\text { RR } 1.21 \\
(0.58 \text { to } \\
2.55)\end{array}$ & $\begin{array}{l}411 \\
\text { (3 RCTs) }\end{array}$ & Low & $\begin{array}{l}\text { Evidence downgraded for study } \\
\text { limitations (insufficient details) } \\
\text { and imprecision (wide confidence } \\
\text { intervals) }\end{array}$ \\
\hline $\begin{array}{l}\text { Brown } 2017 d \\
\text { Insulin versus diet } \\
\text { LGA not defined }\end{array}$ & $\begin{array}{l}133 \text { per } \\
1000\end{array}$ & $\begin{array}{l}113 \text { per } \\
1000 \\
\text { (55 to } 237 \text { ) }\end{array}$ & $\begin{array}{l}\text { RR } 0.85 \\
(0.41 \text { to } \\
1.78)\end{array}$ & $\begin{array}{l}202 \\
(1 \mathrm{RCT})\end{array}$ & Very low & $\begin{array}{l}\text { Evidence downgraded for study } \\
\text { limitations (insufficient details) } \\
\text { and imprecision (single study, low } \\
\text { events, wide confidence intervals) }\end{array}$ \\
\hline $\begin{array}{l}\text { Brown 2017d } \\
\text { Insulin regimen A } \\
\text { versus B } \\
\text { Twice daily versus } \\
\text { four times daily }\end{array}$ & $\begin{array}{l}261 \text { per } \\
1000 \\
158 \text { per } \\
1000\end{array}$ & $\begin{array}{l}303 \text { per } \\
1000 \\
\text { ( } 206 \text { to } 441 \text { ) } \\
55 \text { per } 1000 \\
\text { ( } 6 \text { to } 486)\end{array}$ & $\begin{array}{l}\text { RR } 1.16 ; \\
(0.79 \text { to } \\
1.69) \\
\text { RR } 0.35 ; \\
(0.04 \text { to } \\
3.08)\end{array}$ & $\begin{array}{l}274 \\
(1 \mathrm{RCT}) \\
37 \\
(1 \mathrm{RCT})\end{array}$ & Very low & $\begin{array}{l}\text { Evidence downgraded for study } \\
\text { limitations (insufficient details) } \\
\text { and imprecision (single small } \\
\text { study, wide confidence intervals) }\end{array}$ \\
\hline
\end{tabular}

Three times versus

six times daily

\section{LGA not defined}

\subsection{Perinatal mortality (fetal and neonatal death) and later infant mortality}


Table 8. GRADE Summary of findings table - Child (as neonate, child, adult) (Continued)

\begin{tabular}{|c|c|c|c|c|c|c|}
\hline $\begin{array}{l}\text { Biesty } 2018 \\
\text { Induction of labour }\end{array}$ & $\begin{array}{l}\text { See com- } \\
\text { ment }\end{array}$ & $\begin{array}{l}\text { See com- } \\
\text { ment }\end{array}$ & $\begin{array}{l}\text { RR not es- } \\
\text { timable }\end{array}$ & $\begin{array}{l}425 \\
(1 \mathrm{RCT})\end{array}$ & Very low & $\begin{array}{l}\text { Evidence is based on one small } \\
\text { study with no events and design } \\
\text { limitations }\end{array}$ \\
\hline
\end{tabular}
management

\section{Perinatal death}

\begin{tabular}{|c|c|c|c|c|c|c|}
\hline $\begin{array}{l}\text { Brown } 2017 a \\
\text { Metformin versus } \\
\text { glibenclamide } \\
\text { Perinatal death }\end{array}$ & 6 per 1000 & $\begin{array}{l}5 \text { per } 1000 \\
(0 \text { to } 83)\end{array}$ & $\begin{array}{l}\text { Average RR } \\
0.92(0.06 \\
\text { to } 14.55)\end{array}$ & $\begin{array}{l}359 \\
\text { (2 RCTs) }\end{array}$ & Very low & $\begin{array}{l}\text { "Open label studies with no evi- } \\
\text { dence of blinding of participants } \\
\text { or researchers. Event rates were } \\
\text { very low. One study had no event } \\
\text { of perinatal death in either the } \\
\text { metformin nor the glibenclamide } \\
\text { group. The second study had one } \\
\text { death in each group." }\end{array}$ \\
\hline
\end{tabular}

\begin{tabular}{llllll}
\hline $\begin{array}{l}\text { Brown 2017a } \\
\begin{array}{l}\text { Glibenclamide ver- } \\
\text { sus acarbose }\end{array}\end{array}$ & $\begin{array}{l}\text { 0 per } 1000 \\
\text { (0 to 0) }\end{array}$ & $\begin{array}{l}\text { RR not es- } \\
\text { timable }\end{array}$ & 43 & $\begin{array}{l}\text { Very low } \\
\text { (1 RCT) }\end{array}$ & $\begin{array}{l}\text { "Evidence based on a single small } \\
\text { study with wide confidence inter- } \\
\text { vals. No events were reported in ei- } \\
\text { ther group. There is evidence of se- } \\
\text { lective reporting." }\end{array}$ \\
\hline
\end{tabular}

\begin{tabular}{|c|c|c|c|c|c|c|}
\hline $\begin{array}{l}\text { Han } 2017 \\
\text { Energy- versus no } \\
\text { energy restricted } \\
\text { diet } \\
\text { Perinatal death }\end{array}$ & 0 per 1000 & $\begin{array}{l}0 \text { per } 1000 \\
(0 \text { to } 0)\end{array}$ & $\begin{array}{l}\text { RR not es- } \\
\text { timable }\end{array}$ & $\begin{array}{l}423 \\
\text { (2 RCTs) }\end{array}$ & Low & $\begin{array}{l}\text { "Two studies at unclear risk of se- } \\
\text { lection bias. One study at high risk } \\
\text { of performance bias and unclear } \\
\text { risk of detection bias. There were } \\
\text { no events in either group and rela- } \\
\text { tively small sample sizes." }\end{array}$ \\
\hline
\end{tabular}

\begin{tabular}{|c|c|c|c|c|c|c|}
\hline $\begin{array}{l}\text { Han } 2017 \\
\text { Low- versus high- } \\
\text { carbohydrate diet } \\
\text { Perinatal death }\end{array}$ & 0 per 1000 & $\begin{array}{l}0 \text { per } 1000 \\
(0 \text { to } 0)\end{array}$ & $\begin{array}{l}\text { RR } 3.00 \\
(0.12 \text { to } \\
72.49)\end{array}$ & $\begin{array}{l}150 \\
\text { (1 RCT) }\end{array}$ & Very low & $\begin{array}{l}\text { Evidence is based on one study } \\
\text { and imprecision as wide confi- } \\
\text { dence interval crossing the line } \\
\text { of no effect. Risk of performance } \\
\text { bias as study participants and care } \\
\text { providers were not blinded. Low } \\
\text { event rates (one event in the con- } \\
\text { trol group) }\end{array}$ \\
\hline
\end{tabular}

\begin{tabular}{|c|c|c|c|c|c|c|}
\hline $\begin{array}{l}\text { Brown } 2017 b \\
\text { Lifestyle interven- } \\
\text { tion versus usual } \\
\text { care or diet alone } \\
\text { Perinatal death }\end{array}$ & 5 per 1000 & $\begin{array}{l}0 \text { per } 1000 \\
(0 \text { to } 9)\end{array}$ & $\begin{array}{l}\text { RR } 0.09 \\
(0.01 \text { to } \\
1.70)\end{array}$ & $\begin{array}{l}1988 \\
\text { (2 RCTs) }\end{array}$ & Low & $\begin{array}{l}\text { "There is evidence of imprecision } \\
\text { with wide confidence intervals } \\
\text { and low events rates ( } 5 \text { perinatal } \\
\text { deaths in one trail's control group) } \\
\text { and one of the two trials did not } \\
\text { blind participants/researchers." }\end{array}$ \\
\hline
\end{tabular}

\begin{tabular}{|c|c|c|c|c|c|c|}
\hline $\begin{array}{l}\text { Brown } 2017 \text { c } \\
\text { Exercise versus } \\
\text { control }\end{array}$ & 0 per 1000 & $\begin{array}{l}0 \text { per } 1000 \\
(0 \text { to } 0)\end{array}$ & $\begin{array}{l}\text { RR not es- } \\
\text { timable }\end{array}$ & $\begin{array}{l}19 \\
(1 \mathrm{RCT})\end{array}$ & Very low & $\begin{array}{l}\text { Imprecision - There are no events } \\
\text { in either group and the sample size } \\
\text { is only } 19 \text { infants. } \\
\text { "There is a lack of clarity for most } \\
\text { items associated with risk of bias." }\end{array}$ \\
\hline $\begin{array}{l}\text { Raman } 2017 \\
\text { Telemedicine ver- }\end{array}$ & 0 per 1000 & $\begin{array}{l}0 \text { per } 1000 \\
(0 \text { to } 0)\end{array}$ & $\begin{array}{l}\text { RR not es- } \\
\text { timable }\end{array}$ & $\begin{array}{l}131 \\
\text { (2 RCTs) }\end{array}$ & Very low & $\begin{array}{l}\text { There were no events reported for } \\
\text { this outcome. }\end{array}$ \\
\hline
\end{tabular}

sus standard care 
Table 8. GRADE Summary of findings table - Child (as neonate, child, adult) (Continued) for glucose monitoring

Evidence downgraded for study limitations and imprecision (no events and small sample sizes)

\begin{tabular}{|c|c|c|c|c|c|c|}
\hline $\begin{array}{l}\text { Raman } 2017 \\
\text { Self- versus period- } \\
\text { ic-glucose monitor- } \\
\text { ing }\end{array}$ & 5 per 1000 & $\begin{array}{l}8 \text { per } 1000 \\
(1 \text { to } 57)\end{array}$ & $\begin{array}{l}\text { RR } 1.54 \\
(0.21 \text { to } \\
11.24)\end{array}$ & $\begin{array}{l}400 \\
\text { (2 RCTs) }\end{array}$ & Very low & $\begin{array}{l}\text { Evidence downgraded for study } \\
\text { limitations and imprecision (wide } \\
\text { confidence intervals crossing the } \\
\text { line of no effect and few events). }\end{array}$ \\
\hline $\begin{array}{l}\text { Raman } 2017 \\
\text { Continuous- ver- } \\
\text { sus self-monitoring } \\
\text { blood glucose }\end{array}$ & 0 per 1000 & $\begin{array}{l}0 \text { per } 1000 \\
(0 \text { to } 0)\end{array}$ & $\begin{array}{l}\text { RR not es- } \\
\text { timable }\end{array}$ & $\begin{array}{l}179 \\
(2 \mathrm{RCTs})\end{array}$ & Very low & $\begin{array}{l}\text { There were no events of perinatal } \\
\text { death reported in the two RCTs. } \\
\text { Evidence was downgraded for } \\
\text { study limitations and imprecision } \\
\text { (no events and small sample sizes) }\end{array}$ \\
\hline $\begin{array}{l}\text { Brown } 2017 d \\
\text { Insulin versus oral } \\
\text { therapy }\end{array}$ & 8 per 1000 & $\begin{array}{l}7 \text { per } 1000 \\
\text { ( } 2 \text { to } 20)\end{array}$ & $\begin{array}{l}\text { RR } 0.85 \\
(0.29 \text { to } \\
2.49)\end{array}$ & $\begin{array}{l}1463 \\
(10 \text { RCTs })\end{array}$ & Low & $\begin{array}{l}\text { Evidence downgraded for study } \\
\text { limitations (lack of blinding) and } \\
\text { imprecision (wide confidence in- } \\
\text { tervals and low event rates) }\end{array}$ \\
\hline $\begin{array}{l}\text { Brown 2017d } \\
\text { Insulin versus diet }\end{array}$ & 43 per 1000 & $\begin{array}{l}32 \text { per } 1000 \\
(18 \text { to } 57)\end{array}$ & $\begin{array}{l}\text { RR } 0.74 \\
(0.41 \text { to } \\
1.78)\end{array}$ & $\begin{array}{l}1137 \\
\text { (4 RCTs) }\end{array}$ & Moderate & $\begin{array}{l}\text { Evidence downgraded for study } \\
\text { limitations (insufficient details) }\end{array}$ \\
\hline $\begin{array}{l}\text { Brown } 2017 \text { d } \\
\text { Insulin regimen A } \\
\text { versus B } \\
\text { Twice daily versus } \\
\text { four times daily }\end{array}$ & 0 per 1000 & $\begin{array}{l}0 \text { per } 1000 \\
(0 \text { to } 0)\end{array}$ & $\begin{array}{l}\text { RR } 3.04 \\
(0.13 \text { to } \\
74.07)\end{array}$ & $\begin{array}{l}274 \\
(1 \mathrm{RCT})\end{array}$ & Very low & $\begin{array}{l}\text { Evidence downgraded for impre- } \\
\text { cision (extremely wide confidence } \\
\text { intervals; single small study; very } \\
\text { low event rates). There was one } \\
\text { event in the twice daily group and } \\
\text { no events in the four times daily } \\
\text { group }\end{array}$ \\
\hline
\end{tabular}

10.0 Death or serious morbidity composite (as defined in reviews)

\begin{tabular}{|c|c|c|c|c|c|c|}
\hline $\begin{array}{l}\text { Brown } 2017 a \\
\text { Metformin versus } \\
\text { glibenclamide } \\
\text { Defined as com- } \\
\text { posite of neona- } \\
\text { tal outcomes in- } \\
\text { cluding hypogly- } \\
\text { caemia, hyper- } \\
\text { bilirubinaemia, } \\
\text { macrosomia, res- } \\
\text { piratory illness, } \\
\text { birth injury, still- } \\
\text { birth or neonatal } \\
\text { death }\end{array}$ & $\begin{array}{l}350 \text { per } \\
1000\end{array}$ & $\begin{array}{l}189 \text { per } \\
1000 \\
\text { (109 to } 329)\end{array}$ & $\begin{array}{l}\text { RR } 0.54 \\
(0.31 \text { to } \\
0.94)\end{array}$ & $\begin{array}{l}159 \\
(1 \mathrm{RCT})\end{array}$ & Low & $\begin{array}{l}\text { "Evidence is based on one small } \\
\text { study." } \\
\text { Risk of performance bias as par- } \\
\text { ticipants and personnel were not } \\
\text { blinded }\end{array}$ \\
\hline $\begin{array}{l}\text { Han } 2017 \\
\text { Ethnic specific di- } \\
\text { et versus standard } \\
\text { healthy diet } \\
\text { Defined as com- } \\
\text { posite of neona- }\end{array}$ & 0 per 1000 & $\begin{array}{l}0 \text { per } 1000 \\
(0 \text { to } 0)\end{array}$ & $\begin{array}{l}\text { RR not es- } \\
\text { timable }\end{array}$ & $\begin{array}{l}20 \\
(1 \mathrm{RCT})\end{array}$ & Very low & $\begin{array}{l}\text { Imprecision - evidence is based } \\
\text { on one study. Risk of performance } \\
\text { bias as participants and personnel } \\
\text { were not blinded and selective re- } \\
\text { porting (reporting bias). No events } \\
\text { in either group }\end{array}$ \\
\hline
\end{tabular}


Table 8. GRADE Summary of findings table - Child (as neonate, child, adult) (Continued)

tal outcomes that

included hypogly-

caemia, neonatal

asphyxia, respira-

tory distress syn-

drome (RDS), hy-

perbilirubinaemia

and hypocal-

caemia

\begin{tabular}{|c|c|c|c|c|c|c|}
\hline $\begin{array}{l}\text { Brown } 2017 \mathrm{~b} \\
\text { Lifestyle interven- } \\
\text { tion versus usual } \\
\text { care or diet alone } \\
\text { Defined as com- } \\
\text { posite of death, } \\
\text { shoulder dysto- } \\
\text { cia, bone fracture } \\
\text { and nerve palsy } \\
\text { in one trial and } \\
\text { still birth, neona- } \\
\text { tal death, hypo- } \\
\text { glycaemia, hyper- } \\
\text { bilirubinaemia, } \\
\text { elevated cord- } \\
\text { blood C-peptide } \\
\text { and birth trauma } \\
\text { in the other trial }\end{array}$ & $\begin{array}{l}193 \text { per } \\
1000\end{array}$ & $\begin{array}{l}110 \text { per } \\
1000 \\
\text { (41 to } 299 \text { ) }\end{array}$ & $\begin{array}{l}\text { Average RR } \\
0.57(0.21 \\
\text { to } 1.55)\end{array}$ & $\begin{array}{l}1930 \\
\text { (2 RCTs) }\end{array}$ & Very low & $\begin{array}{l}\text { "Evidence of inconsistency with } 12 \\
>70 \% \text {. One of the two trials did not } \\
\text { blind participants/researchers and } \\
\text { evidence of imprecision with wide } \\
\text { confidence intervals crossing the } \\
\text { line of no effect." }\end{array}$ \\
\hline
\end{tabular}

\begin{tabular}{|c|c|c|c|c|c|c|}
\hline $\begin{array}{l}\text { Brown } 2017 \text { c } \\
\text { Exercise versus }\end{array}$ & 65 per 1000 & $\begin{array}{l}36 \text { per } 1000 \\
\text { (8 to } 169)\end{array}$ & $\begin{array}{l}\text { RR } 0.56 \\
(0.12 \text { to }\end{array}$ & $\begin{array}{l}169 \\
\text { (2 RCTs) }\end{array}$ & Moderate & $\begin{array}{l}\text { Imprecision - wide confidence in- } \\
\text { tervals and low event rates }\end{array}$ \\
\hline
\end{tabular}

control

Defined as mortal-

ity and morbidity composite

\begin{tabular}{|c|c|c|c|c|c|c|}
\hline $\begin{array}{l}\text { Raman } 2017 \\
\text { Telemedicine ver- } \\
\text { sus standard care } \\
\text { for glucose moni- } \\
\text { toring }\end{array}$ & $\begin{array}{l}560 \text { per } \\
1000\end{array}$ & $\begin{array}{l}594 \text { per } \\
1000 \\
\text { (381 to } 930 \text { ) }\end{array}$ & $\begin{array}{l}\text { RR } 1.06 \\
(0.68 \text { to } \\
1.66)\end{array}$ & 57 (1 RCT) & Very low & $\begin{array}{l}\text { Evidence downgraded for impre- } \\
\text { cision (wide confidence intervals } \\
\text { crossing the line of no effect, small } \\
\text { sample size and few events) and } \\
\text { study limitations }\end{array}$ \\
\hline $\begin{array}{l}\text { Defined as com- } \\
\text { posite of neona- } \\
\text { tal intensive care } \\
\text { unit admission, } \\
\text { LGA, respiratory } \\
\text { outcomes (hya- } \\
\text { line membrane } \\
\text { disease, transient } \\
\text { tachypnoea, need } \\
\text { for respiratory } \\
\text { support); hypogly- } \\
\text { caemia; and hy- } \\
\text { perbilirubinaemia }\end{array}$ & & & & & & \\
\hline
\end{tabular}

Treatments for women with gestational diabetes mellitus: an overview of Cochrane systematic reviews (Review) 
Table 8. GRADE Summary of findings table - Child (as neonate, child, adult) (Continued)

\begin{tabular}{|c|c|c|c|c|c|}
\hline Brown 2017d & 319 per & 329 per & RR 1.03 & 760 & Moderate \\
\hline $\begin{array}{l}\text { Insulin versus oral } \\
\text { therapy }\end{array}$ & 1000 & $\begin{array}{l}1000 \\
\text { (268 to } 402 \text { ) }\end{array}$ & $\begin{array}{l}(0.84 \text { to } \\
1.26)\end{array}$ & (2 RCTs) & \\
\hline
\end{tabular}

Evidence was downgraded for study limitations (lack of blinding).

therapy

One trial included resuscitation of the delivery room, preterm birth ( $<37$ weeks), neonatal intensive care unit admission, birth injury or diagnosis of neonatal complication, glucose infusion, antibiotics or phototherapy. A second trial included hypoglycaemia $<2.6$ $\mathrm{mmol} / \mathrm{L}, \mathrm{RDS}$, phototherapy, birth trauma, APGAR $<7$ at 5 minutes, preterm birth $<37$ weeks

\begin{tabular}{|c|c|c|c|c|c|c|}
\hline $\begin{array}{l}\text { Brown } 2017 \text { d } \\
\text { Insulin regimen A } \\
\text { versus B }\end{array}$ & $\begin{array}{l}174 \text { per } \\
1000\end{array}$ & $\begin{array}{l}294 \text { per } \\
1000 \\
\text { (188 to } 459)\end{array}$ & $\begin{array}{l}\text { RR } 1.69 \\
(1.08 \text { to } \\
2.64)\end{array}$ & $\begin{array}{l}274 \\
(1 \mathrm{RCT})\end{array}$ & Very low & $\begin{array}{l}\text { Evidence downgraded for impreci- } \\
\text { sion (Single small study with wide } \\
\text { confidence intervals and low event } \\
\text { rates) }\end{array}$ \\
\hline
\end{tabular}

Twice daily versus

four times daily

\subsection{Neonatal hypoglycaemia (as defined in the reviews)}

\begin{tabular}{|c|c|c|c|c|c|c|}
\hline $\begin{array}{l}\text { Biesty } 2018 \\
\text { Induction of labour } \\
\text { versus expectant }\end{array}$ & 38 per 1000 & $\begin{array}{l}28 \text { per } 1000 \\
(10 \text { to } 79)\end{array}$ & $\begin{array}{l}\text { RR } 0.74 \\
(0.26 \text { to } \\
2.09)\end{array}$ & $\begin{array}{l}425 \\
(1 \mathrm{RCT})\end{array}$ & Very Low & $\begin{array}{l}\text { Evidence downgraded for impreci- } \\
\text { sion (single study with low events) } \\
\text { and study limitations }\end{array}$ \\
\hline
\end{tabular}

versus expectant

management

Not defined

\begin{tabular}{llllll}
\hline Brown 2017a & 11 per 1000 & 21 per 1000 & $\begin{array}{l}\text { RR } 1.97 \\
(0.36 \text { to }\end{array}$ & 375 & Very low \\
$\begin{array}{l}\text { Glibenclamide ver- } \\
\text { sus placebo }\end{array}$ & & $(4$ to 114$)$ & $\begin{array}{l}10.62) \\
\text { (1 RCT) }\end{array}$ &
\end{tabular}

\section{Not defined}

\begin{tabular}{|c|c|c|c|c|c|c|}
\hline $\begin{array}{l}\text { Brown } 2017 a \\
\text { Metformin versus } \\
\text { glibenclamide } \\
\text { Defined as }\end{array}$ & 48 per 1000 & $\begin{array}{l}41 \text { per } 1000 \\
\text { ( } 20 \text { to } 84 \text { ) }\end{array}$ & $\begin{array}{l}\text { RR } 0.86 \\
(0.42 \text { to } \\
1.77)\end{array}$ & $\begin{array}{l}554 \\
\text { (4 RCTs) }\end{array}$ & Low & $\begin{array}{l}\text { "Allocation concealment was un- } \\
\text { clear in one study and one other } \\
\text { study was open label. Event rates } \\
\text { were low (<30), } 12 / 281 \text { for the Met- } \\
\text { formin group and } 13 / 273 \text { for the } \\
\text { Glibenclamide group." }\end{array}$ \\
\hline $\begin{array}{l}<2.2 \mathrm{mmol} / \mathrm{L}(< \\
40 \mathrm{mg} / \mathrm{dL})\end{array}$ & & & & & & \\
\hline
\end{tabular}


Table 8. GRADE Summary of findings table - Child (as neonate, child, adult) (Continued)

\begin{tabular}{|c|c|c|c|c|c|c|}
\hline $\begin{array}{l}\text { Brown } 2017 \text { a } \\
\text { Glibenclamide ver- } \\
\text { sus acarbose } \\
\text { Defined as } \\
<\mathbf{2 . 2} \mathbf{~ m m o l} / \mathbf{L}(<\mathbf{4 0}\end{array}$ & 53 per 1000 & $\begin{array}{l}333 \text { per } \\
1000 \\
\text { ( } 46 \text { to } 1000 \text { ) }\end{array}$ & $\begin{array}{l}\text { RR } 6.33 \\
(0.87 \text { to } \\
46.32)\end{array}$ & $\begin{array}{l}43 \\
(1 \mathrm{RCT})\end{array}$ & Very low & $\begin{array}{l}\text { "There is evidence of selective re- } \\
\text { porting. Evidence based on one } \\
\text { small study with wide confidence } \\
\text { intervals. Low event rates and } \\
\text { sample size with } 8 / 24 \text { in Gliben- } \\
\text { clamide group and } 1 / 19 \text { in acar- } \\
\text { bose group." }\end{array}$ \\
\hline
\end{tabular}
$\mathrm{mg} / \mathrm{dL}$ )

\begin{tabular}{|c|c|c|c|c|c|c|}
\hline $\begin{array}{l}\text { Brown 2016a } \\
\text { Myo-inositol versus } \\
\text { placebo } 2 \\
\text { Not defined }\end{array}$ & $\begin{array}{l}263 \text { per } \\
1000\end{array}$ & $\begin{array}{l}13 \text { per } 1000 \\
(0 \text { to } 224)\end{array}$ & $\begin{array}{l}\text { RR } 0.05 \\
(0.00 \text { to } \\
0.85)\end{array}$ & $\begin{array}{l}73 \\
(1 \mathrm{RCT})\end{array}$ & Low & $\begin{array}{l}\text { "Evidence is based on one small } \\
\text { study with low event rates - } 0 / 35 \\
\text { events in myo-inositol group and } \\
10 / 38 \text { events } \\
\text { in the placebo group." }\end{array}$ \\
\hline
\end{tabular}

\begin{tabular}{|c|c|c|c|c|c|c|}
\hline $\begin{array}{l}\text { Han } 2017 \\
\text { Energy- versus no } \\
\text { energy-restricted } \\
\text { diet } \\
\text { Not defined }\end{array}$ & $\begin{array}{l}190 \text { per } \\
1000\end{array}$ & $\begin{array}{l}201 \text { per } \\
1000 \\
\text { (91 to } 441 \text { ) }\end{array}$ & $\begin{array}{l}\text { RR } 1.06 \\
(0.48 \text { to } \\
2.32)\end{array}$ & $\begin{array}{l}408 \\
\text { (2 RCTs) }\end{array}$ & Very low & $\begin{array}{l}\text { "Evidence is based on two small } \\
\text { studies at unclear risk of selection } \\
\text { bias; one study at high risk of per- } \\
\text { formance bias and unclear risk of } \\
\text { detection bias. Wide confidence in- } \\
\text { tervals crossing the line of no ef- } \\
\text { fect and substantial heterogeneity: } \\
\left.\right|^{2}=75 \% \text { present." }\end{array}$ \\
\hline
\end{tabular}

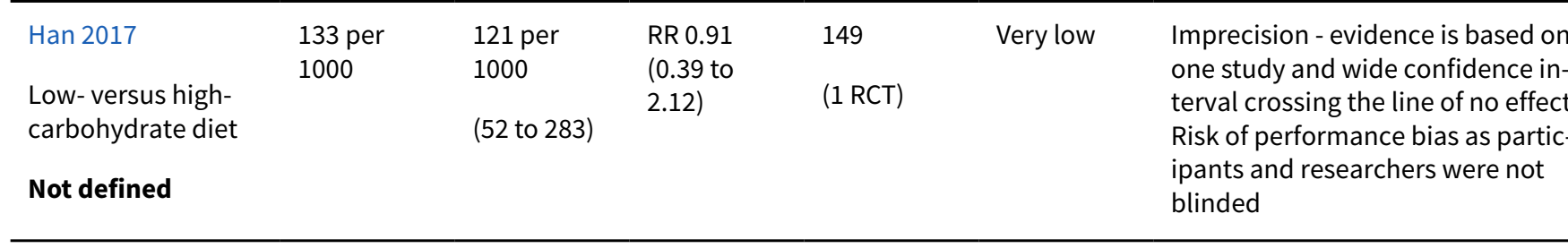

\begin{tabular}{|c|c|c|c|c|c|c|}
\hline $\begin{array}{l}\text { Han } 2017 \\
\text { Soy- versus no soy- } \\
\text { protein diet } \\
\text { Defined as BGL < } \\
\mathbf{1 . 7} \mathbf{~ m m o l / L ~}(<\mathbf{3 0 . 6} \\
\mathbf{~} \mathbf{d} / \mathbf{d L})\end{array}$ & 29 per 1000 & $\begin{array}{l}88 \text { per } 1000 \\
(10 \text { to } 806)\end{array}$ & $\begin{array}{l}\text { RR } 3.00 \\
(0.33 \text { to } \\
27.42)\end{array}$ & $\begin{array}{l}68 \\
(1 \mathrm{RCT})\end{array}$ & Very low & $\begin{array}{l}\text { Imprecision - evidence is based on } \\
\text { one study and wide confidence in- } \\
\text { terval crossing the line of no effect. } \\
\text { Risk of performance bias as par- } \\
\text { ticipants and personnel were not } \\
\text { blinded }\end{array}$ \\
\hline
\end{tabular}

\begin{tabular}{|c|c|c|c|c|c|c|}
\hline $\begin{array}{l}\text { Han } 2017 \\
\text { Ethnic specific di- } \\
\text { et versus standard } \\
\text { healthy diet } \\
\text { Not defined }\end{array}$ & 0 per 1000 & $\begin{array}{l}0 \text { per } 1000 \\
(0 \text { to } 0)\end{array}$ & $\begin{array}{l}\text { RR not es- } \\
\text { timable }\end{array}$ & $\begin{array}{l}20 \\
(1 \mathrm{RCT})\end{array}$ & Very low & $\begin{array}{l}\text { Imprecision - evidence is based } \\
\text { on one study. Risk of performance } \\
\text { bias as participants and person- } \\
\text { nel were not blinded and selective } \\
\text { reporting (reporting bias). There } \\
\text { were no neonatal hypoglycaemic } \\
\text { events in either group }\end{array}$ \\
\hline $\begin{array}{l}\text { Brown 2017b } \\
\text { Lifestyle interven- } \\
\text { tion versus usual } \\
\text { care or diet alone }\end{array}$ & 75 per 1000 & $\begin{array}{l}74 \text { per } 1000 \\
\text { (49 to } 114 \text { ) }\end{array}$ & $\begin{array}{l}\text { Average RR } \\
0.99(0.65 \\
\text { to } 1.52)\end{array}$ & $\begin{array}{l}3000 \\
\text { (6 RCTs) }\end{array}$ & Moderate & $\begin{array}{l}\text { "Allocation concealment was un- } \\
\text { clear in two trials and blinding was } \\
\text { not undertaken in two other tri- } \\
\text { als." }\end{array}$ \\
\hline \multicolumn{7}{|l|}{ Not defined } \\
\hline Brown 2017c & 59 per 1000 & $\begin{array}{l}118 \text { per } \\
1000\end{array}$ & $\begin{array}{l}\text { RR } 2.00 \\
(0.20 \text { to } \\
20.04)\end{array}$ & $\begin{array}{l}34 \\
(1 \mathrm{RCT})\end{array}$ & Very low & $\begin{array}{l}\text { "Imprecision - wide confidence in- } \\
\text { tervals and low event rates. There }\end{array}$ \\
\hline
\end{tabular}


Table 8. GRADE Summary of findings table - Child (as neonate, child, adult) (Continued)

Exercise versus

(12 to 1000$)$

is a lack of clarity for most items control associated with risk of bias."

\section{Not defined}

\begin{tabular}{|c|c|c|c|c|c|c|}
\hline $\begin{array}{l}\text { Han } 2012 \\
\text { Intensive manage- } \\
\text { ment versus routine } \\
\text { care } \\
\text { Defined as: }\end{array}$ & 66 per 1000 & $\begin{array}{l}26 \text { per } 1000 \\
(4 \text { to } 167 \text { ) }\end{array}$ & $\begin{array}{l}\text { RR } 0.39 \\
(0.06 \text { to } \\
2.54)\end{array}$ & $\begin{array}{l}426 \\
\text { (2 RCTs) }\end{array}$ & Very low & $\begin{array}{l}\text { Evidence is based on two studies } \\
\text { with few events and serious/very } \\
\text { serious design limitations. Wide } \\
\text { confidence intervals crossing the } \\
\text { line of no effect and substantial } \\
\text { heterogeneity: } \mathrm{I}^{2}=62 \%\end{array}$ \\
\hline
\end{tabular}

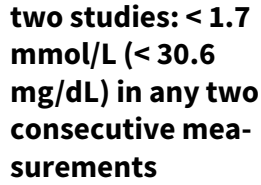

two studies: $<1.7$

$\mathrm{mmol} / \mathrm{L}$ ( $<30.6$

$\mathrm{mg} / \mathrm{dL}$ ) in any two

consecutive mea-

surements

one study: $<1.94$

mmol/L ( $<35 \mathrm{mg}$ /

dL)

\begin{tabular}{|c|c|c|c|c|c|c|}
\hline $\begin{array}{l}\text { Raman } 2017 \\
\text { Telemedicine ver- } \\
\text { sus standard care } \\
\text { for glucose moni- } \\
\text { toring }\end{array}$ & 82 per 100 & $\begin{array}{l}94 \text { per } 1000 \\
\text { (40 to } 224)\end{array}$ & $\begin{array}{l}\text { RR } 1.14 \\
(0.48 \text { to } \\
2.72)\end{array}$ & $\begin{array}{l}198 \\
\text { (3 RCTs) }\end{array}$ & Very low & $\begin{array}{l}\text { Evidence downgraded for impre- } \\
\text { cision (wide confidence intervals } \\
\text { crossing the line of no effect, small } \\
\text { sample sizes) and study limitations }\end{array}$ \\
\hline $\begin{array}{l}\text { Defined as } B G L \\
<2.6 \mathrm{mmol} / \mathrm{L} \text { in } \\
\text { one study }\end{array}$ & & & & & & \\
\hline $\begin{array}{l}\text { Raman } 2017 \\
\text { Self- versus period- } \\
\text { ic-glucose monitor- } \\
\text { ing }\end{array}$ & $\begin{array}{l}173 \text { per } \\
1000\end{array}$ & $\begin{array}{l}111 \text { per } \\
1000 \\
\text { (67 to } 183 \text { ) }\end{array}$ & $\begin{array}{l}\text { RR } 0.64 \\
(0.39 \text { to } \\
1.06)\end{array}$ & $\begin{array}{l}391 \\
\text { (2 RCTs) }\end{array}$ & Low & $\begin{array}{l}\text { Evidence downgraded for impre- } \\
\text { cision (wide confidence intervals } \\
\text { crossing the line of no effect) and } \\
\text { study limitations }\end{array}$ \\
\hline
\end{tabular}

\section{Not defined}

\begin{tabular}{|c|c|c|c|c|c|c|}
\hline $\begin{array}{l}\text { Raman } 2017 \\
\text { Continuous- ver- } \\
\text { sus self-monitoring }\end{array}$ & $\begin{array}{l}130 \text { per } \\
1000\end{array}$ & $\begin{array}{l}103 \text { per } \\
1000 \\
\text { (46 to } 232 \text { ) }\end{array}$ & $\begin{array}{l}\text { RR } 0.79 \\
(0.35 \text { to } \\
1.78)\end{array}$ & $\begin{array}{l}179 \\
\text { (2 RCTs) }\end{array}$ & Very low & $\begin{array}{l}\text { Evidence downgraded for impre- } \\
\text { cision (wide confidence intervals } \\
\text { crossing the line of no effect, small } \\
\text { sample sizes) and study limitations }\end{array}$ \\
\hline
\end{tabular}

blood glucose

Defined as blood

glucose $\leq \mathbf{4 5} \mathrm{mg}$ /

dL (2.5 mmol/L)

\begin{tabular}{|c|c|c|c|c|c|c|}
\hline $\begin{array}{l}\text { Raman } 2017 \\
\text { Post- versus pre- } \\
\text { prandial glucose } \\
\text { monitoring }\end{array}$ & $\begin{array}{l}212 \text { per } \\
1000\end{array}$ & $\begin{array}{l}30 \text { per } 1000 \\
\text { (4 to } 233 \text { ) }\end{array}$ & $\begin{array}{l}\text { RR } 0.14 \\
(0.02 \text { to } \\
1.10)\end{array}$ & $\begin{array}{l}66 \\
(1 \mathrm{RCT})\end{array}$ & Very low & $\begin{array}{l}\text { Evidence downgraded for impre- } \\
\text { cision (wide confidence intervals } \\
\text { crossing the line of no effect, single } \\
\text { trial, small sample sizes) and study } \\
\text { limitations }\end{array}$ \\
\hline $\begin{array}{l}\text { Defined as } \leq 30 \\
\text { mg/dL requiring } \\
\text { glucagon or dex- } \\
\text { trose infusion for } \\
\text { treatment during }\end{array}$ & & & & & & \\
\hline
\end{tabular}

Treatments for women with gestational diabetes mellitus: an overview of Cochrane systematic reviews (Review)

Copyright (c) 2018 The Cochrane Collaboration. Published by John Wiley \& Sons, Ltd. 
Table 8. GRADE Summary of findings table - Child (as neonate, child, adult) (Continued) the first four days after birth

\begin{tabular}{|c|c|c|c|c|c|c|}
\hline $\begin{array}{l}\text { Brown } 2017 d \\
\text { Insulin versus oral } \\
\text { therapy } \\
\text { Defined as < } \mathbf{2 . 6} \\
\text { mmol/L }\end{array}$ & $\begin{array}{l}111 \text { per } \\
1000\end{array}$ & $\begin{array}{l}126 \text { per } \\
1000 \\
\text { (94 to } 1.52 \text { ) }\end{array}$ & $\begin{array}{l}\text { Average RR } \\
1.14(0.85 \\
\text { to } 1.52)\end{array}$ & $\begin{array}{l}3892 \\
(24 \mathrm{RCTs})\end{array}$ & Low & $\begin{array}{l}\text { Evidence downgraded for study } \\
\text { limitations (lack of blinding) and } \\
\text { inconsistency }\end{array}$ \\
\hline $\begin{array}{l}\text { Brown 2017d } \\
\text { Insulin type A ver- } \\
\text { sus B }\end{array}$ & 12 per 1000 & $\begin{array}{l}28 \text { per } 1000 \\
\text { (1 to } 1000)\end{array}$ & $\begin{array}{l}\text { RR } 2.28 \\
(0.06 \text { to } \\
82.02)\end{array}$ & $\begin{array}{l}165 \\
\text { (3 RCTs) }\end{array}$ & Very low & $\begin{array}{l}\text { Evidence downgraded for study } \\
\text { limitations (lack of blinding), im- } \\
\text { precision (wide confidence inter- } \\
\text { vals) and inconsistency }\end{array}$ \\
\hline $\begin{array}{l}\text { Brown 2017d } \\
\text { Insulin versus diet }\end{array}$ & $\begin{array}{l}240 \text { per } \\
1000\end{array}$ & $\begin{array}{l}211 \text { per } \\
1000 \\
\text { (82 to } 583 \text { ) }\end{array}$ & $\begin{array}{l}\text { RR } 0.88 \\
(0.34 \text { to } \\
2.24)\end{array}$ & $\begin{array}{l}176 \\
\text { (3 RCTs) }\end{array}$ & Very low & $\begin{array}{l}\text { Evidence downgraded for study } \\
\text { limitations (lack of blinding), im- } \\
\text { precision (wide confidence inter- } \\
\text { vals) and inconsistency }\end{array}$ \\
\hline $\begin{array}{l}\text { Brown } 2017 d \\
\text { Insulin versus exer- } \\
\text { cise }\end{array}$ & $\begin{array}{l}118 \text { per } \\
1000\end{array}$ & $\begin{array}{l}59 \text { per } 1000 \\
\text { (6 to } 589)\end{array}$ & $\begin{array}{l}\text { RR } 0.50 \\
(0.05 \text { to } \\
5.01)\end{array}$ & $\begin{array}{l}34 \\
(1 \mathrm{RCT})\end{array}$ & Very low & $\begin{array}{l}\text { Evidence downgraded for study } \\
\text { limitations (insufficient details) } \\
\text { and imprecision (single small } \\
\text { study, wide confidence intervals) }\end{array}$ \\
\hline $\begin{array}{l}\text { Brown } 2017 \text { d } \\
\text { Insulin regimen A } \\
\text { versus B }\end{array}$ & 7 per 1000 & $\begin{array}{l}59 \text { per } 1000 \\
\text { ( } 7 \text { to } 464\end{array}$ & $\begin{array}{l}\text { RR } 8.12 \\
(1.03 \text { to } \\
64.03)\end{array}$ & $\begin{array}{l}274 \\
(1 \mathrm{RCT})\end{array}$ & Very low & $\begin{array}{l}\text { Evidence downgraded impreci- } \\
\text { sion (large treatment effect, single } \\
\text { small study, low event rates and } \\
\text { wide confidence intervals) }\end{array}$ \\
\hline $\begin{array}{l}\text { Twice daily versus } \\
\text { four times daily }\end{array}$ & & & & & & \\
\hline
\end{tabular}

\subsection{Adiposity - neonate}

\begin{tabular}{|c|c|c|c|c|c|c|}
\hline $\begin{array}{l}\text { Brown } 2017 b \\
\text { Lifestyle interven- } \\
\text { tion versus usual } \\
\text { care or diet alone } \\
\text { Defined as: neona- } \\
\text { tal fat mass (esti- } \\
\text { mated from skin- } \\
\text { fold thickness) }\end{array}$ & $\begin{array}{l}\text { Mean mass: } \\
427 \mathrm{~g}\end{array}$ & $\begin{array}{l}\text { Mean mass: } \\
37.80 \mathrm{~g} \text { few- } \\
\text { er }(63.97 \\
\mathrm{g} \text { fewer to } \\
10.63 \mathrm{~g} \text { few- } \\
\text { er) }\end{array}$ & $\begin{array}{l}\text { MD }-37.30 \\
g(-63.97 \text { to } \\
-10.63)\end{array}$ & $\begin{array}{l}958 \\
(1 \mathrm{RCT})\end{array}$ & Low & $\begin{array}{l}\text { "Imprecision. Evidence is base } \\
\text { on a single trial and there was } \\
\text { no blinding of participants/re- } \\
\text { searchers." }\end{array}$ \\
\hline $\begin{array}{l}\text { Brown } 2017 d \\
\text { Insulin versus oral } \\
\text { therapy } \\
\text { Defined as per- } \\
\text { centage fat mass } \\
\text { Defined as skin- } \\
\text { fold sum (mm) }\end{array}$ & $\begin{array}{l}\text { The mean } \\
\text { percentage } \\
\text { fat mass } \\
\text { was } 12.8 \% \\
\text { The mean } \\
\text { skinfold } \\
\text { sum was } 16 \\
\mathrm{~mm}\end{array}$ & $\begin{array}{l}\text { MD } 1.6 \% \\
\text { lower ( } 3.77 \\
\% \text { lower to } \\
0.57 \% \text { high- } \\
\text { er) } \\
\text { MD } 0.8 \mathrm{~mm} \\
\text { lower (0.49 } \\
\text { mm lower } \\
\text { to } 0.73 \mathrm{~mm} \\
\text { higher) }\end{array}$ & $\begin{array}{l}\text { MD }-1.60 \\
(-3.77 \text { to } \\
0.57) \\
\text { MD- } 0.80 \\
(-2.33 \text { to } \\
0.73)\end{array}$ & $\begin{array}{l}82 \\
(1 \mathrm{RCT}) \\
82 \\
(1 \mathrm{RCT})\end{array}$ & Very low & $\begin{array}{l}\text { Evidence was downgraded for im- } \\
\text { precision as based on one trial } \\
\text { Evidence was downgraded for im- } \\
\text { precision as based on one trial } \\
\text { with wide confidence intervals and } \\
\text { study limitations (selective report- } \\
\text { ing and other bias detected) }\end{array}$ \\
\hline
\end{tabular}


Table 8. GRADE Summary of findings table - Child (as neonate, child, adult) (Continued)

\subsection{Adiposity - \\ child}

\begin{tabular}{|c|c|c|c|c|c|c|}
\hline 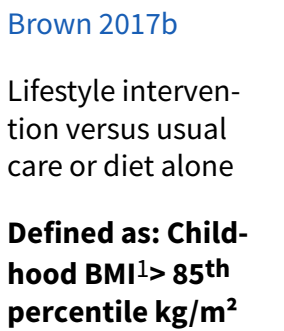 & $\begin{array}{l}350 \text { per } \\
1000\end{array}$ & $\begin{array}{l}318 \text { per } \\
1000 \\
\text { (262 to } 388)\end{array}$ & $\begin{array}{l}\text { RR } 0.91 \\
(0.75 \text { to } \\
1.11)\end{array}$ & $\begin{array}{l}767 \\
\text { (3 RCTs) }\end{array}$ & Moderate & $\begin{array}{l}\text { "Allocation concealment and ran- } \\
\text { domisation was unclear in } 1 / 3 \text { tri- } \\
\text { als and } 1 / 3 \text { trials did not blind par- } \\
\text { ticipants/researchers." }\end{array}$ \\
\hline $\begin{array}{l}\text { Brown } 2017 b \\
\text { Lifestyle interven- } \\
\text { tion versus usual } \\
\text { care or diet alone } \\
\text { Defined as: Child- } \\
\text { hood BMI' } \mathbf{z} \text { score }\end{array}$ & $\begin{array}{l}\text { The mean } \\
\text { childhood } \\
\text { BMI z score } \\
\text { was } 0.49 \\
\text { lower }\end{array}$ & $\begin{array}{l}\text { The child- } \\
\text { hood BMI z } \\
\text { score in the } \\
\text { interven- } \\
\text { tion group } \\
\text { was } 0.08 \\
\text { lower ( } 0.28 \\
\text { lower to } \\
10.63 \text { low- } \\
\text { er) }\end{array}$ & $\begin{array}{l}\text { MD } 0.08 \\
(-0.28 \text { to } \\
0.44)\end{array}$ & $\begin{array}{l}199 \\
(1 \mathrm{RCT})\end{array}$ & Very low & $\begin{array}{l}\text { Imprecision - evidence is based on } \\
\text { one study and wide confidence in- } \\
\text { terval crossing the line of no effect. } \\
\text { Only reports on } 199 \text { children of the } \\
\text { original trial of } 1000 \text { participants }\end{array}$ \\
\hline $\begin{array}{l}\text { Brown } 2017 d \\
\text { Insulin versus oral } \\
\text { therapy } \\
\text { Defined as total fat } \\
\text { mass (\%) up to 2- } \\
\text { years }\end{array}$ & $\begin{array}{l}\text { The mean } \\
\text { childhood } \\
\text { total fat } \\
\text { mass }(\%) \\
\text { was } 16.4 \%\end{array}$ & $\begin{array}{l}\text { MD } 0.5 \% \\
\text { higher }(0.49 \\
\% \text { lower } \\
\text { to } 1.49 \% \\
\text { higher) }\end{array}$ & $\begin{array}{l}\text { MD } 0.50 \\
(-0.49 \text { to } \\
1.49)\end{array}$ & $\begin{array}{l}318 \\
(1 \mathrm{RCT})\end{array}$ & Low & $\begin{array}{l}\text { Evidence downgraded for study } \\
\text { limitations (lack of blinding) and } \\
\text { imprecision as based on a single } \\
\text { study }\end{array}$ \\
\hline
\end{tabular}

13.0 Diabetes

Either no data were reported for this outcome in any of the included Cochrane systematic reviews or none of the included studies in the review pre-specified this outcome

\subsection{Neurosensory disability}

\begin{tabular}{|c|c|c|c|c|c|c|}
\hline $\begin{array}{l}\text { Brown 2017d } \\
\text { Insulin versus oral }\end{array}$ & $\begin{array}{l}104 \text { per } \\
1000\end{array}$ & $\begin{array}{l}111 \text { per } \\
1000\end{array}$ & $\begin{array}{l}\text { RR } 1.07 \\
(0.33 \text { to } \\
3.44)\end{array}$ & 93 (1 RCT) & Low & $\begin{array}{l}\text { Evidence downgraded for impre- } \\
\text { cision as based on a single study } \\
\text { with wide confidence intervals }\end{array}$ \\
\hline therapy & 0 per 1000 & (34 to 385 ) & & & & \\
\hline $\begin{array}{l}\text { Mild developmental } \\
\text { delay (18 months) }\end{array}$ & 21 per 1000 & $\begin{array}{l}0 \text { per } 1000 \\
(0 \text { to } 0)\end{array}$ & $\begin{array}{l}\text { RR } 0.31 \\
(0.01 \text { to } \\
7.49)\end{array}$ & & & \\
\hline $\begin{array}{l}\text { Hearing impair- } \\
\text { ment (18 months) }\end{array}$ & & 6 per 1000 & $\begin{array}{l}\text { RR } 0.03 \text { to } \\
2.90\end{array}$ & & & \\
\hline $\begin{array}{l}\text { Visual impairment } \\
\text { (18 months) }\end{array}$ & & (1 to 60$)$ & & & & \\
\hline
\end{tabular}

*The risk in the intervention group (and its $95 \%$ confidence interval) is based on the assumed risk in the comparison group and the relative effect of the intervention (and its $95 \% \mathrm{Cl}$ ).

Cl: confidence interval; $\mathbf{R C T}$ : randomised controlled trial; RR: risk ratio 
Table 8. GRADE Summary of findings table - Child (as neonate, child, adult) (Continued)

\section{GRADE Working Group grades of evidence}

High quality: We are very confident that the true effect lies close to that of the estimate of the effect

Moderate quality: We are moderately confident in the effect estimate: The true effect is likely to be close to the estimate of the effect, but there is a possibility that it is substantially different

Low quality: Our confidence in the effect estimate is limited: The true effect may be substantially different from the estimate of the effect

Very low quality: We have very little confidence in the effect estimate: The true effect is likely to be substantially different from the estimate of effect

${ }^{1} \mathrm{BMI}$ is an acronym for Body Mass Index

$24 \mathrm{~g}$ myo-inositol $+400 \mu \mathrm{g}$ folic acid orally per day and exercise and dietary advice versus placebo $400 \mu \mathrm{g}$ folic acid orally per day and exercise and dietary advice.

Table 9. GRADE Summary of findings table - Health service use

\begin{tabular}{lllllll}
\hline $\begin{array}{l}\text { Intervention } \\
\text { and compar- } \\
\text { ison and out- } \\
\text { come }\end{array}$ & $\begin{array}{l}\text { Assumed } \\
\text { risk with } \\
\text { compara- } \\
\text { tor }\end{array}$ & $\begin{array}{l}\text { Corre- } \\
\text { sponding } \\
\text { risk with } \\
\text { interven- } \\
\text { tion* }\end{array}$ & $\begin{array}{l}\text { Relative } \\
\text { effect } \\
(95 \% \mathrm{CI})\end{array}$ & $\begin{array}{l}\text { № of par- } \\
\text { ticipants } \\
\text { (studies) }\end{array}$ & $\begin{array}{l}\text { Quality of } \\
\text { the evi- } \\
\text { dence } \\
\text { (GRADE) }\end{array}$ & Comments \\
from overview review authors
\end{tabular}

\subsection{Number of antenatal visits or admissions}

\begin{tabular}{|c|c|c|c|c|c|c|}
\hline $\begin{array}{l}\text { Han } 2017 \\
\text { Soy- versus no } \\
\text { soy-protein diet } \\
\text { Defined as ma- } \\
\text { ternal hospi- } \\
\text { talisation }\end{array}$ & $\begin{array}{l}118 \text { per } \\
1000\end{array}$ & $\begin{array}{l}88 \text { per } 1000 \\
(21 \text { to } 365)\end{array}$ & $\begin{array}{l}\text { RR } 0.75 \\
(0.18 \text { to } \\
3.10)\end{array}$ & 68 (1 RCT) & Very low & $\begin{array}{l}\text { Imprecision - evidence based on one } \\
\text { trial. Evidence of risk of bias as partici- } \\
\text { pants and researchers were not blind- } \\
\text { ed. Wide confidence interval crossing } \\
\text { the line of no effect }\end{array}$ \\
\hline $\begin{array}{l}\text { Brown } 2017 \mathrm{~b} \\
\text { Lifestyle inter- } \\
\text { vention versus } \\
\text { usual care or di- } \\
\text { et alone }\end{array}$ & $\begin{array}{l}273 \text { per } \\
1000\end{array}$ & $\begin{array}{l}289 \text { per } \\
1000 \\
\text { (237 to } 352 \text { ) }\end{array}$ & $\begin{array}{l}\text { RR } 1.06 \\
(0.87 \text { to } \\
1.29)\end{array}$ & $\begin{array}{l}1000 \\
(1 \mathrm{RCT})\end{array}$ & Moderate & $\begin{array}{l}\text { Imprecision, evidence is based on a } \\
\text { single trial }\end{array}$ \\
\hline
\end{tabular}

\begin{tabular}{|c|c|c|c|c|c|c|}
\hline $\begin{array}{l}\text { Raman } 2017 \\
\text { Telemedicine } \\
\text { versus standard } \\
\text { care for glucose } \\
\text { monitoring } \\
\text { Defined as } \\
\text { number of } \\
\text { hospital or } \\
\text { health profes- } \\
\text { sional visits : } \\
\text { face-to-face }\end{array}$ & $\begin{array}{l}\text { Mean num- } \\
\text { ber of face- } \\
\text { to-face vis- } \\
\text { its in the } \\
\text { standard } \\
\text { care group } \\
\text { was } 4.34\end{array}$ & $\begin{array}{l}\text { Mean dif- } \\
\text { ference was } \\
0.36 \text { visits } \\
\text { fewer ( } 0.92 \\
\text { visits fewer } \\
\text { to } 0.20 \text { vis- } \\
\text { its more) }\end{array}$ & $\begin{array}{l}\text { MD }-0.36 \\
\text { visits }(-0.92 \\
\text { to } 0.20)\end{array}$ & 97 (1 RCT) & Very low & $\begin{array}{l}\text { Evidence downgraded for impreci- } \\
\text { sion (wide confidence intervals, sin- } \\
\text { gle study, small sample size) and study } \\
\text { limitations }\end{array}$ \\
\hline Raman 2017 & $\begin{array}{l}\text { Mean num- } \\
\text { ber of vis- } \\
\text { its in the } \\
\text { periodic }\end{array}$ & $\begin{array}{l}\text { Mean dif- } \\
\text { ference was } \\
0.2 \text { visits } \\
\text { more }(1.09\end{array}$ & $\begin{array}{l}\text { MD } 0.20 \\
(-1.09 \text { to } \\
1.49)\end{array}$ & 58 (1 RCT) & Very low & $\begin{array}{l}\text { Evidence downgraded for impreci- } \\
\text { sion (wide confidence intervals, sin- } \\
\text { gle study, small sample size) and study } \\
\text { limitations }\end{array}$ \\
\hline
\end{tabular}


Table 9. GRADE Summary of findings table - Health service use (Continued)

\section{Self- versus pe- riodic-glucose monitoring \\ Defined as vis- \\ its with dia- \\ betes team}

monitoring group was 5.2

\begin{tabular}{|c|c|c|c|c|c|c|}
\hline $\begin{array}{l}\text { Brown 2017d } \\
\text { Insulin versus } \\
\text { oral therapy }\end{array}$ & $\begin{array}{l}\text { Mean num- } \\
\text { ber of vis- } \\
\text { its in the } \\
\text { oral ther- } \\
\text { apy group } \\
\text { was } 11\end{array}$ & $\begin{array}{l}\text { Mean dif- } \\
\text { ference was } \\
1 \text { visit more } \\
\text { ( } 0.08 \text { vis- } \\
\text { its fewer to } \\
2.08 \text { visits } \\
\text { more) }\end{array}$ & $\begin{array}{l}\text { MD } 1.00 \\
(-0.08 \text { to } \\
2.08)\end{array}$ & 404 (1 RCT) & Low & $\begin{array}{l}\text { Evidence downgraded for impreci- } \\
\text { sion (wide confidence intervals, single } \\
\text { study) and study limitations }\end{array}$ \\
\hline
\end{tabular}

\section{ewer to}

1.49 more)

\subsection{Length of postnatal stay (mother)}

\begin{tabular}{lll}
\hline$-1-1$ & - & $\begin{array}{l}\text { Either no data were reported for } \\
\text { this outcome in any of the included } \\
\text { Cochrane systematic reviews or none } \\
\text { of the included studies in the review } \\
\text { pre-specified this outcome }\end{array}$ \\
\hline
\end{tabular}

\subsection{Length of postnatal stay (baby) includingNICU1 or SCBU2}

\begin{tabular}{|c|c|c|c|c|c|c|}
\hline $\begin{array}{l}\text { Han } 2017 \\
\text { Diet + diet-re- } \\
\text { lated behav- } \\
\text { ioural advice } \\
\text { versus diet only } \\
\text { Defined as > } 4 \\
\text { days }\end{array}$ & $\begin{array}{l}260 \text { per } \\
1000\end{array}$ & $\begin{array}{l}346 \text { peer } \\
1000 \\
(190 \text { to } 634)\end{array}$ & $\begin{array}{l}\text { RR } 1.33 \\
(0.73 \text { to } \\
2.44)\end{array}$ & 99 (1 RCT) & Very low & $\begin{array}{l}\text { Imprecision - evidence based on one } \\
\text { small trial. Evidence of risk of bias as } \\
\text { participants and researchers were } \\
\text { not blinded. Wide confidence interval } \\
\text { crossing the line of no effect }\end{array}$ \\
\hline $\begin{array}{l}\text { Raman } 2017 \\
\text { Continuous- } \\
\text { versus self- } \\
\text { monitoring } \\
\text { Defined as } \\
\text { length of stay } \\
\text { in NICU }\end{array}$ & $\begin{array}{l}\text { Mean dura- } \\
\text { tion of stay } \\
\text { in NICU for } \\
\text { the self- } \\
\text { monitoring } \\
\text { group was } \\
3.83 \text { days }\end{array}$ & $\begin{array}{l}\text { The mean } \\
\text { difference } \\
\text { for the con- } \\
\text { tinuous } \\
\text { monitoring } \\
\text { group was } \\
0.83 \text { days } \\
\text { less ( } 2.35 \\
\text { days less to } \\
0.69 \text { days } \\
\text { more) }\end{array}$ & $\begin{array}{l}\text { MD }-0.83 \\
(-2.35 \text { to } \\
0.69)\end{array}$ & 18 (1 RCT) & Very low & $\begin{array}{l}\text { Evidence downgraded for study limi- } \\
\text { tations and imprecision (single trial, } \\
\text { small sample size, wide confidence in- } \\
\text { tervals) }\end{array}$ \\
\hline $\begin{array}{l}\text { Brown } 2017 d \\
\text { Insulin versus } \\
\text { oral therapy } \\
\text { Duration of } \\
\text { stay in NICU }\end{array}$ & $\begin{array}{l}\text { Mean dura- } \\
\text { tion of stay } \\
\text { in NICU for } \\
\text { the oral } \\
\text { therapy } \\
\text { group was } \\
5.9 \text { days }\end{array}$ & $\begin{array}{l}\text { The mean } \\
\text { difference } \\
\text { for the in- } \\
\text { sulin group } \\
\text { was } 0.2 \\
\text { days less } \\
\text { (1.8 days } \\
\text { less to } 1.4 \\
\text { days more) }\end{array}$ & $\begin{array}{l}\text { MD }-0.20 \\
(-1.79 \text { to } \\
1.39)\end{array}$ & $\begin{array}{l}401 \text { (3 } \\
\text { RCTs) }\end{array}$ & Very low & $\begin{array}{l}\text { Evidence downgraded for study limita- } \\
\text { tions; imprecision (wide confidence in- } \\
\text { tervals) and inconsistency }\end{array}$ \\
\hline
\end{tabular}

\subsection{Costs associated with the treatment}


Table 9. GRADE Summary of findings table - Health service use (Continued)

\begin{tabular}{|c|c|c|c|c|}
\hline Brown 2017d & $\begin{array}{l}\text { See com- } \\
\text { ment }\end{array}$ & $\begin{array}{l}\text { See com- } \\
\text { ment }\end{array}$ & $\begin{array}{l}\text { See com- } \\
\text { ment }\end{array}$ & 197 (1 RCT) \\
\hline
\end{tabular}

oral therapy

Evidence from one trial suggested that the costs of insulins (excluding syringes) was higher than for glibenclamide; metformin or for combined metformin and insulin. The data were not suitable for meta-analysis

\begin{tabular}{llllll}
\hline Brown 2017b & $\begin{array}{l}\text { See com- } \\
\text { ment }\end{array}$ & $\begin{array}{l}\text { See com- } \\
\text { ment }\end{array}$ & $\begin{array}{l}\text { See com- } \\
\text { ment }\end{array}$ & 1000 & Moderate \\
Lifestyle inter- & & & & $(1 \mathrm{RCT})$ &
\end{tabular}

vention versus usual care or diet alone

One trial in this review included costs associated with the treatment for mild GDM versus usual care and showed costs were higher in the lifestyle intervention group compared to the control group which is mainly due to increased surveillance and increased contact with health professionals. However, the data were not in a suitable format for inclusion in a meta-analysis and therefore summarised in Table 12

\begin{tabular}{|c|c|c|c|c|c|c|}
\hline $\begin{array}{l}\text { Raman } 2017 \\
\text { Telemedicine } \\
\text { versus standard } \\
\text { care for glucose } \\
\text { monitoring }\end{array}$ & $\begin{array}{l}\text { See com- } \\
\text { ment }\end{array}$ & $\begin{array}{l}\text { See com- } \\
\text { ment }\end{array}$ & $\begin{array}{l}\text { See com- } \\
\text { ment }\end{array}$ & 100 (1 RCT) & Very low & $\begin{array}{l}\text { One trial reported that "in our study, } \\
\text { the telemedicine system not only } \\
\text { made attention more convenient for } \\
\text { the patient, it was also less expensive } \\
\text { for the health systema in terms of the } \\
\text { use of health professionals time." }\end{array}$ \\
\hline
\end{tabular}

Evidence downgraded for imprecision and study limitations

\begin{tabular}{|c|c|c|c|c|c|c|}
\hline $\begin{array}{l}\text { Raman } 2017 \\
\text { Self-monitoring } \\
\text { versus period } \\
\text { glucose moni- } \\
\text { toring }\end{array}$ & $\begin{array}{l}\text { See com- } \\
\text { ment }\end{array}$ & $\begin{array}{l}\text { See com- } \\
\text { ment }\end{array}$ & $\begin{array}{l}\text { See com- } \\
\text { ment }\end{array}$ & 347 (1 RCT) & Very low & $\begin{array}{l}\text { One trial reported costs "the direct } \\
\text { management costs (meter rental, } \\
\text { equipment purchase, and clinical } \\
\text { reagent strip) of the two follow-ups in } \\
\text { considering the transfer to home mon- } \\
\text { itoring. On a weekly basis the expense } \\
\text { was (US dollars): } \$ 10.80 / \text { woman on } \\
\text { home monitoring, } \$ 0.50 / \text { woman with } \\
\text { a breakfast result below } 7.8 \mathrm{mmol} / \mathrm{L} \\
\text { on clinic follow-up, and } \$ 6.80 / \text { woman } \\
\text { with a breakfast result at or above } 7.8 \\
\text { mmol/L on clinic follow-up". Evidence } \\
\text { downgraded for imprecision and study } \\
\text { limitations }\end{array}$ \\
\hline
\end{tabular}

*The risk in the intervention group (and its $95 \%$ confidence interval) is based on the assumed risk in the comparison group and the relative effect of the intervention (and its $95 \% \mathrm{Cl}$ ).

Cl: confidence interval; $\mathbf{R C T}$ : randomised controlled trial; RR: risk ratio

\section{GRADE Working Group grades of evidence}

High quality: We are very confident that the true effect lies close to that of the estimate of the effect

Moderate quality: We are moderately confident in the effect estimate: The true effect is likely to be close to the estimate of the effect, but there is a possibility that it is substantially different

Low quality: Our confidence in the effect estimate is limited: The true effect may be substantially different from the estimate of the effect

Very low quality: We have very little confidence in the effect estimate: The true effect is likely to be substantially different from the estimate of effect

1 NICU - Neonatal Intensive Care Unit

2SCBU - Special Care Baby Unit

Treatments for women with gestational diabetes mellitus: an overview of Cochrane systematic reviews (Review) 


\begin{tabular}{|c|c|c|c|c|c|c|c|c|c|c|}
\hline Review ID & $\begin{array}{l}\text { Biesty } \\
2018\end{array}$ & $\begin{array}{l}\text { Brown } \\
2017 a\end{array}$ & $\begin{array}{l}\text { Brown } \\
2017 b\end{array}$ & $\begin{array}{l}\text { Brown } \\
2017 c\end{array}$ & $\begin{array}{l}\text { Brown } \\
2017 d\end{array}$ & $\begin{array}{l}\text { Brown } \\
2016 a\end{array}$ & Han 2017 & Han 2012 & $\begin{array}{l}\text { Martis } \\
2016 a\end{array}$ & $\begin{array}{l}\text { Raman } \\
2017\end{array}$ \\
\hline \multicolumn{11}{|c|}{$\begin{array}{l}\text { AMSTAR Domains } \\
\text { Answer code: } \sqrt{ }=\text { Yes; } X=\text { No; } ?=\text { Unclear; } N A=\text { Not applicable }\end{array}$} \\
\hline $\begin{array}{l}\text { 1. Was an a priori design provid- } \\
\text { ed? }\end{array}$ & $\sqrt{ }$ & $\sqrt{ }$ & $\sqrt{ }$ & $\sqrt{ }$ & $\sqrt{ }$ & $\sqrt{ }$ & $\sqrt{ }$ & $\sqrt{ }$ & $\sqrt{ }$ & $\sqrt{ }$ \\
\hline $\begin{array}{l}\text { 2. Was there duplicate study se- } \\
\text { lection and data extraction? }\end{array}$ & $\sqrt{ }$ & $\sqrt{ }$ & $\sqrt{ }$ & $\sqrt{ }$ & $\sqrt{ }$ & $\sqrt{ }$ & $\sqrt{ }$ & $\sqrt{ }$ & $\sqrt{ }$ & $\sqrt{ }$ \\
\hline $\begin{array}{l}\text { 3. Was a comprehensive litera- } \\
\text { ture search performed? }\end{array}$ & $\sqrt{ }$ & $\sqrt{ }$ & $\sqrt{ }$ & $\sqrt{ }$ & $\sqrt{ }$ & $\sqrt{ }$ & $\sqrt{ }$ & $\sqrt{ }$ & $\sqrt{ }$ & $\sqrt{ }$ \\
\hline $\begin{array}{l}\text { 4. Was the status of publication } \\
\text { (i.e. grey literature) used as an } \\
\text { inclusion criterion? }\end{array}$ & $\sqrt{ }$ & $\sqrt{ }$ & $\sqrt{ }$ & $\sqrt{ }$ & $\sqrt{ }$ & $\sqrt{ }$ & $\sqrt{ }$ & $\sqrt{ }$ & $\sqrt{ }$ & $\sqrt{ }$ \\
\hline $\begin{array}{l}\text { 5. Was a list of studies (included } \\
\text { and excluded) provided? }\end{array}$ & $\sqrt{ }$ & $\sqrt{ }$ & $\sqrt{ }$ & $\sqrt{ }$ & $\sqrt{ }$ & $\sqrt{ }$ & $\sqrt{ }$ & $\sqrt{ }$ & $\sqrt{ }$ & $\sqrt{ }$ \\
\hline $\begin{array}{l}\text { 6. Were the characteristics of } \\
\text { the included studies provided? }\end{array}$ & $\sqrt{ }$ & $\sqrt{ }$ & $\sqrt{ }$ & $\sqrt{ }$ & $\sqrt{ }$ & $\sqrt{ }$ & $\sqrt{ }$ & $\sqrt{ }$ & $\sqrt{ }$ & $\sqrt{ }$ \\
\hline $\begin{array}{l}\text { 7. Was the scientific quality of } \\
\text { the included studies assessed } \\
\text { and documented? }\end{array}$ & $\sqrt{ }$ & $\sqrt{ }$ & $\sqrt{ }$ & $\sqrt{ }$ & $\sqrt{ }$ & $\sqrt{ }$ & $\sqrt{ }$ & $\sqrt{ }$ & $\sqrt{ }$ & $\sqrt{ }$ \\
\hline $\begin{array}{l}\text { 8. Was the scientific quality of } \\
\text { the included studies used ap- } \\
\text { propriately in formulating con- } \\
\text { clusions? }\end{array}$ & $\sqrt{ }$ & $\sqrt{ }$ & $\sqrt{ }$ & $\sqrt{ }$ & $\sqrt{ }$ & $\sqrt{ }$ & $\sqrt{ }$ & $\sqrt{ }$ & $\sqrt{ }$ & $\sqrt{ }$ \\
\hline $\begin{array}{l}\text { 9. Were the methods used to } \\
\text { combine the findings of studies } \\
\text { appropriate? }\end{array}$ & NA & $\sqrt{ }$ & $\sqrt{ }$ & $\sqrt{ }$ & $\sqrt{ }$ & $\sqrt{ }$ & $\sqrt{ }$ & $\sqrt{ }$ & NA & $\sqrt{ }$ \\
\hline $\begin{array}{l}\text { 10. Was the likelihood of publi- } \\
\text { cation bias assessed?*}\end{array}$ & $x$ & $\sqrt{ }$ & $\sqrt{ }$ & $\sqrt{ }$ & $\sqrt{ }$ & $x$ & $\sqrt{ }$ & $x$ & $x$ & $\sqrt{ }$ \\
\hline
\end{tabular}




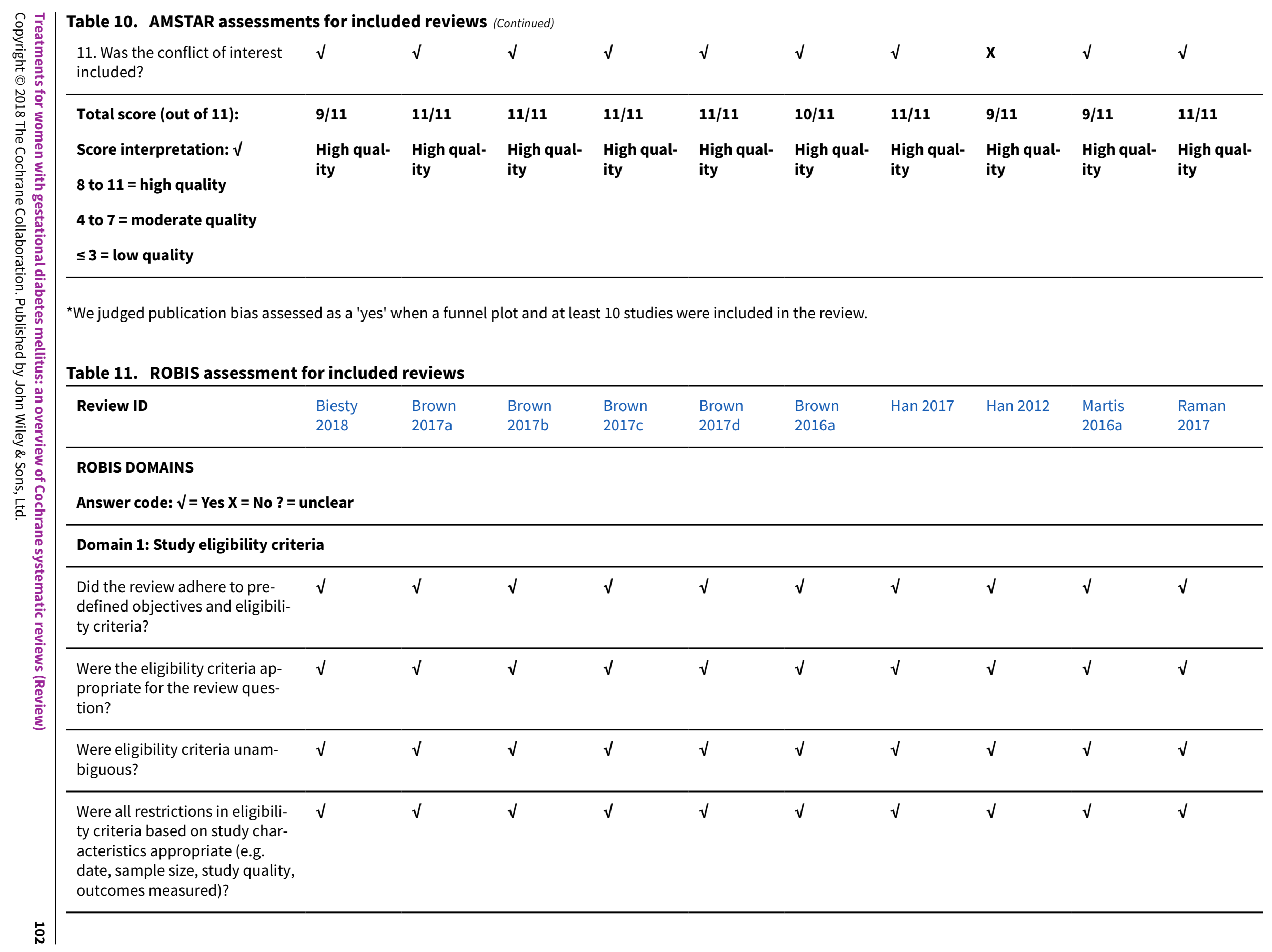




\begin{tabular}{|c|c|c|c|c|c|c|c|c|c|c|}
\hline $\begin{array}{l}\text { Were any restrictions in eligibil- } \\
\text { ity criteria based on sources of } \\
\text { information appropriate (pub- } \\
\text { lication status or format, lan- } \\
\text { guage, availability of data)? }\end{array}$ & $\sqrt{ }$ & $\sqrt{ }$ & $\sqrt{ }$ & $\sqrt{ }$ & $\sqrt{ }$ & $\sqrt{ }$ & $\sqrt{ }$ & $\sqrt{ }$ & $\sqrt{ }$ & $\sqrt{ }$ \\
\hline $\begin{array}{l}\text { Concerns regarding specifica- } \\
\text { tion of study eligibility crite- } \\
\text { ria } \\
\text { LOW, HIGH, UNCLEAR }\end{array}$ & Low & Low & Low & Low & Low & Low & Low & Low & Low & Low \\
\hline \multicolumn{11}{|c|}{ Domain 2: Identification and selection of studies } \\
\hline $\begin{array}{l}\text { Did the search include an ap- } \\
\text { propriate range of databas- } \\
\text { es/electronic sources for pub- } \\
\text { lished and unpublished re- } \\
\text { ports? }\end{array}$ & $\sqrt{ }$ & $\sqrt{ }$ & $\sqrt{ }$ & $\sqrt{ }$ & $\sqrt{ }$ & $\sqrt{ }$ & $\sqrt{ }$ & $\sqrt{ }$ & $\sqrt{ }$ & $\sqrt{ }$ \\
\hline $\begin{array}{l}\text { Were methods additional to } \\
\text { database searching used to } \\
\text { identify relevant reports? }\end{array}$ & $\sqrt{ }$ & $\sqrt{ }$ & $\sqrt{ }$ & $\sqrt{ }$ & $\sqrt{ }$ & $\sqrt{ }$ & $\sqrt{ }$ & $\sqrt{ }$ & $\sqrt{ }$ & $\sqrt{ }$ \\
\hline $\begin{array}{l}\text { Were the terms and structure of } \\
\text { the search strategy likely to re- } \\
\text { trieve as many eligible studies } \\
\text { as possible? }\end{array}$ & $\sqrt{ }$ & $\sqrt{ }$ & $\sqrt{ }$ & $\sqrt{ }$ & $\sqrt{ }$ & $\sqrt{ }$ & $\sqrt{ }$ & $\sqrt{ }$ & $\sqrt{ }$ & $\sqrt{ }$ \\
\hline $\begin{array}{l}\text { Were restrictions based on } \\
\text { date, publication format, or } \\
\text { language appropriate? }\end{array}$ & $\sqrt{ }$ & $\sqrt{ }$ & $\sqrt{ }$ & $\sqrt{ }$ & $\sqrt{ }$ & $\sqrt{ }$ & $\sqrt{ }$ & $\sqrt{ }$ & $\sqrt{ }$ & $\sqrt{ }$ \\
\hline $\begin{array}{l}\text { Were efforts made to minimise } \\
\text { error in selection of studies? }\end{array}$ & $\sqrt{ }$ & $\sqrt{ }$ & $\sqrt{ }$ & $\sqrt{ }$ & $\sqrt{ }$ & $\sqrt{ }$ & $\sqrt{ }$ & $\sqrt{ }$ & $\sqrt{ }$ & $\sqrt{ }$ \\
\hline $\begin{array}{l}\text { Concerns regarding methods } \\
\text { used to identify and/or select } \\
\text { studies: LOW, HIGH, UNCLEAR }\end{array}$ & Low & Low & Low & Low & Low & Low & Low & Low & Low & Low \\
\hline \multicolumn{11}{|c|}{ Domain 3: Data collection and study appraisal } \\
\hline
\end{tabular}




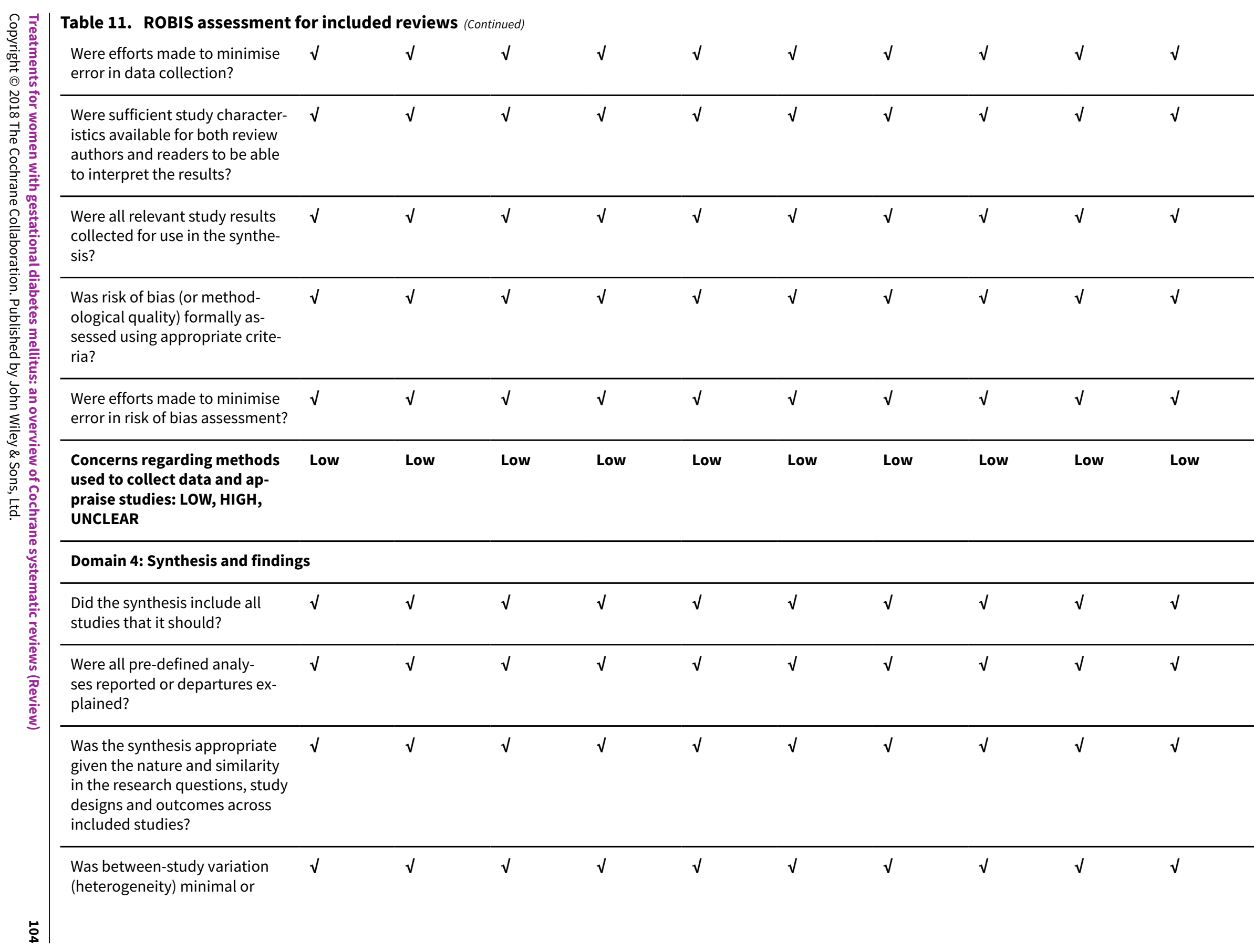




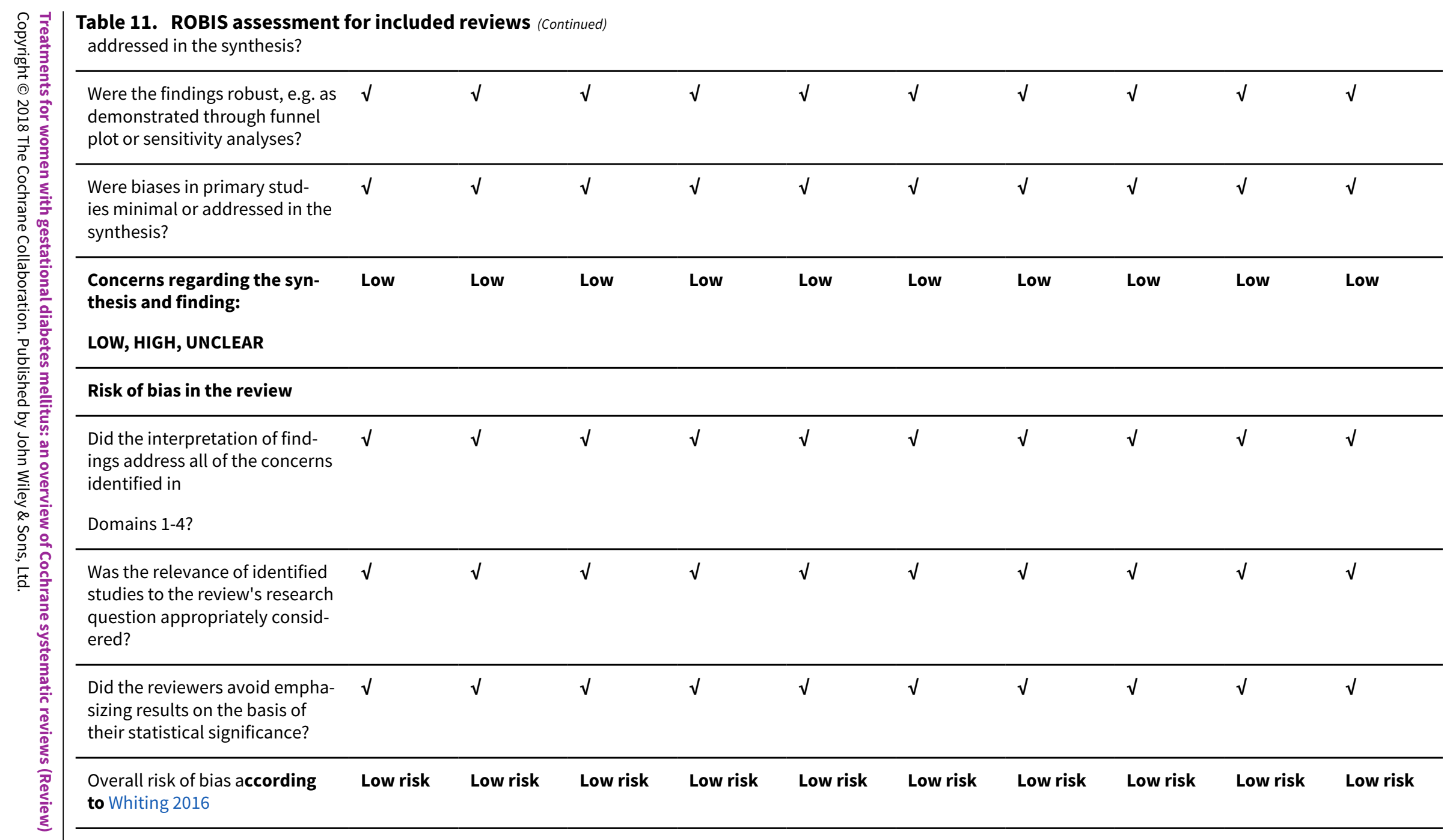


Table 12. Treament costs

\begin{tabular}{lll}
\hline Crowther 2005 & Lifestyle intervention & Usual care \\
\hline Package of treatment for mild GDM versus usual care & & AUD 33,681 \\
\hline Direct costs per 100 women with a singleton & AUD 67,432 & \\
pregnancy - including antenatal clinic & & AUD 524,891 \\
visits, specialist clinics, dietician, diabetes & AUD 545,125 \\
educator, insulin therapy & AUD 612,557 558,572 \\
\hline In-patient costs - hospital costs & AUD 36,749 & AUD 30,229 \\
\hline Total direct health service costs & & \\
\hline Patient/family costs & & \\
\hline
\end{tabular}

Permission granted from John Wiley \& Sons, Ltd. to use this treatment costs table from Brown 2017b (table 11, p. 127)

\section{APPENDICES}

Appendix 1. Ongoing Cochrane systematic reviews (Protocols and Title Registrations)

\begin{tabular}{|c|c|c|c|c|}
\hline $\begin{array}{l}\text { Protocol ID and title } \\
\text { and title registrations }\end{array}$ & Reference & $\begin{array}{l}\text { Inclusion criteria for } \\
\text { types of participants }\end{array}$ & $\begin{array}{l}\text { Comparison in- } \\
\text { terventions }\end{array}$ & $\begin{array}{l}\text { Overview outcomes pre-speci- } \\
\text { fied in the protocols }\end{array}$ \\
\hline $\begin{array}{l}\text { Rao } 2017 \\
\text { Fetal biometry for guid- } \\
\text { ing the medical man- } \\
\text { agement of women } \\
\text { with gestational dia- } \\
\text { betes mellitus for im- } \\
\text { proving maternal and } \\
\text { perinatal health } \\
\text { (Protocol) }\end{array}$ & $\begin{array}{l}\text { Rao U, de Vries B, } \\
\text { Ross GP, Gordon } \\
\text { A. Fetal biome- } \\
\text { try for guiding the } \\
\text { medical manage- } \\
\text { ment of women } \\
\text { with gestation- } \\
\text { al diabetes mel- } \\
\text { litus for improv- } \\
\text { ing maternal and } \\
\text { perinatal health. } \\
\text { Cochrane Data- } \\
\text { base of Systemat- } \\
\text { ic Reviews 2017, } \\
\text { Issue 2. Art. No.: } \\
\text { CD012544. DOI: } \\
\text { 10.1002/14651858.CD }\end{array}$ & $\begin{array}{l}\text { Pregnant women with } \\
\text { singleton pregnancies } \\
\text { who have gestational di- } \\
\text { abetes mellitus (GDM), as } \\
\text { defined by the authors. } \\
\text { Women with multiple } \\
\text { pregnancy are exclud- } \\
\text { ed. Data from studies in- } \\
\text { cluding women with sin- } \\
\text { gle and multiple preg- } \\
\text { nancies will only be ex- } \\
\text { tracted and analysed for } \\
\text { women with single preg- } \\
\text { nancy and where this is } \\
\text { not possible the study } \\
\text { will be only included if } \\
\text { prasetthan } 95 \% \text { of the } \\
\text { participants have a sin- } \\
\text { gleton pregnancy }\end{array}$ & $\begin{array}{l}\text { Comparing the } \\
\text { use of medical } \\
\text { therapy for GDM } \\
\text { guided by mater- } \\
\text { nal blood glucose } \\
\text { values (glycaemic } \\
\text { targets) only with } \\
\text { medical thera- } \\
\text { py guided by fe- } \\
\text { tal biometry on } \\
\text { ultrasound, MRI } \\
\text { or other imaging } \\
\text { methods as well } \\
\text { as maternal gly- } \\
\text { caemic targets. } \\
\text { Where diet and } \\
\text { exercise modifi- } \\
\text { cations are used, } \\
\text { they should be } \\
\text { consistent across } \\
\text { the groups }\end{array}$ & $\begin{array}{l}\text { All overview primary outcomes } \\
\text { for maternal and neonatal out- } \\
\text { comes pre-specified, except } \\
\text { neurosensory disability in later } \\
\text { childhood (as defined in reviews) } \\
\text { for neonatal outcomes pre-speci- } \\
\text { fied (listed as a pre-specified sec- } \\
\text { ondary outcome). } \\
\text { All overview secondary out- } \\
\text { comes for maternal, maternal } \\
\text { long-term (except: development } \\
\text { of type } 2 \text { diabetes), fetal/neona- } \\
\text { tal, later infant/childhood, } \\
\text { child as an adult and health ser- } \\
\text { vices use pre-specified (except: } \\
\text { length of stay in neonatal inten- } \\
\text { sive care unit or special care baby } \\
\text { unit) }\end{array}$ \\
\hline $\begin{array}{l}\text { Dunn } 2016 \text { Planned } \\
\text { elective birth for preg- } \\
\text { nant women with ges- } \\
\text { tational diabetes }\end{array}$ & $\begin{array}{l}\text { Dunne F, Biesty } \\
\text { LM, Egan A, De- } \\
\text { vane D, Dempsey } \\
\text { E, Meskell P, Smith } \\
\text { V }\end{array}$ & $\begin{array}{l}\text { Awaiting protocol publi- } \\
\text { cation }\end{array}$ & $\begin{array}{l}\text { Awaiting protocol } \\
\text { publication }\end{array}$ & Awaiting protocol publication \\
\hline
\end{tabular}


(Continued)

(Title registration)

\begin{tabular}{|c|c|c|c|c|}
\hline $\begin{array}{l}\text { Okesene-Gafa } \mathbf{2 0 1 6} \\
\text { Probiotics for treating } \\
\text { women with gestation- } \\
\text { al diabetes for improv- } \\
\text { ing maternal and fetal } \\
\text { health and well-being } \\
\text { (Title registration) }\end{array}$ & $\begin{array}{l}\text { Okesene-Gafa } \\
\text { KAM, Brown J, } \\
\text { Crowther CA, Mc- } \\
\text { Cowan L }\end{array}$ & $\begin{array}{l}\text { Awaiting protocol publi- } \\
\text { cation }\end{array}$ & $\begin{array}{l}\text { Awaiting protocol } \\
\text { publication }\end{array}$ & $\begin{array}{l}\text { This protocol was published dur- } \\
\text { ing the editing of this overview } \\
\text { Okesene-Gafa } 2018\end{array}$ \\
\hline $\begin{array}{l}\text { Wang } \mathbf{2 0 1 6} \text { Chinese } \\
\text { herbal medicines for } \\
\text { treating gestational dia- } \\
\text { betes mellitus }\end{array}$ & $\begin{array}{l}\text { Wang CC, Li L, Li R, } \\
\text { Tam WH, Dou L }\end{array}$ & $\begin{array}{l}\text { Awaiting protocol publi- } \\
\text { cation }\end{array}$ & $\begin{array}{l}\text { Awaiting protocol } \\
\text { publication }\end{array}$ & Awaiting protocol publication \\
\hline
\end{tabular}

Appendix 2. Cochrane systematic reviews awaiting further classification

\begin{tabular}{ll}
\hline Review citation & $\begin{array}{l}\text { Overview outcomes pre-specified in review with } \\
\text { no outcome data }\end{array}$
\end{tabular}

Culliney KAT, Parry GK, Brown J, Crowther CA. Regimens of fetal surveillance of suspected large-for-gestational-age fetuses for improving health outcomes. Cochrane Database of Systematic Reviews 2016, Issue 4. Art. No.: CD011739. DOI: 10.1002/14651858.CD01173

Overview maternal primary outcomes pre-specified include: Mode of birth (caesarean section).

Overview neonatal primary outcomes pre-specified include: Perinatal (fetal and neonatal death) but not later infant mortality and death or serious morbidity composite (as defined in reviews, e.g. perinatal or infant death, shoulder dystocia, bone fracture or nerve palsy).

Overview secondary outcomes pre-specified for maternal include: Induction of labour, perineal trauma, postpartum haemorrhage, breastfeeding and women's view of care.

No maternal long-term secondary outcomes prespecified.

Secondary pre-specified outcomes for fetal/neonatal, later infant/childhood, child as an adult include: gestational age at birth, birthweight, and z-score, large-for-gestational age, Apgar $<7$, neonatal hypoglycaemia, birth length and $\mathrm{HC}$ and adiposity.

Health services use outcomes pre-specified include: admission to neonatal special care unit or NICU
No studies met the eligibility criteria for inclusion. Future review up-dates may include women with GDM.

"The majority of cases of LGA infants are associated with maternal factors including maternal height, weight, body mass index (BMI), gestational weight gain, ethnicity, parity and maternal age, as well as the presence of pre-gestational or gestational diabetes". "There is no evidence from randomised controlled trials to evaluate regimens of fetal surveillance for suspected large-for-gestational age (LGA) fetuses to improve health outcomes."
East CE, Dolan WJ, Forster DA.

Antenatal breast milk expression by women
No overview primary outcomes for maternal and neonatal outcomes pre-specified. Secondary prespecified outcomes for maternal includes: breastfeeding at six month.
No studies met the eligibility criteria for inclusion. Future review up-dates may include women with GDM. 
(Continued)

with diabetes for improving infant outcomes. Cochrane Database of Systematic Reviews 2014, Issue 7. Art. No.: CD010408.

DOI: 10.1002/14651858.CD010408! plasy outcomes pre-specified.

Secondary pre-specified outcomes for health services use include: economic costs (as defined by trial authors) which may include some of the overview pre-specified outcomes
No maternal long-term secondary outcomes prespecified.

Secondary pre-specified outcomes for fe-

tal/neonatal include: gestational age at birth and neonatal hypoglycaemia.

No later infant/childhood, child as an adult sec-
"There were no published or unpublished randomised controlled trials comparing antenatal expressing with not expressing. One randomised trial is currently underway. There is no high level systematic evidence to inform the safety and efficacy of the practice of expressing and storing breast milk during pregnancy."
Farrar D, Tuffnell DJ, West J, West HM. Continuous subcutaneous insulin infusion versus multiple daily injections of insulin for pregnant women with diabetes. Cochrane Database of Systematic Reviews 2016, Issue 6. Art. No.: CD005542. DOI: 10.1002/14651858.CD005542.pub3
All overview primary outcomes for maternal and neonatal outcomes pre-specified. All overview secondary outcomes for maternal, maternal long-term, fetal/neonatal, later infant/childhood, child as an adult and health services use pre-specified
None of the included trials recruited women with GDM. Future review up-dates may include women with GDM. "There were no trials of appropriate methodological quality that assessed the use of MDI versus CSII for women with GDM" and suggest that as "prevalence of GDM is increasing and these women may require insulin; this is a group of women who should be included in future trials". "Large multi-centre randomised, adequately powered trials are needed to assess the effectiveness of continuous subcutaneous insulin infusion compared with multiple daily injections for women with diabetes (GDM and pre-existing) in pregnancy who require insulin. It would be beneficial if outcomes were consistent across trials and included women's preferences. Further trials to assess the effects of pumps on birthweight and macrosomia rates are needed. Future trials should undertake longer-term follow-up of participants (women and their infants) as well as assessment of associated costs."

No studies met the eligibility criteria for inclusion. Future review up-dates may include women with GDM and gastric balloons. "At present, there is no guidance on the best management of a gastric band during pregnancy and there is variation in care. Some clinicians advocate leaving the balloon filled (inflated) to limit food intake and limit weight gain during pregnancy. This strategy might reduce the likelihood of maternal high blood pressure or gestational diabetes and so improve the outcomes for mother and baby."

\section{Jefferys $A E$, Sias-} sakos D, Draycott T, Akande VA, Fox R. Deballoon in pregnancy for improving outcomes. Cochrane Database of Systematic Reviews 2013, Issue 4. Art. No.: CD010048. DOI: 10.1002/14651858.CD010048 Pyberview maternal long-term secondary outcomes are pre-specified. Overview secondary outcomes pre-specified outcomes for fetal/neonatal include: Apgar score $<7$ at $5 \mathrm{~min}$ utes, preterm birth $<37$ weeks and $<28$ weeks, birthweight, macrosomia, SGA, stillbirth and early neonatal death.

No overview secondary pre-specified outcomes for later infant/childhood, child as an adult and health services use 


\section{CONTRIBUTIONS OF AUTHORS}

Julie Brown (JB) and Caroline A Crowther (CAC) conceived the idea for this overview. Ruth Martis (RM) wrote the first draft of the protocol. CAC and JB provided feedback for all draft protocol versions. Jane Alsweiler (JA) and Michelle R Downie (MRD) provided feedback for the final protocol.

Emily Shepherd (ES) joined the author team for the review. As some of the overview authors were involved as authors in potential Cochrane systematic reviews considered for inclusion, a spreadsheet was created to clearly identify which overview review authors would assess review eligibility, carry out data extractions and assessments. RM was involved with eight reviews, ES with five reviews, JB with four reviews, JA with two reviews, and MRD with one review.

RM prepared the first draft of the review. RM and JB prepared the initial summary of results. All authors commented on drafts of the review and the final version of the overview. JB has dealt with editorial feedback and final submission of the review.

\section{DECLARATIONS OF INTEREST}

Ruth Martis, Julie Brown, Emily Shepherd, Jane Alsweiler and Caroline A Crowther have been involved as authors or co-authors of Cochrane systematic reviews that are included in this overview review. Overview review authors not involved in those reviews assessed the eligibility for inclusion of these reviews.

Julie Brown is an author of systematic reviews included in this overview review. Other researchers were approached to confirm eligibility of these reviews. she was not involved in assessing the included review for quality or data extraction. Since 9 th April 2018, Julie Brown has been employed by a medical communications company. This review was prepared prior to her taking up this appointment.

Caroline A Crowther, Jane Alsweiler, and Julie Brown are lead investigators for a randomised controlled trial of tighter glycaemic targets for women with gestational diabetes. This trial is ongoing and not included in this overview review.

Caroline A Crowther was the lead investigator for the ACHOIS trial that assessed treatment for women with mild gestational diabetes. This trial is reported within an included review. She was not involved in the decision about including this review into this overview, nor involved in any data extraction related to that review.

Michelle R Downie has received honorarium for lectures and partial sponsorship to attend conferences from Novo Nordisk and Sanofi Aventis.

\section{SOURCES OF SUPPORT}

\section{Internal sources}

- Liggins Institute, The University of Auckland, New Zealand. Institutional support.

- ARCH: Australian Research Centre for Health of Women and Babies, Robinson Research Institute, The University of Adelaide, Australia. Institutional support

\section{External sources}

- National Health and Medical Research Council (NHMRC), Australia Funding for the Cochrane Pregnancy and Childbirth Australian and New Zealand Satellite, Australia.

- NIHR: National Institute for Health Research, UK.

Cochrane Review Incentive Scheme Award:16/72/03

\section{INDEX TERMS}

\section{Medical Subject Headings (MeSH)}

${ }^{\star}$ Review Literature as Topic; Diabetes, Gestational [ ${ }^{\star}$ therapy]; Exercise; Hypertension [chemically induced]; Hypoglycemic Agents [adverse effects] [therapeutic use]; Insulin [adverse effects] [therapeutic use]; Labor, Induced; Life Style; Pregnancy Complications, Cardiovascular [chemically induced]; Randomized Controlled Trials as Topic

\section{MeSH check words}

Female; Humans; Infant, Newborn; Pregnancy 